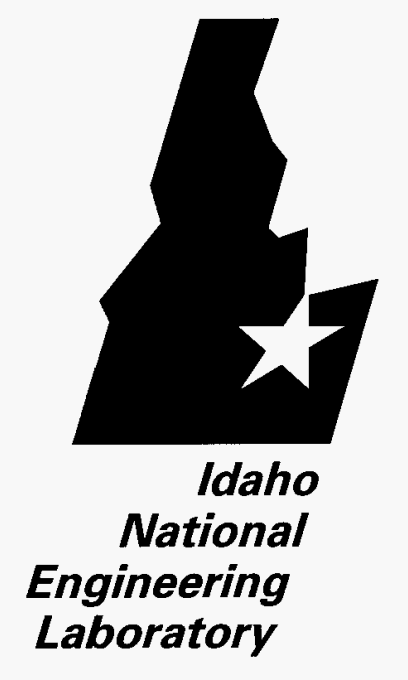

December 1997

\title{
Potential for AP600 In-Vessel Retention through Ex-Vessel Flooding
}

Technical Evaluation Report
J. L. Rempe
D. L. Knudson
RECEIVED
C. M. Allison
G. L. Thinnes
C. L. Atwood
MAR 271999
OSTI
M. J. Cebull

\section{1}

[DIIC QUALTTY CINSPECTTHD

L OCKHEED MARTIN 
INEEL/EXT-97-00779

\title{
Potential for AP600 In-Vessel Retention through Ex-Vessel Flooding
}

\author{
Technical Evaluation Report
}
J. L. Rempe
D. L. Knudson
C. M. Allison
G. L. Thinnes
C. L. Atwood
M. J. Cebull

Published December 1997

DISTRIBUTION OF THIS DOCUIMENT IS UNLMMTED
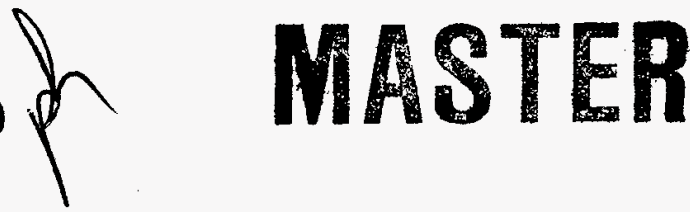

\section{Idaho National Engineering and Environmental Laboratory Nuclear Risk Management Technologies Department Lockheed Martin Idaho Technologies Company Idaho Falls, Idaho 83415}

\author{
Prepared for the \\ Division of Systems Safety and Analysis \\ Office of Nuclear Reactor Regulation \\ U.S. Nuclear Regulatory Commission \\ Washington, D.C. 20555 \\ Under DOE Idaho Operations Office \\ Contract DE-AC07-94ID13223 \\ Job Code No. L2508
}




\section{DISCLAIMER}

This report was prepared as an account of work sponsored by an agency of the United States Government. Neither the United States Government nor any agency thereof, nor any of their employees, makes any warranty, express or implied, or assumes any legal liability or responsibility for the accuracy, completeness, or usefulness of any information, apparatus, product, or process disclosed, or represents that its use would not infringe privately owned rights. Reference herein to any specific commercial product, process, or service by trade name, trademark, manufacturer, or otherwise does not necessarily constitute or imply its endorsemeat, recommendation, or favoring by the United States Government or any agency thereof. The views and opinions of authors expressed herein do not necessarily state or refleet those of the United States Government or.any agency thereof. 


\section{Contents}

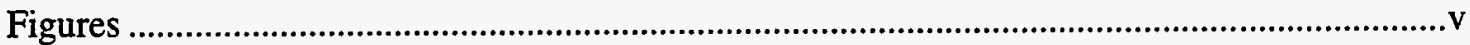

Tables .......................................................................................................................... vii

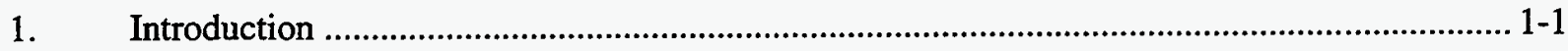

$1.1 \quad$ Review of UCSB Study and Model...................................................................... 1-1

1.2 Review of UCSB Study Peer Reviewer Comments ................................................... 1-4

$1.3 \quad$ Independent INEEL Assessments ............................................................................ 1-6

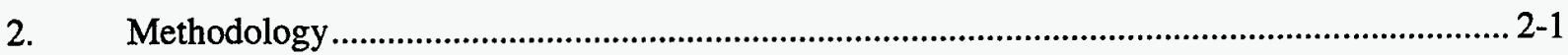

$2.1 \quad$ Debris Configurations..................................................................................... 2-1

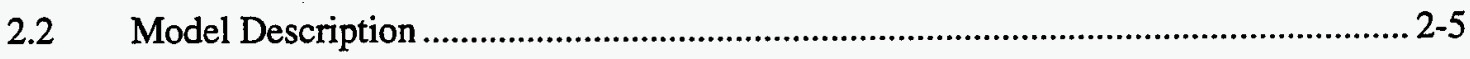

2.3 Input Parameters and Uncertainty Distributions........................................................ 2-7

$2.4 \quad$ Sensitivity Studies ............................................................................................ 2-9

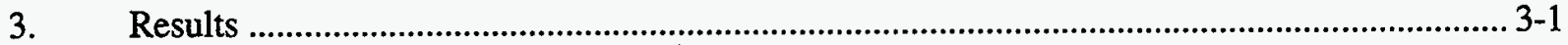

3.1 Verification Calculation Results ............................................................................ 3-1

3.2 INEEL Requantification of UCSB-assumed FIBS ................................................. 3-3

3.3 Alternate Debris Configurations............................................................................. 3-10

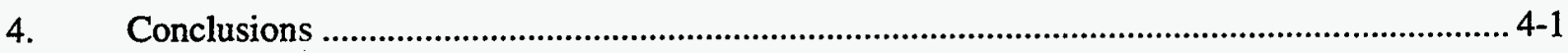

5. References ................................................................................................................... 5-1

Appendix A- VESTA Governing Equations and Nomenclature ………………………………......... A-1

A.1 VESTA Governing Equations............................................................................ A-2

A.2 Nomenclature ............................................................................................. A-13

Appendix B - INEEL Input Uncertainty Distributions ........................................................................

B.1 Heat Transfer Assumptions ................................................................................ B-1

B.2 Decay Heat Assumptions …………………………......................................... B-16

B.3 Material Property Assumptions .................................................................................

Appendix C - Listing of Input .....................................................................................................

Appendix D - Benchmark Calculation Results................................................................................ D-1 


\section{Figures}

1-1. UCSB strategy for demonstrating the effectiveness of AP600 IVR. ............................. 1-2

2-1. UCSB-assumed FIBS debris configuration............................................................ 2-2

2-2. Alternate debris configurations evaluated by INEEL. .............................................. 2-3

2-3. Impact of boiling on heat transfer from a molten pool. ................................................ 2-10

3-1. UCSB (DOE/ID-10460) and VESTA (INEEL-verification) heat fluxes assuming

UCSB FIBS and input distributions..................................................................... 3-2

3-2. UCSB (DOE/ID-10460) and VESTA (INEEL-verification) CHF ratio pdfs assuming

UCSB FIBS and input distributions..................................................................... 3-2

3-3. Comparison of heat fluxes for UCSB-assumed FIBS. .................................................... 3-4

3-4. Comparison of CHF ratios for UCSB-assumed FIBS. ............................................ 3-4

3-5. CHF ratio pdfs for UCSB-assumed FIBS using INEEL input distributions...................... 3-5

3-6. CHF ratios assuming increased upward ceramic pool heat losses for UCSB FIBS. .......... 3-6

3-7. CHF ratio pdfs assuming increased upward ceramic pool heat losses for UCSB FIBS.... 3-7

3-8. CHF ratios assuming additional metallic layer heat source for UCSB FIBS. .................... 3-8

3-9. CHF ratio pdfs assuming additional metallic layer heat source for UCSB FIBS.............. 3-8

3-10. CHF ratios assuming various metallic layer steel masses for UCSB FIBS...................... 3-9

3-11. CHF ratio pdfs assuming a 19,500 kg metallic layer steel mass for UCSB FIBS............ 3-10

3-12. Heat fluxes for Configuration A....................................................................... 3-12

3-13. CHF ratios for Configuration A. .......................................................................... 3-12

3-14. CHF ratio pdfs in the ceramic layer for Configuration $\mathrm{A}(4,187 \mathrm{~kg}$ steel mass)............. 3-13

3-15. CHF ratio pdfs in the metallic layer for Configuration A (4,187 kg steel mass)............. 3-13

3-16. Heat fluxes predicted for Configuration B................................................................ 3-15

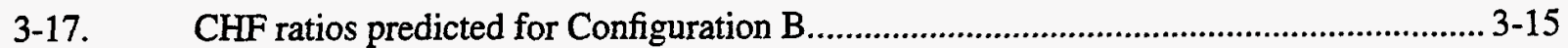

3-18. CHF ratio pdfs in the ceramic layers for Configuration $B$........................................... 3-16

3-19. CHF ratio pdfs in the metallic layer for Configuration B. ............................................ 3-16

3-20. Heat fluxes for Configuration C. ................................................................. 3-18

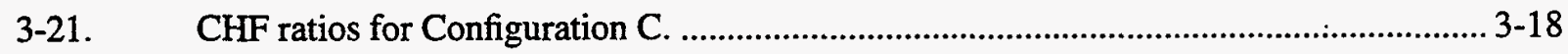

3-22. CHF ratio pdfs in the ceramic layer for Configuration C. .............................................. 3-19

3-23. CHF ratio pdfs in the metallic layer for Configuration C. ......................................... 3-19 


\section{Tables}

1-1. UCSB Peer Reviewer comments requiring additional consideration. ............................. 1-5

2-1. Relocation masses predicted in Reference 3 SCDAP/RELAP5 AP600 analysis .............. 2-3

2-2. Comparison of INEEL and UCSB input assumptions................................................. 2-8

2-3. Sensitivity calculations performed to address phenomenological uncertainties................ 2-9

4-1. ERVC impact on Westinghouse AP600 risk estimates. ................................................. 4-4 


\section{Introduction}

External reactor vessel cooling (ERVC) is a new severe accident management strategy that involves flooding the reactor cavity to submerge the reactor vessel in an attempt to cool core debris that has relocated to the vessel lower head. Advanced and existing light water reactors (LWRs) are considering ERVC as an accident management strategy for in-vessel retention (IVR) of relocated debris. In the probabilistic risk assessment (PRA) for the AP600 design, ${ }^{1}$ Westinghouse credits ERVC for preventing vessel failure during postulated severe accidents with successful reactor coolant system (RCS) depressurization and reactor cavity flooding. To support the Westinghouse position on IVR, the Department of Energy (DOE) contracted the University of California - Santa Barbara (UCSB) to produce the peer-reviewed report, DOE/ID-10460. ${ }^{2}$

To assist in the Nuclear Regulatory Commission's (NRC's) evaluation of IVR of core melt by exvessel flooding of the AP600, the Idaho National Engineering and Environmental Laboratory (INEEL) was tasked to perform the following:

- An in-depth critical review of the UCSB study and the model that UCSB used to assess ERVC effectiveness.

- An in-depth review of the UCSB study peer review comments and of UCSB's resolution method to identify areas where technical concerns weren't addressed.

- An independent analysis effort to investigate the impact of residual concerns on the margins to failure and conclusions presented in the UCSB study.

This Technical Evaluation Report (TER) summarizes results from these tasks. As discussed in Sections 1.1 and 1.2, INEEL's review of the UCSB study and peer reviewer comments suggested that additional analysis was needed to assess: (1) the integral impact of peer reviewer-suggested changes to input assumptions and uncertainties and (2) the challenge present by other credible debris configurations. NRC tasked INEEL to perform an independent assessment to address this need. Section 1.3 summarizes the corresponding analysis approach developed by INEEL. The remainder of this report provides more detailed descriptions of INEEL's analysis methodology, input assumptions, and results.

\subsection{Review of UCSB Study and Model}

As noted in Reference 2, the objective of the UCSB study was to demonstrate the effectiveness of ERVC for an AP600-like design and to provide a readily adaptable path for demonstrating ERVC for other reactor designs. Figure 1-1 illustrates the UCSB approach for demonstrating AP600 vessel integrity for cases with complete RCS depressurization and ERVC. As indicated in this figure, the UCSB study attempts to demonstrate vessel integrity by proving two assertions:

Assertion 1: For all heat fluxes at or below the critical heat flux (CHF), the corresponding minimum vessel wall thicknesses are sufficient that the vessel remains intact.

Assertion 2: Heat fluxes from relocated melt to the lower head always remain below the CHF.

The above assertions assume that vessel heat fluxes exceeding CHF lead to vessel failure. Sections 3 and 4 of the UCSB report contend that the "boiling crisis is a sufficient condition for lower head failure," noting that once vessel heat fluxes reach CHF, “...vessel temperatures rise to values where the steel loses essentially all of its strength, and it becomes susceptible to creep, and structural instability...” 


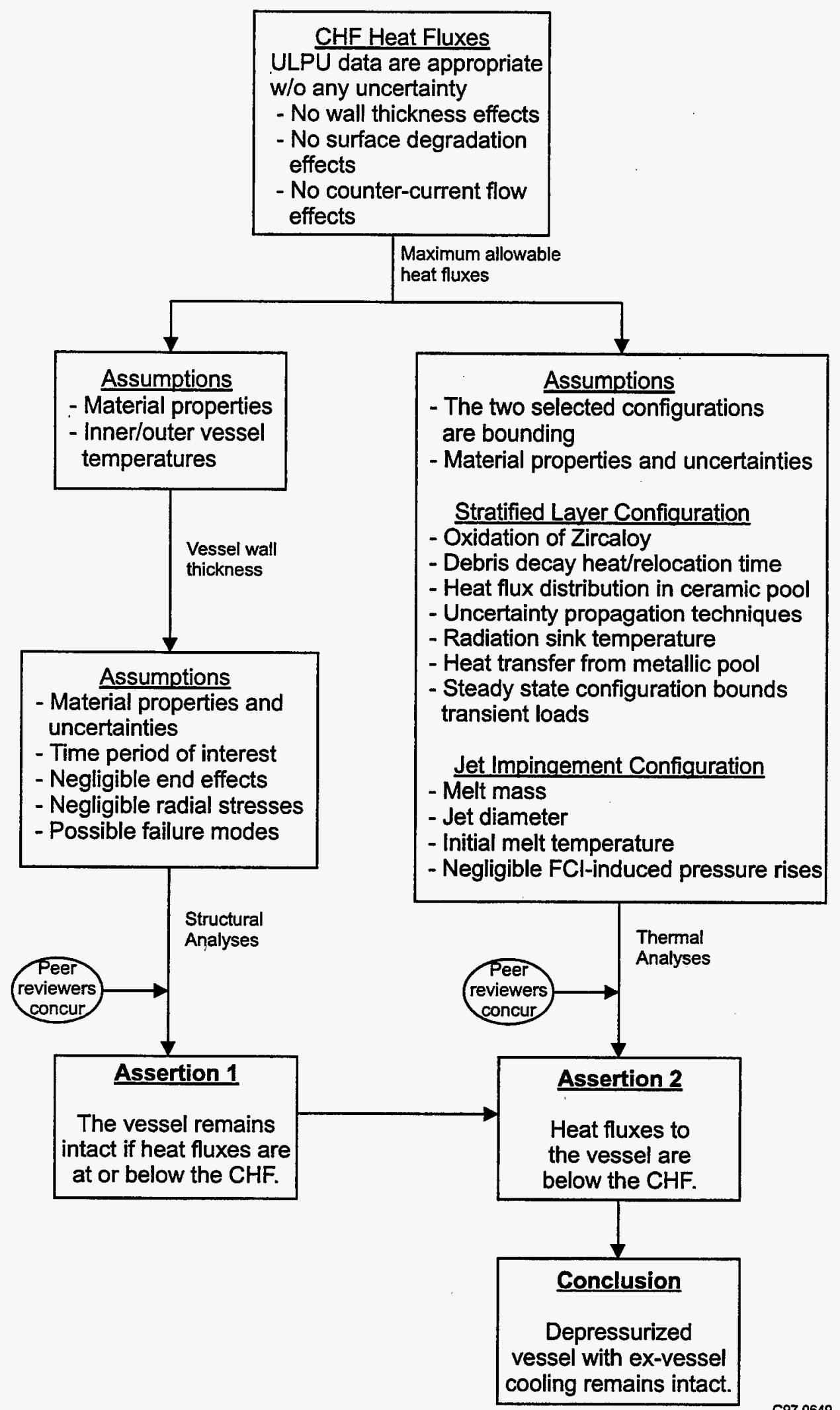

Figure 1-1. UCSB strategy for demonstrating the effectiveness of AP600 IVR. 
The UCSB study relied on various types of information (analyses, experiments, and assumptions) to support each assertion. Starting at the top of Figure 1-1, the UCSB study applied CHF data from the UCSB ULPU tests to estimate a minimum vessel thickness for the structural analyses and provide bounding heat fluxes for the thermal analyses. For the minimum vessel wall thicknesses, structural calculations demonstrated that the vessel remains intact if heat fluxes are at or below values assumed for CHF (Assertion 1). Thermal analyses and data from UCSB-sponsored experiments provided a basis for estimating maximum possible heat fluxes for two debris configurations that were assumed to "bound" the thermal loads from all other debris configurations that can "reasonably be expected". One configuration was dominated by transient forced convection and jet impingement effects, and the other was dominated by natural convection in the final steady state, their postulated "FInal Bounding State" or "FIBS". Analyses described in the UCSB report suggested that vessel failure would not occur due to jet impingement and that thermal loads to the vessel for their assumed FIBS were more challenging. The UCSB study found that heat fluxes (and associated uncertainties) for their FIBS were below values assumed for CHF (Assertion 2). Hence, the UCSB study concluded in Section 9 that "thermally-induced failure of an externally flooded, AP600-like reactor vessel is physically unreasonable." The UCSB study claimed that peer reviewer concurrence validated assumptions supporting their assertions. INEEL's review indicates that some peer reviewers did not concur with several UCSB analysis assumptions. Section 1.2 identifies key UCSB peer reviewer comments and the manner in which the UCSB study addressed these comments.

The INEEL review effort focussed on assessing the impact of residual uncertainties that were not considered in the UCSB study's integral solution. INEEL considered modeling assumptions, input values, uncertainty distributions, and experimental data pertinent to the following aspects of the UCSB analyses:

- Molten pool heat transfer (average and local values);

- CHF estimates for heat transfer from a reactor vessel to a flooded reactor cavity;

- Molten metal layer heat transfer;

- Decay heat;

- Decay power split between ceramic and metallic melts;

- Heat addition due to oxidation and activation of metallic layer materials;

- Melt progression (relocation timing, structural mass becoming molten);

- Material properties (melting temperatures, thermal conductivity, density, specific heat capacity, emissivity);

- Structural calculations;

- Radiative heat transfer assumptions;

- "Bounding" debris configuration assumptions.

To quantify uncertainties in UCSB study conclusions, INEEL considered other relevant experimental data and severe accident analysis code calculations. For example, SCDAP/RELAP5, ${ }^{3}$ MELCOR, ${ }^{4}$ and MAAP AP600 calculation results ${ }^{5}$ were used to assess results presented in the UCSB report. INEEL also considered recent studies performed by the University of California - Los Angeles ${ }^{6,7}$ and the Royal Institute of Technology in Stockholm, Sweden. ${ }^{8}$ As part of their review, INEEL prepared questions for Westinghouse; these questions were transmitted by NRC to Westinghouse as Requests for Additional Information (RAIs). ${ }^{9-11}$ INEEL's evaluation incorporated Westinghouse's responses to these questions. ${ }^{12,13}$ In addition, INEEL considered comments from the NRC Office of Research. ${ }^{14}$ Section 2.3 
summarizes key findings from INEEL's review of input values and uncertainty distributions assumed by UCSB. Appendix B provides more detailed information about INEEL's review.

\subsection{Review of UCSB Study Peer Reviewer Comments}

Seventeen international "experts" reviewed selected sections of the UCSB study. Comments from these reviewers and the manner in which the UCSB authors addressed these comments are included as UCSB study appendices. INEEL reviewed these comments to determine if significant issues were adequately addressed. INEEL concluded that the UCSB study doesn't fully address many peer review comments.

INEEL identified peer review comments that collectively have the potential to impact vessel response and as such are considered outstanding items based on information in DOE/ID-10460 Appendices $\mathrm{O}, \mathrm{P}, \mathrm{S}, \mathrm{T}, \mathrm{U}$ and $\mathrm{V}$ and responses to RAIs. Table 1-1 summarizes these issues, the peer reviewers mentioning the issue, the approach taken in the UCSB study for resolution, and INEEL's approach for resolution. In some cases, INEEL judged that a peer reviewer comment about an issue significantly impacting vessel response wasn't adequately addressed, although the peer reviewer may not have noted that the comment was an outstanding item in Appendix V. In other cases, INEEL may agree with the reviewer that the comment wasn't adequately addressed, but INEEL omitted the comment from Table 1-1 because INEEL judged that the issue did not significantly impact vessel response.

As indicated in Table 1-1, INEEL found that the UCSB study typically addressed comments by performing a sensitivity study where only one particular parameter was varied from its base case value by itself or with a limited number of other parameters. These sensitivity studies typically involved point estimate calculations rather than requantification of input for their integral analysis. Although UCSB's response provides insights about the impact of a change in the varied parameter, their sensitivity calculations didn't reveal integral effects of the changes suggested by peer reviewers. Because integral effects may significantly impact estimated vessel failure margins, INEEL developed a calculational model that could be used to independently address peer reviewer comments regarding input parameter uncertainty distributions in an integral manner (see Section 1.3).

Another key area identified in Table 1-1 is that the UCSB study dismissed the potential for the occurrence of other, more challenging, debris configurations. For example, several peer reviewers (Olander, Seiler, Sehgal, Tuomisto, and Turland) expressed concern that intermediate configurations were credible and could present more challenging heat loads to the reactor vessel. In addition, one peer reviewer (Sehgal) noted in Appendix V that the UCSB authors failed to address comments by himself and other reviewers (Chu, Levy, Olander, and Turland) about the potential formation of a heavier, lower metallic layer. Because such configurations can not be excluded, INEEL evaluated heat loads from several alternate debris configurations.

Additional information about issues that INEEL considers as outstanding items may be found in Section 2.3. Section 3 calculation results demonstrate the impact of these issues on vessel response. 
Table 1-1. UCSB Peer Reviewer comments requiring additional consideration.

\begin{tabular}{|c|c|c|}
\hline Issue (Paraphrased Reviewer Comments ${ }^{\mathrm{a}}$ ) & UCSB Treatment & INEEL Treatment \\
\hline $\begin{array}{l}\text { Uncertainty Distributions Broader uncer- } \\
\text { tainty distributions for various input } \\
\text { parameters (steel melt mass, steel emissiv- } \\
\text { ity, metal eutectic temperature, decay heat, } \\
\text { zircaloy oxidation fraction, convection } \\
\text { heat transfer coefficients, CHF values) } \\
\text { should be considered. [Kress-2,3,4,5; } \\
\text { Olander-7,8; Seiler-4,9; and Turland- } \\
26,30]\end{array}$ & $\begin{array}{l}\text { Provided sensitivity studies (Section } 7.3 \text {, } \\
\text { App. O, App. P, and RAI } 480.946 \\
\text { response) in which a limited number of } \\
\text { parameters were varied. }\end{array}$ & $\begin{array}{l}\text { Used revised input distributions for } \\
\text { parameters described in Section } 2.3 \text { in an } \\
\text { independent requantification. }\end{array}$ \\
\hline $\begin{array}{l}\text { Alternate Debris Configurations or Inter- } \\
\text { mediate Debris States Several credible } \\
\text { alternate debris configurations or interme- } \\
\text { diate states may be more challenging. } \\
\text { [Cheung- } 2 \text {, Chu-17, Levy-9,14,15, 32, } \\
\text { Olander- } 7,8,9,10 \text {; Sehgal-5, } 6,28 \text {; Seiler- } \\
2 \text {, Spencer-3; Tuomisto-3; and Turland- } \\
25,26^{\text {d }} \text { ] }\end{array}$ & $\begin{array}{l}\text { Provided sensitivity calculations (App. O, } \\
\text { App. P, and RAI } 480.946 \text { response) } \\
\text { assuming thinner metallic layers and } \\
\text { higher decay heat values. Although heat } \\
\text { fluxes for some cases exceeded CHF, } \\
\text { concluded that such cases were unlikely } \\
\text { (referencing App. O information). }\end{array}$ & $\begin{array}{l}\text { Performed uncertainty calculations for } \\
\text { several debris configurations and inter- } \\
\text { mediate debris states (see Section 2.1.2). }\end{array}$ \\
\hline $\begin{array}{l}\text { Power in the Metallic Layer The metallic } \\
\text { layer may contain volumetric heat sources } \\
\text { from oxidation, metallic fission product } \\
\text { retention, or dissolved uranium. [Levy- } \\
33 \text {, Olander-1, 3,6; Sehgal-6; and } \\
\text { Turland-6,21] }\end{array}$ & $\begin{array}{l}\text { Provided sensitivity calculations (App. P } \\
\text { and RAI } 480.946 \text { response) assuming } \\
\text { that the ceramic pool's decay was trans- } \\
\text { ferred to the metallic layer }\end{array}$ & $\begin{array}{l}\text { Included appropriate amounts of metallic } \\
\text { layer decay heat in independent requanti- } \\
\text { fication. Also, performed sensitivity stud- } \\
\text { ies considering additional metallic layer } \\
\text { heat sources. }\end{array}$ \\
\hline $\begin{array}{l}\text { Emissivity of Metallic Layer Assumed } \\
\text { emissivity from the metallic layer was too } \\
\text { high. [Kress-16 and Seiler-8] }\end{array}$ & $\begin{array}{l}\text { Performed sensitivity calculations (Sec- } \\
\text { tion } 7.3, \text { App. P. and RAI } 480.946 \\
\text { response) in which emissivity was varied } \\
\text { with other selected inputs. }\end{array}$ & $\begin{array}{l}\text { Used an emissivity input uncertainty dis- } \\
\text { tribution based on unoxidized molten } \\
\text { metal emissivity data in an independent } \\
\text { requantification. }\end{array}$ \\
\hline $\begin{array}{l}\text { Critical Heat Flux question applicability } \\
\text { of ULPU data and impact of various phe- } \\
\text { nomena (insulation effects, surface foul- } \\
\text { ing, uncertainty) on CHF. [Cheung- } \\
4,5,6,7 ; \text { Chu-2,9,10,11; Dhir-2,3,4,5,9; } \\
\text { Levy-2,3,4,5,6,7,8; Seiler-22; Tuomisto- } \\
8 \text {; and Turland-30] }\end{array}$ & $\begin{array}{l}\text { Asserted that CHF assumptions were } \\
\text { appropriate because ULPU fouling simu- } \\
\text { lates AP600 reactor cavity conditions, } \\
\text { insulation didn't affect ULPU results, and } \\
\text { assumed "minimum" ULPU values } \\
\text { require no uncertainty assumptions. Pro- } \\
\text { vided one point estimate assuming } 10 \% \\
\text { lower values (RAI } 480.946 \text { response). }\end{array}$ & $\begin{array}{l}\text { Used SBLB-based CHF values and } \\
\text { uncertainty distributions in an indepen- } \\
\text { dent requantification. When SBLB tests } \\
\text { with insulation are completed, additional } \\
\text { calculations may be needed to assess the } \\
\text { impact of insulation. }\end{array}$ \\
\hline $\begin{array}{l}\text { Cavity Flooding Time question the impact } \\
\text { of partially flooded cavities (less subcool- } \\
\text { ing because of reduced gravity head). } \\
\text { [Levy-12, Seiler-22, and Shewmon-1] }\end{array}$ & $\begin{array}{l}\text { Contended that AP } 600 \text { design and proce- } \\
\text { dure changes ensure that cavity flooding } \\
\text { occurs prior to the time that they believe a } \\
\text { molten pool occurs in the lower head. }\end{array}$ & $\begin{array}{l}\text { Assumed CHF values corresponding to } \\
\text { earlier molten pool formation times pre- } \\
\text { dicted by severe accident analysis codes } \\
\text { in independent requantification. }\end{array}$ \\
\hline $\begin{array}{l}\text { Decay Heat Load High decay heat loads } \\
\text { (especially with earlier melt relocations) } \\
\text { may occur. [Kress-5,6,7 and Sehgal-4] }\end{array}$ & $\begin{array}{l}\text { Performed sensitivity studies (Section } \\
7.3, \text { App. P. and RAI } 480.946 \text { response) } \\
\text { assuming increased decay heat loads. }\end{array}$ & $\begin{array}{l}\text { Revised input distributions for decay heat } \\
\text { loads and other values described in } \\
\text { Section } 2.3 \text { in an independent requantifi- } \\
\text { cation. }\end{array}$ \\
\hline $\begin{array}{l}\text { Validity of ACOPO Correlations - Proto- } \\
\text { typic Material Effects Prototypic material } \\
\text { test results are needed to confirm the } \\
\text { applicability of ACOPO data. [Spencer- } \\
6,8 \text { and Turland-7,15] }\end{array}$ & $\begin{array}{l}\text { Responded that prototypic ACOPO tests } \\
\text { would only be useful for confirmatory } \\
\text { purposes. Performed sensitivity calcula- } \\
\text { tions (Section } 7.3 \text {, App. P. and RAI } \\
480.946 \text { response) assuming different } \\
\text { correlations. }\end{array}$ & $\begin{array}{l}\text { Included heat transfer correlation uncer- } \\
\text { tainties in an independent requantifica- } \\
\text { tion. Also, performed sensitivity } \\
\text { calculations to address some prototypic } \\
\text { material effects, but recommended that } \\
\text { prototypic RASPLAV test results be used } \\
\text { to resolve this issue. }\end{array}$ \\
\hline
\end{tabular}


Table 1-1. UCSB Peer Reviewer comments requiring additional consideration. (continued)

\begin{tabular}{|c|c|c|}
\hline Issue (Paraphrased Reviewer Comments ${ }^{\mathbf{a}}$ ) & UCSB Treatment & INEEL Treatment \\
\hline $\begin{array}{l}\text { Validity of ACOPO during Transient Time } \\
\text { Periods Higher heat fluxes may occur at } \\
\text { locations where CHF values are lower dur- } \\
\text { ing transient time periods. [Levy-18 and } \\
\text { Sehgal-8,28] }\end{array}$ & $\begin{array}{l}\text { Asserted that time periods required for } \\
\text { steady-state behavior at the boundaries is } \\
\text { much shorter than time periods required } \\
\text { for steady-state bulk behavior and } \\
\text { claimed that ACOPO results resolved this } \\
\text { issue. }\end{array}$ & $\begin{array}{l}\text { Did not address because additional data } \\
\text { are needed to specify heat flux distribu- } \\
\text { tion. }\end{array}$ \\
\hline $\begin{array}{l}\text { Validity of ACOPO Comelations - Vapor } \\
\text { Transport Effects Vapor from steel or } \\
\text { other lower boiling point materials would } \\
\text { rise up through oxidic pool and enhance } \\
\text { heat transfer). [Olander-10, Levy-10, and } \\
\text { Tuomisto-5 and UCSB response to Seh- } \\
\text { gal-24] }\end{array}$ & $\begin{array}{l}\text { Dismissed comment, contending that } \\
\text { there is no mechanism for entrapping sig- } \\
\text { nificant quantifies of steel in the oxidic } \\
\text { melt. }\end{array}$ & $\begin{array}{l}\text { Performed sensitivity studies to assess } \\
\text { this phenomenon. }\end{array}$ \\
\hline $\begin{array}{l}\text { Vessel Wall Melting Temperature Range } \\
\text { of possible eutectic temperatures wasn't } \\
\text { evaluated. [Levy-17 and Olander-4,9] }\end{array}$ & $\begin{array}{l}\text { Asserted assumed melting temperature is } \\
\text { conservative for iron-rich compositions } \\
\text { possible in metallic layer, but included } \\
\text { sensitivity studies (App. P) examining } \\
\text { higher temperature. }\end{array}$ & $\begin{array}{l}\text { Estimated melting temperatures based on } \\
\text { predicted metallic layer compositions in } \\
\text { an independent requantification, sensitiv- } \\
\text { ity studies, and analyses of alternate } \\
\text { debris configurations. }\end{array}$ \\
\hline $\begin{array}{l}\text { Ceramic Pool Liquidus Temperature Other } \\
\text { possible ceramic pool liquidus tempera- } \\
\text { ture should be considered. [Levy-32 and } \\
\text { Olander-5] }\end{array}$ & $\begin{array}{l}\text { Dismissed comment, contending that } \\
\text { ceramic pool liquidus temperatures } \\
\text { assumptions aren't important. }\end{array}$ & $\begin{array}{l}\text { Assumed correct liquidus temperatures in } \\
\text { an independent requantifcation, sensitiv- } \\
\text { ity studies, and analyses of alternate } \\
\text { debris configurations. }\end{array}$ \\
\hline
\end{tabular}

a. Reviewers include: F. B. Cheung (Penn State), T. Y. Chu (SNL), V. K. Dhir (UCLA), M. Epstein (FAI), R. E. Henry (FAI), T. S. Kress (ORNL), S. Levy (Levy and Assoc.), F. Mayinger (U. Munich), R. E. Nickell (AST), D. R. Olander (UC-Berkeley), R. C. Schmidt (SNL), B. R. Sehgal (RIT), J. M. Seiler (CEN-G), P. Shewmon (OSU), B. W. Spencer (ANL), H. Tuomisto (IVO), B. D. Turland (AEA).

b. Designates Comments 2, 3, 4, and 5 from Reviewer Kress. Comment numbering is consistent with numbering provided in DOE/ID10460 Appendix T.

c. Because INEEL's review indicated that metallic mass assumptions should be treated as a discrete function, sensitivity calculations were performed to address the impact of steel melt mass combined with other input parameter uncertainty distribution assumptions. d. Also, see Turland's Additional Comment \#3 in Appendix V.

e. Although RASPLAV tests use a nonprototypic geometry, data can be compared with other data from similar geometries.

\subsection{Independent INEEL Assessments}

In order to independently verify UCSB study results and to assess the impact of additional uncertainties and other debris configurations, INEEL developed the VEssel Statistical Thermal Analysis (VESTA) Code. VESTA is similar to the model used in the UCSB report. However, VESTA was developed in a more general fashion so that it could assess a wider range of conditions.

Section 2 of this report describes VESTA and the types of calculations that were performed with this code. Governing equations encoded into VESTA and a nomenclature defining variables used in this document may be found in Appendix A. Results from VESTA calculations are presented in Section 3. Appendix $C$ lists input uncertainty distributions assumed for these calculations. Figures comparing VESTA and UCSB model benchmark calculation results may be found in Appendix D. Section 4 presents conclusions about the potential for vessel failure to occur for various debris configurations. Section 4 also discusses the impact of VESTA results on AP600 PRA results. 


\section{Methodology}

After evaluating peer review comments, INEEL concluded that additional study was needed to assess the integral effect of different input uncertainty distributions and the potential for other, credible debris configurations to present more severe challenges to vessel integrity. This section describes several alternate debris configurations having the potential to challenge vessel integrity, and the INEEL-developed model for assessing the potential for vessel failure for these debris configurations. Input values and uncertainty distributions assumed in the UCSB study and in the INEEL requantification for the UCSBassumed FIBS are compared, and sensitivity studies to assess the impact of phenomena significantly different than assumptions for this case are identified.

\subsection{Debris Configurations}

A key assumption in the UCSB study is their assumed debris configuration that is supposed to "bound" thermal loads from any other configurations that can "reasonably be expected." INEEL's review suggests that the UCSB FIBS doesn't bound possible thermal challenges from other debris configurations. This section describes the UCSB FIBS and other possible, more challenging, debris configurations.

\subsubsection{UCSB FIBS}

The UCSB FIBS assumes a molten ceramic pool lies beneath a metallic layer (Figure 2-1). As discussed in Section 5 of the UCSB study, this configuration assumes that the ceramic pool contains all of the oxidic core components (mainly $\mathrm{UO}_{2}$ and $\mathrm{ZrO}_{2}$ ). Heat transfer from the pool is governed by turbulent steady-state natural convection associated with volumetric heat sources. The molten pool experiences sufficient cooling that it is surrounded by thin crusts that impose uniform temperature boundary conditions on the melt (i. e., its liquidus temperature). The metallic layer is assumed to contain all unoxidized metallic components, and is thin compared to its diameter. It is heated from below and cooled from above and its sides. However, only the side boundary temperature is fixed - at the metallic layer liquidus.

UCSB FIBS calculations invoked several key assumptions that may significantly impact estimated vessel failure margins. Some key assumptions questioned by INEEL and/or peer reviewers include:

- All the decay heat resides in the ceramic pool;

- No additional heat sources (due to oxidation or steel activation) exist in the metallic layer;

- The probability density function (pdf) for relocated structural steel mass (UCSB Figure 7.5) applies;

- UCSB Mini-ACOPO molten pool natural convection correlations apply;

- UCSB ULPU CHF lower bound correlations apply;

- Emissivity from the metallic layer may be represented by a point value of 0.45 ;

- Metallic layer liquidus temperature may be represented by a point value of $1600 \mathrm{~K}$;

- The pdf for shutdown time applies (UCSB Figure 7.7);

- Limited or no uncertainty distributions on heat transfer correlations, material properties, decay heat, and radiation heat sink surface area are appropriate;

- Density differences allow rapid separation of the ceramic and metallic components.

INEEL calculations presented in this study assess the impact of modifications to the above assumptions on the probability of vessel heat fluxes exceeding CHF. 


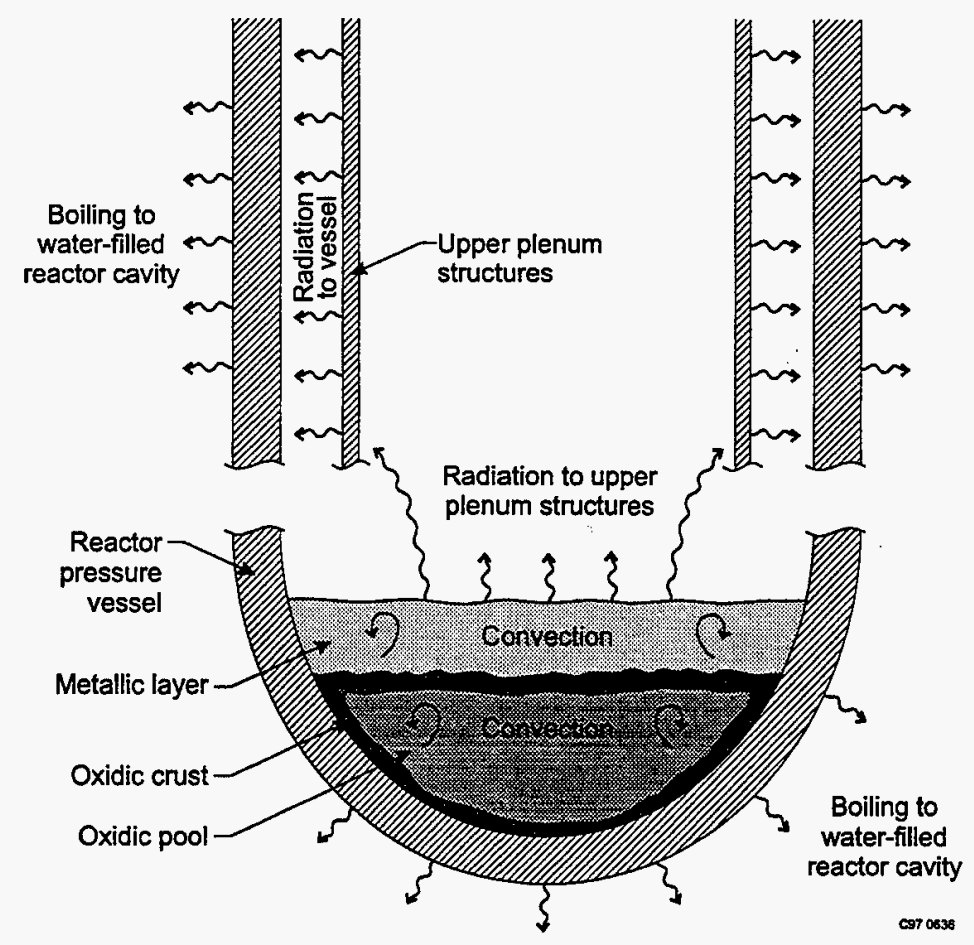

Figure 2-1. UCSB-assumed FIBS debris configuration.

\subsubsection{Alternate Debris Configurations}

As indicated in Table 1-1, several peer reviewers noted that the UCSB-assumed FIBS is not necessarily the bounding or even the most plausible configuration for the stratification of frozen and molten material (see Section 1.2). These concerns were expressed by many peer reviewers in their original Appendix $\mathrm{T}$ comments, and several peer reviewers reiterated these concerns in their final comments documented in Appendix V of the UCSB report. Figure 2-2 illustrates several possible axisymmetric configurations that may be more challenging than the UCSB-assumed configuration. These configurations were selected by INEEL based on peer reviewer comments, experimental results, and severe accident code calculation results. Brief descriptions of each configuration are provided below. Section 3.3 and Appendix $C$ provide additional information about INEEL calculations for these configurations.

Configuration A. Configuration A is similar to the FIBS assumed in the UCSB study, but it is evaluated at an earlier time period, before all of the metallic and ceramic material relocates to the lower head. SCDAPI RELAP5 calculation results ${ }^{3}$ provided the basis for the masses assumed to relocate in Configuration A. Specifically, calculations assumed masses predicted to relocate by 12,047 seconds (see Table $2-1$ ). This configuration is characterized by a large oxidic pool ( $\sim 50 \%$ of the core inventory) with a small metallic component ( $-3800 \mathrm{~kg}$ of unoxidized zircaloy and $\sim 2600 \mathrm{~kg}$ of stainless steel). Configuration A developed primarily as a result of a series of localized relocations through the reflector sidewall. The stainless steel component is associated with the melting of gray rods and the addition of lower plenum structures that melted as a result of being submerged by the debris. Although SCDAP/RELAP5 results presented in Table 2-1 indicate that this configuration will only persist for 13 minutes, this SCDAP/RELAP5 analysis assumed that all relocations immediately fall though perforations in the core plate. If subsequent relocations were to be retained on the core plate, calculations suggest that Configuration A could persist 

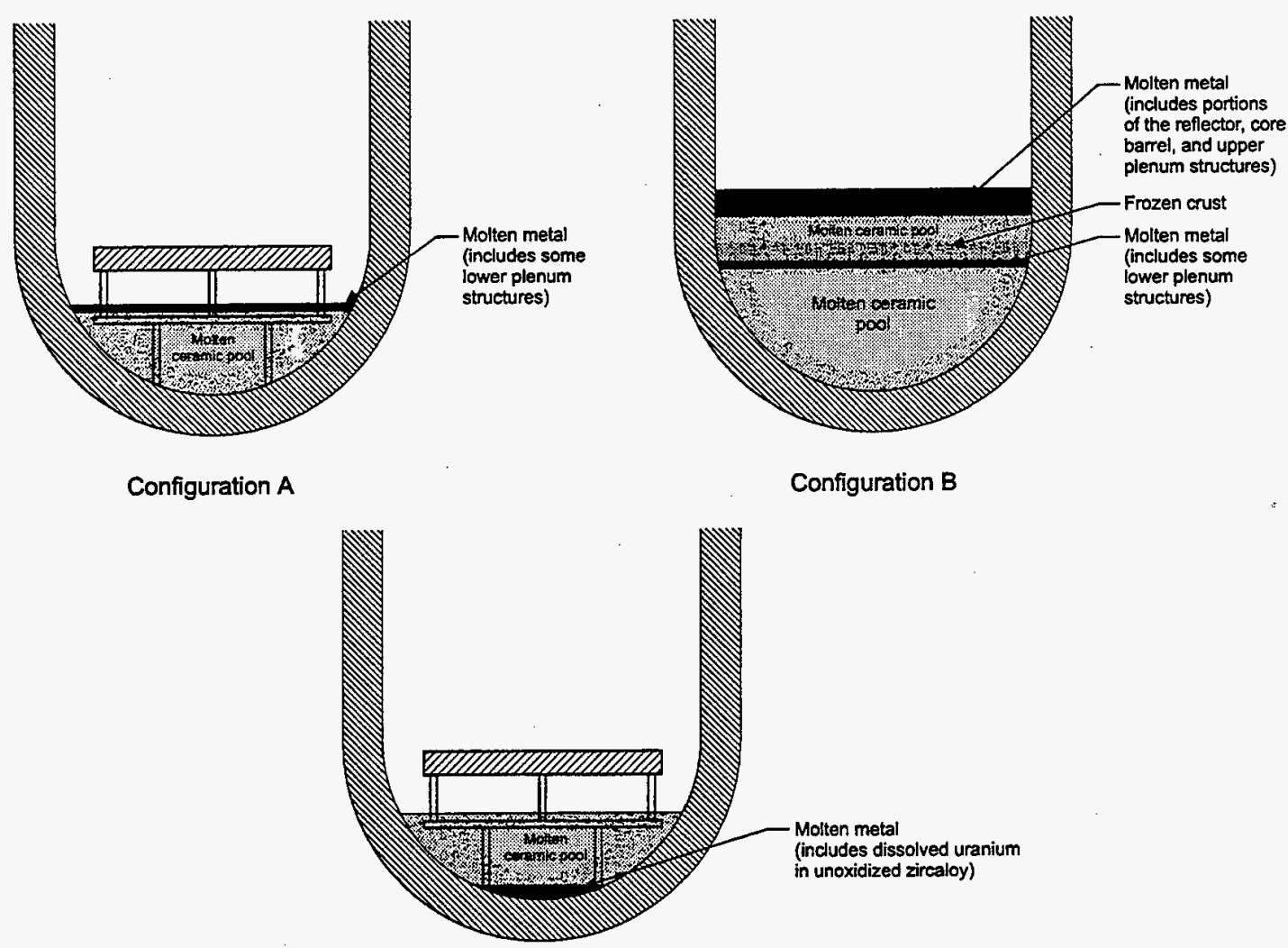

Configuration $\mathrm{C}$

$\cot 1118$

Figure 2-2. Alternate debris configurations evaluated by INEEL.

for more than an hour. Hence, this configuration could persist longer than the vessel thermal front penetration time ( 10 minutes); and it is appropriate to consider Configuration $\mathrm{A}$ as a "quasi-steady" state.

Table 2-1. Relocation masses predicted in Reference 3 SCDAP/RELAP5 AP600 analysis

\begin{tabular}{|c|c|c|c|c|c|}
\hline \multirow{2}{*}{ Time (s) } & \multicolumn{5}{|c|}{ Relocated Mass (kg) } \\
\hline & $\mathrm{UO}_{2}$ & $\mathrm{ZrO}_{2}$ & $\overline{Z r}$ & SS & Ag-In-Cd \\
\hline 10970 & 7145 & 807 & 822 & 556 & \\
\hline 11126 & 8438 & 964 & 863 & 1342 & \\
\hline 11232 & 4559 & 525 & 464 & 157 & \\
\hline 11513 & 10478 & 1226 & 1046 & 343 & \\
\hline 11891 & & & & & 956 \\
\hline 11987 & & & & & 628 \\
\hline 12047 & 6596 & 792 & 638 & 205 & \\
\hline 12189 & & & & & 954 \\
\hline 12263 & & & & & 174 \\
\hline 12431 & & & & & 59 \\
\hline 12844 & 26788 & 3278 & 1733 & 748 & \\
\hline
\end{tabular}


Because there are no experimental data proving that density differences overcome convective currents, SCDAP/RELAP5 doesn't assume that density differences cause melt segregation to occur. If one assumes that materials segregate as postulated in the UCSB FIBS, ${ }^{a}$ the metallic layer would be $\sim 10 \mathrm{~cm}$ thick, which is well below the threshold of $15 \mathrm{~cm}$ given in the UCSB study as the thickness necessary to insure vessel integrity under 'focussed' heat loads. Note that asymmetries could be expected in the core region as a result of the break location and the conditions that could develop in the vicinity of other major vessel penetrations. These asymmetries could significantly reduce reflector steel melting and, ultimately, the thickness of the 'focusing' layer assumed in the UCSB study.

Several peer reviewers (Olander, Sehgal, Seiler, Tuomisto, and Turland) discussed concerns about the potential for a Configuration A condition to present more severe challenges to the vessel. The UCSB authors added Appendix $O$ to address such concerns. However, several peer reviewers still expressed concerns about a thinner metallic layer in their final Appendix $\mathrm{V}$ comments. As observed by Peer Reviewer Sehgal, "The fear that some intermediate states may give higher thermal loading on the vessel is not completely alleviated." Likewise, Peer Reviewer Seiler contends in Appendix V that he is still not convinced that one should rule out an alternate scenario that would result in a thin metal layer due to the overlying steel core plate remelting before the oxidic debris remelts and a portion of the steel draining to fill porosity in the oxidic debris.

Configuration B. Configuration B represents a hypothesized endstate that is based on the same SCDAP/ RELAP5 calculations that formed the basis for Configuration A. At a time after Configuration A develops, SCDAP/RELAP5 predicts a final relocation in which an additional $35 \%$ of the core materials relocates via a failure of the bottom crust of the in-core pool. These additional core materials are assumed to form a molten pool with an upper surface that submerges part of the lower core support plate. Specific masses assumed for this configuration correspond to masses predicted to have relocated by 12,844 seconds in Table 2-1. The masses in the initial metallic layer would be heated from below by the molten pool and above by the overlying pool and crust. Metal in this layer would become molten and eventually superheated, possibly resulting in a more severe vessel heat load than that postulated in the UCSB study.

In this configuration, the region of concern is the initial thin metallic layer that is sealed below the additional $35 \%$ of materials relocating to form a second molten pool. As in the UCSB-assumed FIBS and Configuration $\mathrm{A}$, this configuration assumes that less dense, metallic components have segregated from the ceramic components of the initial pour. As observed by UCSB authors in their response to Peer Reviewer Turland's comments in Appendix V, ceramic crusts form upon contact with metals because "molten ceramic simply cannot exist in contact with a metallic melt." Hence, the metallic layer from the first relocations would be sealed by the upper and lower ceramic crusts. The boiling point for some components of the metallic layer is estimated to be around $3000 \mathrm{~K}$ (based on the boiling points of control materials and iron discussed in References 15, 16, and 17). Hence, much of the metallic layer will trapped between these crusts, focussing its heat on the vessel wall.

Several peer reviewers (Levy, Sehgal) commented about the potential for multi-layered, intermediate states to present more severe thermal challenges to the vessel. In addition, several analyses predicted geometries similar to Configuration B. For example, sensitivity analyses were performed by INEEL in

a. In Appendix O, UCSB authors refute peer review comments about the potential occurrence of a homogeneous melt by stating, without offering any evidence, that a "... slurry consistency is impossible to maintain at these power densities and at macroscopic dimensions..." 
which varying amounts of debris quenching was assumed for each of the debris relocations predicted by SCDAP/RELAP5. These analyses led to a Configuration B geometry where quenched, particulate ceramic debris is beneath and above the core plate. Calculations predict that the core plate will become molten approximately 2 hours after it is sandwiched between ceramic debris. The "Lead-in Intermediate State" postulated in Appendix $O$ of the UCSB study also considers a geometry where ceramic debris is beneath and above the core plate. However, the UCSB study postulates that their FIBS occurs because molten ceramic debris above the core plate relocates sideways into the lower molten pool and lifts the core plate or because heat loads from the ceramic debris melt the core plate and core plate steel rises due to buoyancy forces. Configuration $B$ considers the heat loads occurring in the metallic layer during the transitional period before the UCSB-assumed FIBS

Configuration $\mathrm{C}$. Configuration $\mathrm{C}$ represents a case where sufficient uranium dissolves into unoxidized zirconium to form a heavier metallic layer. As in the UCSB-assumed FIBS and Configurations A and B, this configuration assumes that more dense components have segregated from less dense components. However, the metallic layer sinks in this configuration. Heat loads are "focussed" on the bottom of the lower head where heat rejection is a minimum (see CHF values plotted in see Figure B-6).

For this analysis, INEEL assumed the same relocation masses assumed for Configuration A. However, INEEL assumed that the metallic layer contained a sufficient amount of relocated uranium to be heavier than the ceramic layer but remain below $40 \mathrm{wt} \%$ uranium. This uranium mass $(4291 \mathrm{~kg})$ is less than half the number of moles of unoxidized zirconium that SCDAP/RELAP5 predicted to relocate during times when intermediate configurations could occur.

Several peer reviewers (Chu, Levy, Olander, Sehgal, Turland) commented on the potential for this configuration to occur. In Appendix $\mathrm{O}$, the authors dismissed this configuration as "a non-confirmed hypothesis..." However, a convincing probability argument against this configuration requires experimental data refuting several sources of data supporting U-Zr formation ${ }^{18,19,20}$ or calculations illustrating that forces associated with turbulent natural convection overcome gravity forces that allow melt stratification because of density differences.

\subsection{Model Description}

In order to independently verify UCSB study results and to assess the impact of additional uncertainties and other debris configurations, INEEL developed the VESTA code. VESTA contains equations similar to the equations reported in the UCSB study. However, VESTA was developed in a more general fashion in order to evaluate phenomena and debris configurations not considered in the UCSB study.

VESTA allows consideration of several debris configurations, including the UCSB-assumed FIBS with a ceramic pool beneath a metallic layer (see Figure 2-1) and selected alternate debris configurations (see Figure 2-2). VESTA and the UCSB model include the following heat transfer processes:

- steady-state turbulent natural convection within a volumetrically-heated (by decay heat), molten ceramic pool;

- convection within the metallic layer;

- conduction through the ceramic crust surrounding the molten pool, upper plenum structures, and the vessel; 
- radiation heat transfer from the upper surface of top metallic layers to the inner surface of the upper plenum structures and the outer surface of the upper plenum structures to the vessel;

- boiling heat transfer from the vessel outer surface (through an assumed outer surface temperature boundary condition).

In both models, vessel wall heat fluxes are compared with critical heat flux correlations. In VESTA, the uncertainty distributions are Bayesian distributions, which are ultimately combined by a Monte Carlo sampling to yield a distribution on the probability of vessel heat fluxes exceeding CHF. Both models presume that vessel heat fluxes exceeding CHF is a sufficient and necessary condition for vessel failure (see Sections 3 and 4 of the UCSB study). Once the boiling crisis is reached, the bubble density becomes so large that bubbles coalesce, forming a vapor film that blankets the vessel surface. Although heat transfer may still occur via conduction and radiation across the vapor film, neither of these two processes is very effective. Hence, heat transfer coefficients would decrease significantly and the temperature of the outer vessel wall would increase to values where the steel essentially loses its strength and becomes susceptible to structural instability.

To address peer reviewer comments and INEEL concerns about limitations of the UCSB model, VESTA was developed to allow users to consider the following:

- Selected alternate debris configurations (users may select either Configuration A, B, or C);

- Decay heat power production associated with actinide and fission product heating;

- Metallic layer heat sources based on the fraction of actinide or fission product decay heat and/or other heat sources in the metallic material;

- Material property (density, specific heat, viscosity, thermal conductivity, volumetric coefficient of thermal expansion, eutectic temperatures) uncertainties and dependencies on temperature and/or composition;

- Various metallic layer emissivity uncertainty distributions;

- Various decay heat load uncertainty distributions (although VESTA includes a time-dependent decay power curve, the user may specify a decay power uncertainty distribution);

- Various metallic layer heat transfer correlation uncertainty distributions (users may specify constants and associated uncertainty parameters for their desired correlations);

- Various molten pool heat transfer correlation uncertainty distributions (users may specify constants and associated uncertainty parameters for their desired correlation for estimating average and angular dependent heat transfer coefficients);

- Various CHF correlation uncertainty distributions (users may specify constants and associated uncertainty parameters for their desired CHF correlation);

- Input parameter uncertainties [users may designate the type of distribution (normal, log-normal, Student's $t$, uniform, user-specified, or point estimate) and characteristic uncertainty distribution parameters (median value, standard deviation, degrees of freedom, etc.)].

Many of the capabilities implemented into VESTA were in response to unresolved UCSB peer review comments. For example, one peer reviewer (Olander) observed that the main solution in the UCSB report neglected metallic layer heat sources associated with retained fission products. Furthermore, several peer reviewers (Chu, Levy, Olander, Sehgal, Turland) observed that there was the potential for uranium to dissolve into the metallic layer, creating a more dense layer with actinide decay heating. Appendix $\mathbf{R}$ was 
added to the UCSB report to respond to Peer Reviewer Olander's comments, and Appendix P of the UCSB study presents results from a point estimate sensitivity study (UCSB Figure P.5) in which fractions of the decay heat are shifted to the metallic layer of their FIBS. Although UCSB authors concur that decay heat is present in the metallic layer, no integral evaluation was performed to assess the impact of this energy shift with other uncertainties in model input parameters or to assess the impact of a heavier metallic layer with internal heat sources. INEEL developed VESTA in a general fashion so that users may specify the fraction of uranium dissolving into the metallic layer, the decay heat associated with fission products and actinides, and the fraction of fission product decay heat retained by the metallic layer.

Appendix A lists VESTA modeling equations. Appendix B provides details about many of the modeling changes incorporated into VESTA. VESTA was verified using information presented in the UCSB study. Results from these benchmark calculations are presented in Appendix D.

\subsection{Input Parameters and Uncertainty Distributions}

INEEL's review indicates that many of the uncertainty distributions assumed in the UCSB FIBS analysis should be modified. Many of these modifications may affect the estimated margin to failure for the UCSB-assumed FIBS and other possible, more challenging debris configurations identified in Section 2.1.2. This section summarizes INEEL best estimate input uncertainty distributions for the UCSBassumed FIBS. The details regarding the development of INEEL uncertainty distributions are found in Appendix B. Where appropriate, Appendix B provides comparisons between input assumed by UCSB and INEEL and other data available in the literature.

Table 2-2 compares UCSB and INEEL analysis input for the UCSB-assumed FIBS. For these calculations, both studies assumed the same debris configuration, i.e., a debris bed containing $88,870 \mathrm{~kg}$ of ceramic material beneath a metallic layer containing $79,600 \mathrm{~kg}$ of metallic material. However, other input parameters and uncertainty distributions differed significantly. Significant differences in input used by INEEL include:

- Replacing the UCSB Mini-ACOPO (a 1/8th scale facility) molten pool natural convection heat transfer correlations with correlations that INEEL derived using larger-scale, ACOPO (a 1/2 scale facility) data [Sections B.1.1 and B.1.2];

- Replacing the UCSB ULPU CHF correlation with the Pennsylvania State University (Penn State) Subscale Boundary Layer Boiling (SBLB) CHF correlations (both the UCSB study and INEEL assumed input for tests without insulation) [Section B.1.3];

- Assuming appropriate uncertainties in heat transfer correlations and decay power curves [Sections B.1 and B.2];

- Assuming a metallic layer heat source corresponding to the fraction of fission products residing in the metallic layer [Section B.2.2];

- Basing melt relocation times, which affects decay power density, on severe accident analysis code predictions rather than qualitative analyses [Section B.2.1];

- Basing material properties and uncertainties on a wider range of published experimental data (particularly, metallic layer emissivity) [Section B.3].

Section 3 calculation results illustrate the impact of these input assumptions on the magnitude and distribution of heat fluxes predicted on the lower head. 
Table 2-2. Comparison of INEEL and UCSB input assumptions.

\begin{tabular}{|c|c|c|}
\hline Phenomena & UCSB Input for FIBS & INEEL Input for UCSB-assumed FIBS Requantification \\
\hline \multicolumn{3}{|l|}{ Heat Transfer } \\
\hline $\begin{array}{l}\text { Molten Ceramic Pool Heat } \\
\text { Transfer }\end{array}$ & $\begin{array}{l}\text { Correlations based on Mini-ACOPO data; no } \\
\text { uncertainties. }\end{array}$ & $\begin{array}{l}\text { Correlations and uncertainties for average heat transfer based on } \\
\text { INEEL best-fit of ACOPO data. }\end{array}$ \\
\hline - Average Upward & - UCSB Equation 5.11 & - INEEL Equation (B-6) \\
\hline - Average Downward & - UCSB Equation 5.28 & - INEEL Equation (B-7) \\
\hline - Localized Downward & - UCSB Equations 5.30a and 5.30b & $\begin{array}{l}\text { - UCSB Equations 5.30a and 5.30b; uncertainties from ACOPO } \\
\text { data. }\end{array}$ \\
\hline $\begin{array}{l}\text { Critical Heat Flux from a Ves- } \\
\text { sel to a Flooded Cavity }\end{array}$ & $\begin{array}{l}\text { Correlations based on ULPU data (UCSB } \\
\text { Equation E.3); no uncertainties. }\end{array}$ & $\begin{array}{l}\text { Correlations and uncertainties based on Cheung SBLB data } \\
{[(\mathrm{H} / \mathrm{R}=3) \text { curve INEEL Figure B-7]. }}\end{array}$ \\
\hline $\begin{array}{l}\text { Molten Metal Layer Heat } \\
\text { Transfer }\end{array}$ & $\begin{array}{l}\text { Correlations based on MELAD data (UCSB } \\
\text { Equations } 5.40 \text { and } 5.41 \text { ); no uncertainties. }\end{array}$ & $\begin{array}{l}\text { Correlations based on MELAD data (UCSB Equations } 5.40 \text { and } \\
5.41 \text { ); uncertainties from MELAD data. }\end{array}$ \\
\hline \multicolumn{3}{|l|}{ Decay Power Density } \\
\hline Ceramic Pool & $\begin{array}{l}\text { Statistical combination of decay power curve } \\
\text { (UCSB Figure 7.1), zirconium oxidation } \\
\text { fraction pdf (UCSB Figure 7.3), and melt } \\
\text { relocation time pdf (UCSB Figure 7.7). }\end{array}$ & $\begin{array}{l}\text { Statistical combination of UCSB decay power curve (UCSB } \\
\text { Figure 7.1) with ANS 5.1 Standard-recommended uncertainty dis- } \\
\text { tribution, UCSB zirconium oxidation fraction pdf (UCSB Figure } \\
\text { 7.3), and INEEL-recommended shift of } 1 \text { hour in the UCSB-pro- } \\
\text { posed melt relocation time curve (UCSB Figure 7.7). Resulting pdf } \\
\text { reduced by metallic layer decay heat fraction. }\end{array}$ \\
\hline Metallic Layer & No heat sources in the metallic layer. & $\begin{array}{l}\text { Time-dependent fission product decay power fractions and uncer- } \\
\text { tainties associated with zirconium, niobium, tellurium group, and } \\
\text { noble metals group. }\end{array}$ \\
\hline \multicolumn{3}{|l|}{ Material Properties } \\
\hline \multicolumn{3}{|l|}{ Ceramic Pool and Crust } \\
\hline -Specific Heat Capacity & $\begin{array}{l}\text { Mass average UCSB Table } 7.1 \text { values; no } \\
\text { uncertainties. }\end{array}$ & $\begin{array}{l}\text { Mass average UCSB Table } 7.1 \text { values; uncertainties associated with } \\
\text { each component's value and with mass averaging. }\end{array}$ \\
\hline -Thermal Conductivity & $\begin{array}{l}\text { UCSB Table } 7.1 \text { values; reduced } \\
\text { Appendix } L \text { uncertainties }\end{array}$ & $\begin{array}{l}\text { Composition-dependent values; uncertainties from UCSB } \\
\text { Appendix L. }\end{array}$ \\
\hline - Melting Temperature & $2973 \mathrm{~K}$; no uncertainties & $2850 \mathrm{~K}$; no uncertainties \\
\hline $\begin{array}{l}\text {-Volumetric Coefficient of } \\
\text { Expansion }\end{array}$ & $\begin{array}{l}\text { UCSB Table } 7.1 \text { value; reduced Appendix } L \\
\text { uncertainties }\end{array}$ & UCSB Table 7.1 value; uncertainties from UCSB Appendix L. \\
\hline -Density & $\begin{array}{l}\text { Volume average UCSB Table } 7.1 \text { values; no } \\
\text { uncertainties }\end{array}$ & $\begin{array}{l}\text { Volume average UCSB Table } 7.1 \text { values; uncertainties associated } \\
\text { with each component's value and with volume averaging. }\end{array}$ \\
\hline \multicolumn{3}{|l|}{ Metallic Layer } \\
\hline -Specific Heat Capacity & $\begin{array}{l}\text { Mass average UCSB Table } 7.1 \text { values; no } \\
\text { uncertainties }\end{array}$ & $\begin{array}{l}\text { Mass average UCSB Table } 7.1 \text { values; uncertainties associated with } \\
\text { each component's value and with mass averaging }\end{array}$ \\
\hline -Thermal Conductivity & $\begin{array}{l}\text { UCSB Table } 7.1 \text { values; reduced Appendix } \\
\text { L uncertainties }\end{array}$ & $\begin{array}{l}\text { Composition-dependent values; uncertainties from UCSB } \\
\text { Appendix L }\end{array}$ \\
\hline $\begin{array}{l}\text {-Volumetric Coefficient of } \\
\text { Expansion }\end{array}$ & $\begin{array}{l}\text { UCSB Table } 7.1 \text { value; reduced Appendix L } \\
\text { uncertainties }\end{array}$ & $\begin{array}{l}\text { Volume average UCSB Table } 7.1 \text { values; uncertainties associated } \\
\text { with each component's value and with volume averaging }\end{array}$ \\
\hline -Density & $\begin{array}{l}\text { Volume average UCSB Table } 7.1 \text { values; no } \\
\text { uncertainties }\end{array}$ & $\begin{array}{l}\text { Volume average UCSB Table } 7.1 \text { values; uncertainties associated } \\
\text { with each component's value and with volume averaging }\end{array}$ \\
\hline -Emissivity & 0.45 (UCSB tests); no uncertainties & $\begin{array}{l}\text { Median value of } 0.29 \text {; standard deviation of } 0.04 \text { (based on pub- } \\
\text { lished data) }\end{array}$ \\
\hline \multicolumn{3}{|l|}{ Vessel Wall } \\
\hline -Thermal Conductivity & $\begin{array}{l}\text { Point estimates based on UCSB Figure L.3 } \\
\text { Upper Wall: Not clear } \\
\text { Lower Wall: } 32 \mathrm{~W} / \mathrm{m}^{2} \mathrm{~K} \text {; no uncertainties }\end{array}$ & $\begin{array}{l}\text { Median values and uncertainties based on UCSB Figure L.3. } \\
\text { Upper wall: } 41 \pm 1 \mathrm{~W} / \mathrm{mK} \text {; } \\
\text { Lower Wall: } 32 \pm 2 \mathrm{~W} / \mathrm{mK}\end{array}$ \\
\hline -Melting Temperature & $1600 \mathrm{~K}$; no uncertainties & $\mathrm{Zr}$-Fe phase diagram; no uncertainties \\
\hline \multicolumn{3}{|l|}{ Upper Internal Structures } \\
\hline -Thermal Conductivity & $30 \mathrm{~W} / \mathrm{mK}$; no uncertainties & $\begin{array}{l}\text { Temperature-dependent values; standard deviation of } 0.6 \mathrm{~W} / \mathrm{mK} \\
\text { (based on published data) }\end{array}$ \\
\hline -Emissivity & 0.8 ; no uncertainties & $\begin{array}{l}\text { Median value of } 0.85 \text {; standard deviation of } 0.03 \text { (based on pub- } \\
\text { lished data) }\end{array}$ \\
\hline
\end{tabular}




\subsection{Sensitivity Studies}

INEEL identified phenomenological uncertainties associated with some parameters that would be better addressed by performing sensitivity studies or additional calculations. Table 2-3 summarizes calculations that were completed to address these uncertainties. This section provides additional information on these phenomena. In addition, this section discusses phenomenological uncertainties that INEEL and NRC deemed as not requiring additional investigation.

Table 2-3. Sensitivity calculations performed to address phenomenological uncertainties.

\begin{tabular}{|l|l|l|}
\hline \multicolumn{1}{|c|}{ Phenomena } & \multicolumn{1}{|c|}{ Effect } & \multicolumn{1}{c|}{ Calculation } \\
\hline \hline $\begin{array}{l}\text { Vapor transport effects on natural } \\
\text { convection }\end{array}$ & $\begin{array}{l}\text { Increased upward heat losses from } \\
\text { molten ceramic pool. }\end{array}$ & $\begin{array}{l}\text { Uncertainty analyses assuming a factor of 10 increase } \\
\text { in upward heat transfer. }\end{array}$ \\
\hline $\begin{array}{l}\text { Additional metallic layer heat } \\
\text { sources (due to steel activation or } \\
\text { oxidation). }\end{array}$ & $\begin{array}{l}\text { More heat "focussed" from metallic } \\
\text { layer. }\end{array}$ & $\begin{array}{l}\text { Uncertainty analysis assuming additional heat in } \\
\text { metallic layer that encompasses steel structure } \\
\text { activation and oxidation. }\end{array}$ \\
\hline Reduced metallic melt mass & $\begin{array}{l}\text { More heat "focussed" from metallic } \\
\text { layer. }\end{array}$ & $\begin{array}{l}\text { Point estimates assuming various metallic masses; } \\
\text { uncertainty analysis for mass yielding } q / \mathrm{q} \text { cHF }=1.0\end{array}$ \\
\hline
\end{tabular}

\subsubsection{Vapor-Enhanced Upward Heat Transfer from the Ceramic Pool}

If the temperature in the ceramic pool exceeds the boiling temperature of one or more metallic components, vaporization and pool boiling may occur, enhancing upward heat transfer from the molten pool. Phenomena and/or mechanisms that could result in the presence of lower boiling temperature components in the ceramic pool were identified by several peer reviewers (Levy, Olander, Tuomisto). As noted in Tuomisto's peer review comments, the question of steel boiling was identified in a March 1994 Grenoble Workshop on "Large Molten Pool Heat Transfer." However, UCSB study authors indicated that the quantities of metallics that they believed would exist in the ceramic pool were too small to impact heat transfer.

As observed by Peer Reviewer Olander, the presence of such lower vaporization temperature materials is supported by voids measured in examinations of debris from the Three Mile Island Unit 2 (TMI-2) vessel. ${ }^{21}$ Voids were also observed in severe fuel damage tests, such as the INEL Loss of Fluid Test LP-FP-2 (LOFT LP-FP-2) ${ }^{22}$ and the SNL Damaged Fuel 4 (DF-4) test. ${ }^{23}$ (Porosities of approximately $20 \%$ were typically measured in debris specimens.) Using correlations based on experiments performed by Greene, et al., ${ }^{24}$ INEEL performed calculations to estimate the impact of vapor on heat transfer to the side walls. ${ }^{25}$ As shown in Figure 2-3, Reference 25 calculations indicate that boiling significantly increases upward heat transfer for pool Rayleigh numbers of interest $\left(10^{14}<\mathrm{Ra}_{\mathrm{p}}{ }^{\prime}<10^{17}\right)$.

Peer Reviewer Levy commented that there is the potential for additional metallics to fall into the molten ceramic pool at later times, citing mechanisms such as melting upper plenum metallic structures. Although such transient mechanisms would eventually cease if heat fluxes from the vessel remain below CHF, it is possible for this transient state to exist for sufficient times that it is appropriate to characterize it as a quasi-steady state. Hence, INEEL performed a sensitivity calculation to determine if the enhanced heat transfer associated with vaporization and pool boiling was sufficient to cause vessel heat fluxes to exceed CHF. Because of the limited data available for assessing the impact of vapors on heat transfer, INEEL assumed a factor of 10 increase in the upward heat transfer correlation for this sensitivity 
calculation. This factor of 10 bounds the increase in heat transfer shown in Figure 2-3 for void fractions and Rayleigh numbers of interest.

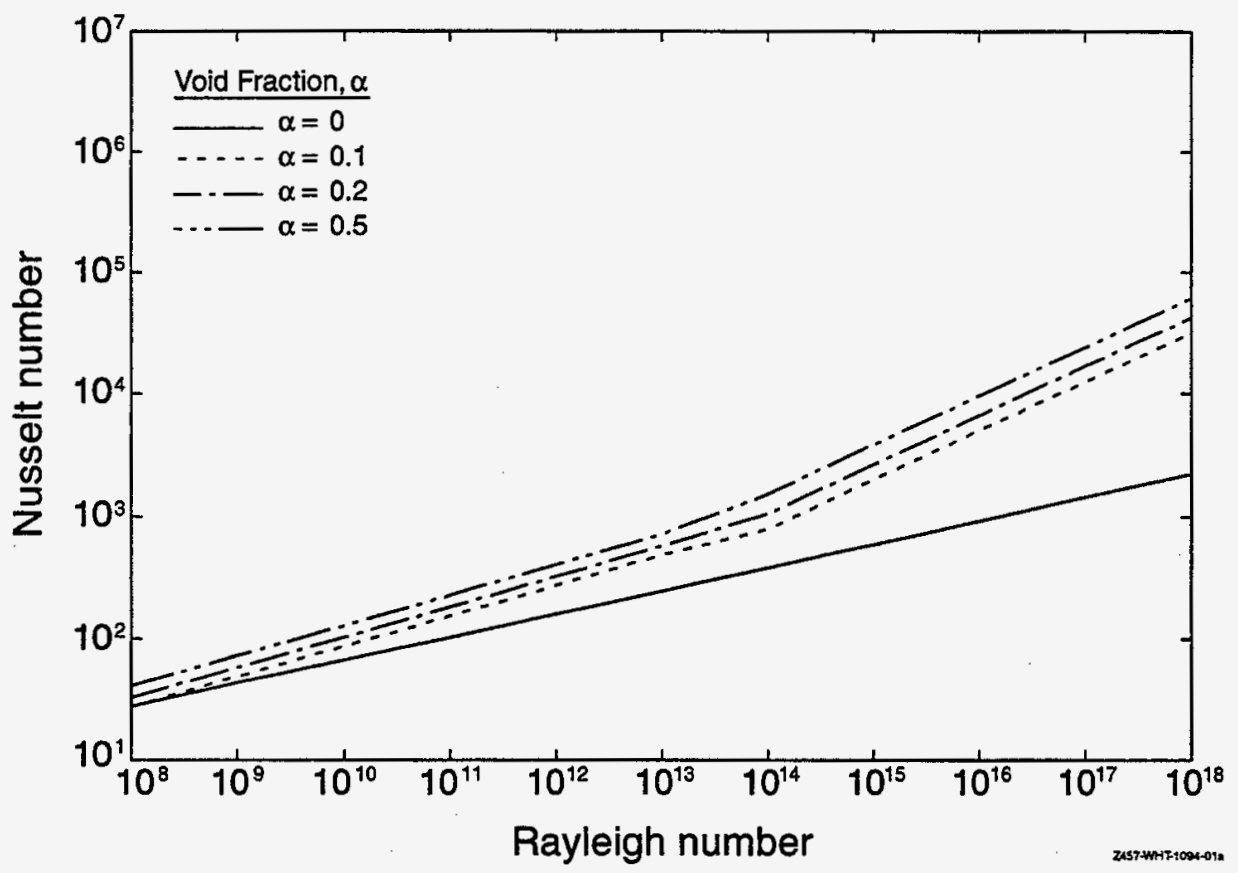

Figure 2-3. Impact of boiling on heat transfer from a molten pool.

\subsubsection{Additional Metallic Layer Heat Sources}

There is a potential for the metallic layer to contain additional heat sources due to activation of stainless steel and oxidation of materials in the metallic layer. Although there is considerable uncertainty associated with the magnitude of such heat sources, INEEL performed a sensitivity study to investigate the effects of additional metallic layer heat sources.

INEEL performed scoping ORIGEN2 calculations to estimate the magnitude of the additional heat source associated with stainless steel activation. ${ }^{26}$ These calculations suggest that the isotope of concern is Manganese-56, which has a 2.578 hour half-life. For time periods of interest (between 2 and 6 hours after shutdown), ORIGEN2 calculations suggest that the heat source associated with activation of stainless steel may lie between 4 and 8 percent of the core's power. At later times (between 6 and 12 hours), the heat source is smaller (between 2 and 4 percent of the core's power). For a FIBS point estimate calculation, this translates into the metallic layer heat source being increased from approximately $17 \%$ to a maximum of $25 \%$ of the core's power. It should be noted that these calculations are scoping. There was considerable uncertainty associated with several input assumptions, such as the flux distribution, the composition of SS304, and activation libraries for ORIGEN2.

Peer Reviewer Olander observed that there is also the potential for heat sources associated with oxidation of materials in the metallic layer. Using equations in Reference 27, INEEL performed scoping calculations to bound the energy released from oxidation. For a steam environment, these calculations 
indicate that $\sim 1 \mathrm{MW}$ will be released during the first few seconds of oxidation. In cases where the upper surface of the metallic layer isn't disturbed by turbulent convection or additional structural material, calculations indicate that within fairly short time periods $(<5$ minutes), the oxidation energy rapidly decreases to less than $1 \%$ of the molten pool's decay heat. Although higher amounts of energy ( $\sim \mathrm{MW})$ may be released when zirconium or stainless steel reacts with air, it isn't clear that there will be a continuous source of air into the reactor vessel. Hence, INEEL considers that the metallic layer heat source assumed in this sensitivity case bounds the energy addition associated with metallic layer oxidation.

\subsubsection{Reduced Metallic Melt Mass}

INEEL's review indicates that a key assumption for the UCSB-assumed FIBS is the mass of relocated vessel internal structures (reflector, core barrel, core plate, etc.) in the metallic layer. Because this layer has a higher thermal conductivity, the mass of metals assumed in the metallic layer significantly affects the estimated magnitude of the heat fluxes "focussed" toward the adjacent vessel sidewall. Larger metallic masses result in lower heat loads to the vessel wall because the heat in the metallic layer is dissipated over larger surface areas.

Figure 7.5 of the UCSB report illustrates their assumed pdf for the amount of structural steel that melts. As noted in Section 7 (p. 7-5), the minimum value in this pdf corresponds to all of the core plate $(\sim 25,000 \mathrm{~kg})$, all of the reflector $(\sim 40,000 \mathrm{~kg})$, and all of the lower internal structures $(\sim 2,000 \mathrm{~kg})$ forming the metallic layer. ${ }^{a}$ In addition, the pdf considers the potential for lower portions of the core barrel and some of the upper internal structures to be included in the metallic layer. Several peer reviewers (Kress, Olander, Sehgal, Seiler, Tuomisto, and Turland) specifically questioned the UCSB pdf for metallic layer mass, observing that the UCSB-assumed FIBS doesn't necessarily bound challenges to the vessel wall from postulated intermediate states. Several analyses (SCDAP/RELAP5, ${ }^{3}$ MELCOR, ${ }^{4}$ MAAP, ${ }^{5}$ and expert opinion $\left.{ }^{14}\right)$ estimate smaller steel masses $(\sim 6,000-27,000 \mathrm{~kg})$ than the minimum mass $(67,000 \mathrm{~kg})$ shown in the Figure $7.5 \mathrm{pdf}$ for relocated steel.

Differences in metallic melt mass assumptions are due to current limitations in modeling core melt progression and relocation, uncertainties inherent in code calculations, and differences in opinion about how melt progression would proceed in the AP600. Many severe accident analysis codes contain models that allow localized reflector and/or core plate failure. These models were developed based on postaccident examinations of material in the TMI- 2 vessel. The UCSB study provides qualitative arguments as a basis for assuming that the massive steel reflector and core plate delay relocation of ceramic material, and therefore, that it is not possible to get substantial relocation of ceramic material without including the mass of the core plate and the reflector. However, the UCSB study doesn't provide any data or detailed, transient thermal hydraulic analyses to substantiate their AP600 melt progression assumptions.

The large impact that steel melt mass has on analysis results (see Section 7 of the UCSB report) suggests that a single pdf that considers the entire range of postulated melt masses possible at various times in the transient would not yield meaningful results. Hence, INEEL performed a series of VESTA point estimate calculations in which the metallic mass assumed for the UCSB-assumed FIBS was reduced until vessel heat fluxes were predicted to equal CHF. For the case in which the assumed metallic mass resulted

a. Steel structural mass estimates by UCSB and INEEL differ. INEEL estimated that the core plate mass is $21,000 \mathrm{~kg}$, the reflector is $52,000 \mathrm{~kg}$, and the lower internal structure mass is $2,400 \mathrm{~kg}$. 
in $\mathrm{q}^{\prime \prime}(\theta) / \mathrm{q}^{\prime \prime}(\theta)_{\mathrm{CHF}}=1.0$ at some locations, INEEL applied VESTA to obtain a typical pdf for CHF ratios exceeding unity at other locations.

\subsubsection{Additional Uncertainties not Addressed by INEEL Sensitivity Studies}

As discussed above, there were several uncertainties identified by UCSB study peer reviewers and by INEEL as having the potential to affect UCSB study results that were not addressed by additional INEEL calculations. These uncertainties are discussed below.

\subsubsection{Transient Natural Convection}

Heat fluxes to the vessel wall from a volumetrically heated ceramic pool with fully-developed steady-state natural convection vary with angle (see Section B.1.2). Near the base of the hemisphere, the heat fluxes are considerable smaller, approximately 1/10th the average downward flux and near the top heat fluxes are larger, nearly twice the average downward heat flux. Likewise, CHF values vary in a similar manner with angle (see Section B.1.3). Variations in angle between vessel wall heat fluxes from the ceramic pool and CHF values result in a minimum margin-to-failure near the top of the pool. However, a fully-developed steady-state heat flux profile may not exist at certain times in the molten pool. For example, there are intermediate states that exist before steady-state natural convection is established. If upper plenum structures continue to melt into the pool, these intermediate states may continue for significant time periods. Several peer reviewers discussed the impact of these transient time periods (Levy, Schmidt, and Sehgal), observing that the challenges to the lower head may be more severe at certain locations than heat fluxes predicted for the UCSB-assumed FIBS. Because heat flux profiles (for heat transfer from the pool to the RPV wall) may be flatter before steady state turbulent natural convection is established, it may be possible for vessel heat fluxes at the bottom of the vessel to exceed CHF during such intermediate states. However, there are little data available for quantifying such transient heat flux profiles. Hence, no additional calculations were performed to address this phenomena.

\subsubsection{Metallic Layer Natural Convection}

As discussed above, several peer reviewers (Levy, Olander, Sehgal, and Turland) noted that there may be volumetric heat sources present in the metallic layer, and these heat sources were included in the INEEL requantification. In the UCSB study, heat transfer to the vessel wall due to natural convection within the metallic layer is modeled using heat transfer correlations for fluids without volumetric heat sources. However, correlations considering the presence of volumetric heat sources may be more appropriate for the metallic layer. Although many of the natural convection correlations for pools with volumetric heating were obtained for pools with Rayleigh numbers similar to values predicted for the metallic layer, few tests were performed with other relevant boundary conditions existing in the metallic layer, e.g., a heated lower surface and constant sidewall temperatures. As discussed in Appendix B (see Section B.1.4), turbulent natural convection correlations developed for pools with volumetric heat sources yield comparable or lower values than heat transfer coefficients predicted with the correlations assumed in the UCSB study. Hence, no additional calculations were performed to investigate this phenomena; and the UCSB-assumed correlations were retained in the INEEL requantification (although INEEL considered uncertainty associated with these correlations). 


\subsubsection{Upper Plenum Surface Area}

The upper internal structure surface area defines the surface area to which heat is transferred from the upper surface of metallic layer (see Equations 6.10 and 6.12 of DOE/ID-10460). This area varies with the mass of molten ceramic and metallic material in the molten pool. For the range of core barrel masses assumed to melt in the UCSB study (see page 7-1 of DOE/ID-10460), INEEL calculations indicate that the internal surface area of the core barrel may range from 26 to $56 \mathrm{~m}^{2}$.

In their responses to RAI questions 480.459 and $480.965,{ }^{a}$ Westinghouse indicated that a single value was assumed for the upper internal structure surface area above the melt of $75.36 \mathrm{~m}^{2}$. The Westinghouse response to RAI 480.966 includes a limited number of point estimate calculations in which the upper plenum surface area was varied from approximately 40 to $75 \mathrm{~m}^{2}$. These point estimate calculations indicate that the ratio of $q^{\prime \prime}(\theta) / q^{\prime \prime}(\theta)_{C H F}$ decreased by less than $10 \%$ when the upper internal structure surface area decreased by over $45 \%$. Although INEEL believes that the area assumed for upper internal structure surface should be decreased in the main solution for the UCSB-assumed FIBS, sensitivity studies indicate that this area did not significantly impact results. Hence, the INEEL requantification assumed $75.36 \mathrm{~m}^{2}$ and no additional calculations were performed to address this uncertainty.

\subsubsection{Structural Analyses}

The UCSB study includes several analyses to provide insights about vessel integrity when the vessel wall is reduced to CHF-limited thicknesses:

- Section 4.1 uses a "basic principles" approach to determine that the vessel must be at least $0.15 \mathrm{~mm}$ thick in order to support dead loads (without considering thermal stresses) when the vessel is at full strength.

- Section 4.2 applies "basic principles" to determine that the load carrying capacity is governed by the wall thickness under tension, which is considerably larger than $0.15 \mathrm{~mm}(-5 \mathrm{~mm})$.

- The Section 4 Addendum uses a finite element, elastic-perfectly-plastic thermal structural analysis to provide a more rigorous indication of the ablated section's structural capacity.

- Appendix G presents a finite element structural creep analysis for a vessel with an internal pressure of 400 psi to provide additional insights.

The Section 4 structural analyses only consider dead loads and buoyancy forces in a completely depressurized, thin-walled hemispherical vessel. The vessel is assumed to have a linear temperature distribution through its thickness, with an outside wall temperature of $400 \mathrm{~K}$ and an inside temperature of $1573 \mathrm{~K}$ (the liquidus temperature of their assumed iron/zircaloy eutectic composition).

a. The UCSB study did not document what value was assumed for this surface area. In the response to RAI Question 480.459 , Westinghouse indicated that $57.4 \mathrm{~m}^{2}$ was assumed. However, their response to RAI Question 480.965 indicates that a value of $75.36 \mathrm{~m}^{2}$ was assumed and cites the dimensions used to estimate this number (a cylinder for the core barrel with inner diameter $=2 \mathrm{~m}$; and height $=5 \mathrm{~m}$ topped by a disk with radius $=2 \mathrm{~m}$ ). Hence, INEEL assumed that there is a typographical error in the Westinghouse response to RAI Question 480.459. 
In their initial comments, the UCSB study peer reviewers questioned several aspects of the UCSB structural analyses. Two peer reviewers requested that additional analyses be performed to investigate ductile tearing at the inside surface of the vessel due to reversed longitudinal bending. UCSB study authors added the Section 4 Addendum to address these peer review questions. INEEL's evaluation of final peer review final comments in Appendix $\mathrm{V}$ indicates that the peer reviewers typically believed that their questions on the structural analysis were addressed.

However, INEEL identified the following concerns about the UCSB structural analyses:

- INEEL observed that the UCSB study neglected the radial stress component in their solution for thermal stresses in a cylinder (Equation 4.1 of DOE/ID-10460). INEEL calculations indicate that this radial stress, calculated elastically, is about $10 \mathrm{MPa}$, which is considerably less than elastic tangential stresses of around $1500 \mathrm{MPa}$. Therefore, INEEL calculations confirm that it was appropriate for UCSB to neglect radial stresses.

- Section 4 implies that an inner region of the vessel wall remains elastic and is available, with the outer segment in the vessel wall that is in tension and slightly yielded due to thermal stress, for some additional load-carrying capacity. Because there is no additional tensile load-carrying capacity in a material that is assumed to be elastic-perfectly-plastic and previously tensionyielded, INEEL's review indicates that the load capacity margin of the vessel may be less than inferred in the UCSB study.

- Although the elastic-perfectly-plastic thermal structural analysis documented in the Addendum to Section 4 gives a good idea of how thermal stress would redistribute and confirms the existence of a vessel wall inner segment that could be called on for longer term dead weight loading capacity, the analysis appears to neglect creep effects and doesn't include details about assumed boundary conditions, mechanical loading, or mechanical properties.

- The UCSB study lacks a finite element analysis of the ablated region of the vessel in which creep and thermal stresses are simultaneously considered and boundary conditions, mechanical loads, and mechanical properties are clearly specified.

In summary, more defensible estimates of the vessel's margin could be obtained if the Appendix G UCSB model was modified to consider thermal creep stresses and applied to the ablated region of the vessel. Although INEEL's review indicates that the load capacity margin of the vessel is less than inferred in the UCSB study, margins predicted for the vessel for the various structural analyses presented in the UCSB study suggests that no additional structural analyses are needed. 


\section{Results}

This section presents VESTA calculation results. As shown in this section, VESTA benchmark calculations verify UCSB study results. VESTA results for the UCSB-assumed FIBS with INEEL input demonstrate the impact of uncertainty distribution assumptions. Results from VESTA calculations considering alternate debris configurations identified in Section 2.1.2 indicate that heat fluxes induced by some credible debris configurations may exceed CHF.

\subsection{Verification Calculation Results}

In addition to verifying UCSB study results, benchmark calculations indicate that INEEL correctly interpreted equations applied in the UCSB analyses and correctly encoded these equations into VESTA. Results from VESTA were compared with results presented in DOE/ID-10460 Appendix Q. Appendix D of this document contains a complete set of figures comparing benchmark calculation results. This section summarizes these results.

Input distributions used by INEEL for these benchmark calculations are listed in Columns 2 and 3 of Table C-1 in this report. Note that this is INEEL's interpretation of UCSB input based on information in the UCSB study and Westinghouse's responses to RAIs. The distributions assumed for some input parameters in the UCSB study aren't well documented, and UCSB study results suggest that some of their calculations may have assumed inconsistent FIBS input parameters. For example, the three sets of FIBS results included in the UCSB study differ in vessel wall heat fluxes predicted at locations within the metallic layer. [For locations adjacent to the metallic layer, Appendix P (Figure P.5) suggests heat fluxes to the water are $550 \mathrm{~W} / \mathrm{m}^{2}$ and that the ratio of $\mathrm{q}^{\prime \prime}(\theta) / \mathrm{q}^{\prime \prime}(\theta)_{\mathrm{CHF}}$ is 0.4 ; Appendix $\mathrm{Q}$ (Figure $\mathrm{Q} .1$ ) suggests heat fluxes to the water are $500 \mathrm{~W} / \mathrm{m}^{2}$, and Section 7 (Figure 7.10) suggests that the median value of the ratio of $\mathrm{q}^{\prime \prime}(\theta) / \mathrm{q}^{\prime \prime}(\theta)_{\mathrm{CHF}}$ is 0.49 ].

Figure 3-1 compares point estimate vessel wall heat fluxes predicted by VESTA (designated INEEL verification) and the UCSB model (designated DOE/ID-10460), and Figure 3-2 compares CHF pdfs predicted by each model at selected locations along the vessel lower head. Figure 3-1 indicates that the VESTA and UCSB model predictions differ by less than ten percent at locations adjacent to the ceramic pool (between 0 and $\sim 76^{\circ}$ ) and by approximately twenty percent at locations adjacent to the metallic layer (greater than $\sim 76^{\circ}$ ). However, the CHF ratio pdfs shown in Figure 3-2 appear to match fairly well in both the ceramic and metallic layers. As discussed above, the three sets of FIBS results included in the UCSB study differ in vessel wall heat fluxes predicted at locations near the metallic layer. Hence, differences in Figure 3-1 heat flux results may be due to undocumented differences in UCSB input assumptions.

a. INEEL calculations indicate that point estimate UCSB assumptions would yield a ceramic pool that has a maximum depth of $1.52 \mathrm{~m}$, which corresponds to an angle of $75.9^{\circ}$. 


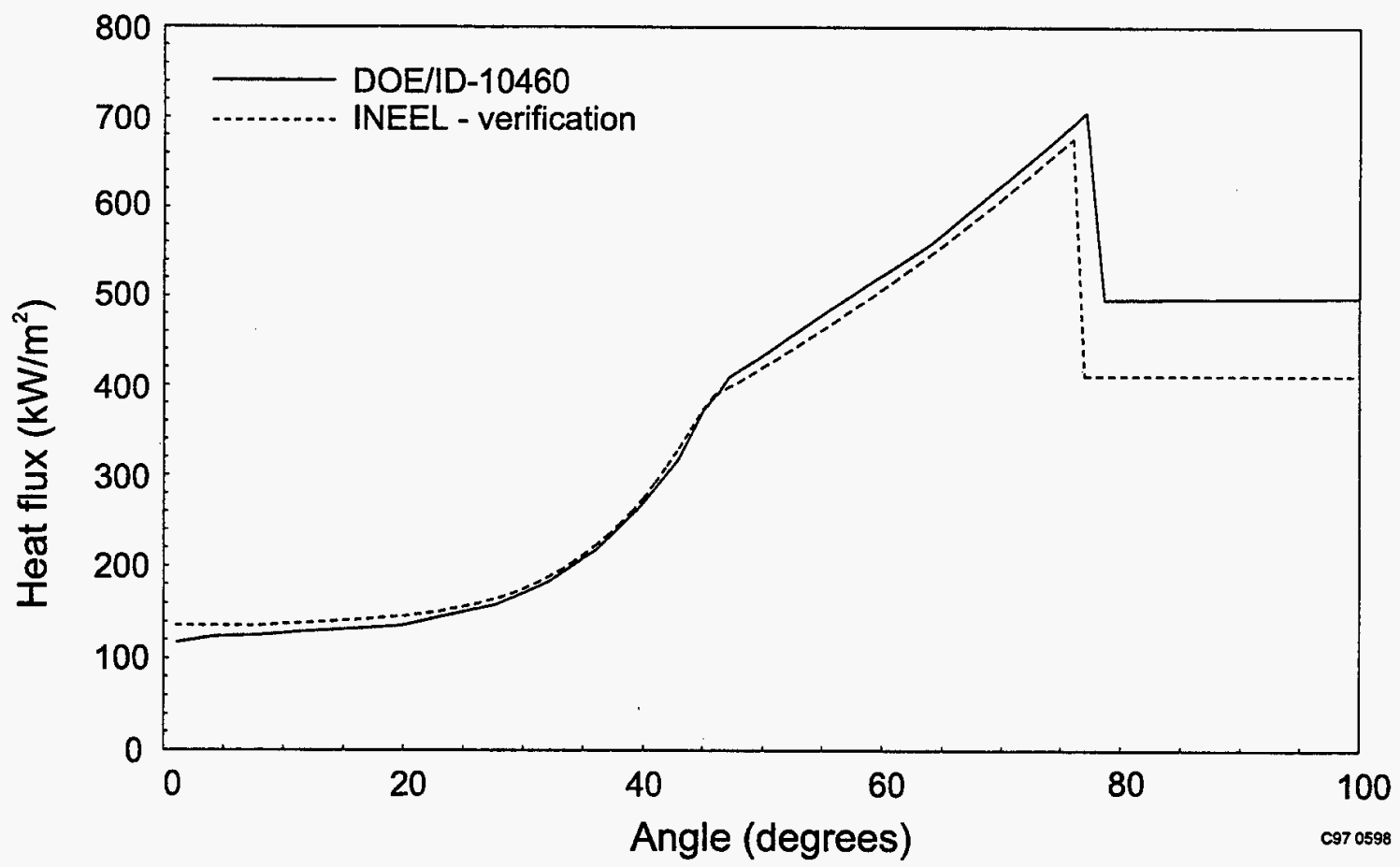

Figure 3-1. UCSB (DOE/ID-10460) and VESTA (INEEL-verification) heat fluxes assuming UCSB FIBS and input distributions.

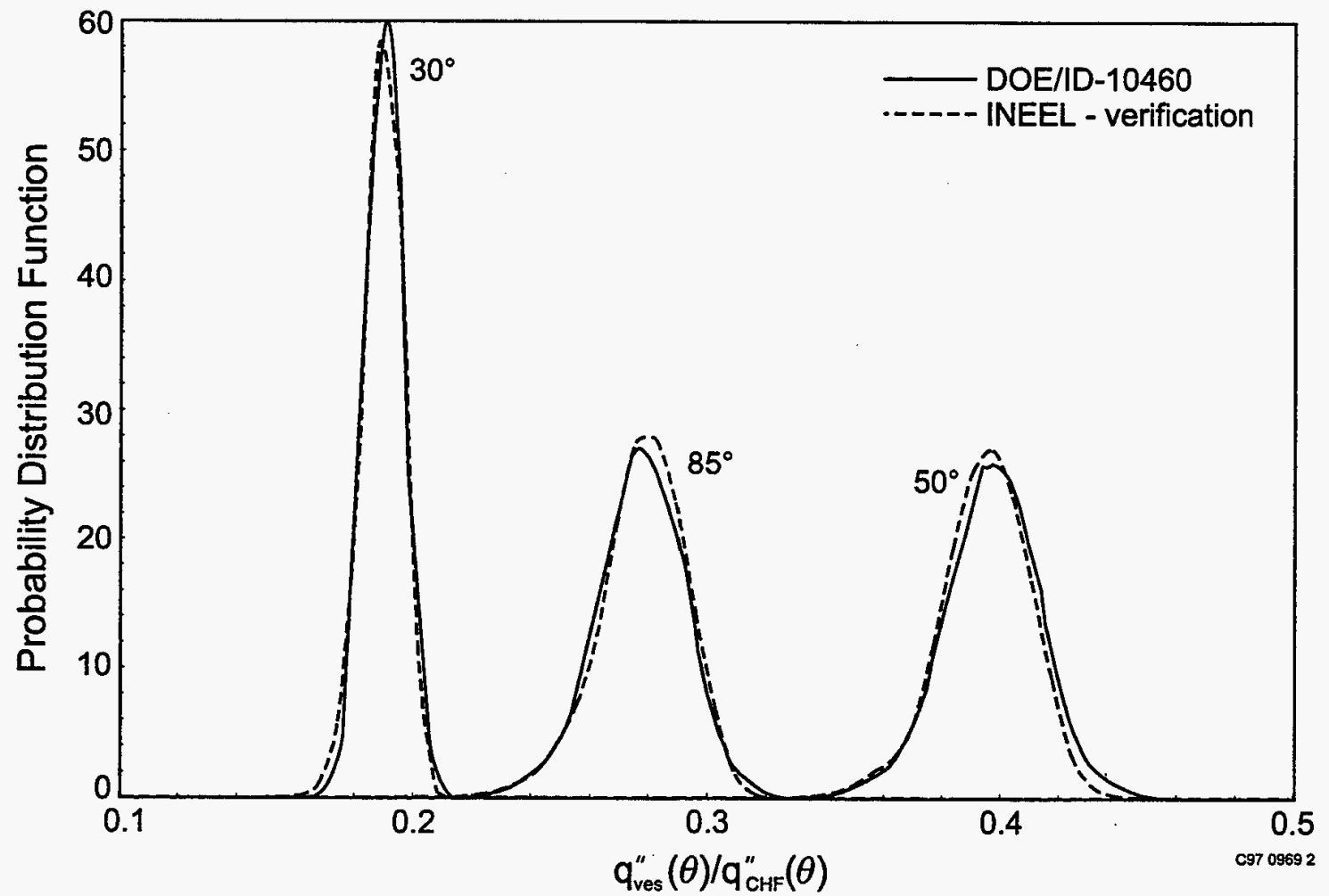

Figure 3-2. UCSB (DOE/ID-10460) and VESTA (INEEL-verification) CHF ratio pdfs assuming UCSB FIBS and input distributions. 


\subsection{INEEL Requantification of UCSB-assumed FIBS}

As discussed in Section 2.3, some peer reviewers questioned several input parameter distributions assumed in the UCSB study. Therefore, the UCSB-assumed FIBS was evaluated using INEEL input uncertainty distributions discussed in Section 2.3. (Specific input values used for these benchmark calculations are listed in Columns 4 and 5 of Table $\mathrm{C}-1$ of this report). As discussed in this section, calculations assuming INEEL input parameter distributions confirm that heat fluxes are below CHF for the UCSB-assumed FIBS but indicate that the heat flux distribution is significantly different than predicted in the UCSB study. In addition, INEEL performed sensitivity calculations to assess the impact of phenomenological uncertainties associated with input parameters. Sensitivity studies indicate that some phenomenological uncertainties identified in Section 2.4 can significantly reduce margin to failure estimates.

\subsubsection{INEEL Input Uncertainty Distributions}

When the UCSB-assumed FIBS is evaluated using INEEL input uncertainty distributions, the distribution of vessel failure margins differs significantly. Figure 3-3 compares point estimate values for vessel heat fluxes predicted assuming INEEL input (the curve labeled INEEL) with the UCSB input (the curve labeled DOE/ID-10460). Vessel heat flux to CHF ratios predicted for these cases are compared in Figure 3-4. CHF ratio pdfs predicted with INEEL input distributions are plotted in Figure 3-5.

As shown in these figures, INEEL input uncertainty distributions significantly affect heat flux predictions. INEEL calculations predict that the margin to failure is smallest at vessel locations adjacent to the metallic layer (above $-76.2^{\circ}$ ). In addition, Figure 3-5 indicates that INEEL input distributions decrease the margin to failure in the metallic layer and broaden uncertainty distributions predicted for CHF ratios. As shown in Figure 3-5, the pdf for $\mathrm{q}^{\prime \prime}(\theta) / \mathrm{q}^{\prime \prime}(\theta)_{\mathrm{CHF}}$ at $85^{\circ}$ extends from 0.3 to 0.6 and is centered around 0.48 . For UCSB input, Figure 3-2 indicates that the pdf for $q^{\prime \prime}(\theta) / q^{\prime \prime}(\theta)_{C H F}$ at $85^{\circ}$ extends from 0.22 to 0.32 and is centered around 0.28 .

Differences in results are primarily attributed to differences in assumptions related to metallic layer heat sources, metallic layer emissivity, and CHF correlations. Modeling decay heat sources in the metallic layer and reducing metallic layer emissivity increased vessel heat flux estimates at vessel locations in contact with the metallic layer. Assuming the Cheung SBLB CHF correlations decreased CHF estimates at vessel locations in contact with the metallic layer (see Figure B-7). The net effect of these changes led to increased CHF ratio predictions at vessel locations near and in contact with the metallic layer (at angles greater than $\sim 76.2^{\circ}$ ). Note that the allocation of some decay heat to the metallic layer reduces ceramic pool heat sources and that assuming Cheung SBLB CHF correlations decreases CHF estimates at locations where the vessel is adjacent to the ceramic pool. However, INEEL's assumed increase in decay heat (due to an assumed earlier core relocation time) partially offsets reductions predicted for the heat flux and heat flux ratio at vessel locations adjacent to the ceramic pool. Finally, the pdfs predicted with INEEL's recommended input tend to be less peaked because INEEL input considers uncertainties in many parameters that UCSB calculations assumed as point estimate parameters. 


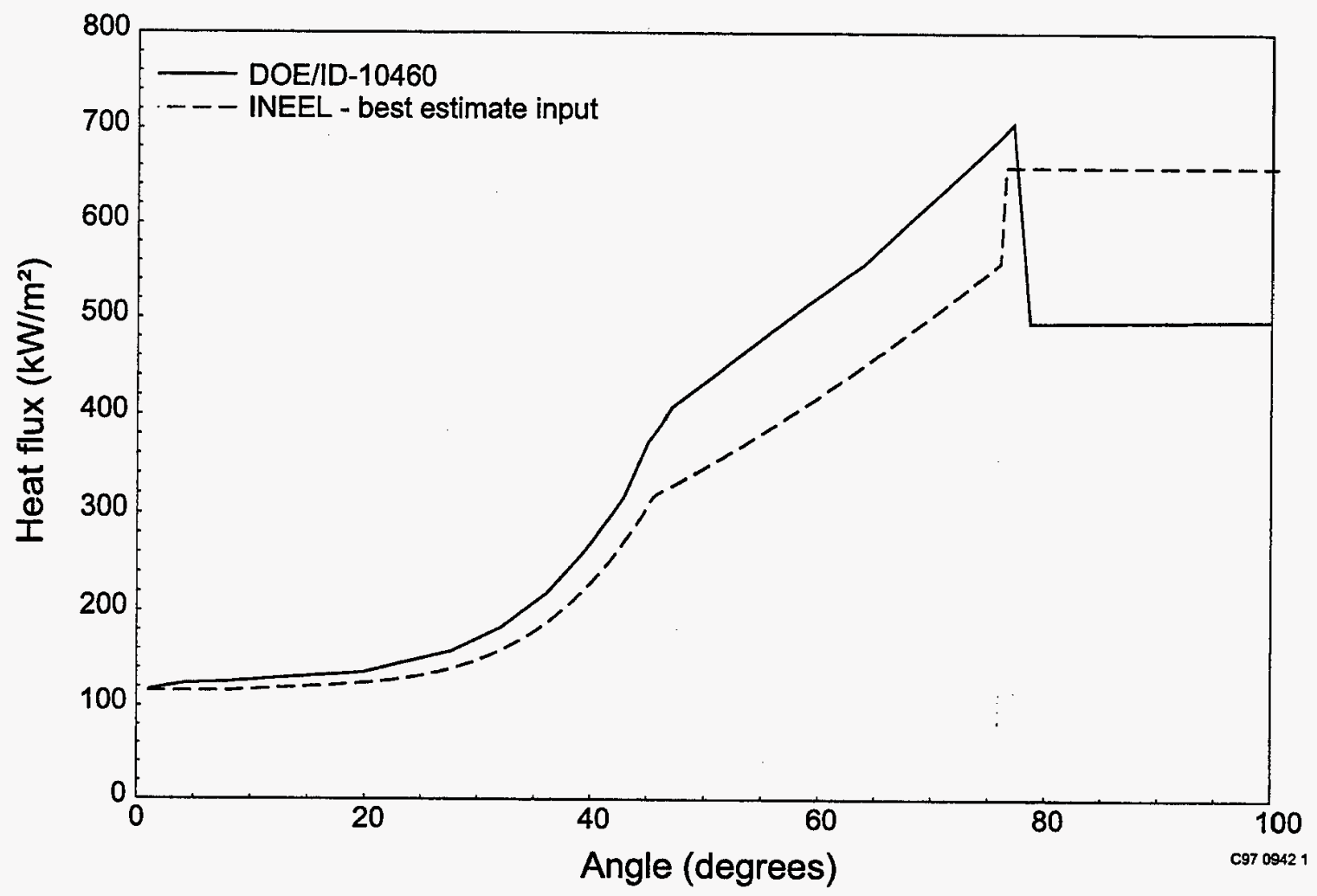

Figure 3-3. Comparison of heat fluxes for UCSB-assumed FIBS.

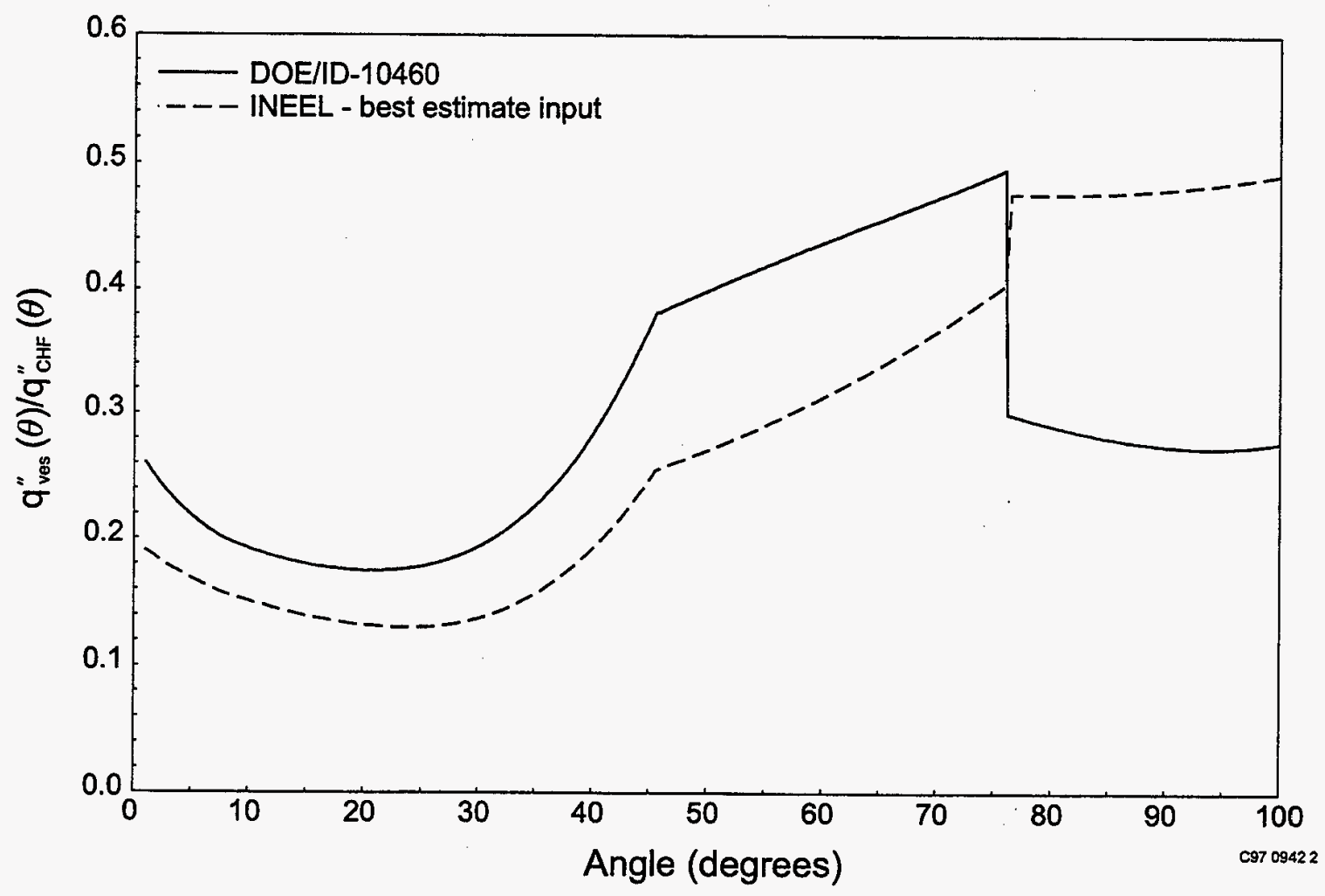

Figure 3-4. Comparison of CHF ratios for UCSB-assumed FIBS. 


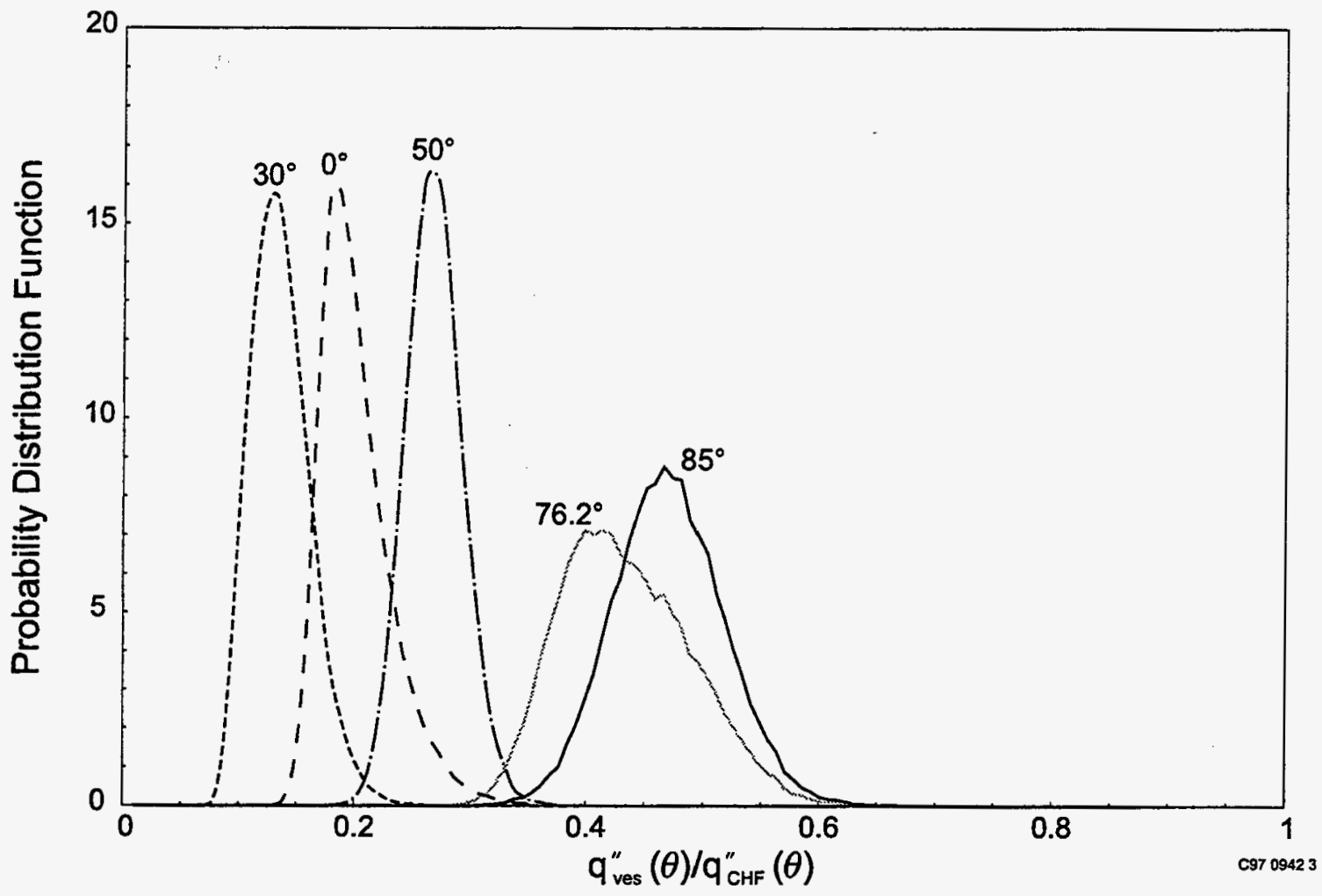

Figure 3-5. CHF ratio pdfs for UCSB-assumed FIBS using INEEL input distributions.

\subsubsection{Sensitivity Studies}

As discussed above, VESTA predicts that CHF ratios remain below unity when INEEL input uncertainty distributions are assumed for the UCSB FIBS. However, there are several input parameters for which phenomenological uncertainties precluded input uncertainty distributions from being conclusively defined. Section 2.4 identifies sensitivity calculations that were defined to investigate phenomenological uncertainties. This section presents results from these sensitivity calculations. Note that INEEL sensitivity studies look at the integral effect of varying an assumed input parameter distribution or modeling assumption. In these calculations, INEEL input parameter uncertainty distributions for the UCSB FIBS (Columns 4 and 5 in Table C-1 of this document) were assumed except for the parameter(s) or equations that were modified to assess the phenomena of interest. Modifications required for each analysis and results from each analysis are discussed below.

\subsubsection{Vapor-Enhanced Upward Heat Transfer in the Molten Ceramic Pool}

As discussed in Section 2.4.1, vaporization and boiling of lower vaporization temperature materials, such as metal structures or control materials, enhance upward heat losses from the molten ceramic pool in the lower head. Although it is recognized that mechanisms introducing lower vaporization temperature metallics into relocated melt are a transient stage, such mechanisms may exist for sufficient time periods that it is appropriate to characterize this transient stage as a quasi-steady state (see Section 2.4.1). INEEL assessed the impact of enhanced upward heat losses by increasing the upward heat transfer correlation by a factor of 10 . Specifically, INEEL increased the median value of the input variable, $\mathrm{C}_{6}$, to 24.42 (Table $\mathrm{C}$ 1 , Column 4). 
Results from this analysis are summarized in Figures 3-6 and 3-7. As shown in Figure 3-6, the heat flux from the vessel at locations adjacent to the ceramic pool are reduced significantly (below $\sim 76.2^{\circ}$ ). Typically, increased upward heat losses decreased downward heat fluxes by a factor of six. Hence, the heat fluxes from the vessel at angles below $\sim 76.2^{\circ}$ are dominated by the heat flux associated with heat generation in the crust surrounding the molten pool. At vessel locations in contact with the metallic layer (at angles above $\sim 76.2^{\circ}$ ), heat fluxes from the vessel are nearly $63 \%$ higher than values estimated for the base case. Higher predicted heat fluxes are due to the increased heat input from the ceramic pool into the metallic layer. Uncertainty calculation results in Figure 3-7 indicate that the probability of vessel heat fluxes exceeding unity is small at locations adjacent to the metallic layer. At an angle of $76.2^{\circ}$, approximately $0.13 \%$ of the $\mathrm{CHF}$ ratios at locations exceed unity, or

$\int_{1}^{\infty} \operatorname{pdf}\left[q^{\prime \prime}(\theta) / q^{\prime \prime}{ }_{C H F}(\theta)\right] d\left[q^{\prime \prime}(\theta) / q_{C H F}^{\prime \prime}(\theta)\right]=0.0013$.

Hence, the probability of the vessel heat fluxes exceeding CHF for this case is approximately $0.13 \%$.

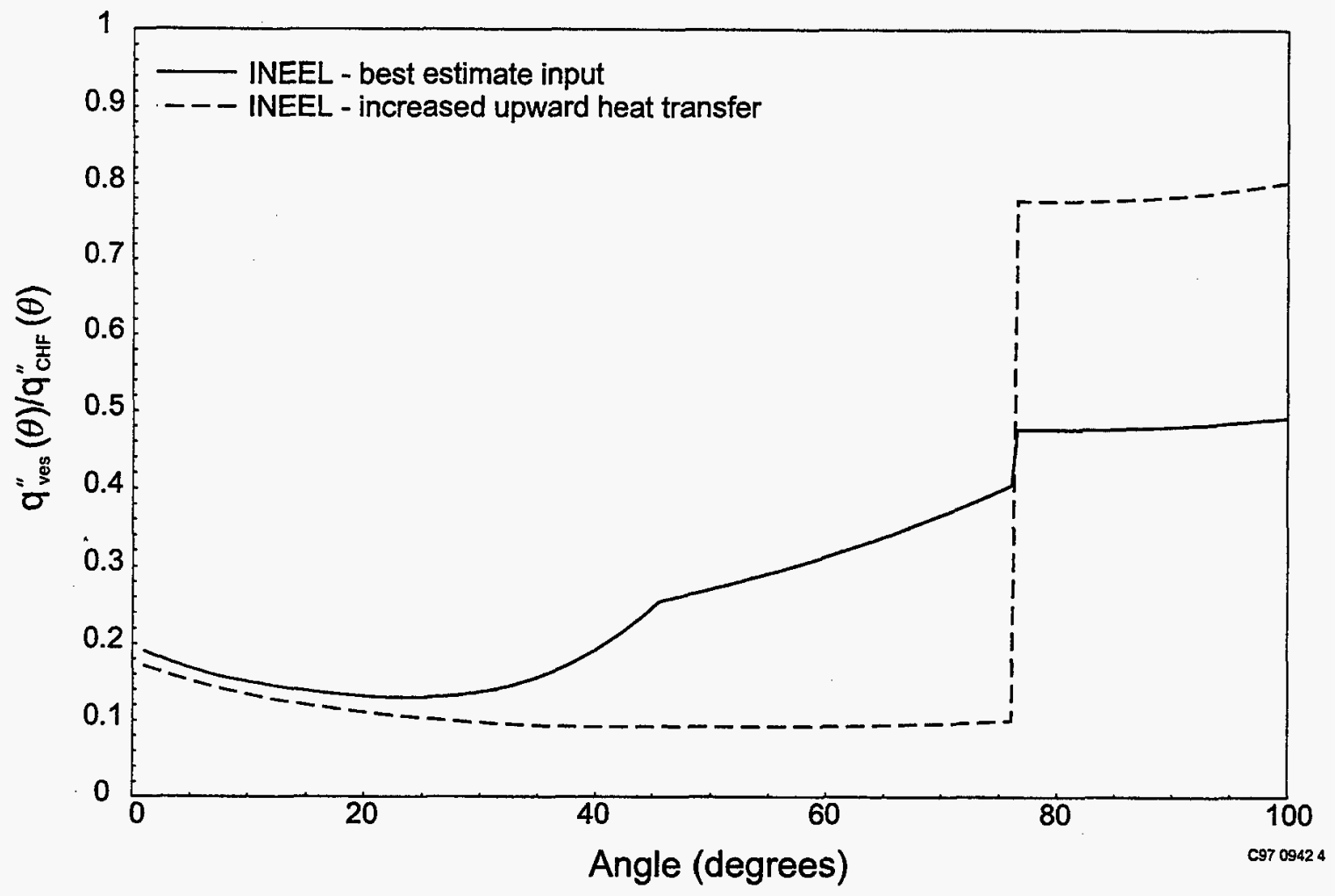

Figure 3-6. CHF ratios assuming increased upward ceramic pool heat losses for UCSB FIBS. 


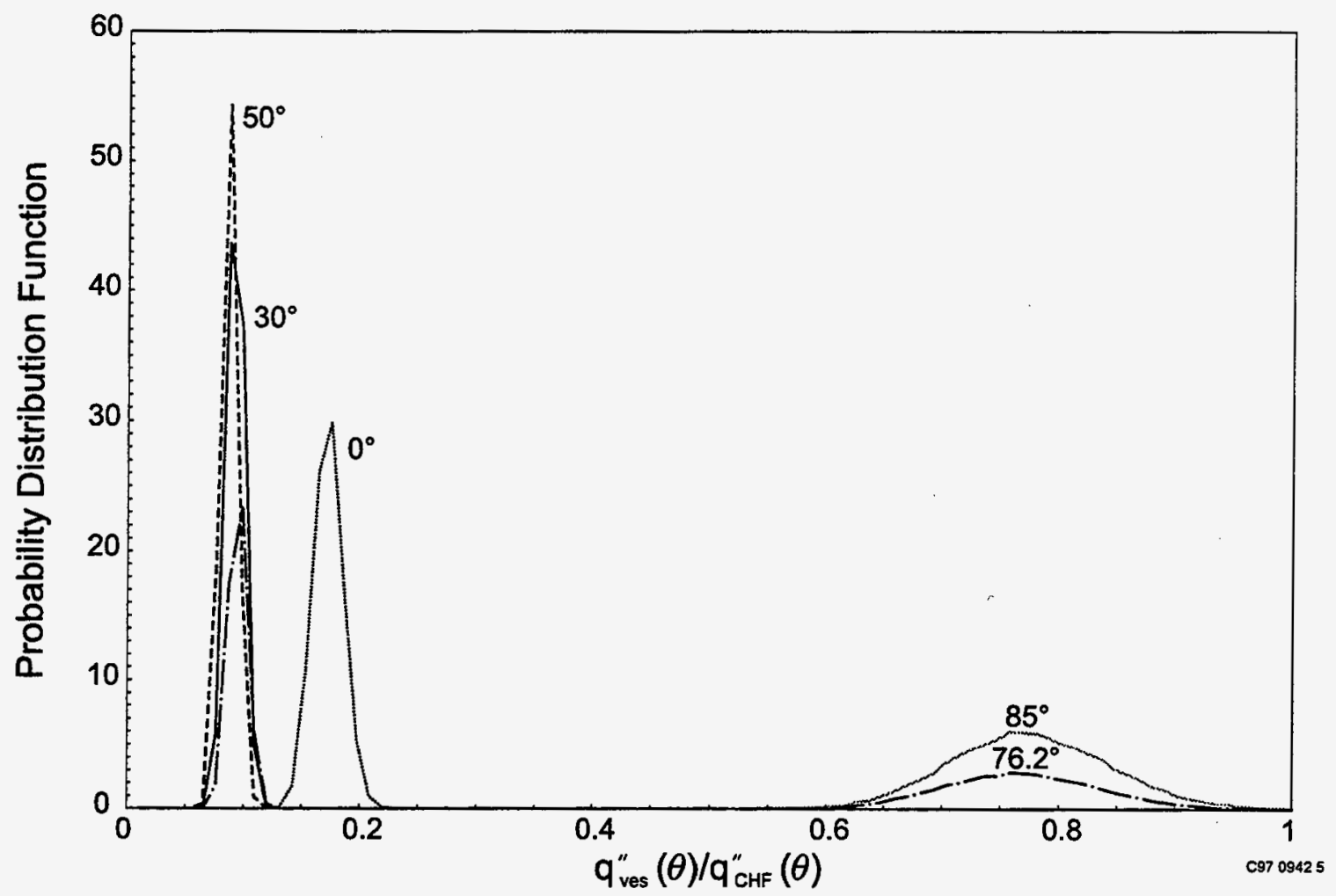

Figure 3-7. CHF ratio pdfs assuming increased upward ceramic pool heat losses for UCSB FIBS.

\subsubsection{Additional Metallic Layer Heat Sources}

As discussed in Section 2.4.2, additional heat sources may be present in the metallic layer because of stainless steel activation. To address the impact of these heat sources, a sensitivity calculation was performed assuming "upper bound" estimates for stainless steel activation heat sources. Specifically, INEEL assumed an additional heat source in the metallic layer that corresponded to $8 \%$ of the core's power at times between 2 and 6 hours after shutdown and to $4 \%$ of the core's power at times between 6 and 12 hours after shutdown (see Section 2.4.2). This additional heat source was implemented into a VESTA calculation by adding a time-dependent variable to the parameter, $f_{\text {metal }}$ in the first term of Equation (A-117). As discussed in Section 2.4.2, this sensitivity study also addresses the impact of additional heat sources associated with oxidation of material in the metallic layer.

Results from this analysis are summarized in Figures 3-8 and 3-9. Additional heat sources only affect metallic layer results. Point estimate calculations for the INEEL requantification of the UCSB-assumed FIBS indicate that approximately $17 \%$ of the core's power is allocated to the metallic layer. Hence, the metallic layer heat source will be increased up a maximum of $25 \%$ of the core's power. As shown in Figure 3-8, this additional heat source increases heat flux ratios at locations adjacent to the metallic layer by approximately $15 \%$. Comparisons between Figures 3-5 and 3-9 uncertainty distributions indicate that additional heat sources in the metallic layer broaden the uncertainty distributions for the pdfs in the metallic layer (at angles above $\sim 76.2^{\circ}$ ). 


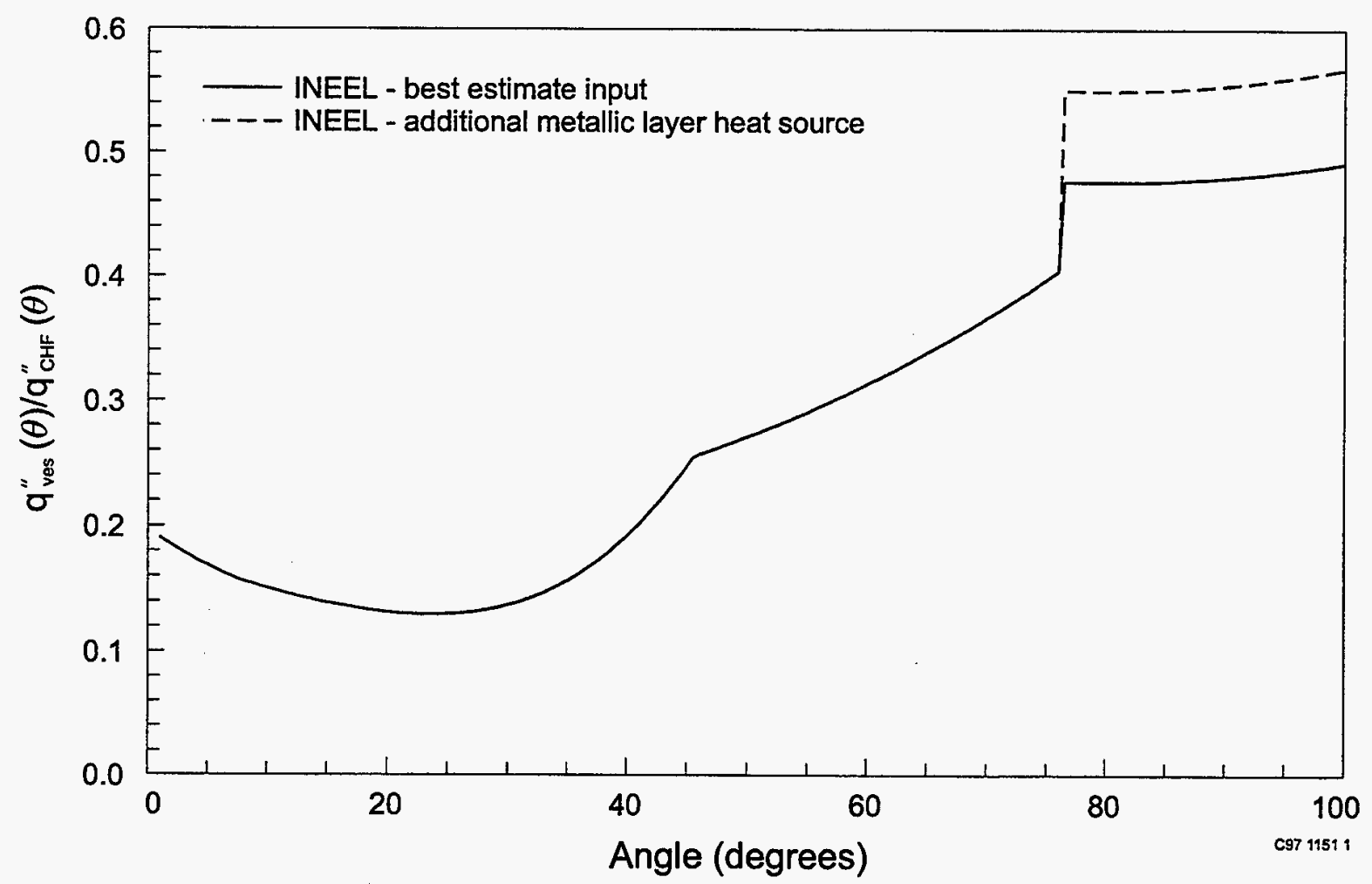

Figure 3-8. CHF ratios assuming additional metallic layer heat source for UCSB FIBS.

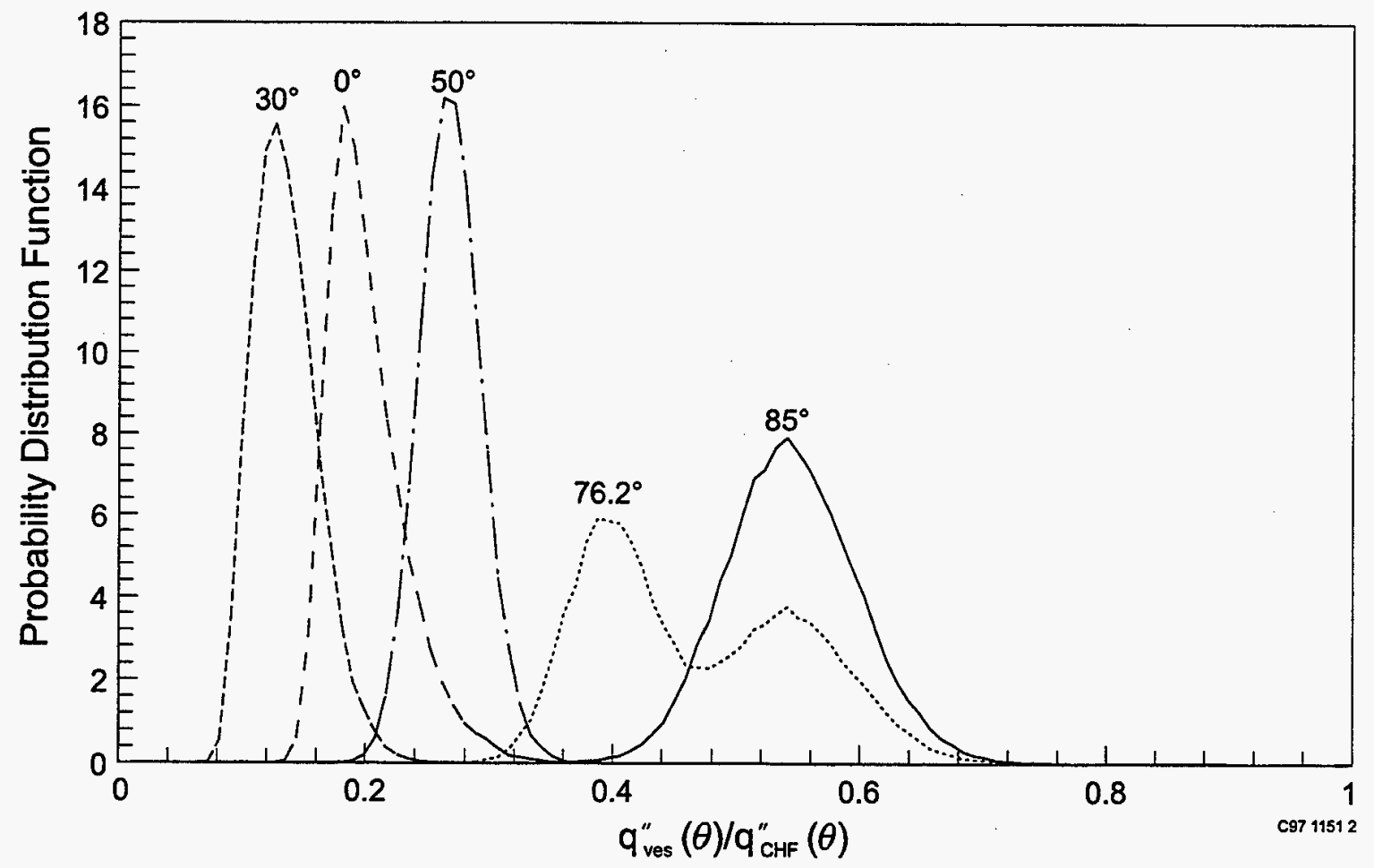

Figure 3-9. CHF ratio pdfs assuming additional metallic layer heat source for UCSB FIBS. 


\subsubsection{Reduced Metallic Layer Mass}

For point estimate calculations, the UCSB study apparently assumed that the metallic layer contains approximately $9,600 \mathrm{~kg}$ of unoxidized zircaloy cladding and approximately $70,000 \mathrm{~kg}$ of vessel internal structure steel. As discussed in Section 2.4.3, a key assumption for UCSB's FIBS is the mass of vessel internal structures in the metallic layer. Because steel melt mass assumptions significantly impact analysis results, a single pdf that encompasses the entire range of postulated melt masses possible at various times in the accident would not yield meaningful results. Hence, INEEL performed a series of VESTA point estimate calculations to determine the mass of relocated stainless steel in the UCSB-assumed FIBS that would produce $q^{\prime \prime}(\theta) / q^{\prime \prime}(\theta)_{C H F}=1.0$ at some vessel locations. In these calculations, INEEL varied the median value for the steel mass, $\mathrm{M}_{\text {ss-tot }}$ (Table $\mathrm{C}-1$, Column 4). For the steel mass yielding a CHF ratio of unity, a VESTA uncertainty calculation was performed to determine the associated probability of vessel heat fluxes exceeding $\mathrm{CHF}$ at other locations.

Results from these calculations are summarized in Figures 3-10 and 3-11. Reductions in the steel relocation mass only affect metallic layer results because ceramic pool heat fluxes are independent of metallic layer mass assumptions. As shown in Figure 3-10, CHF ratios at vessel locations in contact with the metallic layer approach unity for steel melt masses equal to $19,500 \mathrm{~kg}$. Uncertainty distributions in Figure 3-11 suggest that this less than a factor of four reduction in steel melt mass (from 70,000 to $19,500 \mathrm{~kg}$ ) results in non-negligible probabilities of the vessel heat fluxes exceeding CHF in the metallic layer. For example, at an angle of $85^{\circ}$, VESTA results indicate that there is a 52\% probability of exceeding CHF [based on Equation (3-1)]. Similar to UCSB study results for their FIBS, Figure 3-11 shows a doublehump at an angle of $76.2^{\circ}$ because input parameter uncertainties result in some trials predicting that this position is in the oxidic pool and other trials predicting that this position is in the metallic layer.

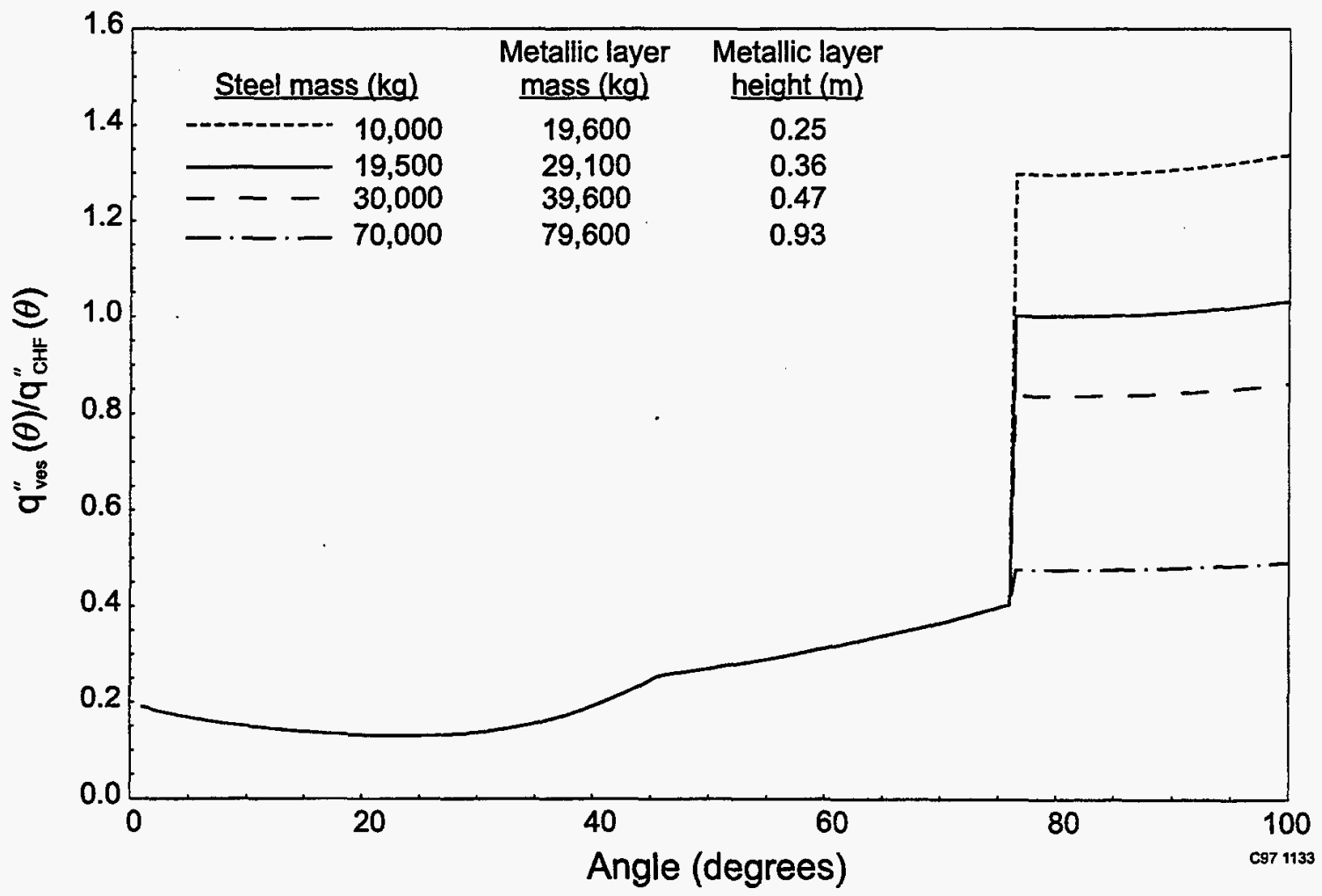

Figure 3-10. CHF ratios assuming various metallic layer steel masses for UCSB FIBS. 


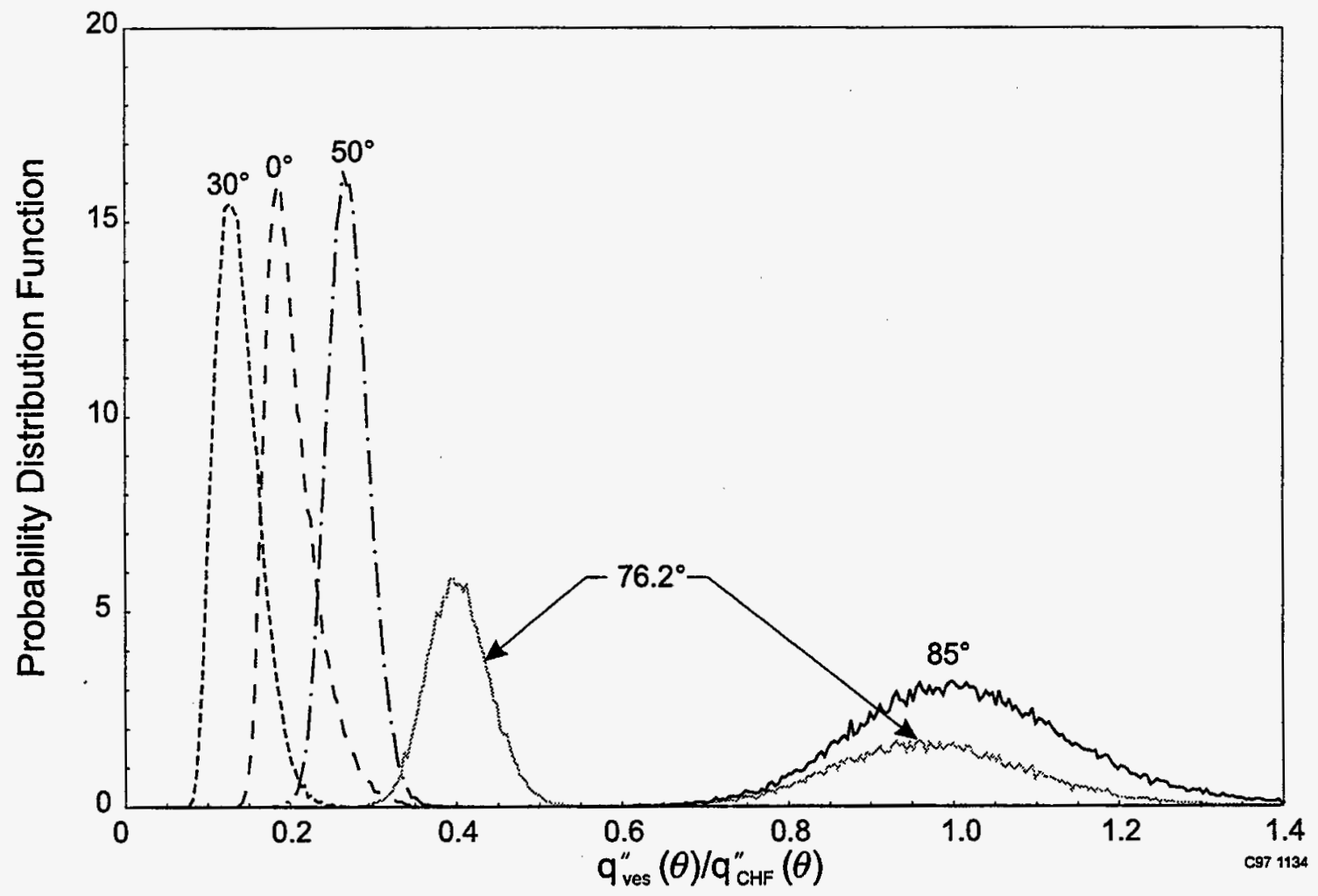

Figure 3-11. CHF ratio pdfs assuming a 19,500 kg metallic layer steel mass for UCSB FIBS.

\subsection{Alternate Debris Configurations}

Section 2.1.2 describes three debris configurations having the potential to challenge the integrity of the vessel lower head. Configuration A represents an intermediate configuration with less metallic material relocating to form a thinner metallic layer than assumed for the UCSB FIBS. Configuration B corresponds to a case where a limited amount of relocated metallic melt is trapped between ceramic materials before the massive amounts of steel structures relocate. Configuration $\mathrm{C}$ considers a case where a more dense metallic layer, consisting of uranium dissolved in zirconium, sinks below the oxidic pool. As discussed in Section 2.1.2, these debris configurations were investigated to address unresolved peer reviewer comments. VESTA was applied to each of these configurations. As discussed in this section, each of these configurations have the potential to produce vessel heat fluxes that exceed CHF.

\subsubsection{Configuration A}

As discussed in Section 2.1.2, Configuration A corresponds to an intermediate state where approximately $50 \%$ of the core inventory forms a ceramic pool with a small metallic component associated with melting of gray rods and submerged lower plenum structures. As discussed in Section 2.1.2, SCDAP/ RELAP5 calculations assuming that melt relocations immediately traveled through core plate perforations predict that this configuration would only persist for 13 minutes. However, calculations assuming that relocations were retained by the core plate suggest that Configuration A could persist for more than an hour. Hence, this configuration could persist longer than the vessel thermal front penetration time ( 10 minutes); and it is appropriate to characterize it as a quasi-steady state configuration. 
VESTA equations allow this configuration to be analyzed by modifying a select number of input parameters: relocated metallic material mass, relocated ceramic material mass, oxidation fraction, decay heat, fraction of decay heat produced by actinides, metallic layer emissivity, and CHF correlation coefficients. Specific input values used in this VESTA analysis are listed in Table C-2 of Appendix C. Metal and ceramic material masses, zirconium oxidation fractions, debris relocation time, and debris decay heat assumptions (power and fraction produced by actinides) were based on a SCDAP/RELAP5 AP600 $3 B E$ analysis. ${ }^{3}$ Several references ${ }^{15,28,29}$ indicate that the location of relocated control material isn't known, although experimental data suggest that relocated cadmium would be vaporized, relocated silver would be retained by zirconium, and relocated indium would be split between oxide and metallic debris. Hence, INEEL performed two Configuration A calculations: a case in which none of the control material was retained in relocated material (simulated with a $0.10 \mathrm{~m}$-]thick metallic layer containing $2,603 \mathrm{~kg}$ of steel); and a case in which all control material was retained in the metallic layer (simulated with $0.13 \mathrm{~m}$ thick metallic layer containing $4,187 \mathrm{~kg}$ of steel). ${ }^{a}$ Metallic melt emissivity and CHF correlation coefficients were selected to reflect conditions expected at earlier time periods when intermediate configurations occur. Specifically, the CHF Cheung $(H / R=2)$ curve values were selected to correspond to time periods before the reactor cavity becomes fully flooded (see Section B.1.3) and the metallic melt emissivity was lowered to reflect the presence of steam in the reactor vessel (see Section B.3.3)

Configuration A point estimate calculation results are shown in Figures 3-12 and 3-13. Depending on control material relocation assumptions, peak heat fluxes in Figure 3-12 range from 2.5 to 3.5 times larger than predicted for the UCSB-assumed FIBS in Figure 3-3. These higher heat fluxes are primarily due to the reduced metallic mass in the lower head, causing heat to be "focussed" on a smaller area of the vessel sidewall. In addition, the reduced metallic layer emissivity and higher decay heats (associated with earlier relocation times) increase metallic layer vessel heat flux predictions. Figure 3-13 results indicate that the ratio of the vessel heat flux to CHF values typically range from 1.5 to 2.0 at vessel locations in contact with the metallic layer (at locations above $\sim 59^{\circ}$ ). This result is primarily due to increased vessel heat flux predictions. Although CHF values are also slightly reduced for the Cheung ( $H / R=2)$ curve (relative to the $H / R=3)$ curve, Figure $B-7$ indicates that Cheung $(H / R=2) C H F$ values are not significantly different from ULPU CHF values at locations where the vessel is adjacent to the metallic layer (at locations above $\sim 59^{\circ}$ ). Plots in Figures 3-12 and 3-13 indicate that the increased mass associated with control material in the metallic layer would decrease peak heat fluxes and associated CHF ratios. However, vessel heat fluxes exceeded CHF irrespective of assumptions pertaining to control material location.

Uncertainty calculation results are presented in Figures 3-14 and 3-15 for the Configuration A case in which all control materials are assumed to be retained within the metallic layer (a steel mass of $4,187 \mathrm{~kg}$ ). Figure 3-14 illustrate that CHF ratios remain below unity at vessel wall locations adjacent to the ceramic pool. However, results presented in Figure 3-15 indicate that the probability of vessel heat fluxes exceeding CHF at locations where the vessel is in contact with the metallic layer is significant. At an angle of $59^{\circ}$, VESTA calculations indicate that approximately $85 \%$ of the CHF ratios predicted are above unity, or that the probability of vessel heat fluxes exceeding CHF for Configuration A debris conditions is approximately $85 \%$ [based on Equation (3-1)]. It should be noted that the standard deviation for this pdf is much larger at vessel locations in contact with the metallic layer. This is due to the larger uncertainty associated with input parameters for this configuration.

a. A more exact approach would have required that control material properties be added to VESTA. However, this approach simulated the effects associated with an increased metallic layer mass. 


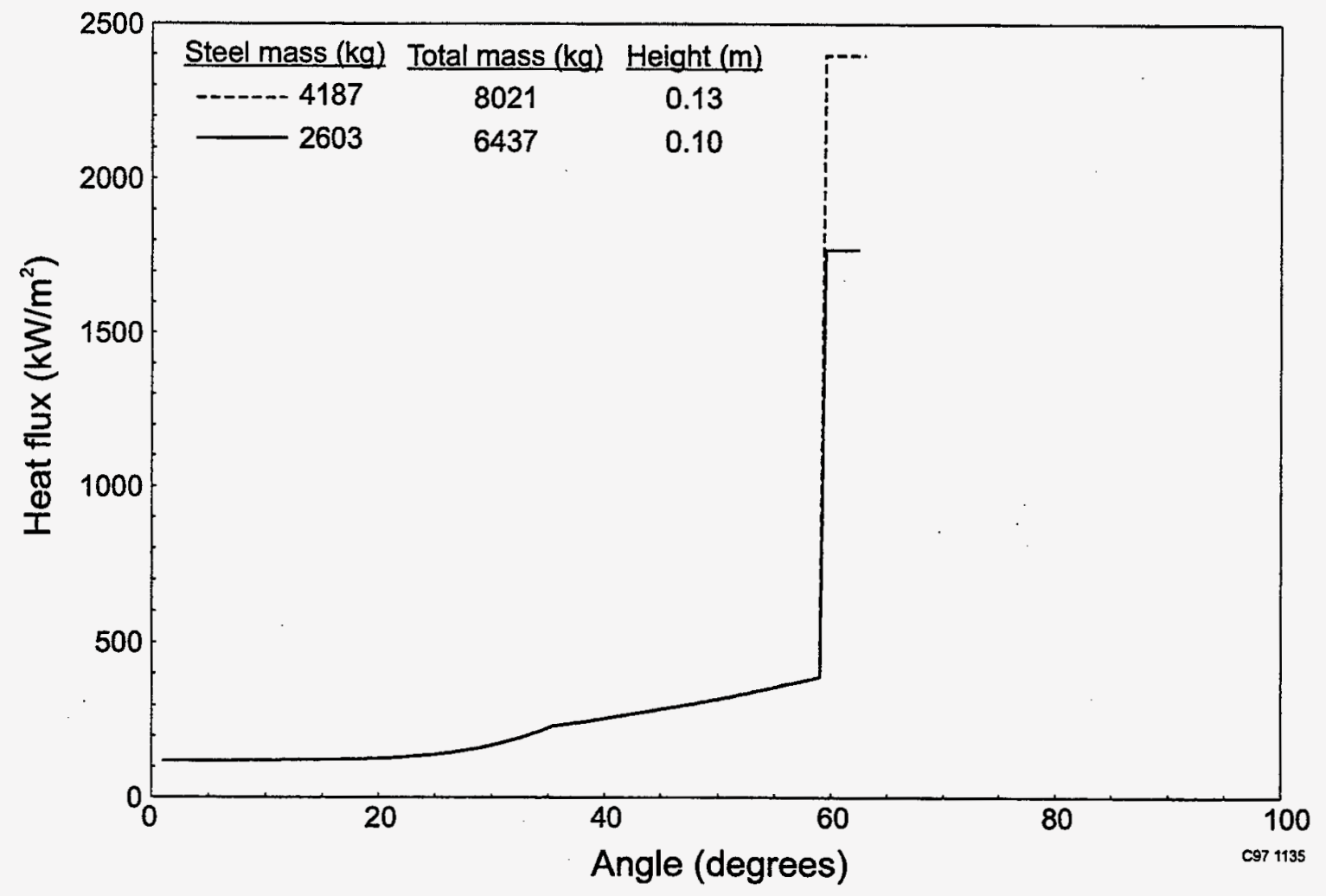

Figure 3-12. Heat fluxes for Configuration A.

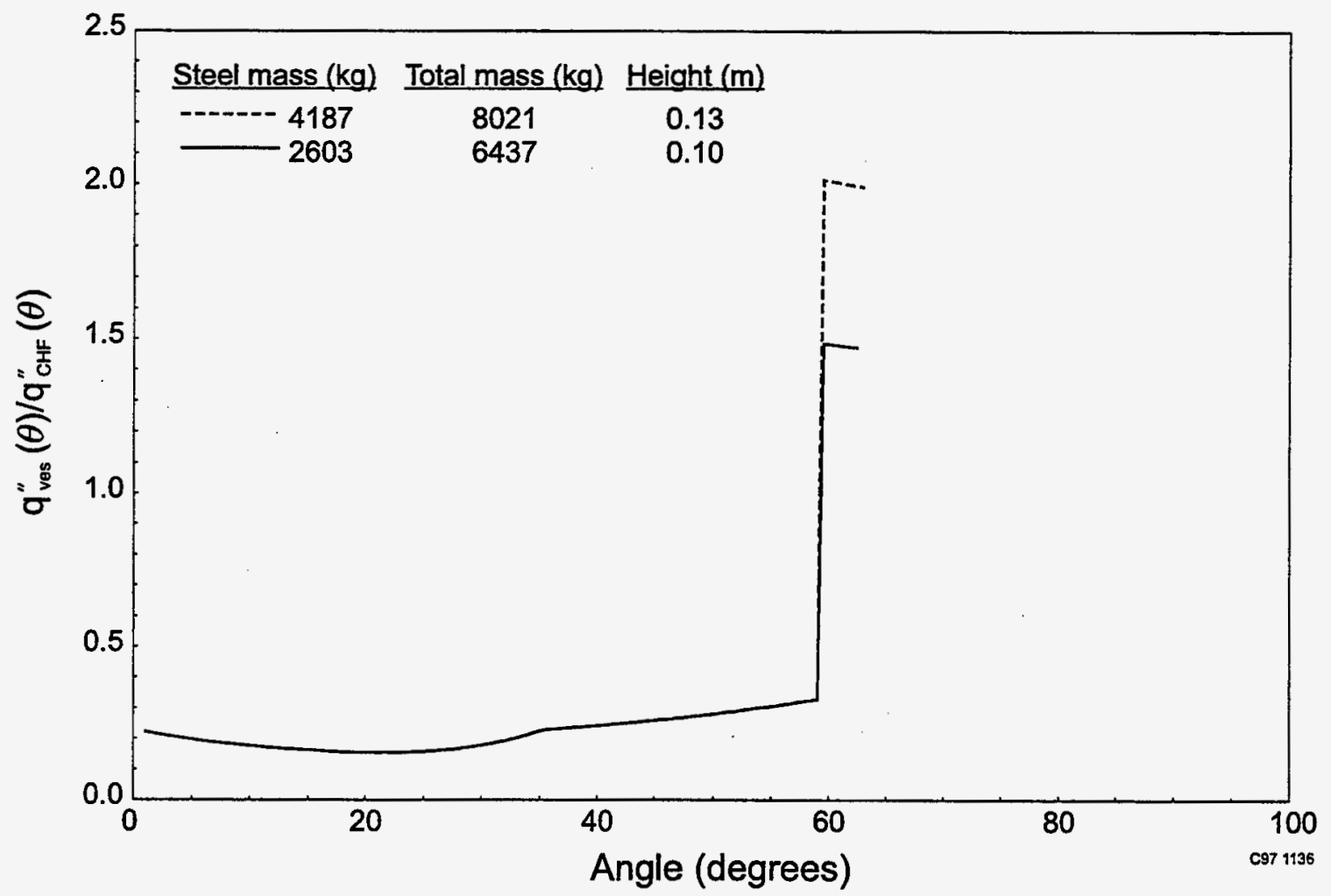

Figure 3-13. CHF ratios for Configuration $\mathrm{A}$. 


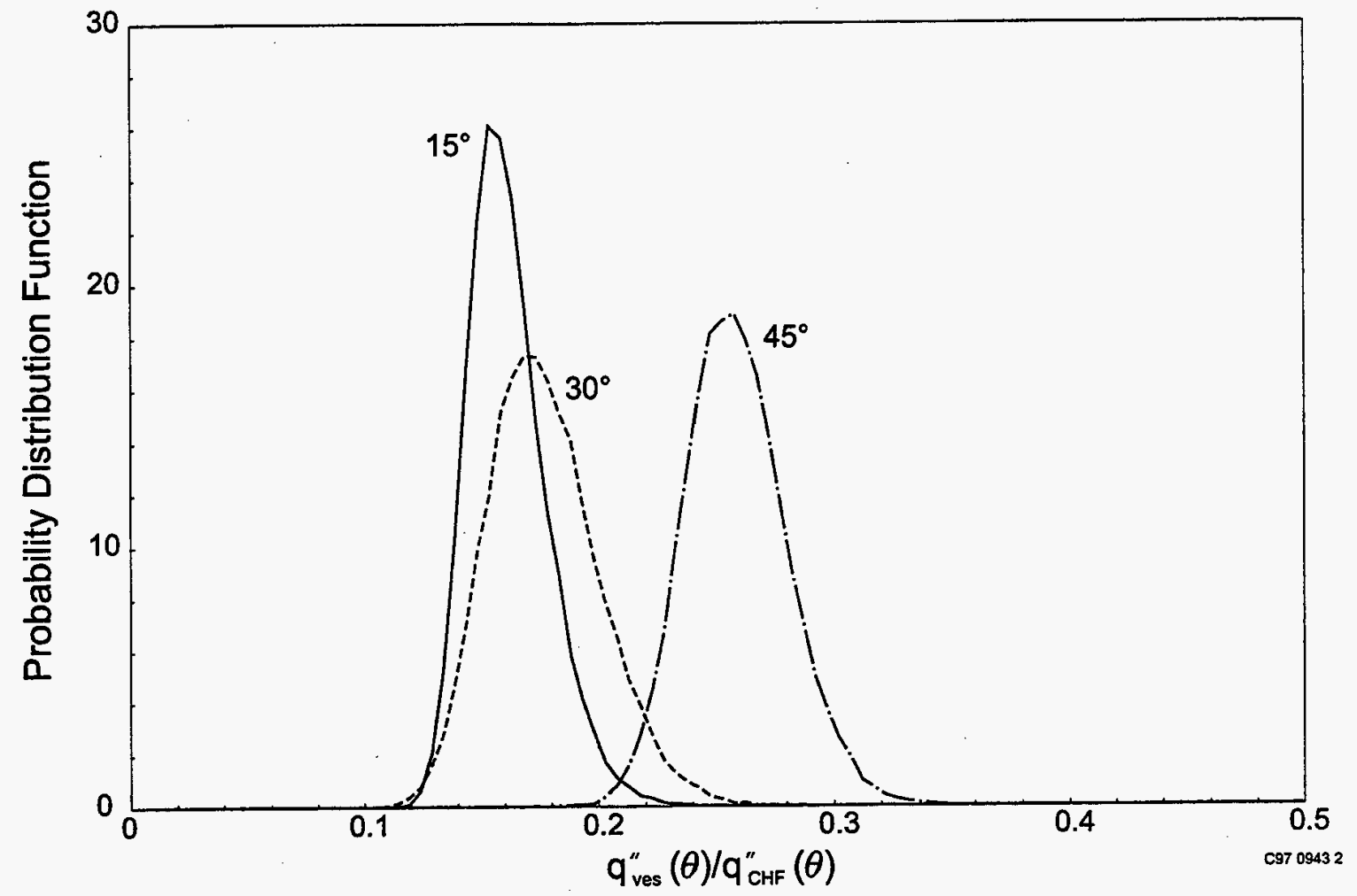

Figure 3-14. CHF ratio pdfs in the ceramic layer for Configuration $\mathrm{A}(4,187 \mathrm{~kg}$ steel mass).

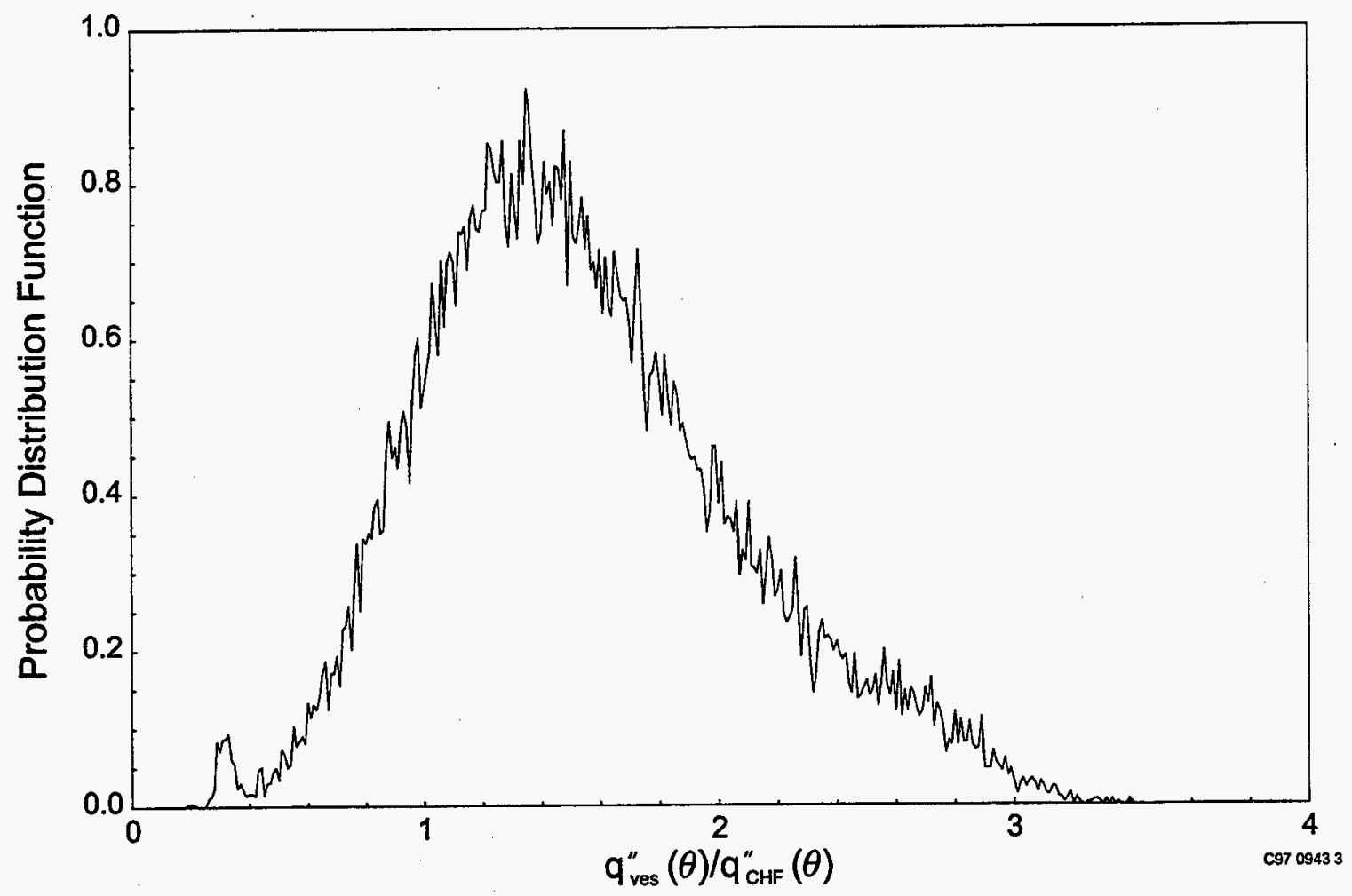

Figure 3-15. CHF ratio pdfs in the metallic layer for Configuration A (4,1,87 kg steel mass). 
Finally, it should be noted that VESTA (or UCSB model) heat flux predictions exceeding CHF are beyond the range of applicability for these models. In a detailed transient analysis, heat fluxes in excess of CHF would cause vessel temperatures to rise to values where the steel loses its strength, experiencing creep structural instability. Because governing equations in VESTA (and the UCSB model) are limited to cases where heat fluxes are below $\mathrm{CHF}$, heat flux predictions exceeding CHF should merely be viewed as an indicator of the probability of vessel failure.

\subsubsection{Configuration B}

As discussed in Section 2.1.2, Configuration B corresponds to a debris configuration that occurs sometime after Configuration A (which involved approximately $50 \%$ of the core). It assumes that an additional 35\% of core materials relocate to form a molten pool with an upper surface that submerges part of the lower core support plate. The initial 0.13 m-thick metallic layer (containing $8,021 \mathrm{~kg}$ ) would be heated from below by the molten pool and above by the overlying pool and crust.

Equations incorporated into VESTA allow this configuration to be analyzed by modifying a select number of input parameter distributions: the mass of metal assumed to relocate into each layer, the mass of ceramic materials assumed to relocate into each layer, the oxidation fraction of zirconium and uranium in each layer, the decay heat, the amount of decay heat produced by actinides, the metallic layer emissivity, and CHF correlation coefficients. Specific input values used in this VESTA analysis are listed in Table C3 of Appendix C. Metal and ceramic material masses, zirconium oxidation fractions, melt relocation time, and debris decay heat assumptions (power and fraction produced by actinides) were based on SCDAP/ RELAP5 calculation results. ${ }^{3} \mathrm{CHF}$ correlation coefficients were selected to reflect conditions expected at the earlier time periods when this intermediate configuration occurs. Specifically, the CHF Cheung (H/ $R=2$ ) curve values were selected to correspond to time periods before the reactor cavity becomes fully flooded (see Section 2.1.2).

Configuration B point estimate calculation results are shown in Figures 3-16 and 3-17, and uncertainty calculation results are shown in Figures 3-18 and 3-19. Peak vessel heat fluxes shown in Figure 3-16 occur at locations where the vessel is in contact with the metallic layer and are approximately a factor of 4.5 times larger than predicted for Configuration A (see Figure 3-12). These higher heat fluxes are primarily due to the combined heat load to this metallic layer from the upper and lower ceramic pools. Figure 3-17 results indicate that the ratio of the vessel heat flux to CHF values are predicted to typically be approximately 25 at vessel locations adjacent to the metallic layer (at locations above $\sim 59^{\circ}$ ). As shown in Figure 3-18, VESTA predicts that CHF ratios remain below unity at vessel wall locations adjacent to either ceramic pool. For locations where the vessel is in contact with the metallic layer, results presented in Figure 3-19 indicate that all of the CHF ratios will exceed unity.

Because two-dimensional heat transfer effects might dissipate the focussing effects from the thin layer assumed in Configuration B, INEEL also performed sensitivity calculations in which the mass of the stainless steel was increased. VESTA predicts that even if the stainless steel mass were increased to the mass assumed in the UCSB point estimate FIBS analyses (a $0.93 \mathrm{~m}$ thick metallic layer containing $70,000 \mathrm{~kg}$ of steel), CHF ratios of approximately 3.9 will occur at locations where the vessel is in contact with the metallic layer. 


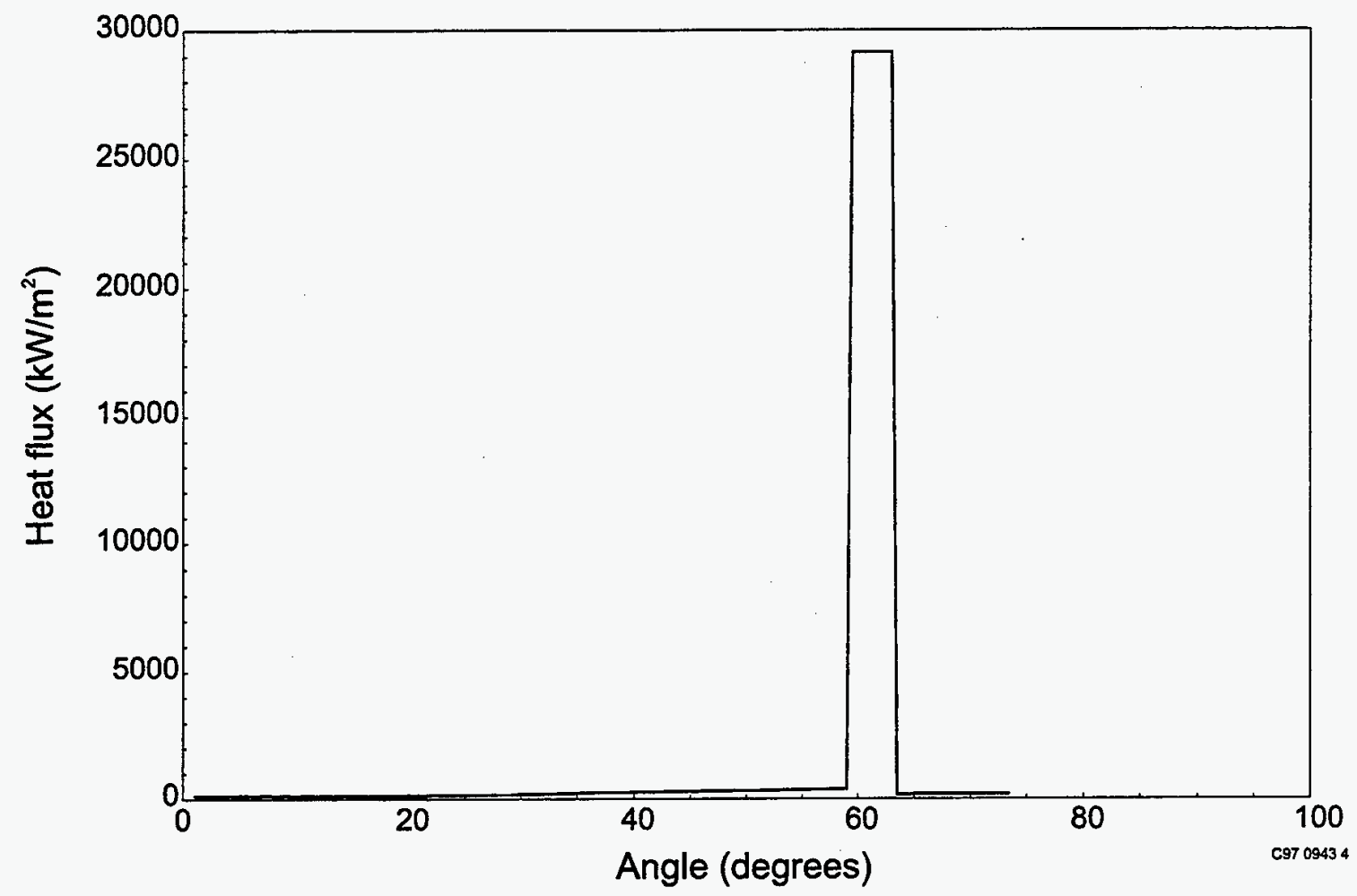

Figure 3-16. Heat fluxes predicted for Configuration B.

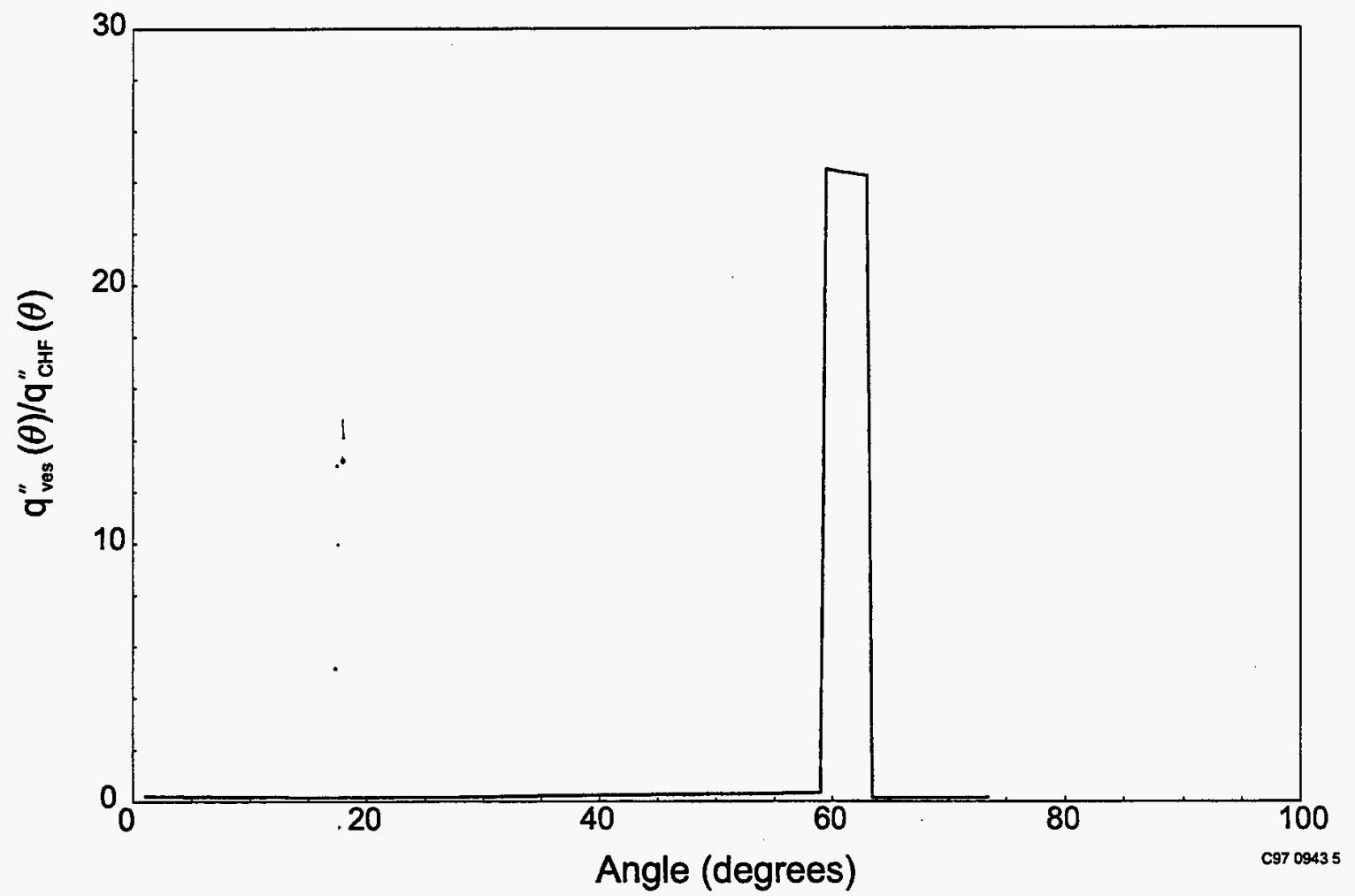

Figure 3-17. CHF ratios predicted for Configuration $B$. 


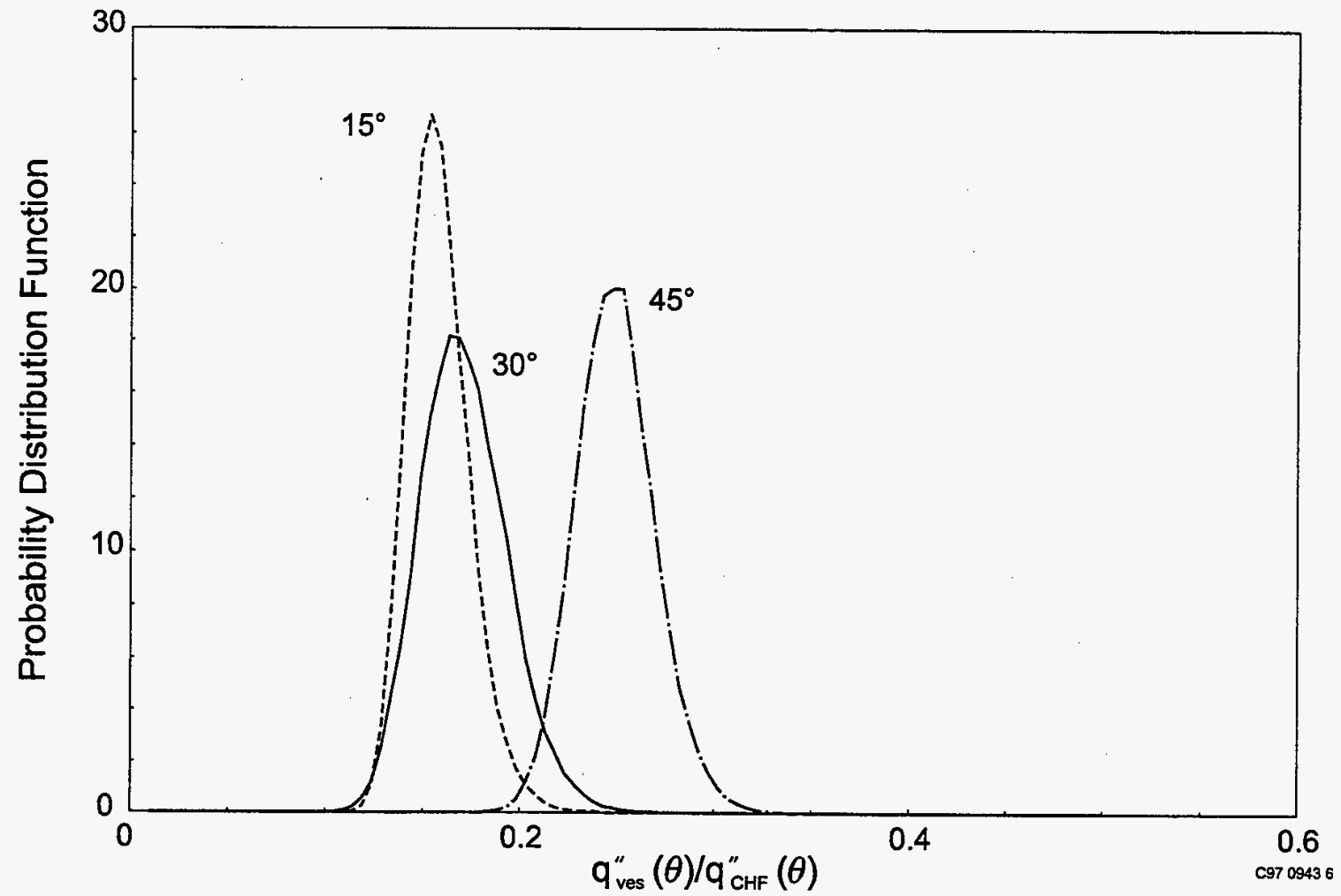

Figure 3-18. CHF ratio pdf in the ceramic layers for Configuration B.

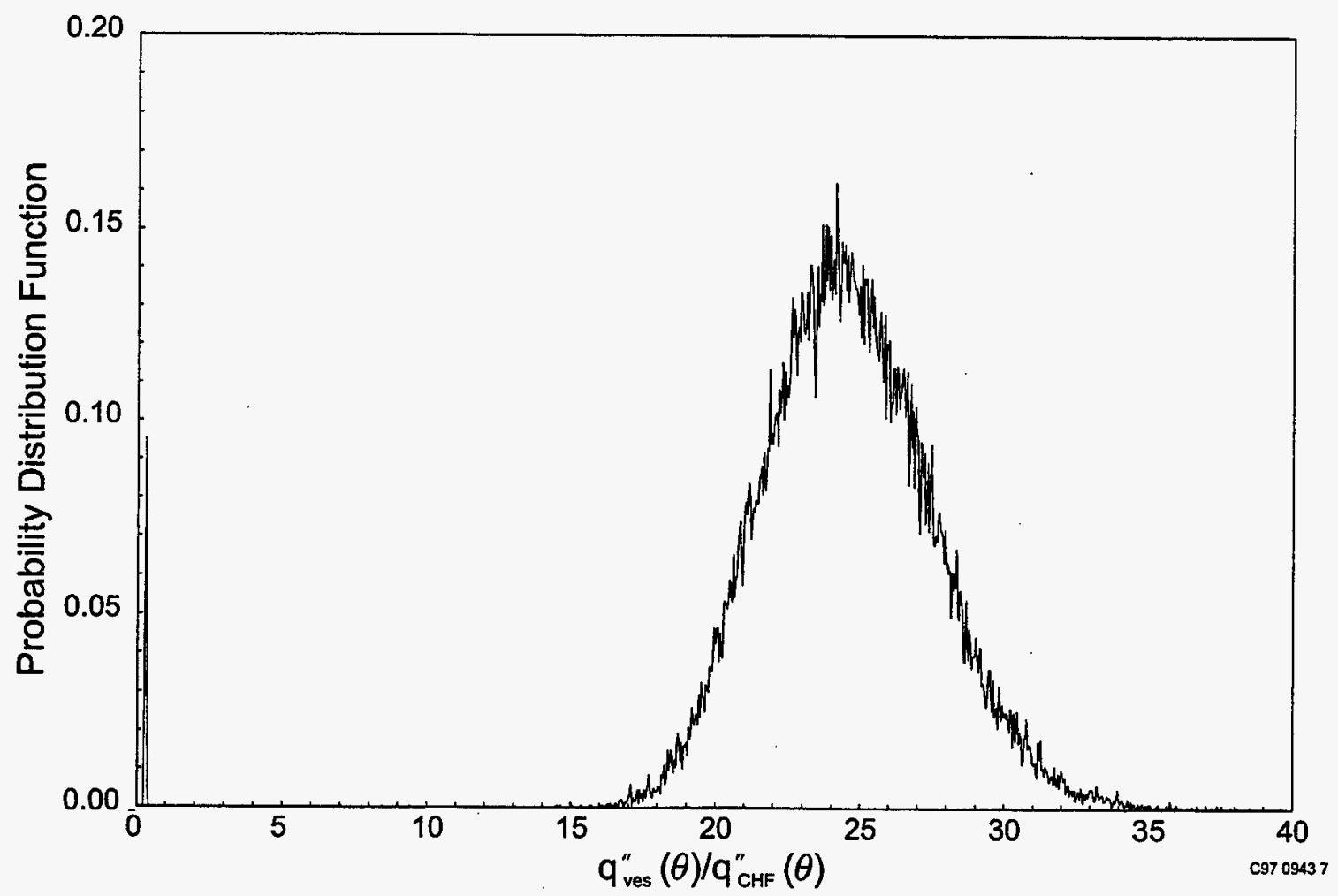

Figure 3-19. CHF ratio pdf in the metallic layer for Configuration $B$.

INEEL/EXT-97-00779

3-16 
As discussed in Section 3.3.1, VESTA (or UCSB model) heat flux predictions exceeding CHF are beyond the range of applicability for these models. In a detailed transient analysis, heat fluxes in excess of CHF would cause vessel temperatures to rise to values where the steel loses its strength, experiencing creep structural instability. Because governing equations in VESTA (and the UCSB model) are limited to cases where heat fluxes are below CHF, heat flux predictions exceeding CHF should merely be viewed as an indicator of the probability of vessel failure.

\subsubsection{Configuration C}

As discussed in Section 2.1.2, Configuration $\mathrm{C}$ corresponds to a case where a more dense metallic layer, consisting of uranium dissolved in zirconium, has sunk below the oxidic pool. Heat loads from the lower metallic layer are "focussed" to the bottom of the vessel lower head where heat rejection is a minimum (see CHF values plotted in see Figure B-6).

Equations incorporated into VESTA allow this configuration to be analyzed by modifying a select number of input parameters: the mass of relocated metal in each layer, the mass of relocated ceramic materials in each layer, the oxidation fraction of zirconium and uranium in each layer, the decay heat, the amount of decay heat produced by actinides, the metallic layer emissivity, and CHF correlation coefficients. Specific input values used in this VESTA analysis are listed in Table C-3 of Appendix C. Metal and ceramic material masses, zirconium oxidation fractions, melt relocation time, and debris decay heat assumptions (power and fraction produced by actinides) were based on SCDAP/RELAP5 calculation results. ${ }^{3} \mathrm{CHF}$ correlation coefficients were selected to reflect conditions expected at earlier time periods when this intermediate configuration occurs. Specifically, the CHF Cheung $(H / R=2)$ curve values were selected to correspond to time periods before the reactor cavity becomes fully flooded (see Section 2.1.2). The uranium oxidation fraction and amount of unoxidized uranium assumed to be present in the lower layer were specified by determining the minimum mass of uranium that would cause the metallic layer to become more dense. Then, metallic layer constituents were checked to insure that the mass fraction of uranium remained below the maximum $40 \mathrm{wt} \%$ uranium cited by Peer Reviewer Olander in his comments. The $4,291 \mathrm{~kg}$ of unoxidized uranium assumed to be dissolved into the metallic layer is less than half the number of moles of unoxidized zirconium that SCDAP/RELAP5 predicted to relocate during times when intermediate configurations could occur. This dissolved uranium mass resulted in a total metallic layer mass of $12,112 \mathrm{~kg}$, which results in a maximum metallic layer height of $0.50 \mathrm{~m}$.

Configuration $C$ point estimate calculation results are shown in Figures 3-20 and 3-21. As shown in Figure 3-20, peak vessel heat fluxes occur at locations where the vessel is in contact with the metallic layer (at locations below $\sim 42^{\circ}$ ). As shown in Figure 3-21, the ratio of the vessel heat flux to CHF values range from 4 to 8 at locations adjacent to the metallic layer (at locations below $\sim 42^{\circ}$ ), but remain below unity at locations adjacent to the overlying ceramic pool (at locations above $\sim 42^{\circ}$ ). This result is due to high heat fluxes from the metallic layer (due to decay heat from fission product and actinides in the metallic layer) and to lower heat rejection rates possible at lower angles (see SBLB CHF values plotted in Figure B-7).

Configuration $C$ uncertainty calculation results are shown in Figures 3-22 and 3-23. As shown in Figure 3-22, VESTA predicts that CHF ratios remain below unity at vessel wall locations adjacent to the ceramic pool. However, results presented in Figure 3-23 indicate that CHF ratios exceed unity at locations where the vessel is in contact with the lower metallic layer. 


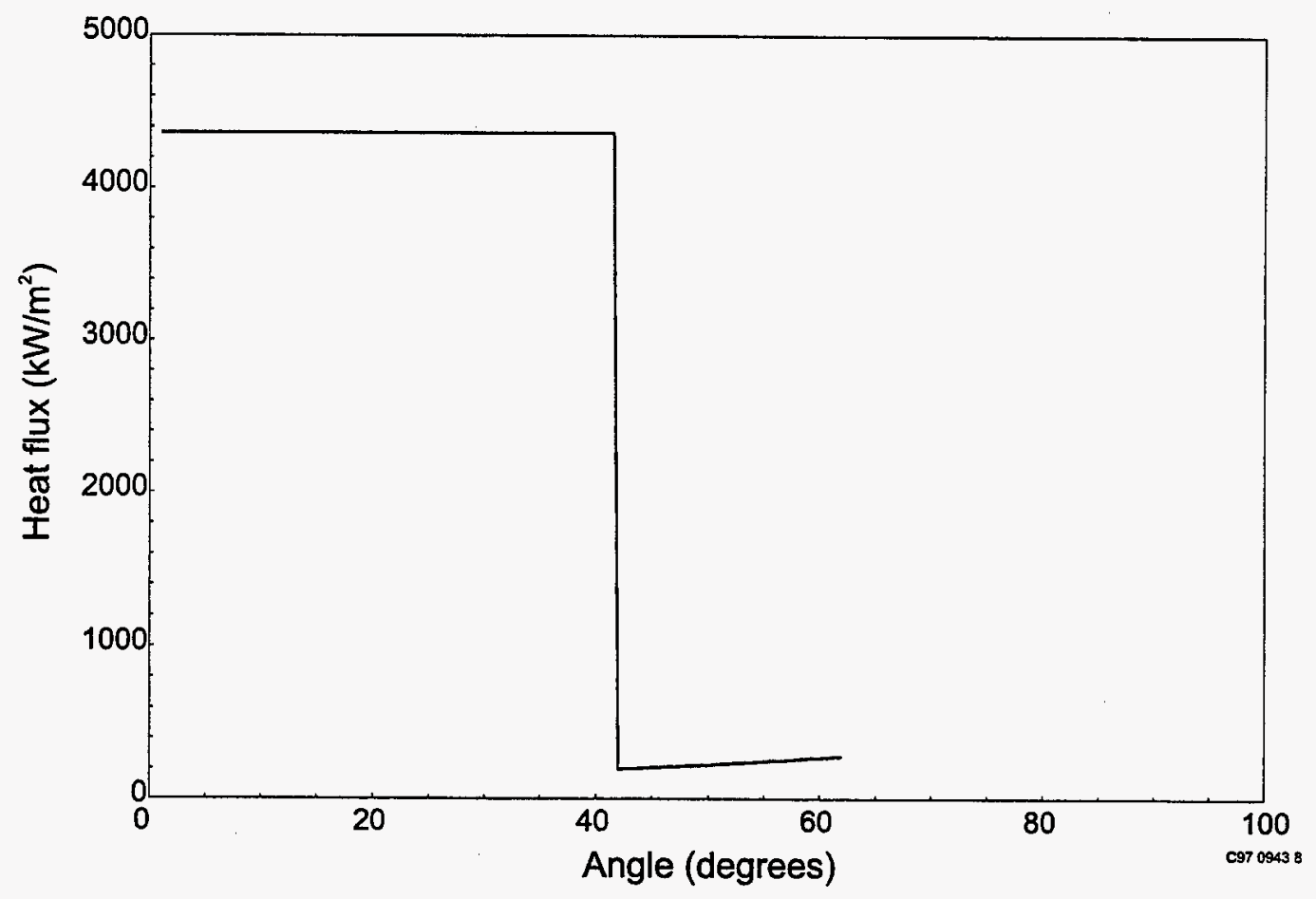

Figure 3-20. Heat fluxes for Configuration C.

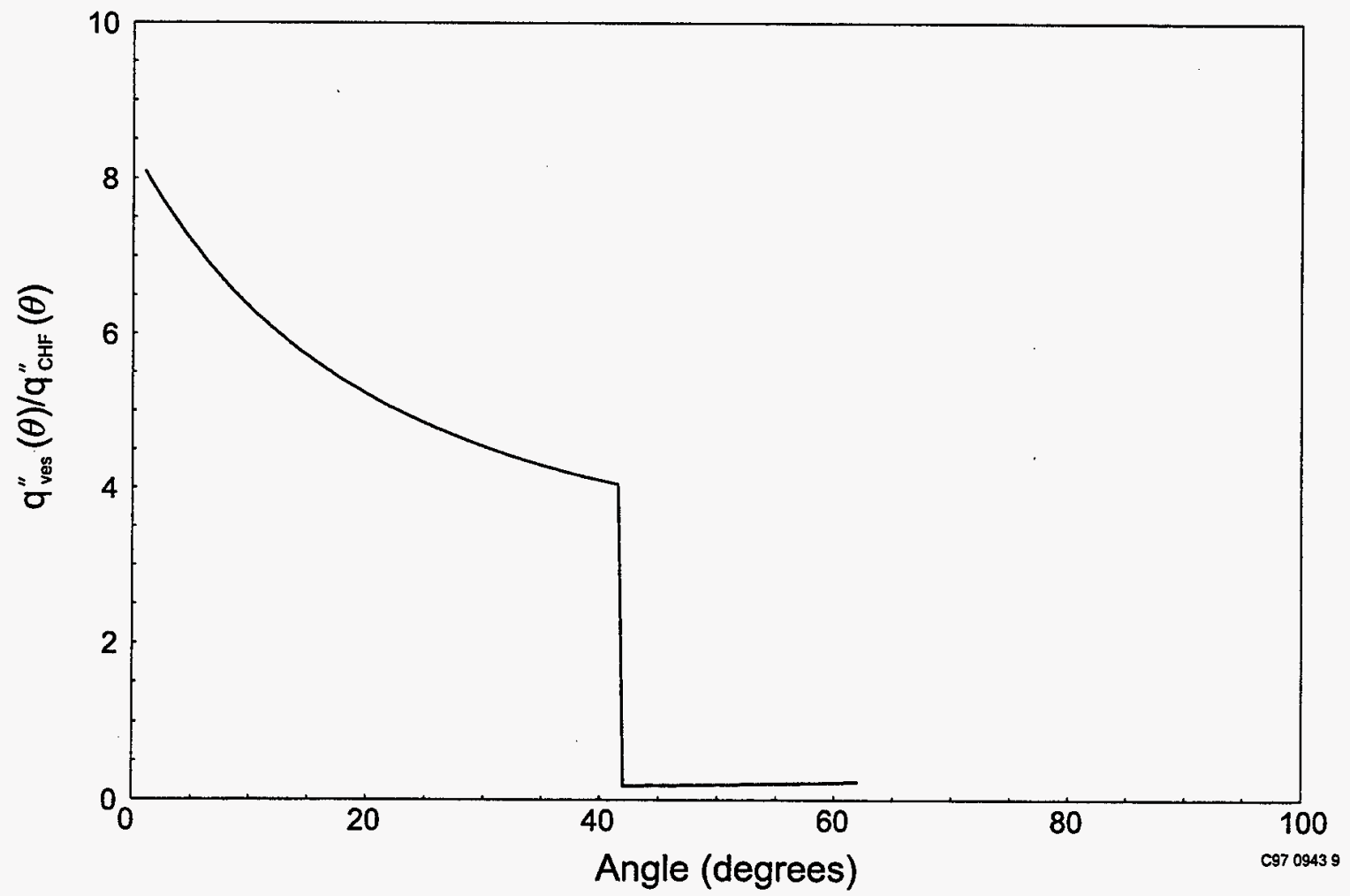

Figure 3-21. CHF ratios for Configuration C. 


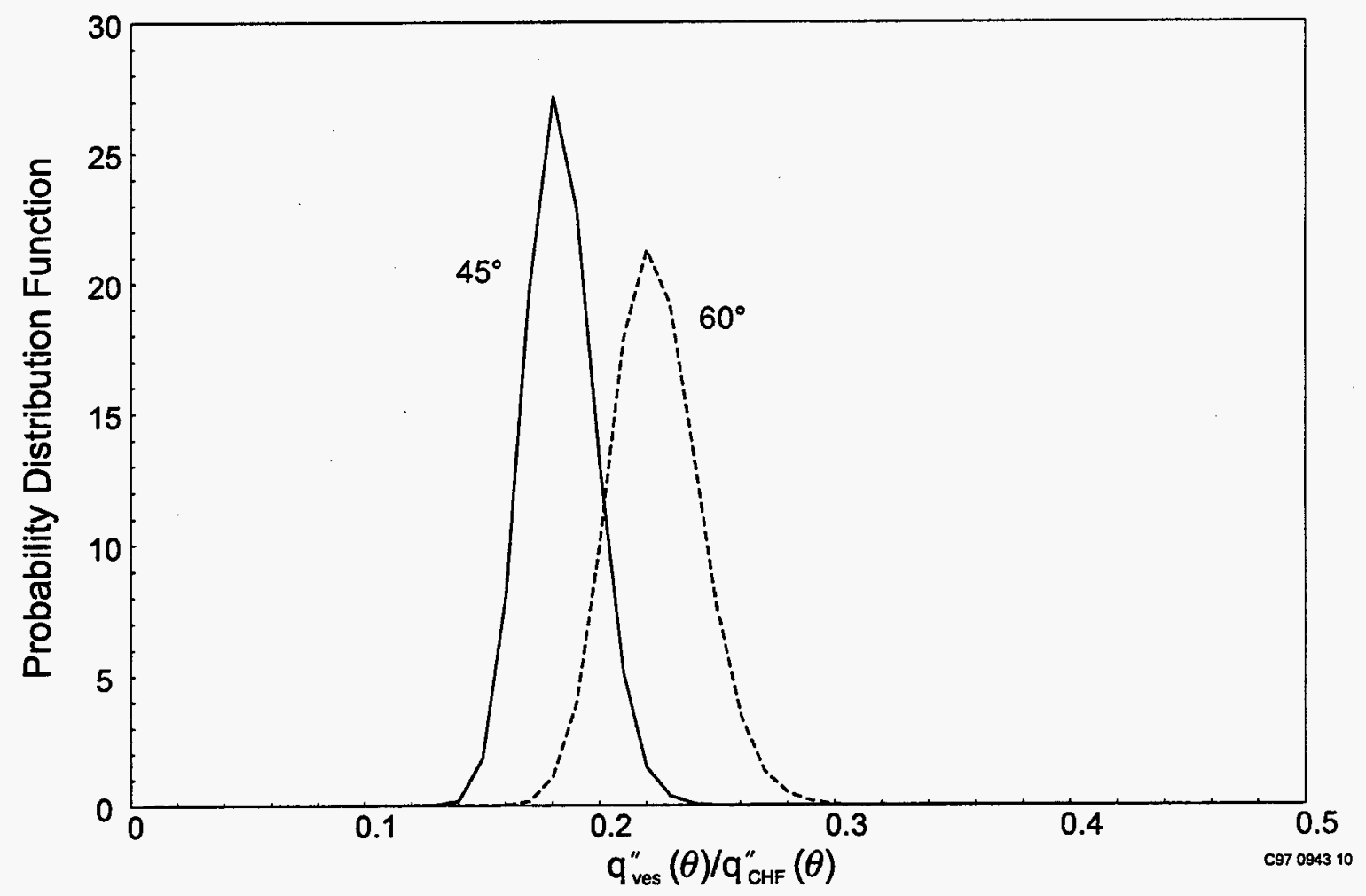

Figure 3-22. CHF ratio pdfs in the ceramic layer for Configuration $\mathrm{C}$.

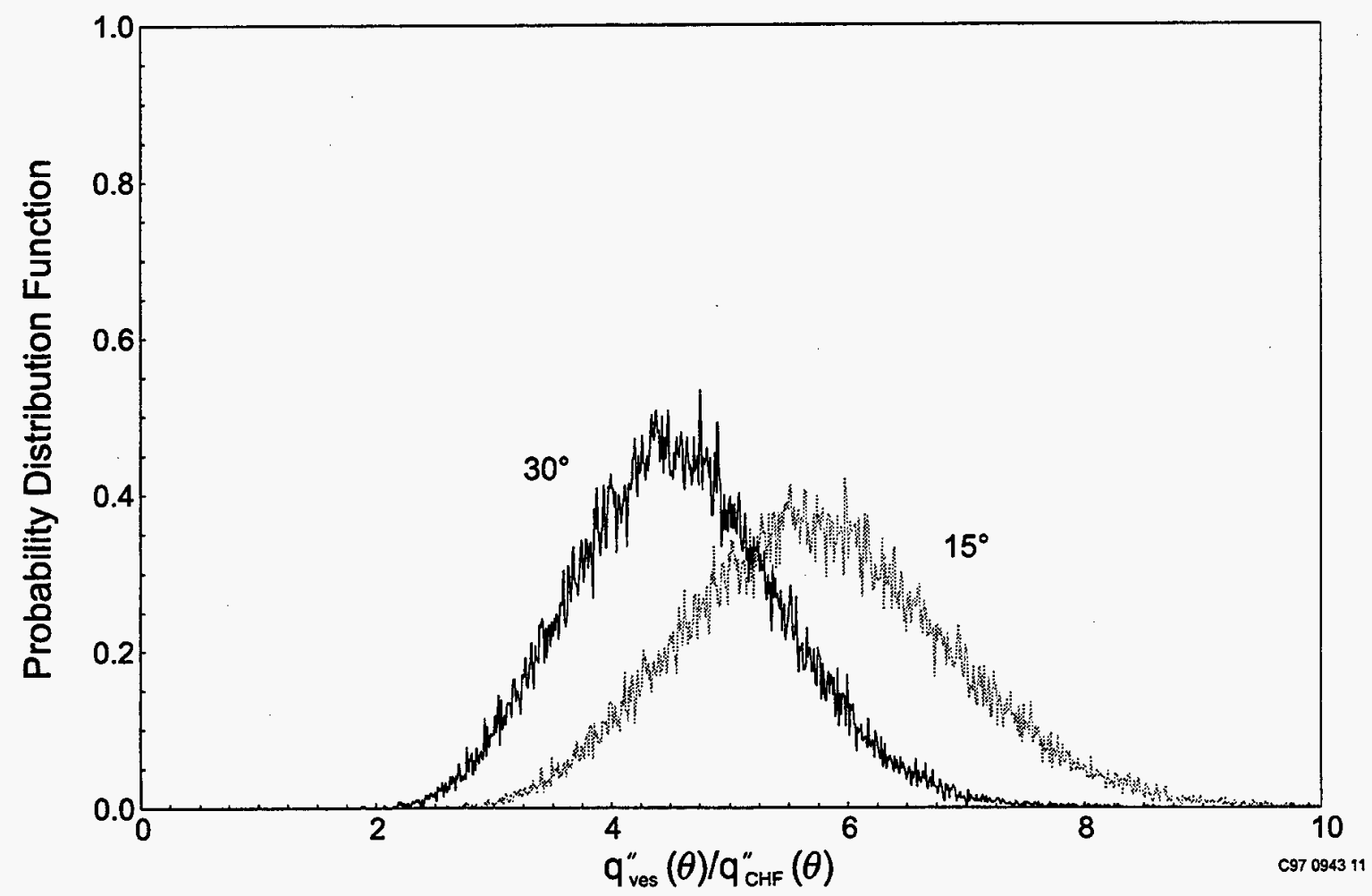

Figure 3-23. CHF ratio pdfs in the metallic layer for Configuration C. 
As discussed in Section 3.3.1, VESTA (or UCSB model) heat flux predictions exceeding CHF are beyond the range of applicability for these models. In a detailed transient analysis, heat fluxes in excess of CHF would cause vessel temperatures to rise to values where the steel loses its strength, experiencing creep structural instability. Because governing equations in VESTA (and the UCSB model) are limited to cases where heat fluxes are below CHF, heat flux predictions exceeding CHF should merely be viewed as an indicator of the probability of vessel failure. 


\section{Conclusions}

Results presented in Section 3 confirm that the vessel will remain intact for the UCSB-assumed FIBS, but suggest that failure margins are smaller than predicted by UCSB at some vessel locations. Furthermore, Section 3 results demonstrate that a key assumption in the UCSB approach (see Figure 1-1), that the UCSB-assumed FIBS bounds all credible thermal challenges to the vessel wall, isn't valid. For all alternate debris configurations and for several sensitivity studies analyzed in Section 3, INEEL found that the heat load to the vessel could exceed CHF. This section summarizes some of the key findings from INEEL's review and discusses the impact of these findings on AP600 PRA results.

\section{UCSB study approach and peer review comments}

If all the assumptions were valid in the UCSB approach, it is logical to make the assertions and associated conclusion identified in Figure 1-1. However, INEEL found that several key assumptions invoked in the UCSB study weren't valid. Specifically, INEEL's review and evaluation determined the following:

- The UCSB-assumed FIBS doesn't bound all credible thermal challenges to the vessel. Independent INEEL calculations indicate that heat fluxes from the vessel for several alternate debris configurations could exceed CHF.

- Independent INEEL calculations indicate that heat fluxes from the vessel for the UCSBassumed FIBS are below CHF. However, the margins to CHF for the UCSB-assumed FIBS are overestimated at some locations in the UCSB study for the following reasons:

- The presence of fission product decay heat in the metallic layer is neglected;

- The decay heat estimated for the ceramic pool differs from values recommended by existing standards and severe accident code predictions;

- Some UCSB-assumed material property assumptions aren't supported by the existing database;

- Uncertainties associated with heat transfer correlations, decay heat, and some material properties are neglected.

- The UCSB study typically addressed peer reviewer comments by sensitivity studies, but didn't assess integral effects associated with changes suggested by peer reviewers.

INEEL assessed the impact of these and other deficiencies on UCSB study conclusions.

\section{Vessel integrity for UCSB-assumed FIBS}

Using the INEEL-developed VESTA code, INEEL performed three types of calculations considering the UCSB-assumed FIBS. First, INEEL performed benchmark calculations assuming input parameter uncertainty distributions consistent with values assumed in the UCSB study. Second, INEEL performed calculations assuming revised input parameter distributions that reflected UCSB study peer reviewer and INEEL review comments. Finally, INEEL performed several sensitivity studies to address phenomenological uncertainties associated with several UCSB input assumptions. These calculations provided several important insights. 
- $\quad$ Agreement between UCSB and INEEL calculation results when UCSB input distributions are assumed (see Figures 3-1 and 3-2). This agreement suggests that governing equations listed in the UCSB study were correctly encoded into both models.

- Analysis of the UCSB-assumed FIBS with INEEL input uncertainty distributions (Figures 3-3 through 3-5):

- confirm UCSB predictions that the vessel remains intact;

- indicate that margins-to-failure are smaller than predicted by UCSB at some vessel locations; and

- indicate that minimum margins-to-failure occur at vessel locations that are in contact with the metallic layer (in contrast, the UCSB study predicts that minimum margins occur at vessel locations adjacent to the ceramic pool near the metallic layer and ceramic pool interface).

- Sensitivity calculations indicate that certain phenomenological uncertainties significantly impact vessel heat flux estimates. Specifically,

- increased upward heat fluxes associated with vaporization and boiling of lower vaporization temperature materials, such as metal structures or control materials, increased vessel heat flux estimates by $63 \%$;

- additional metallic layer heat sources due to stainless steel activation or oxidation did not significantly impact vessel heat fluxes;

- less than a factor of four decrease in relocated steel mass results in a $52 \%$ probability of the vessel heat fluxes exceeding CHF for the UCSB-assumed FIBS.

\section{Vessel integrity for alternate debris configurations}

VESTA was applied to consider thermal challenges presented by three alternate debris configurations. Configuration A is an intermediate state, similar to the UCSB-assumed FIBS in which less ceramic and less metallic materials have relocated to the lower head. Configuration B is an intermediate state in which the thinner metallic layer evaluated for Configuration $A$ is sandwiched between two ceramic pools. Configuration $\mathrm{C}$ considers the impact of unoxidized uranium dissolution into unoxidized zirconium causing the metallic layer to sink beneath the ceramic pool. VESTA analyses of these alternate configurations indicate:

- The UCSB-assumed FIBS doesn't bound all heat loads. Specifically, vessel heat fluxes associated with all three postulated configurations (Configurations $\mathrm{A}, \mathrm{B}$, and $\mathrm{C}$ ) are predicted to exceed CHF.

The formation of these alternate debris configurations is hypothetical. Additional analyses and experimental data are needed to substantiate whether such configurations are viable. However, based on the current state of knowledge, these configurations cannot be ruled out.

\section{Impact of AP600 risk assessment results}

A straightforward approach for estimating the impact of INEEL calculation results would be to multiply the probability of vessel failure for each postulated debris configuration by the probability of the debris configuration to occur. However, there are insufficient data available to estimate the probability of 
various proposed debris configurations to occur. Hence, INEEL applied a bounding approach to investigate the impact of calculation results on the AP600 risk assessment. This bounding approach attempted to answer the question,

What is the maximum increase in AP600 plant risk if all cavity flooding scenarios lead to vessel failure?

In the Westinghouse PRA, the six release categories summarized in Table 4-1 are used to estimate plant risk. Representative releases for five of these six release groups (all but the BP release category) are based on variations of the $3 \mathrm{BE}$ accident class in which successful cavity flooding is assumed to preclude vessel failure. However, in the $\mathrm{CFE}$ and $\mathrm{CI}$ release categories, the reduction in source term associated with ERVC is ineffective because other events (hydrogen detonation and failure of containment isolation) cause containment failure.

In order to bound the maximum increase in plant risk associated with ERVC failure, ERVC failure was conservatively assumed to result in vessel and containment failure. ${ }^{2}$ The impact of this conservative assumption was estimated by transferring the estimated frequency of the IC, CFI, and CFL release groups in which ERVC prevented vessel failure to the CFE release category (see Table 4-1). Because CFE release estimates are based on a 3BE transient in which early vessel and containment occurs because of severe accident phenomena, CFE releases were assumed as a reasonable bound for doses predicted for the remaining release groups, which were also based on $3 \mathrm{BE}$ transients. (CI releases provided an unrealistic upper bound for the IC, CFI, and CFL releases because containment isolation failure occurs early in $\mathrm{CI}$ transients).

Section 49 of the PRA presents two types of 24 and 72 hour dose estimates [mean effective committed dose (EDE) and acute whole body dose] that can be used to estimate plant risk. Table 4-1 summarizes PRA-estimated 24 hour doses and release probabilities for the six release groups. As indicated in Table 4-1, plant risk will increase by a factor of twenty if ERVC is unsuccessful (irrespective of the type of dose considered). Table 4-1 indicates that the sum of the probabilities of events with releases exceeding 25 rem would equal $1.6 \times 10^{-7}$ events per reactor year, which is still a factor of 6 below the $1 \times 10^{-6}$ events per reactor year Westinghouse design goal from the Electric Power Research Institute Advanced Light Water Reactor Requirements Document. ${ }^{30}$

a. This is a conservative assumption. However, as observed by Westinghouse in their response to RAI 720.388 , no significant benefit is achieved by assuming that the containment doesn't fail at early times because there is so much uncertainty associated with ex-vessel debris spreading, coolability, and hydrogen generation and combustion. 
Table 4-1. ERVC impact on Westinghouse AP600 risk estimates.

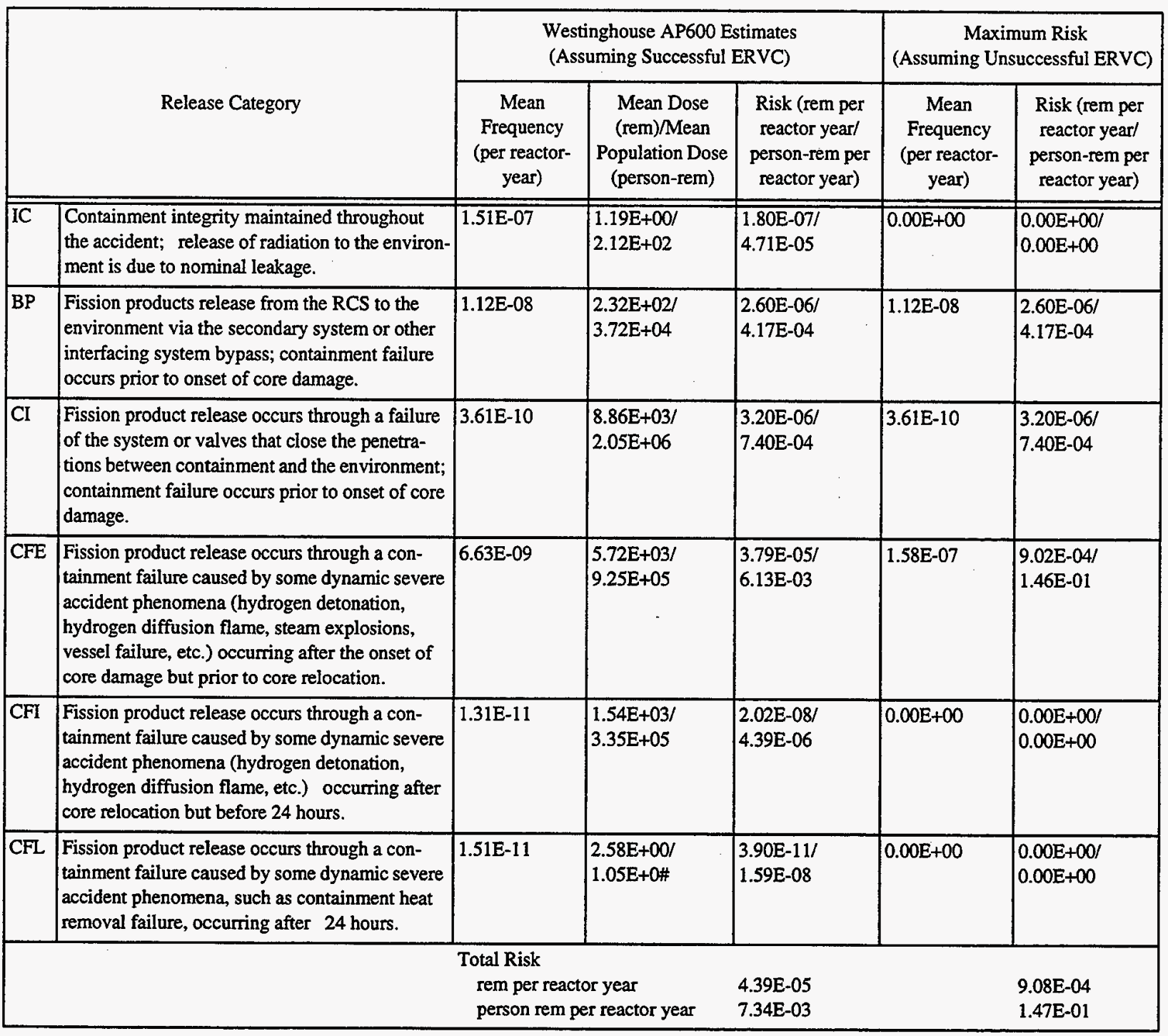




\section{References}

1. Westinghouse Electric Corporation, AP600 Probabilistic Risk Assessment, Revision 8, September 1996.

2. T. G. Theofanous et al., In-Vessel Coolability and Retention of a Core Melt, DOE/ID-10460, Revised October 1996.

3. D. L. Knudson, A SCDAP/RELAP5 Analysis of An AP600 3BE Transient with Ex-vessel Flooding, April 26, 1996, Attachment to letter from D. Knudson, INEL, to Y. Chen, NRC-RES, "Transmittal of Task 18 Letter Report under JCN L2330, DLK-2-96.

4. M. T. Leonard et al., "MELCOR Calculations Supporting the NRC/NRR AP600 Design Certification Review," Sandia National Laboratories Preliminary Draft Report, ITS/SNL-95-006, August 1995.

5. Letter from B. A. McIntyre, Westinghouse, to T. R. Quay, U. S. NRC, NSD-NRC-96-4687, DCP/ NRC0493, Docket No: STN-52-003, April 4, 1996.

6. Kastenberg, W. E., Editor, A Framework for the Assessment of Severe Accident Management Strategies, NUREG/CR-6056, September 1993.

7. Lim, H., "The Impact of Phenomenological Uncertainties on an Accident Management Strategy, University of California - Los Angeles Doctoral Dissertation, 1994.

8. $\quad$ B. R. Sehgal, et al., "Heat Transfer Processes in Reactor Vessel Lower Plenum during Late Phase of In-Vessel Core Melt Progression," to be published in Advances in Nuclear Science and Technology, Volume 27.

9. Letter from J. Sebrosky, U.S. NRC, to N. J. Liparulo, Westinghouse, Followon Questions Regarding Reactor Vessel Integrity during Severe Accident Core Melts, November 7, 1996.

10. Letter from J. Sebrosky, U.S. NRC, to N. J. Liparulo, Westinghouse, Followon Questions Regarding External Reactor Vessel Cooling for the AP600, February 24, 1997.

11. Letter from J. Sebrosky, U.S. NRC, to N. J. Liparulo, Westinghouse, Followon Questions Regarding External Reactor Vessel Cooling for the AP600, March 10, 1997.

12. Letter from B. A. McIntyre, Westinghouse, to T. R. Quay, U. S. NRC, NSD-NRC-96-4913, DCP/ NRC0683, Docket no: STN-52-003, December 13, 1996.

13. Letter from B. A. McIntyre, Westinghouse, to T. R. Quay, U. S. NRC, NSD-NRC-97-5067, DCP/ NRC0683, Docket no: STN-52-003, April 15, 1997.

14. A. Rubin, et al., Review of "In-Vessel Coolability and Retention of a Core Melt, DOE/ID-10460, July 1995, Attachment to letter from M. W. Hodges, U.S. NRC-RES, to G. M. Holahan, NRCNRR, "Review of DOE Report, In-Vessel Coolability and Retention of a Core Melt, DOE/ID10460, July 1995," May 19, 1997.

15. R. R. Hobbins, D. A. Petti, and D. L. Hagrman, "Fission Product Release from Fuel under Severe Accident Conditions," Nuclear Technology, Vol. 101, March 1993.

16. O. Kubaschewski and C. Alcock, Metallurgical Thermochemistry, 5th Edition, Pergamon Press, 1979.

17. Y. S. Touloukian and C. Y. Ho, "Properties of Selected Ferrous Alloying Elements," McGraw-Hill CINDAS Data Series on Material Properties, Volume III-01, 1981. 
18. G. W. Parker and S. A. Hodge, "Small Scale BWR Core Debris Eutectics Formation and Melting Experiment," Nuclear Engineering and Design, 121, 1990, pp 341-347.

19. K. T. Kim and D. R. Olander, "Dissolution of Uranium Dioxide by Molten Zircaloy," Journal of Nuclear Materials, 154, 1988, pp. 85-101.

20. P. J. Hayward, and I. M. George, "Dissolution of $\mathrm{UO}_{2}$ in Molten Zircaloy-4, Part 4: Phase Evolution during Dissolution and Cooling of 2000 to $2500^{\circ} \mathrm{C}$ Specimens," Journal of Nuclear Materials, 232, 1996, pp 13-22.

21. D. W. Akers, S. M. Jensen, and B. K. Scheutz, Examination of Relocated Fuel Debris Adjacent to the Lower Head of the TMI-2 Reactor Vessel, NUREG/CR-61995, TMI V(92)EG10, July 1992.

22. S. Jensen, D. Akers, B. Pregger, Postirradiation Examination Data and Analysis for OECD LOFT Fission Product Experiment LP-FP-2, OECD LOFT-3810, Vol. I, December 1989.

23. R. Gauntt, et al., The DF-4 Fuel Damage Experiment in ACRR with a BWR Control Blade and Channel Box, NUREG/CR-4671, SAND86-1443, November 1989.

24. G. A. Greene, O. C. Jones Jr., C. E. Schwartz, and N. Abuaf, Heat Removal Characteristics of Volume Heated Boiling Pools with Inclined Boundaries, NUREG/CR-1357, BNL-NUREG-51157, 1980.

25. C. M. Allison, J. L. Rempe, and S. A. Chavez, Design Report on SCDAP/RELAP5 Model Improvements - Debris Bed and Molten Pool Behavior, INEL-94-0174, November 1994.

26. J. Stephen Herring, Notes on the Activation of SS304 in the AP600, Unpublished notes, dated April $18,1996$.

27. C. Allison et. al., SCDAP/RELAP5/MOD3.1 Code Manuals, Volume 4: MATPRO-A Library of Materials Properties for Light Water Reactor Accident Analysis, Idaho National Engineering Laboratory Report, NUREG/CR-6150, EGG-2720, June 1995.

28. Personal conversation between J. Rempe, INEEL, and D. Petti, INEEL, September 1997.

29. Personal conversation between J. Rempe, INEEL, and R. R. Hobbins, RRH Consulting, September 1997.

30. Electric Power Research Institute, "Advanced Light Water Reactor Requirements Document," Volume III, Annex B of Appendix A to Chapter 1, "PRA Key Assumptions and Groundrules," Revs. 5 \& 6, December 1993.

31. T. G. Theofanous et al., "The First Results from the ACOPO Experiment," Transactions from the International Topical Meeting on Probabilistic Safety Assessment (PSA '96), Park City, Utah, September 1996.

32. S. Angelini, "ACOPO Data Discrepancies," email from S. Angelini, to S. Sorrell, US DOE, December 8, 1997.

33. F. B. Cheung, H. K. Haddad, and Y. C. Liu, "A Scaling Law for the Local CHF on the External Bottom Side of a Fully Submerged Reactor Vessel," presented at the 1996 Light Water Reactor Safety Information Meeting, October 1996.

34. F. B. Cheung, K. H. Haddad, and Y. C. Liu, Critical Heat Flux (CHF) Phenomenon on a Downward Facing Curved Surface, NUREG/CR-6507, PSU-ME-NRC-06-95, June 1997.

35. Personal conversation between J. Rempe, INEEL, and M. Leonard, ITS, April 1997. 
36. Personal conversation between J. Rempe, INEEL, and J. Scobel, Westinghouse, April 1997.

37. Personal conversation between J. Rempe, INEL, and T. Y. Chu, SNL, April 1996.

38. Personal conversations between J. Rempe, INEEL, and F. B. Cheung, Penn State, April 1997.

39. Personal conversation between Cory Atwood, INEEL, and J. Rempe, INEEL, October 1997.

40. S. Globe and D. Dropkin, "Natural-Convection Heat Transfer in Liquids Confined by Two Horizontal Plates and Heated from Below," Transactions of the ASME, p. 24, February 1959.

41. G. Fieg, "Experimental Investigations of Heat Transfer Characteristics in Liquid Layers with Internal Heat Sources," Proceedings of the ANS-ENS International Meeting on Fast Reactor Safety and Related Physics," Chicago, USERDA Report CONF-761001-P4, 1976, pp. 2047-2055.

42. F. A. Kulacki and A-T Nguyen, Hydrodynamic Instability and Thermal Convection in a Horizontal Layer of Two Immiscible Fluids with Internal Heat Generation, NUREG/CR-2619R3, 1980.

43. J. L. O'Toole and P. L. Silverston, "Correlations of Convective Heat Transfer in Confined Horizontal Layers," AlChE, Chem. Engng. Progr. Symp. Ser., 57(32) , pp 81-86, 1961.

44. T. C. Chawla and S. H. Chan, "Heat Transfer from Vertical/Inclined Boundaries of Heat Genreating Boiling Pools," J. of Heat Transfer, Tranactions of the ASME, Vol. 104, pp. 465-473, 1982.

45. American Nuclear Society Standard ANSI/ANS-5.1-1979, "Decay Heat Power in Light Water Reactors", 1979.

46. "Residual Decay Energy for Light Water Reactors for Long-Term Cooling," Auxiliary and Power Conversion Systems Branch Technical Position Paper, APCSB9-2, p. 9.25-8, November 11, 1975.

47. D. R. Olander, Fundamental Aspects of Nuclear Reactor Fuel Elements, Technical Information Center, Energy Research and Development Administration, 1976.

48. Personal conversation between J. Rempe, INEEL, and J. Sienicki, ANL, April 9, 1997.

49. Personal conversation between J. Rempe, INEEL, and B. Schnitzler, INEEL, April 8, 1997.

50. T. R. England and W. B. Wilson, TMI-2 Decay Power: LASL Fission-Product and Actinide Decay Power Calculations for the President's Commission on the Accident at Three Mile Island, LAS8041-MS, Revised, Informal Report, March 1980.

51. J. K. Fink and L. Leibowitz, "An Analysis of Measurements of the Thermal Conductivity of Liquid Urania," High Temperatures-High Pressures, 1985, Volume 17, pages 17-26, pp 17-26.

52. C. S. Kim, et al., Measurement of Thermal Diffusivity of Molten $\mathrm{UO}_{2}$, Proceedings of the Seventh Symposium on Thermophysical Properties, ed. A. Cezairliyan, ASME, New York p. 338, May 1012, 1977.

53. K. A. Romberger, C. F. Bates, Jr., H. H. Stone, "Phase Equilibrium Studies in the $\mathrm{UO}_{2}-\mathrm{ZrO}_{2}$ System, Journal of Inorganic and Nuclear Chemistry, 29, 1966, pp. 1619-1630.

54. "Density of Liquid Uranium Dioxide," International Nuclear Safety Center Database, /I www.insc.anl.gov/index.html, April 1997.

55. Y. S. Touloukian and D. P. DeWitt, "Thermal Radiative Properties - Metallic Elements and Alloys," Thermophysical Properties of Matter, Volume 7, IFI/Plenum, New York, 1970. 
56. A. J. Rulison and W.-K. Rhim, "Constant-Pressure Specific Heat to Hemispherical Total Emissivity Ratio for Undercooled Liquid Nickel, Zirconium, and Silicon," Metallurgical and Materials Transactions B, Volume 26B, June 1995, pp 503-508.

57. S. Krishnan and P. C. Nordine, "Spectral Emissivities in the Visible and Infrared of Liquid, Zr, Ni, and Nickel-based Binary Alloys," Journal of Applied Physics, Volume 80 (3), August 1996, pp 1735-1742.

58. D. L. Hagrman, ISS, personal conversation with J. L. Rempe, INEEL, April 7, 1997.

59. R. A. Moen, Thermophysical Properties of Ferrous Structural Alloys, Hanford Engineering Development Laboratory Report HEDL-TME 78-47, UC-79b,h, April 1978.

60. Pelton, A.D., L. Leibnowitz, and R. A. Blomquist, 1994, Journal of Nuclear Matter, 210, 1994, pp 324-332.

61. Nuclear Systems Materials Handbook, Volumes 1 and 2, Property Code 3112, Revision 3, August $1,1977$.

62. General Electric Company, Chart of the Nuclides, Twelfth Edition, Schenectady, NY, 1977.

63. J. R. Welty, C. E. Wicks, and R. E. Wilson, Fundamentals of Momentum, Heat, and Mass Transfer, Second Edition, John Wiley \& Sons, New York, NY, 1976.

64. P. J. Hayward, and I. M. George, "Dissolution of $\mathrm{UO}_{2}$ in Molten Zircaloy-4, Part 4: Phase Evolution during Dissolution and Cooling of 2000 to $2500^{\circ} \mathrm{C}$ Specimens," Journal of Nuclear Materials, 232, 1996, pp 13-22.

65. J. H. Min and F. A. Kulacki, Steady and Transient Natural Convection with Volumetric Energy Sources in a Fluid Layer Bounded from Below by a Segment of a Sphere - Annual Report 6, July 1976- September 1977, NUREG/CR-0006, February, 1976.

66. J. T. Bittel, L. H. Sjodahl, and J. F. White, "Oxidation of 304L Stainless Steel by Steam and Air," Corrosion 25, pp. 7-14, 1969.

67. L. Leibowitz, et al., "Solidus and Liquidus Temperatures in the Uranium-Plutonium-Zirconium System," Journal of Nuclear Materials, 154, 1988, pp 145-153. 


\section{Appendix A- VESTA Governing Equations and Nomenclature}

In order to independently verify UCSB study results and to assess the impact of additional uncertainties and other debris configurations, INEEL developed the VEssel Statistical Thermal Response Analysis (VESTA) model. VESTA governing equations are listed in Section A.1. Variables used in Section A.1 equations and in other sections of this report are defined in Section A.2.

Figure A-1 illustrates the generalized geometry of the lower head and debris assumed for this model. As indicated by this figure, VESTA is more general than the UCSB model. VESTA includes equations for predicting three debris configurations: Configuration A contains a molten ceramic pool beneath a molten metallic layer; Configuration B contains a molten metallic layer sandwiched between two ceramic pools; and Configuration $C$ contains a molten metallic pool beneath a ceramic layer. Section 2.1 provides additional details about each of these debris configurations.

VESTA is written in MODULA-2 using SAGE libraries and was compiled using the Stoneybrook compiler. It is designed to run on an IBM or IBM-compatible PC with MS Windows 95/NT operating systems. The model requires 16MB RAM and 2 MB diskspace. On a P120 (Pentium computer with a 120 $\mathrm{MHz}$ processor), VESTA can perform an uncertainty calculation with 1,000 iterations within approximately 1 minute.

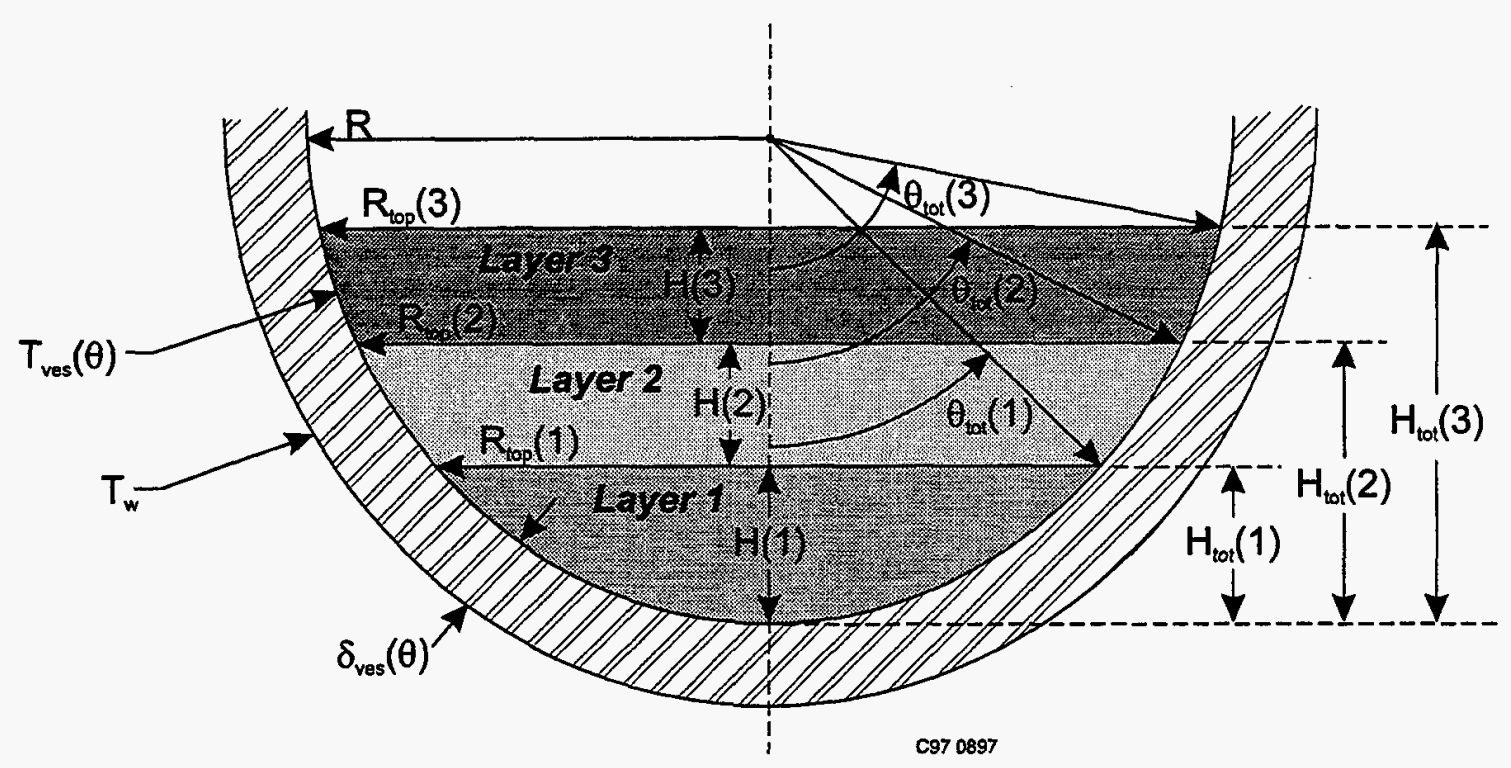

Figure A-1. Geometry assumed for VESTA analyses. 


\section{A.1 VESTA Governing Equations}

\section{A.1.1 CHF from Vessel Outer Surface}

For point estimates calculations:

$$
q^{\prime \prime}{ }_{C H F}(\theta)=C_{1}+C_{2} \theta+C_{3} \theta^{2}+C_{4} \theta^{3}+C_{5} \theta^{4}
$$

For calculations considering uncertainties:

$$
q^{\prime \prime}{ }_{C H F}(\theta)=\exp \left(C_{C H F}\right)\left(C_{1}+C_{2} \theta+C_{3} \theta^{2}+C_{4} \theta^{3}+C_{5} \theta^{4}\right)
$$

\section{A.1.2 Initialization and Material Properties}

\section{A.1.2.1 Ceramic Regions}

$$
\mathrm{M}_{\mathrm{UO}_{2}}(\mathrm{n})=\mathrm{M}_{\mathrm{UO}_{2}-\mathrm{tot}} \mathrm{f}_{\mathrm{ox}-\mathrm{U}} \mathrm{f}_{\mathrm{UO}_{2}}(\mathrm{n})
$$

For $\mathrm{M}_{\mathrm{UO}_{2}}(\mathrm{n})>0$ :

$$
\begin{aligned}
& M_{\mathrm{Zr}}(\mathrm{n})=\mathrm{f}_{\mathrm{ox}-\mathrm{Zr}} \mathrm{M}_{\mathrm{Zr}-\mathrm{tot}} \mathrm{f}_{\mathrm{ZrO}_{2}}(\mathrm{n}) \\
& \mathrm{V}_{\mathrm{UO}_{2}}(\mathrm{n})=\frac{\mathrm{M}_{\mathrm{UO}_{2}}(\mathrm{n})}{\rho_{\mathrm{UO}_{2}}} \\
& \mathrm{~N}_{\mathrm{UO}_{2}}(\mathrm{n})=\frac{\mathrm{M}_{\mathrm{UO}_{2}}(\mathrm{n})}{\mathrm{Z}_{\mathrm{UO}_{2}}} \\
& N_{Z_{r}}(n)=\frac{M_{Z_{r}}(n)}{Z_{Z_{r}}} \\
& \mathrm{~N}(\mathrm{n})=\mathrm{N}_{\mathrm{Zr}}(\mathrm{n})+\mathrm{N}_{\mathrm{UO}_{2}}(\mathrm{n}) \\
& \mathrm{f}_{\mathrm{N}-\mathrm{UO}_{2}}(\mathrm{n})=\mathrm{N}_{\mathrm{UO}_{2}}(\mathrm{n}) / \mathrm{N}(\mathrm{n}) \\
& \mathrm{f}_{\mathrm{N}-\mathrm{ZrO}_{2}}(\mathrm{n})=\mathrm{N}_{\mathrm{Zr}}(\mathrm{n}) / \mathrm{N}(\mathrm{n}) \\
& \mathrm{M}_{\mathrm{O}_{2}}(\mathrm{n})=\mathrm{N}_{\mathrm{Zr}}(\mathrm{n}) 2 \mathrm{Z}_{\mathrm{O}} \\
& \mathrm{M}_{\mathrm{ZrO}_{2}}(\mathrm{n})=\mathrm{M}_{\mathrm{Zr}}(\mathrm{n})+\mathrm{M}_{\mathrm{O}_{2}}(\mathrm{n}) \\
& \mathrm{M}(\mathrm{n})=\mathrm{M}_{\mathrm{ZrO}_{2}}(\mathrm{n})+\mathrm{M}_{\mathrm{UO}_{2}}(\mathrm{n}) \\
& \mathrm{f}_{\mathrm{m}-\mathrm{UO}_{2}}(\mathrm{n})=\mathrm{M}_{\mathrm{UO}_{2}}(\mathrm{n}) / \mathrm{M}(\mathrm{n}) \\
& \mathrm{f}_{\mathrm{m}-\mathrm{ZrO}_{2}}(\mathrm{n})=\mathrm{M}_{\mathrm{ZrO}_{2}}(\mathrm{n}) / \mathrm{M}(\mathrm{n}) \\
& \mathrm{V}_{\mathrm{ZrO}_{2}}(\mathrm{n})=\mathrm{M}_{\mathrm{ZrO}_{2}}(\mathrm{n}) / \rho_{\mathrm{ZrO}_{2}} \\
& \mathrm{~V}(\mathrm{n})=\mathrm{V}_{\mathrm{UO}_{2}}(\mathrm{n})+\mathrm{V}_{\mathrm{ZrO}_{2}}(\mathrm{n})
\end{aligned}
$$


$(6 \varepsilon-\nabla)$

$(8 \varepsilon-\forall)$

$(L \varepsilon-\forall)$

$(9 \varepsilon-\forall)$

$(\varsigma \varepsilon-\forall)$

$(\downarrow \varepsilon-\forall)$

$(\varepsilon \varepsilon-\forall)$

$(Z \varepsilon-\forall)$

$(I \varepsilon-\forall)$

$(0 \varepsilon-\forall)$

$(6 \tau-\forall)$

$(8 Z-\forall)$

$(L Z-\forall)$

$(9 Z-\forall)$

$(\varsigma \tau-\forall)$

$(t z-\forall)$

$(\varepsilon \tau-\forall)$

$(z Z-\forall)$

$(I Z-\forall)$

$(0 z-\forall)$

$(6 I-\forall)$

$(8 I-7)$ $(\mathrm{u}) \mathrm{N} /(\mathrm{u})^{\mathrm{n}_{\mathrm{N}}} \mathrm{N}=(\mathrm{u})^{\mathrm{n}-\mathrm{N}_{\mathfrak{J}}}$

$(u)_{N} /(u)^{s s} \mathrm{~N}=(u)^{s s-N_{J}}$

(u) $N /(u)^{s} \mathbf{Z}=(u)^{I z-N_{J}}$

$(u)^{\mathrm{n}} \mathrm{N}+(\mathrm{u})^{\mathrm{ss}} \mathrm{N}+(\mathrm{u})^{\mathrm{I}} \mathrm{N}=(\mathrm{u}) \mathrm{N}$

$$
\frac{\mathrm{n}_{Z}}{(u)^{\mathrm{n}} \mathrm{W}}=(\mathrm{u})^{\mathrm{n}} \mathrm{N}
$$$$
\frac{{ }^{s s} Z}{(u)^{s s} W}=(u)^{s s} N
$$

$\frac{{ }^{\mathrm{z}} \mathrm{Z}}{(\mathrm{u})^{\mathrm{s}} \mathrm{W}}=(\mathrm{u})^{\mathrm{s}} \mathrm{N}$

(u) $W /(u)^{n} W=(u)^{n-u_{f}}$

(u) $W /(u)^{s s} W=(u)^{s s-u t} J$

(u) $\left.W /(u)^{\mathrm{d} Z} W=(u)^{\mathrm{J} Z-\mathrm{u}}\right\}$

$(u)^{n} \mathrm{~W}+(u)^{s s} \mathrm{~W}+(\mathrm{u})^{\mathrm{s}} \mathrm{Z} \mathrm{W}=(\mathrm{u}) \mathrm{W}$

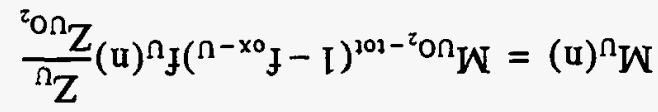
$(u)^{I Z} \mathfrak{f}^{101-J Z} W\left({ }^{J Z-x o} \mathfrak{f}-I\right)=(u)^{s Z} W$ $: 0<(\mathrm{U})^{\text {ss }} \mathrm{W}$ IOH

$(u)^{s s} f^{201-s s} W=(u)^{s s} W$

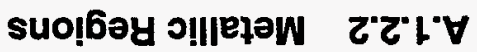

$$
\begin{aligned}
& (u)^{d-d} \supset(u)^{d} d /(u)^{d} x=(u)^{d} x
\end{aligned}
$$

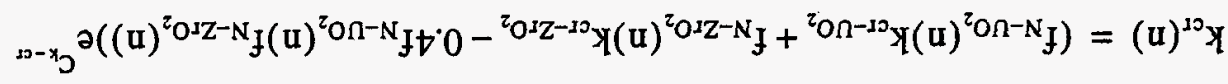

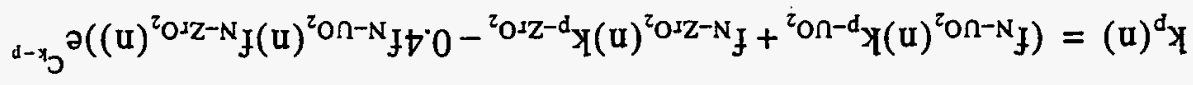

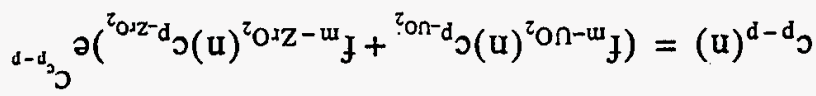

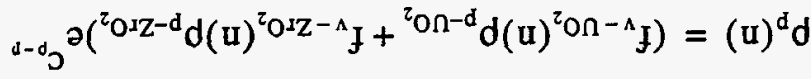

$$
\begin{aligned}
& \text { (u) } \Lambda /(u)^{z}{ }^{X} Z \Lambda=(u)^{z_{O} Z-\Lambda} J \\
& \text { (u) } \Lambda /(u)^{z} \text { on } \Lambda=(u)^{z} \text { on-A } \mathrm{J} \\
& 0<(\mathrm{u})_{\Lambda} \text { 10у }:(\mathrm{u}) \Lambda \mathrm{Z}={ }^{\mathrm{d}} \Lambda
\end{aligned}
$$




$$
\begin{aligned}
& V_{Z r}(n)=M_{Z r}(n) / \rho_{Z_{r}} \\
& V_{s s}(n)=M_{s s}(n) / \rho_{s s} \\
& V_{U}(n)=M_{U}(n) / \rho_{U} \\
& V(n)=V_{Z r}(n)+V_{s s}(n)+V_{U}(n) \\
& V_{1}=\sum V(n) ; \text { for } V(n)>0 \\
& f_{v-Z r}(n)=V_{Z r}(n) / V(n) \\
& f_{v-s s}(n)=V_{s s}(n) / V(n) \\
& f_{v-U}(n)=V_{U}(n) / V(n) \\
& \rho_{l}(n)=\left(f_{v-Z_{r}}(n) \rho_{Z r}+f_{v-s s}(n) \rho_{s s}+f_{v-U}(n) \rho_{U}\right) e^{c_{p-1}} \\
& c_{p-1}(n)=\left(f_{m-Z r}(n) c_{p_{-Z r}}+f_{m-s s}(n) c_{p_{-s s}}+f_{m-U}(n) c_{p_{-U}}\right) e^{c_{c_{p}-1}}
\end{aligned}
$$

For UCSB-assumed FIBS and Configurations $\mathrm{A}$ and $\mathrm{B}$ :

$$
k_{1}(n)=\left(f_{m-Z r}(n) k_{1-Z r}+f_{m-s s}(n) k_{1-s s}-0.72 f_{m-Z r}(n) f_{m-s s}(n) \mid k_{1-Z r}-k_{1-s s}\right) e^{c_{k-1}}
$$

For Configuration C:

$$
\begin{aligned}
& k_{1}(n)=\left(f_{N-Z r}(n) k_{Z r}+f_{N-s s}(n) k_{s s}+f_{N-U}(n) k_{U}\right) e^{C_{k-1}} \\
\beta_{l}(n)= & \left(f_{v-Z r}(n) \beta_{Z r}+f_{v-s s}(n) \beta_{s s}+f_{v-U}(n) \beta_{U}\right) e^{C_{\beta-1}} \\
\alpha_{l}(n)= & \frac{k_{l}(n)}{\rho_{1}(n) c_{p-1}(n)}
\end{aligned}
$$

\section{A.1.3 Geometry}

$$
\begin{aligned}
& V_{\text {hem }}=\frac{2}{3} \pi R^{3} \\
& V_{\text {tot }}(n)=\sum_{z=1}^{n} V(z)
\end{aligned}
$$

For $V_{\text {tot }}(n) \leq V_{\text {hem }}$ :

Obtain $\left.\mathrm{H}_{\text {tot }}(\mathrm{n})\right|_{\mathrm{n}=1,3}$ by iteratively solving:

$$
\begin{aligned}
& V_{\text {tot }}(n)=(1 / 3) \pi H_{\text {tot }}(n)^{2}\left(3 R-H_{t o t}(n)\right) \\
& R_{t o p}(n)=\left[\frac{2 V_{t o t}(n)}{\pi H_{t o t}(n)}-\frac{H_{t o t}(n)^{2}}{3}\right]^{0.5} \\
& \theta_{\text {tot }}(n)=\arcsin \left(R_{t o p}(n) / R\right) \\
& S_{\text {up }}(n)=\pi R_{\text {top }}(n)^{2}
\end{aligned}
$$


$(8 L-\forall)$

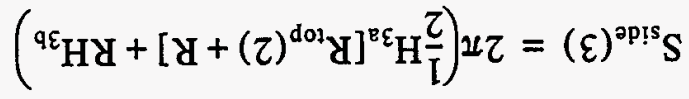

$$
\begin{aligned}
& {\left[(I)^{d 01} y+(\tau)^{d o l} y\right](z) H^{\mathscr{L}}=(z)^{\text {op!s }} S} \\
& (\tau)^{101} \mathrm{H}+(\varepsilon) \mathrm{H}=(\varepsilon)^{103} \mathrm{H} \\
& (\mathrm{I})^{203} \mathrm{H}-(\mathrm{Z})^{103} \mathrm{H}=(\mathrm{Z}) \mathrm{H} \\
& (\mathrm{I})^{\mathrm{I01}} \mathrm{H}=(\mathrm{I}) \mathrm{H} \\
& { }^{9 \varepsilon} \mathrm{H}+{ }^{\mathrm{B}} \varepsilon_{\mathrm{H}}=(\varepsilon) \mathrm{H}
\end{aligned}
$$

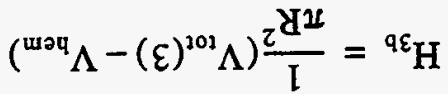

$$
\begin{aligned}
& (Z)^{201} \mathrm{H}-\mathrm{X}={ }^{\mathrm{D}} \mathrm{E} \mathrm{H}
\end{aligned}
$$

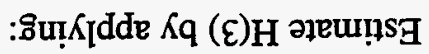

$(0 L-\forall)$ $\left(\mathrm{d} /(\mathrm{u})^{\mathrm{dol}} \mathrm{y}\right)$ u!sore $=(\mathrm{u})^{101} \theta$

$(69-\forall)$

$$
\tau^{(u)^{d o l}} \mathrm{~d} u=(u)^{d n} S
$$

$(89-\forall)$

$$
{ }_{s 0}\left[\frac{\varepsilon}{(u)^{201} H}-\frac{(u)^{103} H u}{(u)^{201} \Lambda \tau}\right]=(u)^{d 01} y
$$

$$
\tau=\mathrm{u} \text { pure } \mathrm{I}=\mathrm{u} \text { IоH }
$$

$$
\left((u)^{303} \mathrm{H}-\mathrm{y} \varepsilon\right)_{\tau}(\mathrm{u})^{301} \mathrm{H}^{\mathscr{L}}(\varepsilon / \mathrm{I})=(\mathrm{u})^{103} \Lambda
$$

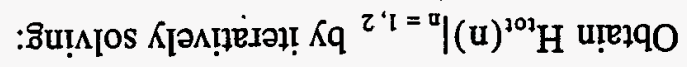

$$
:{ }^{\text {waq }} \Lambda<(\varepsilon)^{101} \Lambda \text { pure }{ }^{\text {wə4 }} \Lambda>(\tau)^{103} \Lambda \text { 10马 }
$$

$(99-\nabla)$

$$
(I-u)^{d n} S=(u)^{u p} S
$$

$(s 9-7)$

$$
\left[(I-u)^{d 01} y+(u)^{d 01} y\right](u) H^{\mathscr{U}}=(u)^{a p ! s} S
$$

$$
: \varepsilon=\mathrm{u} \text { pure } \tau=\mathrm{u} \mathrm{IO}_{\mathrm{H}}
$$

$$
00=(I)^{\text {ap!s }} S
$$

$(\varepsilon 9-\forall)$

$$
\text { (I) } \mathrm{H} \mathscr{H} \mathscr{Z Z}=(\mathrm{I})^{\mathrm{up}} \mathrm{S}
$$

$(29-\forall)$

$(\tau)^{103} \mathrm{H}-(\varepsilon)^{103} \mathrm{H}=(\varepsilon) \mathrm{H}$

$(19-\forall)$

$(\mathrm{I})^{101} \mathrm{H}-(\tau)^{101} \mathrm{H}=(\tau) \mathrm{H}$

$(09-\forall)$

$$
(\mathrm{l})^{101} \mathrm{H}=(\mathrm{I}) \mathrm{H}
$$




$$
\begin{aligned}
& R_{\text {top }}(3)=R \\
& S_{d n}(1)=2 \pi R H(1)
\end{aligned}
$$

For $n=2$ and $n=3$ :

$$
S_{\mathrm{dn}}(\mathrm{n})=\pi \mathrm{R}_{\mathrm{top}}(\mathrm{n}-1)^{2}
$$

\section{A.1.4 Decay Heat}

$$
\begin{aligned}
& \mathrm{f}_{\text {Group 4 }}\left(\mathrm{t}_{\mathrm{rel}}\right)=\mathrm{M}_{\text {Group } 4}\left(\mathrm{t}_{\mathrm{rel}}\right) \mathrm{t}_{\mathrm{rel}}+\mathrm{B}_{\text {Group } 4}\left(\mathrm{t}_{\mathrm{rel}}\right) \\
& \mathrm{f}_{\text {Group } 6}\left(\mathrm{t}_{\mathrm{rel}}\right)=\mathrm{M}_{\text {Group } 6}\left(\mathrm{t}_{\text {rel }}\right) \mathrm{t}_{\text {rel }}+\mathrm{B}_{\text {Group } 6}\left(\mathrm{t}_{\text {rel }}\right) \\
& f_{Z_{r} \& N b}\left(t_{r e l}\right)=M_{Z r \& N b}\left(t_{r e l}\right) t_{r e l}+B_{Z r \& N b}\left(t_{r e l}\right) \\
& f_{\text {metal }}=\left(1-f_{\text {ox }-Z_{r}}\right)\left[f_{\text {Group } 4}\left(t_{\text {rel }}\right)+f_{Z_{r} \& ~ N b}\left(t_{\text {rel }}\right)\right]+f_{\text {Group } 6}\left(t_{\text {rel }}\right) \\
& P_{\text {decay }-t o t}\left(t_{\text {rel }}\right)=e^{C_{\text {dec }}} P_{\text {decay-UCSB }}\left(t_{\text {rel }}\right) \\
& P_{\text {decay }-F P}\left(t_{\text {rel }}\right)=\left(1-f_{\text {ACT }}\left(t_{\text {rel }}\right)\right) P_{\text {decay - tot }}\left(t_{\text {rel }}\right) \\
& P_{\text {decay-ACT }}\left(t_{\text {rel }}\right)=f_{A C T}\left(t_{\text {rel }}\right) P_{\text {decay-tot }}\left(t_{\text {rel }}\right)
\end{aligned}
$$

For ceramic materials:

$$
\dot{Q}(n)=\left(\frac{f_{\text {ox }-U}}{V_{p}}\right)\left[P_{\text {decay }-F P}\left(t_{\text {rel }}\right)\left(1-f_{\text {metal }}\right)+P_{\text {decay }-A C T}\left(t_{\text {rel }}\right)\right]
$$

For metallic materials:

$$
\dot{Q}(n)=P_{\text {decay }-F P}\left(t_{\text {rel }}\right)\left(\frac{f_{\text {metal }} f_{\text {ox }-U}}{V_{1}}\right)+P_{\text {decay }-A C T}\left(\frac{f_{U}(n)\left(1-f_{\text {ox }-U}\right)}{V(n)}\right)
$$

\section{A.1.5 Heat Transfer}

\section{A.1.5.1 Equations for Ceramic Pools}

For $n$ with $\mathrm{M}_{\mathrm{UO}_{2}}(\mathrm{n})>0$ :

$$
\begin{aligned}
& \overline{T_{p}(n)}=T_{p, m}(n)+0.5 T_{p-d e l}(n) \quad\left(\text { Initially assume } T_{p-d e l}(n)=0\right) \\
& \mu_{p}(n)=1.5868 \times 10^{-4} \exp \left(\frac{10430}{\overline{T_{p}(n)}}\right)+C_{\mu-p} \\
& v_{p}(n)=\mu_{p}(n) / \rho_{p}(n) \\
& \operatorname{Ra}_{p}(n)^{\prime}=\frac{g \beta_{p}(n) Q(n) H(n)^{5}}{\alpha_{p}(n) v_{p}(n) k_{p}(n)}
\end{aligned}
$$




$$
\begin{aligned}
& \overline{\mathrm{Nu}}_{\mathrm{p}-\mathrm{up}}(\mathrm{n})=\mathrm{C}_{6}\left[\operatorname{Ra}_{\mathrm{p}}(\mathrm{n})^{\prime \mathrm{C}_{7}}\right]\left[10^{\left[\sigma_{N \mathrm{p}_{\mathrm{p}-\mathrm{v}_{p}}}\left(\mathrm{Ra}_{\mathrm{p}}(\mathrm{n})^{\prime}\right)\right]}\right]^{\mathrm{a}} \\
& \overline{N u}_{p-d n}(n)=C_{8}\left[R a_{p}(n)^{, C_{9}}\right](H(n) / R)^{0.25}\left(10^{\left[\sigma_{N_{p}-d n}\left(R a_{p}(n)^{\prime}\right)\right]}\right)^{a} \\
& R(n)^{\prime}=\overline{N u}_{p-u p}(n) / \overline{N u}_{p-d n}(n) \\
& \left.\overline{q_{p-d n}^{\prime \prime}(n)}=\frac{\dot{Q}(n) V(n)}{\left(S_{\text {side }}(n)+S_{d n}(n)+S_{u p}(n) R(n)^{\prime}\right)}, \text { (note that } S_{\text {side }}(1)=0\right) \\
& T_{p-d e l}(n)=\frac{\overline{q^{\prime \prime} p-d n}(n)}{\frac{k_{p}(n)}{H(n)} \overline{N u}_{p-d n}(n)}=T_{p, \text { max }}(n)-T_{p, m}(n)
\end{aligned}
$$

Check pool temperature assumption for calculating viscosity

$$
\begin{aligned}
& \left.\overline{T_{p}(n)}=T_{p, m}(n)+0.5 T_{p-d e l}(n) \text { (Repeat until estimates for } \overline{T_{p}(n)} \text { are within } 10 K\right) \text {. } \\
& \overline{q_{p-u p}^{\prime \prime}(n)}=\frac{\dot{Q}(n) V(n)-\overline{q_{p-d n}^{\prime \prime}(n)}\left[S_{\text {side }}(n)+S_{d n}(n)\right]}{S_{u p}(n)}
\end{aligned}
$$

For $\left[\theta(n) / \theta_{\text {tot }}(n) \leq 0.1\right]$

$$
q_{p-d n}^{\prime \prime}(\theta, n) / \overline{q_{p-d n}^{\prime \prime}(n)}=\operatorname{Max}\left[0.01,\left(C_{l o c a l}+q_{p-d n}^{\prime \prime}\left[0.1 \theta_{t o t}(n)\right] / \overline{q_{p-d n}^{\prime \prime}(n)}\right)\right]
$$

For $\left[0.1<\theta(n) / \theta_{\text {tot }}(n) \leq 0.6\right]$

$$
\begin{aligned}
& \mathrm{q}_{\mathrm{p}-\mathrm{dn}}^{\prime \prime}(\theta, \mathrm{n}) / \overline{\mathrm{q}_{\mathrm{p}-\mathrm{dn}}^{\prime \prime}(\mathrm{n})}= \\
& \quad \operatorname{Max}\left[0.01,\left(\mathrm{C}_{\text {local }}+\mathrm{C}_{10}+\mathrm{C}_{11}\left(\theta(\mathrm{n}) / \theta_{\mathrm{tot}}(\mathrm{n})\right)+\mathrm{C}_{12}\left(\theta(\mathrm{n}) / \theta_{\text {tot }}(\mathrm{n})\right)^{2}+\mathrm{C}_{13}\left(\theta(\mathrm{n}) / \theta_{\mathrm{tot}}(\mathrm{n})\right)^{3}\right)\right]
\end{aligned}
$$

For $\left[0.6<\theta(\mathrm{n}) / \theta_{\mathrm{tot}}(\mathrm{n}) \leq 1.0\right]$

$$
\mathrm{q}_{\mathrm{p}-\mathrm{d} n}^{\prime \prime}(\theta, \mathrm{n}) / \overline{\mathrm{q}_{\mathrm{p}-\mathrm{dn}}^{\prime \prime}(\mathrm{n})}=\mathrm{C}_{\text {local }}+\mathrm{C}_{14}+\mathrm{C}_{15}\left(\theta(\mathrm{n}) / \theta_{\mathrm{tot}}(\mathrm{n})\right)+\mathrm{C}_{16}\left(\theta(\mathrm{n}) / \theta_{\mathrm{tot}}(\mathrm{n})\right)^{2}
$$

For $n$, such that $n>1$ and $\mathrm{M}_{\mathrm{UO}_{2}}(\mathrm{n})>0$ :

$$
\left.\overline{q_{p-d n}^{\prime \prime}(n)}\right|_{n \text { to }-1}=\frac{2 \pi R^{2}}{S_{u p}(n-1)} \int_{0}^{\theta_{t o t}(n-1)} q_{p-d n}^{\prime \prime}(\theta, n) \sin \theta \cos \theta d \theta
$$

a. As described in Section B.1.1, $\sigma_{\mathrm{Nu}_{\mathrm{p}-\mathrm{up}}}\left(\mathrm{Ra}_{\mathrm{p}}(\mathrm{n})^{\prime}\right)$ and $\sigma_{\mathrm{Nu} \mathrm{p}_{\mathrm{p} \text { d }}}\left(\mathrm{Ra}_{\mathrm{p}}(\mathrm{n})^{\prime}\right)$ are given by:

$$
\begin{aligned}
& \sigma_{\mathrm{Nu}_{\mathrm{p}-\mathrm{up}}}\left(\operatorname{Ra}_{\mathrm{p}}(\mathrm{n})^{\prime}\right)=\left[\mathrm{se}_{\mathrm{C}_{6}}^{2}+\operatorname{se}_{\mathrm{C}_{7}}^{2}\left(\log \left(\operatorname{Ra}_{\mathrm{p}}(\mathrm{n})^{\prime}\right)-15.0148\right)^{2}\right]^{1 / 2} T \\
& \sigma_{\mathrm{Nu}_{\mathrm{p}-\mathrm{dn}}}\left(\operatorname{Ra}_{\mathrm{p}}(\mathrm{n})^{\prime}\right)=\left[\operatorname{se}_{\mathrm{C}_{8}}^{2}+\operatorname{se}_{\mathrm{C}_{9}}^{2}\left(\log \left(\operatorname{Ra}_{\mathrm{p}}(\mathrm{n})^{\prime}\right)-14.9701\right)^{2}\right]^{1 / 2} T
\end{aligned}
$$


For $\mathrm{n}$ with $\mathrm{MUO}_{2}(\mathrm{n})>0$ :

If $n=1$, for $\theta(1) \leq \theta_{\text {tot }}(1)$, or if $n>1$, for $\theta_{\text {tot }}(n-1)<\theta(n) \leq \theta_{\text {tot }}(n) \leq \pi / 2$, the heat flux to the vessel wall, $q^{\prime \prime}{ }_{\text {ves }}(\theta)$, is obtained from the following equation, where either the vessel wall temperature, $T_{\text {ves }}(\theta)$, or vessel wall thickness, $\delta_{\text {ves }}(\theta)$ and the crust thickness, $\delta_{\mathrm{cr}}(\theta, \mathrm{n})$, are unknown. ${ }^{\mathrm{a}}$

First, assume $\delta_{\text {ves }}(\theta)=0.15 \mathrm{~m}$ and solve for $\delta_{\mathrm{cr}}(\theta, \mathrm{n})$ and $\mathrm{T}_{\mathrm{ves}}(\theta)$ using:

$$
\begin{gathered}
0=\frac{\dot{Q}(n) \delta_{\mathrm{cr}}^{2}(\theta, \mathrm{n})}{2 \mathrm{k}_{\mathrm{cr}}(\mathrm{n})}+\delta_{\mathrm{cr}}(\theta, \mathrm{n})\left(\frac{\mathrm{q}_{\mathrm{p}-\mathrm{dn}}^{\prime \prime}(\theta, \mathrm{n})}{\mathrm{k}_{\mathrm{cr}}(\mathrm{n})}+\frac{\dot{\mathrm{Q}}(\mathrm{n}) \delta_{\mathrm{ves}}(\theta)}{\mathrm{k}_{\mathrm{ves}-\mathrm{h}}}\right) \\
\left(-\mathrm{T}_{\mathrm{p}, \mathrm{m}}(\mathrm{n})\right)+\frac{\mathrm{q}_{\mathrm{p}-\mathrm{dn}}^{\prime \prime}(\theta, \mathrm{n}) \delta_{\mathrm{ves}}(\theta)}{\mathrm{k}_{\mathrm{ves}-\mathrm{h}}}+\mathrm{T}_{\mathrm{w}} \\
\mathrm{T}_{\mathrm{ves}}(\theta)=\frac{\left[\mathrm{q}_{\mathrm{p}-\mathrm{dn}}^{\prime \prime}(\theta, \mathrm{n})+\dot{\mathrm{Q}}(\mathrm{n}) \delta_{\mathrm{cr}}(\theta, \mathrm{n})\right] \delta_{\mathrm{ves}}(\theta)}{\mathrm{k}_{\mathrm{ves}-\mathrm{h}}}+\mathrm{T}_{\mathrm{w}}
\end{gathered}
$$

If $T_{v e s}(\theta)>T_{p-v e s, m}$, then solve for $\delta_{c r}(\theta, n)$ and $\delta_{v e s}(\theta)$ using

$$
\begin{aligned}
& 0=\frac{\dot{Q}(n) \delta_{c r}^{2}(\theta, n)}{2 k_{c r}(n)}+\delta_{c r}(\theta, n)\left(\frac{q_{p-d n}^{\prime \prime}(\theta, n)}{k_{c r}(n)}\right)-T_{p, m}(n)+T_{p-v e s, m} \\
& \delta_{v e s}(\theta)=k_{v e s-h} \frac{\left(T_{p-v e s, m}-T_{w}\right)}{q_{p-d n}^{\prime \prime}(\theta, n)+Q(n) \delta_{c r}(\theta, n)}
\end{aligned}
$$

Then, obtain the heat flux to the vessel wall, $\mathrm{q}^{\prime \prime}{ }_{\text {ves }}(\theta)$, using

$$
q^{\prime \prime}{ }_{\text {ves }}(\theta)=q_{p-d n}^{\prime \prime}(\theta, n)+\dot{Q}(n) \delta_{c r}(\theta, n)
$$

\section{A.1.5.2 Equations for the Metallic Layer - UCSB-assumed FIBS and Configuration A}

Iteratively solve the next equations to obtain $T_{1-\text { top }}(2), T_{1-\text { bot }}(2), T_{1-b u l k}(2), T_{s-1}, T_{s-0}$, and $T_{v e s}$

First, solve for $A_{1-t o p}(2), A_{1-b o t}(2)$, and $A_{1-\text { side }}(2)$ by evaluating at the appropriate temperatures (initially assume metal layer is at its liquidus temperature and upper plenum structures are at $1000 \mathrm{~K}$ ).

$$
\begin{aligned}
& \mu_{f 1-i}(2)=1.1081 \times 10^{-4} \exp \left(\frac{5776}{T_{f 1-i}(2)}\right)+C_{\mu-1} \\
& v_{f 1-i}(2)=\mu_{f 1-i}(2) / \rho_{1}(2) \\
& k_{s}\left(\bar{T}_{s}\right)=\left(1.4154 \times 10^{-2} \bar{T}_{s}+9.9214\right) e^{C_{k-s}} \\
& A_{1-\text { top }}(2)=C_{17} e^{C_{t o p}} k_{1}(2)\left[v_{f 1-t o p}(2) / \alpha_{1}(2)\right]^{C_{18}}\left(\frac{g \beta_{1}(2)}{v_{f 1-t o p}(2) \alpha_{1}(2)}\right)^{C_{19}} \\
& A_{1-\text { bot }}(2)=C_{17} e^{C_{b o t}} k_{l}(2)\left[v_{f 1-b o t}(2) /\left(\alpha_{1}(2)\right)\right]^{C_{18}}\left(\frac{g \beta_{1}(2)}{v_{f 1-b o t}(2) \alpha_{1}(2)}\right)^{C_{19}}
\end{aligned}
$$

a. For $n=3$, calculate $\delta_{\mathrm{cr}}(\theta, 3)$ for $0 \leq \theta(3) \leq \theta_{\mathrm{tot}}(3)$. 


$$
A_{1-\text { side }}(2)=\frac{C_{20} e^{c_{\text {side }}} k_{1}(2)\left(\frac{g \beta_{1}(2)}{v_{f 1-\text { side }}(2) \alpha_{1}(2)}\right)^{C_{22}}}{\left(1+\left(\frac{0.492}{\left(v_{f 1-\text { side }}(2) / \alpha_{1}(2)\right)}\right)^{9 / 16}\right)^{16 / 27}}
$$

Second, assume $\mathrm{T}_{\mathrm{s}-\mathrm{i}}$ and solve the next equation for $\mathrm{T}_{1-\text { top }}(2)$

$$
\begin{aligned}
& \mathrm{f}_{\text {metal }} \dot{Q}(2) \mathrm{V}(2)+\mathrm{S}_{\mathrm{dn}}(2)\left[\frac{\overline{q_{\mathrm{p}-\mathrm{up}}^{\prime \prime}(1)}}{\mathrm{H}(2)^{3 \mathrm{C}_{22}-1}}\right]=\left(\frac{\sigma\left(\mathrm{T}_{1-\text { top }}^{4}(2)-\mathrm{T}_{\mathrm{s}-\mathrm{i}}^{4}(2)\right)}{\frac{1}{\varepsilon_{1}}+\frac{1-\varepsilon_{\mathrm{s}}}{\varepsilon_{\mathrm{s}}}\left(\frac{\mathrm{Sp}_{\mathrm{pp}}(2)}{\mathrm{S}_{\mathrm{s}}}\right)}\right)\left(\frac{\mathrm{S}_{\mathrm{up}}(2)}{\mathrm{H}(2)^{3 \mathrm{C}_{22}-1}}\right)+ \\
& A_{1-\text { side }}(2) S_{\text {side }}(2)\left(\left[\left(\frac{\sigma\left[T_{1-\text { top }}^{4}(2)-T_{s-i}^{4}\right]}{\frac{1}{\varepsilon_{1}}+\frac{1-\varepsilon_{s}}{\varepsilon_{s}}\left(\frac{S_{u p}(2)}{S_{s}}\right)}\right)\left(\frac{1}{A_{1-\text { top }} H(2)^{3 C_{19}-1}}\right)\right]^{\frac{1}{C_{19}+1}}+T_{1-\text { top }}(2)-T_{1, m}(2)\right)^{C_{2}+1}
\end{aligned}
$$

Third, use $\mathrm{T}_{\mathrm{s}-\mathrm{i}}$ and $\mathrm{T}_{1-\text { top }}(2)$ to estimate $\mathrm{T}_{\mathrm{s}-\mathrm{o}}$ from

$$
T_{s-0}=T_{s-i}-\frac{\delta_{s}}{k_{s}\left(\bar{T}_{s}\right)}\left(\frac{\sigma\left[T_{1-\text { top }}^{4}(2)-T_{s-i}^{4}\right]}{\frac{1}{\varepsilon_{1}}\left(\frac{S_{s}}{S_{u p}(2)}\right)+\frac{1-\varepsilon_{s}}{\varepsilon_{s}}}\right)
$$

Fourth, use the following two equations to estimate $T_{\text {ves }}$

$$
\begin{aligned}
& \mathrm{T}_{\text {ves }}=\left[\mathrm{T}_{s-0}^{4}-\frac{\mathrm{k}_{\mathrm{s}}(2)}{\delta_{\mathrm{s}} \sigma \varepsilon_{\mathrm{s}}}\left(\mathrm{T}_{\mathrm{s}-\mathrm{i}}-\mathrm{T}_{\mathrm{s}-\mathrm{o}}\right)\right]^{0.25} \\
& \mathrm{~T}_{\text {ves }}=\frac{\mathrm{k}_{\mathrm{s}}\left(\overline{\mathrm{T}}_{\mathrm{s}}\right) \delta_{\mathrm{o}}}{\mathrm{k}_{\mathrm{ves}-\mathrm{c}} \mathrm{\delta}_{\mathrm{s}}}\left(\mathrm{T}_{\mathrm{s}-\mathrm{i}}-\mathrm{T}_{\mathrm{s}-\mathrm{o}}\right)+\mathrm{T}_{\mathrm{w}}
\end{aligned}
$$

When both equations yield the same $T_{\text {ves }}$, use the following equations to find $T_{1-b o t}(2)$ and $T_{1-\text { bulk }}(2)$

$$
\begin{aligned}
& T_{1-\text { bulk }}(2)=\left[\left(\frac{\sigma\left[T_{1-\text { top }}^{4}(2)-T_{s-i}^{4}\right]}{\frac{1}{\varepsilon_{1}}+\frac{1-\varepsilon_{s}}{\varepsilon_{s}}\left(\frac{S_{u p}(2)}{S_{s}}\right)}\right)\left(\frac{1}{A_{1-\text { top }}(2) H(2)^{3 C_{19}-1}}\right)\right]^{\frac{1}{C_{19}+1}}+T_{1-\text { top }}(2) \\
& T_{1-\text { bot }}(2)=\left[\frac{\overline{q_{p-\text { up }}^{\prime \prime}(1)}}{A_{1-\text { bot }}(2) H(2)^{3 C_{19}-1}}\right]^{\frac{1}{C_{19}+1}}+T_{1-\text { bulk }}(2)
\end{aligned}
$$

Then, re-evaluate above equations using

$$
\begin{aligned}
& T_{f 1-\text { top }}(2)=\frac{1}{2}\left[T_{1-\text { top }}(2)+T_{1-\text { bulk }}(2)\right] \\
& T_{f 1-\text { bot }}(2)=\frac{1}{2}\left[T_{1-\text { bot }}(2)+T_{1-\text { bulk }}(2)\right]
\end{aligned}
$$




$$
\begin{aligned}
& T_{f 1-\text { side }}(2)=\frac{1}{2}\left[T_{1, m}(2)+T_{1-\text { bulk }}(2)\right] \\
& T_{s}=\frac{1}{2}\left[T_{s-i}+T_{s-o}\right]
\end{aligned}
$$

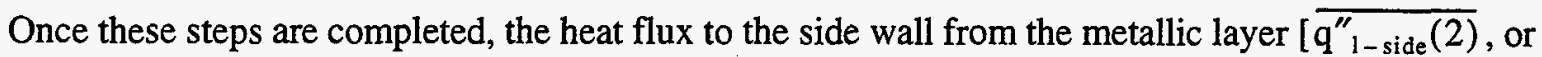
$\mathrm{q}^{\prime \prime}{ }_{\text {ves }}(\theta)$, for $\left.\theta_{\text {tot }}(1)<\theta \leq \theta_{\text {tot }}(2)\right]$ and sidewall vessel thickness are estimated using

$$
\begin{aligned}
& \overline{\mathrm{q}_{1-\text { side }}^{\prime \prime}(2)}=A_{1-\text { side }}(2)\left[\mathrm{T}_{1-\text { bulk }}(2)-\mathrm{T}_{1, \mathrm{~m}}(2)\right]^{\mathrm{C}_{22}+1} \\
& \left.\delta_{1 \text {-ves }}(2)=\frac{\mathrm{k}_{\text {ves }-\mathrm{h}}}{\overline{\mathrm{q}^{\prime \prime}}\left[\mathrm{T}_{1-\mathrm{side}}(2)\right.}(2)-\mathrm{T}_{\mathrm{w}}\right]
\end{aligned}
$$

The existence and thickness of a crust between the ceramic pool and the metallic layer is verified by solving the following quadratic equation:

$$
0=\frac{\dot{Q}(1)}{2 \mathrm{k}_{\mathrm{cr}}(1)} \delta_{1-\mathrm{cr}}^{2}(1)+\frac{\overline{\mathrm{q}_{\mathrm{p}-\mathrm{up}}^{\prime \prime}(1)}}{\mathrm{k}_{\mathrm{cr}}(1)} \delta_{1-\mathrm{cr}}(1)-\left[\mathrm{T}_{\mathrm{p}, \mathrm{m}}(1)-\mathrm{T}_{1-\mathrm{bot}}(2)\right]
$$

In the metal layer, the crust thickness, $\delta_{1-\mathrm{cr}}(1)$, should satisfy the following relationship in order to be considered thin

$0<\frac{\delta_{1-\mathrm{cr}}(1) \dot{\mathrm{Q}}(1)}{\overline{\mathrm{q}_{\mathrm{p}-\mathrm{up}}^{\prime \prime}(1)}} \leq 0.03$

The ratio of the crust volume to the pool volume should be calculated to verify that it is small using $\frac{\pi / 180}{\mathrm{~V}_{\mathrm{p}}}\left(\int_{0}^{\theta_{\mathrm{p}}} \delta_{\mathrm{cr}}(\theta, 1) 2 \pi \mathrm{R} \sin \theta \mathrm{d} \theta\right)+\frac{1}{\mathrm{~V}_{\mathrm{p}}} \pi \mathrm{R}_{\mathrm{top}}(1)^{2} \delta_{1-\mathrm{cr}}(1) \leq 0.05$

\section{A.1.5.3 Equations for the Metallic Layer- Configuration B}

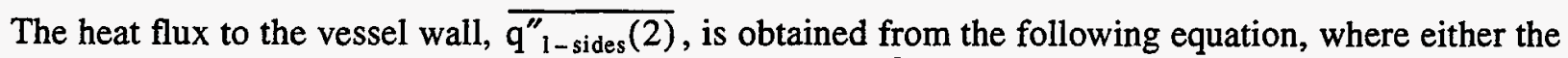
vessel wall temperature, $T_{1-v e s}(2)$ or vessel wall thickness, $\delta_{1-\text { ves }}(2)$ is unknown.

First, assume $\delta_{1-\text { ves }}(2)=0.15 \mathrm{~m}$ and solve for $\mathrm{T}_{1 \text {-ves }}(2)$ using

$$
\dot{\mathrm{Q}}(2) \mathrm{V}(2)+\overline{\mathrm{q}_{\mathrm{p}-\mathrm{up}}^{\prime \prime}(1)} \mathrm{S}_{\mathrm{up}}(1)+\left.\overline{\mathrm{q}_{\mathrm{p}-\mathrm{dn}}^{\prime \prime}(3)}\right|_{3 \mathrm{to} 2} \mathrm{~S}_{\mathrm{dn}}(3)=\frac{\mathrm{S}_{\text {side }}(2) \mathrm{k}_{\text {ves }-\mathrm{h}}}{\delta_{1-\text { ves }}(2)}\left(\mathrm{T}_{1-\mathrm{ves}}(2)-\mathrm{T}_{\mathrm{w}}\right)
$$

If $T_{1-v e s}(2)>T_{1, m}(2)$, assume $T_{1-v e s}(2)=T_{1, m}(2)$ and solve Equation (A-132) for $\delta_{1-\text { ves }}(2)$.

The heat flux to the side wall from the metallic layer $\left[\overline{q_{1-\text { sides }}^{\prime \prime}(2)}\right.$, or $q^{\prime \prime}$ ves $(\theta)$, for $\left.\theta_{\text {tot }}(1)<\theta \leq \theta_{\text {tot }}(2)\right]$ is then estimated using

$\overline{q_{1-\text { sides }}^{\prime \prime}(2)}=\frac{k_{\text {ves }-h}}{\delta_{1-\text { ves }}(2)}\left(T_{1-\text { ves }}(2)-T_{w}\right)$

Estimate a minimum $\mathrm{h}_{1-\mathrm{dn}}(2)$

$$
h_{1-d_{m i n}}(2) \geq \operatorname{Min}\left[\frac{\overline{q_{1-\text { sides }}^{\prime \prime}(2)}}{T_{p, m}(1)-T_{1-v e s}(2)}, \frac{\overline{q_{1-\text { sides }}^{\prime \prime}(2)}}{T_{p, m}(3)-T_{1-v e s}(2)}\right]
$$


Because $h_{1-d n}(2)$ isn't known, compare possible values:

$$
\begin{aligned}
& T_{1-\text { bulk }}(2)=0.25\left[T_{p, m}(1)+T_{p, m}(3)+2 T_{1-\text { ves }}(2)\right] \\
& \mu_{1}(2)=1.1081 \times 10^{-4} \exp \left(\frac{5776}{T_{1-\text { bulk }}(2)}\right)+C_{\mu-1} \\
& v_{1}(2)=\mu_{1}(2) / \rho_{1}(2) \\
& \operatorname{Ra}_{1}^{\prime}(2)=\frac{g \beta_{1}(2) Q(2) H(2)^{5}}{v_{1}(2) \alpha_{1}(2) k_{1}(2)} \\
& h_{1-\text { dn } / A C O P O}(2)=0.1857\left(\frac{k_{1}(2)}{H(2)}\right) R_{1}^{\prime}(2)^{0.2304}\left(\frac{H(2)}{R}\right)^{0.25} \quad \text { (ACOPO) } \\
& \operatorname{Ra}_{1}(2)=\frac{g \beta_{1}(2)\left[0.5\left(T_{p, m}(1)+T_{p, m}(3)\right)-T_{1-\text { ves }}(2)\right] H(2)^{3}}{v_{1}(2) \alpha_{1}(2)} \\
& h_{1-\text { dn } / \mathrm{GD}}(2)=0.1\left(\frac{k_{1}(2)}{H(2)}\right) R_{1}(2)^{0.31} \quad \text { (Globe-Dropkin) }
\end{aligned}
$$

Then, verify that the crust above and below the metallic layer is thin by applying the following equations:

$$
\begin{aligned}
& 0=\left(\frac{\dot{Q}(1)}{2}\right) \delta_{1-\mathrm{cr}}(1)^{2}+\left.\overline{\mathrm{q}_{\mathrm{p}-\mathrm{up}}^{\prime \prime}(1)}\right|_{1 \text { to } 2} \delta_{1-\mathrm{cr}}(1)-\mathrm{k}_{\mathrm{cr}}(1)\left[\mathrm{T}_{\mathrm{p}, \mathrm{m}}(1)-\mathrm{T}_{1-\mathrm{bulk}}(2)\right] \\
& 0<\frac{\delta_{1-\mathrm{cr}}(1) \dot{Q}(1)}{\overline{\mathrm{q}_{\mathrm{p}-\mathrm{up}}^{\prime \prime}(1)}} \leq 0.03 \\
& 0=\left(\frac{\dot{Q}(3)}{2}\right) \delta_{1-c r}(3)^{2}+\left.\overline{q_{p-d n}^{\prime \prime}(3)}\right|_{3 \text { to } 2} \delta_{1-c r}(3)-k_{c r}(3)\left(T_{p, m}(3)-T_{1-b u l k}(2)\right) \\
& 0<\left.\frac{\delta_{1-\mathrm{cr}}(3) \dot{Q}(3)}{\mathrm{q}_{\mathrm{p}-\mathrm{dn}}^{\prime \prime}(3)}\right|_{3 \text { to } 2} \leq 0.03
\end{aligned}
$$

Finally, calculate the ratio of the crust volume to the pool volume to verify that it is small using

$$
\begin{aligned}
& \frac{\pi / 180}{\mathrm{~V}(1)}\left(\int_{0}^{\theta_{\mathrm{tor}}(1)} \delta_{\mathrm{cr}}(\theta, 1) 2 \pi \mathrm{R} \cos \theta \mathrm{d} \theta\right)+\frac{1}{\mathrm{~V}(1)} \pi \mathrm{R}_{\mathrm{top}}(1)^{2} \delta_{1-\mathrm{cr}}(1) \leq 0.05 \\
& \frac{\pi / 180}{\mathrm{~V}(3)}\left(\int_{0}^{\theta_{\mathrm{tor}}(3)} \delta_{\mathrm{cr}}(\theta, 3) 2 \pi \mathrm{R} \cos \theta \mathrm{d} \theta\right)+\frac{1}{\mathrm{~V}(3)} \pi \mathrm{R}_{\mathrm{top}}(2)^{2} \delta_{1-\mathrm{cr}}(3) \leq 0.05
\end{aligned}
$$

\section{A.1.5.4 Equations for the Metallic Layer- Configuration C}

The heat flux to the vessel wall, $\overline{q_{1-d n}^{\prime \prime}(1)}$, is obtained from the following equation, where either the vessel wall temperature, $T_{1-v e s}(1)$ or vessel wall thickness, $\delta_{1-\text { ves }}(1)$ is unknown.

First, assume $\delta_{1-\text { ves }}(1)=0.15 \mathrm{~m}$ and solve for $T_{1-\text { ves }}(1)$ using

$$
\dot{Q}(1) V(1)+\left.\overline{q_{p-d n}^{\prime \prime}(2)}\right|_{2 \text { to } 1} S_{d n}(2)=\frac{S_{d n}(1) k_{v e s-h}}{\delta_{1-v e s}(1)}\left(T_{1-v e s}(1)-T_{w}\right)
$$


If $T_{1-\mathrm{ves}}(1)>T_{1, \mathrm{~m}}(1)$, assume $T_{1-\mathrm{ves}}(1)=T_{1, m}(1)$ and solve Equation $(A-148)$ for $\delta_{1-\mathrm{ves}}(1)$.

The heat flux to the side wall from the metallic layer $\left[{\overline{q^{\prime \prime}}}_{1-\text { side }}(1)\right.$, or $q^{\prime \prime}{ }_{\text {ves }}(\theta)$, for $\left.\theta \leq \theta_{\text {tot }}(1)\right]$ is then estimated using

$\overline{\mathrm{q}_{1-\mathrm{dn}}^{\prime \prime}(1)}=\frac{\mathrm{k}_{\mathrm{ves}-\mathrm{h}}}{\delta_{1-\mathrm{ves}}(1)}\left(\mathrm{T}_{1-\mathrm{ves}}(1)-\mathrm{T}_{\mathrm{w}}\right)$.

Estimate a minimum $\mathrm{h}_{1-\mathrm{dn}}(1)$

$\mathrm{h}_{\mathrm{l}-\mathrm{dn} \mathrm{n}_{\min }}(1) \geq \frac{\overline{\mathrm{q}^{\prime \prime}{ }_{1-\mathrm{dn}}(1)}}{\mathrm{T}_{\mathrm{p}, \mathrm{m}}(2)-\mathrm{T}_{1-\mathrm{ves}}(1)}$

Because $h_{1-d n}(1)$ isn't know, estimate possible values:

$$
\begin{aligned}
& \mathrm{T}_{1-\text { bulk }}(1)=0.5\left(\mathrm{~T}_{\mathrm{p}, \mathrm{m}}(2)+\mathrm{T}_{1-\mathrm{ves}}(1)\right) \\
& \mu_{1}(1)=1.1081 \times 10^{-4} \exp \left(\frac{5776}{\mathrm{~T}_{1-\text { bulk }}(1)}\right)+\mathrm{C}_{\mu-1} \\
& v_{l}(1)=\mu_{1}(1) /\left(\rho_{1}(1)\right) \\
& R a_{1}^{\prime}(1)=\frac{g \beta_{1}(1) Q(1) H(1)^{5}}{v_{1}(1) \alpha_{1}(1) k_{1}(1)} \\
& \mathrm{h}_{1-\mathrm{dn} / \mathrm{ACOPO}}(1)=0.1857\left(\frac{\mathrm{k}_{1}(1)}{\mathrm{H}(1)}\right) \mathrm{Ra}_{1}^{\prime}(1)^{0.2304}\left(\frac{\mathrm{H}(1)}{\mathrm{R}}\right)^{0.25} \quad \text { (ACOPO) } \\
& \mathrm{Ra}_{1}(1)=\frac{\mathrm{g} \beta_{1}(1)\left[\mathrm{T}_{\mathrm{p}, \mathrm{m}}(2)-\mathrm{T}_{1-\mathrm{ves}}(1)\right] \mathrm{H}(1)^{3}}{v_{1}(1) \alpha_{1}(1)} \\
& h_{1-d n / G D}(1)=0.1\left(\frac{k_{1}(1)}{H(1)}\right) R a_{1}(1)^{0.31} \quad \text { (Globe-Dropkin) }
\end{aligned}
$$

Then, verify that the crust above the metallic layer is thin by applying the following equations:

$$
\begin{aligned}
& 0=\left(\frac{\dot{Q}(2)}{2}\right) \delta_{1-\mathrm{cr}}(2)^{2}+\left.\overline{\mathrm{q}_{\mathrm{p}-\mathrm{dn}}^{\prime \prime}(2)}\right|_{2 \text { to } 1} \delta_{1-\mathrm{cr}}(2)-\mathrm{k}_{\mathrm{cr}}(2)\left(\mathrm{T}_{\mathrm{p}, \mathrm{m}}(2)-\mathrm{T}_{1-\text { bulk }}(1)\right) \\
& 0<\frac{\delta_{1-\mathrm{cr}}(2) \dot{Q}(2)}{\left.\mathrm{q}_{\mathrm{p}-\mathrm{dn}}^{\prime \prime}(2)\right|_{2 \text { to } 1}} \leq 0.03
\end{aligned}
$$

Finally, calculate the ratio of the crust volume to the pool volume to verify that it is small using

$$
\frac{\pi / 180}{\mathrm{~V}(2)}\left(\int_{0}^{\theta_{\mathrm{tor}}(2)} \delta_{\mathrm{cr}}(\theta, 2) 2 \pi \mathrm{R} \sin \theta \mathrm{d} \theta\right)+\frac{1}{\mathrm{~V}(2)} \pi \mathrm{R}_{\mathrm{top}}(1)^{2} \delta_{1-\mathrm{cr}}(2) \leq 0.05
$$




\section{A.2 Nomenclature}
$\mathrm{c}_{\mathrm{p}}(\mathrm{n}) \quad=$
Specific heat capacity of melt in layer $\mathbf{n}$ [may be further designated by the subscript (l) for metallic layer, (p) for ceramic layer, (ss) for stainless steel, (U) for uranium, $\left(\mathrm{UO}_{2}\right)$ for uranium dioxide, $(\mathrm{Zr})$ for zirconium, or $\left(\mathrm{ZrO}_{2}\right)$ for zirconium dioxide] $(\mathrm{J} / \mathrm{kg}-\mathrm{K})$ the subscript (ss) for stainless steel, $(\mathrm{U})$ for unoxidized uranium, $\left(\mathrm{UO}_{2}\right)$ for oxidized uranium, $(\mathrm{Zr})$ for unoxidized zirconium, and $\left(\mathrm{ZrO}_{2}\right)$ for oxidized zirconium]
$\mathrm{f}(\mathrm{n}) \quad=\quad$ Mass fraction of total relocated species in layer, $\mathrm{n}$ [may be further designated by
$f\left(t_{\text {sel }}\right)=$ Fractional contribution to decay power [contribution may be further designated by the subscript (ACT) for actinide, (Group 4) for Group 4, (Group 6) for Group 6 , or $(\mathrm{Zr} \& \mathrm{Nb})$ for zirconium and niobium]
$\mathrm{f}_{\text {metal }}=\quad$ Fraction of fission product decay power residing in the metallic layer
$\mathrm{f}_{\mathrm{m}}(\mathrm{n}) \quad=\quad$ Mass fraction in layer $\mathrm{n}$ [may be further designated by the subscript (ss) for stainless steel, $(\mathrm{U})$ for uranium, $\left(\mathrm{UO}_{2}\right)$ for uranium dioxide, $(\mathrm{Zr})$ for zirconium, or $\left(\mathrm{ZrO}_{2}\right)$ for zirconium dioxide]
$f_{N}(n)=\quad$ Mole fraction in layer $n$ [may be further designated by the subscript (ss) for stainless steel, $(\mathrm{U})$ for uranium, $\left(\mathrm{UO}_{2}\right)$ for uranium dioxide, $(\mathrm{Zr})$ for zirconium, or $\left(\mathrm{ZrO}_{2}\right)$ for zirconium dioxide]
$\mathrm{f}_{\mathrm{ox}} \quad=\quad$ Fraction of species oxidized [may be further designated by the subscript $(\mathrm{U})$ for uranium, or ( $\mathrm{Zr}$ ) for zirconium]

$\mathrm{f}_{\mathrm{v}}(\mathrm{n})=\quad$ Volume fraction in layer $\mathrm{n}$ [may be further designated by the subscript (ss) for stainless steel, $(\mathrm{U})$ for uranium, $\left(\mathrm{UO}_{2}\right)$ for uranium dioxide, $(\mathrm{Zr})$ for zirconium, or $\left(\mathrm{ZrO}_{2}\right)$ for zirconium dioxide]

g $=\quad$ Gravitational acceleration $\left(9.8 \mathrm{~m} / \mathrm{s}^{2}\right)$

$h_{1-d n}(n)=\quad$ Heat transfer coefficient from the bottom of metallic layer $n$ [may be further designated by the subscript (min) for minimum value, (ACOPO) for value predicted by correlation based on ACOPO data, or (GD) for correlation based on Globe-Dropkin data] $\left(\mathrm{W} / \mathrm{m}^{2} \mathrm{~K}\right)$
$\mathbf{k}(\mathrm{n})=$ Thermal conductivity in layer $\mathrm{n}$ [may be further designated by the subscript (cr) for ceramic crust, $\left(\mathrm{cr}-\mathrm{UO}_{2}\right)$ for ceramic crust uranium dioxide, $\left(\mathrm{cr}-\mathrm{ZrO}_{2}\right)$ for ceramic crust zirconium dioxide, (1) for metallic layer, (p) for ceramic melt, ( $p$ - $\mathrm{UO}_{2}$ ) for ceramic melt uranium dioxide, $\left(\mathrm{p}-\mathrm{ZrO}_{2}\right)$ for ceramic melt zirconium dioxide, (1-ss) for metallic layer stainless steel, (1-Zr) for metallic layer zirconium, or (1-U) for metallic layer uranium] (W/mK)




$$
\begin{aligned}
& \mathrm{k}_{\mathrm{s}}\left(\overline{\mathrm{T}}_{\mathrm{s}}\right)=\quad \text { Upper plenum structure thermal conductivity }(\mathrm{W} / \mathrm{mK}) \\
& \mathbf{k}_{\mathrm{ves}} \quad=\quad \text { Vessel wall effective thermal conductivity [may be further designated by the }
\end{aligned}
$$

$q^{\prime \prime}(\theta)=\quad$ Angular -dependent heat flux [may be further designated by the subscript (CHF) for vessel surface critical heat flux or (ves) for heat flux to the vessel] $\left(\mathrm{W} / \mathrm{m}^{2}\right)$

$\mathrm{q}_{\mathrm{p}-\mathrm{dn}}^{\prime \prime}(\theta, \mathrm{n})=\quad$ Angular-dependent downward heat flux from melt in ceramic layer $\mathrm{n}\left(\mathrm{W} / \mathrm{m}^{2}\right)$

$\overline{\mathrm{q}^{\prime \prime}(\mathrm{n})} \quad=\quad$ Average heat flux in layer $\mathrm{n}$ [may be further designated by the subscript (1-dn) for downward heat flux from metallic layer, (1-side) for sidewall heat flux from metallic layer, $(\mathrm{p}-\mathrm{dn}$ ) for downward heat flux from ceramic layer or ( $\mathrm{p}$-up) for upward heat flux from ceramic layer] $\left(\mathrm{W} / \mathrm{m}^{2}\right)$

$\mathrm{t}_{\mathrm{Tel}} \quad=\quad$ Debris relocation time $(\mathrm{s})$

$\mathrm{A}_{1}(\mathrm{n})=$ Coefficient for estimating heat transfer from the surface of metallic layer [may be further designated by the subscript (bot) for lower surface, (side) for side surfaces, or (top) for upper surface] $\left(\mathrm{W} / \mathrm{m}^{2} \mathrm{~K}^{4}\right)$

$\mathrm{B}\left(\mathrm{t}_{\mathrm{rel}}\right)=$ Constant for estimating fractional contribution to fission product decay power [may be further designated by the subscript (Group 4) for Group 4 contribution, (Group 6) for Group 6 contribution, or ( $\mathrm{Zr} \& \mathrm{Nb}$ ) for zirconium and niobium contribution]

$\mathrm{C}_{\mathrm{n}}=$ Constants [may be further designated by the subscript (1-5) for estimating critical heat flux, (6-9) for estimating ceramic layer heat transfer, (10-16) for estimating local heat transfer from the ceramic layer, or (17-22) for estimating heat transfer from the metallic layer]

C = Uncertainty parameter [may be further designated by the subscript (bot) for estimating metallic layer lower surface heat transfer, $\left(c_{p}-p\right)$ for estimating ceramic layer specific heat, $\left(c_{\mathrm{p}}-1\right)$, for estimating metallic layer specific heat, (dec) for estimating decay heat, (k-cr) for estimating ceramic crust thermal conductivity, (k-l) for estimating metallic layer thermal conductivity, $(k-p)$ for estimating ceramic layer thermal conductivity, $(k-s)$ for estimating upper plenum structure thermal conductivity, (local) for estimating angular-dependent downward heat fluxes, (side) for estimating metallic layer side surface heat transfer, (top) for estimating metallic layer upper surface heat transfer, (CHF) for estimating critical heat flux, $(\beta-1)$ for estimating metallic layer coefficient of thermal expansion, ( $\rho-1)$ for estimating metallic layer density, or $(\rho-p)$ for estimating ceramic layer density] 


\begin{tabular}{|c|c|c|}
\hline $\mathrm{C}_{\mu}$ & $=$ & $\begin{array}{l}\text { Uncertainty parameter for estimating viscosity [may be further designated by } \\
\text { the subscript (l) for the metallic layer or (p) for the ceramic layer] (Pa-s) }\end{array}$ \\
\hline$H(n)$ & $=$ & $\begin{array}{l}\text { Height of layer } n \text { [may be further designated by the subscript ( } 3 a \text { ) for height of } \\
\text { layer } 3 \text { below the hemisphere, ( } 3 b \text { ) for height of layer } 3 \text { above the hemisphere, } \\
\text { (tot) for cumulative height of relocated debris up through layer } n \text { ] (m) }\end{array}$ \\
\hline$M(n)$ & $=$ & $\begin{array}{l}\text { Mass of relocated debris in layer } n \text { [may be further designated by the subscript } \\
\left(\mathrm{O}_{2}\right) \text { for oxide, }\left(\mathrm{UO}_{2}\right) \text { for uranium dioxide, }(\mathrm{U}) \text { for uranium, }(\mathrm{Zr}) \text { for zirconium, } \\
\left(\mathrm{ZrO}_{2}\right) \text { for zirconium dioxide] }(\mathrm{kg})\end{array}$ \\
\hline$M\left(t_{\text {rel }}\right)$ & $=$ & $\begin{array}{l}\text { Coefficient for estimating fractional contribution to fission product decay power } \\
\text { [may be further designated by the subscript (Group } 4 \text { ) for Group } 4 \text { contribution, } \\
\text { (Group 6) for Group } 6 \text { contribution, or }(\mathrm{Zr} \& \mathrm{Nb}) \text { for zirconium and niobium } \\
\text { contribution] }\left(\mathrm{s}^{-1}\right)\end{array}$ \\
\hline $\mathbf{M}$ & $=$ & $\begin{array}{l}\text { Mass [may be further designated by the subscript }(1) \text { for metallic layer, }(1-\mathrm{Zr}) \text { for } \\
\text { metallic layer zirconium, (p) for ceramic layer, }(\mathrm{p}-\mathrm{Zr}) \text { for ceramic layer zirco- } \\
\text { nium, (ss) for metallic layer stainless steel, (ss-tot) for total relocated stainless } \\
\text { steel, (tot) for total relocated debris, (U) for uranium, }\left(\mathrm{UO}_{2} \text {-tot) for total relo- }\right. \\
\text { cated } \mathrm{UO}_{2} \text {, or ( } \mathrm{Zr} \text {-tot) for total relocated zirconium] }(\mathrm{kg})\end{array}$ \\
\hline$N(n)$ & $=$ & $\begin{array}{l}\text { Number of moles in layer } \mathrm{n} \text { [may be further designated by the subscript (ss) for } \\
\text { stainless steel, }(\mathrm{U}) \text { for uranium, }\left(\mathrm{UO}_{2}\right) \text { for } \mathrm{UO}_{2} \text {, or }(\mathrm{Zr}) \text { for zirconium] }\end{array}$ \\
\hline $\mathrm{Nu}_{1}$ & $=$ & $\begin{array}{l}\text { Metallic layer Nusselt number [may be further designated by the subscript } \\
\text { (horz) for horizontal, (vert) for vertical, or (up) for upward] }\end{array}$ \\
\hline$\overline{\mathrm{Nu}}_{\mathrm{p}}(\mathrm{n})$ & $=$ & $\begin{array}{l}\text { Average Nusselt number for molten material in ceramic layer } n \text { [may be further } \\
\text { designated by the subscript (up) for the upward direction or (dn) for the } \\
\text { downward direction] }\end{array}$ \\
\hline \multicolumn{2}{|c|}{$N u_{p-d n}(\theta, n)=$} & $\begin{array}{l}\text { Nusselt number in the downward direction at the angle, } \theta \text {, for molten material } \\
\text { in ceramic layer } n\end{array}$ \\
\hline$P_{\text {decay }}\left(t_{r e}\right.$ & & $\begin{array}{l}\text { Decay power [may be further designated by the subscript (tot) for total decay } \\
\text { power, (UCSB) for decay power shown in DOE/ID-10460 Figure 7.1, (FP) for } \\
\text { decay power associated with fission products, or (ACT) for decay power } \\
\text { associated with actinides] (W) }\end{array}$ \\
\hline $\mathrm{Pr}_{1}$ & $=$ & Metallic layer Prandtl number \\
\hline$\dot{Q}(n)$ & $=$ & Heat generation rate in layer $n\left(W / \mathrm{m}^{3}\right)$ \\
\hline $\mathbf{R}$ & $=$ & Vessel radius (m) \\
\hline$R_{\text {top }}(n)$ & $=$ & Upper radius for layer $n(m)$ \\
\hline
\end{tabular}




\begin{tabular}{|c|c|c|}
\hline $\mathrm{R}(\mathrm{n})^{\prime}$ & $=$ & Ratio of upward to downward heat fluxes in ceramic layer $n$ \\
\hline $\mathrm{Ra}_{1}(\mathrm{n})$ & $=$ & Rayleigh number based on temperature difference of melt in metallic layer $n$ \\
\hline $\operatorname{Ra}(n)^{\prime}$ & $=$ & $\begin{array}{l}\text { Rayleigh number based on volumetric heating of melt in layer } n \text { [may be further } \\
\text { designated by the subscript (l) for metallic layer or }(p) \text { for ceramic layer] }\end{array}$ \\
\hline$S(n)$ & $=$ & $\begin{array}{l}\text { Area of volume } n \text { [may be further designated by the subscript (dn) for lower } \\
\text { surface, (side) for side surfaces, or (up) for upper surface] }\left(\mathrm{m}^{2}\right)\end{array}$ \\
\hline$S_{s}$ & $=$ & Upper plenum structures' surface area $\left(\mathrm{m}^{2}\right)$ \\
\hline$T_{f 1}(n)$ & $=$ & $\begin{array}{l}\text { Film temperature at surface of metallic layer } n \text { [may be further designated by } \\
\text { the subscript (bot) for lower surface, (side) for side surfaces, or (top) for upper } \\
\text { surface] (K) }\end{array}$ \\
\hline$\overline{T_{p}(n)}$ & $=$ & Average temperature of molten material in ceramic layer $n(K)$ \\
\hline $\mathrm{T}_{1}(\mathrm{n})$ & $=$ & $\begin{array}{l}\text { Temperature of metallic layer n [may be further designated by the subscript } \\
\text { (bot) for lower surface, (bulk) for bulk, (m) for liquidus, or (top) for upper } \\
\text { surface] (K) }\end{array}$ \\
\hline $\mathrm{T}_{1-\mathrm{ves}}(\mathrm{n})$ & $=$ & $\begin{array}{l}\text { Vessel steel inner surface temperature at locations adjacent to metallic } \\
\text { layer } n(K)\end{array}$ \\
\hline $\mathrm{T}_{\mathrm{p}}(\mathrm{n})$ & $=$ & $\begin{array}{l}\text { Liquidus temperature of molten material in ceramic layer } n \text { [may be further } \\
\text { designated by the subscript }(m) \text { for liquidus or }(\max ) \text { for maximum] }(K)\end{array}$ \\
\hline $\mathrm{T}_{\mathrm{p}-\mathrm{del}}(\mathrm{n})$ & $=$ & Difference between maximum and minimum temperature in ceramic layer $n(K)$ \\
\hline$\overline{\mathrm{T}_{\mathrm{s}}}$ & $=$ & Upper plenum structures average temperature $(\mathrm{K})$ \\
\hline$T_{s}$ & $=$ & $\begin{array}{l}\text { Upper plenum structures' temperature [may be further designated by the } \\
\text { subscript (i) for inner surface or (o) for outer surface] }(K)\end{array}$ \\
\hline $\mathrm{T}_{\text {ves }}(\theta)$ & $=$ & $\begin{array}{l}\text { Angular-dependent vessel temperature on inner vessel surface at locations } \\
\text { adjacent to ceramic layers }(\mathrm{K})\end{array}$ \\
\hline $\mathrm{T}_{\mathrm{ves}}$ & $=$ & $\begin{array}{l}\text { Average vessel temperature on vessel inner surface at locations above the } \\
\text { metallic layer }(\mathrm{K})\end{array}$ \\
\hline $\mathrm{T}_{\mathrm{p}-\mathrm{ves}, \mathrm{m}}$ & $=$ & Vessel steel liquidus temperature at locations adjacent to the ceramic layers (K) \\
\hline $\mathrm{T}_{\mathrm{w}}$ & $=$ & Vessel temperature on outer surface $(\mathrm{K})$ \\
\hline
\end{tabular}




\begin{tabular}{|c|c|c|}
\hline$V(n)$ & $=$ & $\begin{array}{l}\text { Volume of layer } \mathrm{n} \text { [may be further designated by the subscript (ss) for stainless } \\
\text { steel, }(\mathrm{U}) \text { for uranium, }\left(\mathrm{UO}_{2}\right) \text { for uranium dioxide, }(\mathrm{Zr}) \text { for zirconium, or }\left(\mathrm{ZrO}_{2}\right) \\
\text { for zirconium dioxide] }\left(\mathrm{m}^{3}\right)\end{array}$ \\
\hline $\mathrm{V}_{\text {hem }}$ & $=$ & Volume of vessel hemisphere $\left(\mathrm{m}^{3}\right)$ \\
\hline $\mathrm{V}_{1}$ & $=$ & Total volume of metallic layers $\left(\mathrm{m}^{3}\right)$ \\
\hline $\mathrm{V}_{\mathrm{p}}$ & $=$ & Total volume of ceramic layers $\left(\mathrm{m}^{3}\right)$ \\
\hline $\mathrm{V}_{\text {tot }}(\mathrm{n})$ & $=$ & Cumulative volume of relocated debris up through layer $n\left(\mathrm{~m}^{3}\right)$ \\
\hline $\mathbf{Z}$ & $=$ & $\begin{array}{l}\text { Molecular weight [may be further designated by the subscript }\left(\mathrm{O}_{2}\right) \text { for oxygen } \\
(15.994 \mathrm{~kg} / \mathrm{kg} \text {-moles), (ss) for stainless steel }(55.066 \mathrm{~kg} / \mathrm{kg} \text {-moles), }(\mathrm{U}) \text { for } \\
\text { uranium }\left(238.029 \mathrm{~kg} / \mathrm{kg} \text {-moles), }\left(\mathrm{UO}_{2}\right) \text { for } \mathrm{UO}_{2}(270.02 \mathrm{~kg} / \mathrm{kg} \text {-moles), or }(\mathrm{Zr})\right. \\
\text { for zirconium }(91.22 \mathrm{~kg} / \mathrm{kg} \text {-moles)] }\end{array}$ \\
\hline$\alpha(n)$ & $=$ & $\begin{array}{l}\text { Thermal diffusivity in layer } n \text { [may be further designated by the subscript }(1) \text { for } \\
\text { metallic layer or }(p) \text { for ceramic layer] }\left(\mathrm{m}^{2} / \mathrm{s}\right)\end{array}$ \\
\hline$\beta(n)$ & $=$ & $\begin{array}{l}\text { Volumetric coefficient of thermal expansion in layer } n \text { [may be further } \\
\text { designated by the subscript }(1) \text { for metallic layer or }(p) \text { for ceramic layer] }\left(\mathrm{K}^{-1}\right)\end{array}$ \\
\hline$\beta$ & $=$ & $\begin{array}{l}\text { Volumetric coefficient of thermal expansion [may be further designated by the } \\
\text { subscript (ss) for stainless steel, (U) for uranium, or }(\mathrm{Zr}) \text { for zirconium] }\left(\mathrm{K}^{-1}\right)\end{array}$ \\
\hline$\delta_{c r}(\theta, n)$ & $=$ & $\begin{array}{l}\text { Angular-dependent thickness of crust along lower and side surfaces of ceramic } \\
\text { layer } n(\mathrm{~m})\end{array}$ \\
\hline$\delta_{1-c r}(n)$ & $=$ & Crust thickness on upper surface of ceramic layer $n(m)$ \\
\hline$\delta_{1-\text { ves }}(n)$ & $=$ & Thickness of vessel wall near metallic layer $n$ (m) \\
\hline$\delta_{0}$ & $=$ & Thickness of vessel wall to estimate heat transfer from metallic layer (m) \\
\hline$\delta_{\mathrm{p}-\mathrm{cr}}(\theta)$ & $=$ & Thickness of crust on lower surface of ceramic layer $(\mathrm{m})$ \\
\hline$\delta_{\mathrm{s}}$ & $=$ & Thickness of upper plenum structures (m) \\
\hline$\delta_{\text {ves }}(\theta)$ & $=$ & Thickness of vessel wall adjacent to ceramic layers (m) \\
\hline$\varepsilon$ & $=$ & $\begin{array}{l}\text { Emissivity [may be further designated by the subscript (l) for metallic layer or } \\
\text { (s) for upper plenum structure] }\end{array}$ \\
\hline$\theta$ & $=$ & Angle from the bottom center of the vessel lower head (degrees) \\
\hline$\theta(n)$ & $=$ & Angle from the bottom center of each layer $\mathbf{n}$ (degrees) \\
\hline
\end{tabular}




\begin{tabular}{|c|c|c|}
\hline$\theta_{\text {tot }}(n)$ & $=$ & $\begin{array}{l}\text { Maximum angle from upper surface of volume, } V_{\text {tot }}(n) \text {, with upper radius, } \\
R_{\text {top }}(n) \text {, and height, } H_{\text {tot }}(n) \text { (degrees) }\end{array}$ \\
\hline$\mu(n)$ & $=$ & $\begin{array}{l}\text { Viscosity of molten material in layer } \mathrm{n} \text { [may be further designated by the } \\
\text { subscript (fl-side, fl-top, or fl-bot) for metallic layer film temperature at the side, } \\
\text { upper, or lower surfaces, (l) for metallic layer at the bulk temperature, (p) for } \\
\text { ceramic layer at the bulk temperature] ( } \mathrm{Pa}-\mathrm{s} \text { ) }\end{array}$ \\
\hline$\rho(n)$ & $=$ & $\begin{array}{l}\text { Density of layer } n \text { [may be further designated (l) for metallic layer or ( } p \text { ) for } \\
\text { ceramic layer] }\left(\mathrm{kg} / \mathrm{m}^{3}\right)\end{array}$ \\
\hline$\rho$ & $=$ & $\begin{array}{l}\text { Density [may be further designated by the subscript }(1-\mathrm{ss}) \text { for molten stainless } \\
\text { steel in metallic layer, }(1-\mathrm{Zr}) \text { for molten zirconium in metallic layer, }(1-\mathrm{U}) \text { for } \\
\text { molten uranium in metallic layer, }\left(\mathrm{p}-\mathrm{ZrO}_{2}\right) \text { for molten zirconium dioxide in } \\
\text { ceramic layer, or }\left(\mathrm{p}-\mathrm{UO}_{2}\right) \text { for molten uranium dioxide in ceramic layer] }\left(\mathrm{kg} / \mathrm{m}^{3}\right)\end{array}$ \\
\hline$\sigma$ & $=$ & Stefan-Boltzmann constant $\left(5.672 \times 10^{-8} \mathrm{~W} / \mathrm{m}^{2} \mathrm{~K}^{4}\right)$ \\
\hline$\sigma_{\mathrm{Nu}_{\mathrm{p}}}$ & $=$ & $\begin{array}{l}\text { Standard deviation for estimating the average Nusselt number for molten } \\
\text { material in ceramic layer } n \text { [may be further designated by the subscript (dn) for } \\
\text { downward or (up) for upward] }\end{array}$ \\
\hline$v(\mathrm{n})$ & $=$ & $\begin{array}{l}\text { Kinematic viscosity of material in layer } \mathbf{n} \text { [may be further designated by the } \\
\text { subscript (fl-side, fl-top, or fl-bot) for metallic layer film temperature at the side, } \\
\text { upper, or lower surfaces, (l) for metallic layer or (p) for ceramic layer] }\left(\mathrm{m}^{2} / \mathrm{s}\right)\end{array}$ \\
\hline
\end{tabular}




\section{Appendix B - INEEL Input Uncertainty Distributions}

VESTA calculations use Bayesian uncertainty distributions, which are ultimately combined by a Monte Carlo sampling to yield a distribution on the probability of vessel heat fluxes exceeding CHF. As discussed in Section 2.3, INEEL determined that many of the input uncertainty distributions assumed in the UCSB study should be modified. Collectively, these modifications affect results for the UCSBassumed FIBS, Table B-1 compares INEEL and UCSB-assumed input, and Section 2.3 summarizes INEEL input uncertainty distributions for the UCSB-assumed FIBS. This appendix provides additional information used to derive INEEL input uncertainty distributions.

\section{B.1 Heat Transfer Assumptions}

\section{B.1.1 Average Convection Heat Transfer from a Molten Pool}

DOE/ID-10460 Approach. In DOE/ID-10460, correlations for predicting average heat transfer from a molten pool containing a fluid that is volumetrically heated with turbulent natural convection were based on data from the UCSB Mini-ACOPO tests. Further testing was subsequently carried out in the ACOPO facility, which is a larger scale version of Mini-ACOPO (Mini-ACOPO is a 1/8th scale facility; ACOPO is a $1 / 2$ scale facility). ${ }^{31}$ Correlations obtained from the Mini-ACOPO and ACOPO tests differ. Although $\mathrm{DOE} / \mathrm{ID}-10460$ Appendix $\mathrm{V}$ suggests that correlations based on ACOPO are more appropriate, it concludes that differences in these correlations don't impact their conclusions because the upward to downward heat loss ratio is preserved. No uncertainties are considered in the Mini-ACOPO correlations, although sensitivity studies were performed in the UCSB study to assess the impact of assuming a limited number of other correlations.

INEEL Approach. The Mini-ACOPO and ACOPO facilities use a unique approach to obtain natural convection heat transfer data for high Rayleigh number, volumetrically-heated molten pools. Rather than trying to produce uniform volumetric heating in a fluid, the Mini-ACOPO and ACOPO tests simulate volumetric heating by suddenly cooling the boundaries of a system containing preheated fluid and interpreting the transient system cooldown as a sequence of quasi-stationary natural convection states. Figures B-1 and B-2 compare correlations obtained from the Mini-ACOPO tests with various correlations from facilities containing volumetrically heated fluids (see Reference 25 for references describing the tests and facilities from which other correlations were obtained). Each correlation in Figures B-1 and B-2 is plotted over the Rayleigh number for which it was obtained. Although Mini-ACOPO correlations differ from correlations obtained from other natural convection tests, the authors of DOE/ID-10460 maintain that their correlations are the most appropriate because higher Rayleigh number fluids were tested in a hemispherical facility in the Mini-ACOPO tests. 
Table B-1. Comparison of INEEL and UCSB input assumptions.

\begin{tabular}{|c|c|c|}
\hline Phenomena & UCSB Input for FIBS & INEEL Input for UCSB-assumed FIBS Requantification \\
\hline \multicolumn{3}{|l|}{ Heat Transfer } \\
\hline $\begin{array}{l}\text { Molten Ceramic Pool Heat } \\
\text { Transfer }\end{array}$ & $\begin{array}{l}\text { Correlations based on Mini-ACOPO data; } \\
\text { no uncertainties. }\end{array}$ & $\begin{array}{l}\text { Correlations and uncertainties for average heat transfer based on } \\
\text { INEEL best-fit of ACOPO data. }\end{array}$ \\
\hline - Average Upward & - UCSB Equation 5.11 & - INEEL Equation (B-6) \\
\hline - Average Downward & - UCSB Equation 5.28 & - INEEL Equation (B-7) \\
\hline - Localized Downward & - UCSB Equations 5.30a and 5.30b & $\begin{array}{l}\text { - UCSB Equations 5.30a and 5.30b; uncertainties from ACOPO } \\
\text { data. }\end{array}$ \\
\hline $\begin{array}{l}\text { Critical Heat Flux from a } \\
\text { Vessel to a Flooded Cavity }\end{array}$ & $\begin{array}{l}\text { Correlations based on ULPU data (UCSB } \\
\text { Equation E.3); no uncertainties. }\end{array}$ & $\begin{array}{l}\text { Correlations and uncertainties based on Cheung SBLB data } \\
{[(\mathrm{H} / \mathrm{R}=3) \text { curve INEEL Figure } \mathrm{B}-7] \text {. }}\end{array}$ \\
\hline $\begin{array}{l}\text { Molten Metal Layer Heat } \\
\text { Transfer }\end{array}$ & $\begin{array}{l}\text { Correlations based on MELAD data (UCSB } \\
\text { Equations } 5.40 \text { and 5.41); no uncertainties. }\end{array}$ & $\begin{array}{l}\text { Correlations based on MELAD data (UCSB Equations } 5.40 \text { and } \\
5.41 \text { ); uncertainties from MELAD data. }\end{array}$ \\
\hline \multicolumn{3}{|l|}{ Decay Power Density } \\
\hline Ceramic Pool & $\begin{array}{l}\text { Statistical combination of decay power } \\
\text { curve (UCSB Figure 7.1), zirconium oxida- } \\
\text { tion fraction pdf (UCSB Figure 7.3), and } \\
\text { melt relocation time pdf (UCSB Figure 7.7). }\end{array}$ & $\begin{array}{l}\text { Statistical combination of UCSB decay power curve (UCSB } \\
\text { Figure 7.1) with ANS 5.1 Standard-recommended uncertainty dis- } \\
\text { tribution, UCSB zirconium oxidation fraction pdf (UCSB Figure } \\
\text { 7.3), and INEEL-recommended shift of } 1 \text { hour in the UCSB-pro- } \\
\text { posed melt relocation time curve (UCSB Figure 7.7). Resulting pdf } \\
\text { reduced by metallic layer decay heat fraction. }\end{array}$ \\
\hline Metallic Layer & No heat sources in the metallic layer. & $\begin{array}{l}\text { Time-dependent fission product decay power fractions and uncer- } \\
\text { tainties associated with zirconium, niobium, tellurium group, and } \\
\text { noble metals group. }\end{array}$ \\
\hline \multicolumn{3}{|l|}{ Material Properties } \\
\hline \multicolumn{3}{|l|}{ Ceramic Pool and Crust } \\
\hline -Specific Heat Capacity & $\begin{array}{l}\text { Mass average UCSB Table } 7.1 \text { values; no } \\
\text { uncertainties. }\end{array}$ & $\begin{array}{l}\text { Mass average UCSB Table } 7.1 \text { values; uncertainties associated with } \\
\text { each component's value and with mass averaging. }\end{array}$ \\
\hline -Thermal Conductivity & $\begin{array}{l}\text { UCSB Table } 7.1 \text { values; reduced } \\
\text { Appendix L uncertainties }\end{array}$ & $\begin{array}{l}\text { Composition-dependent values; uncertainties from UCSB } \\
\text { Appendix L. }\end{array}$ \\
\hline - Melting Temperature & $2973 \mathrm{~K}$; no uncertainties & $2850 \mathrm{~K}$; no uncertainties \\
\hline $\begin{array}{l}\text {-Volumetric Coefficient of } \\
\text { Expansion }\end{array}$ & $\begin{array}{l}\text { UCSB Table } 7.1 \text { value; reduced Appendix L } \\
\text { uncertainties }\end{array}$ & UCSB Table 7.1 value; uncertainties from UCSB Appendix $L$. \\
\hline -Density & $\begin{array}{l}\text { Volume average UCSB Table } 7.1 \text { values; no } \\
\text { uncertainties }\end{array}$ & $\begin{array}{l}\text { Volume average UCSB Table } 7.1 \text { values; uncertainties associated } \\
\text { with each component's value and with volume averaging. }\end{array}$ \\
\hline \multicolumn{3}{|l|}{ Metallic Layer } \\
\hline -Specific Heat Capacity & $\begin{array}{l}\text { Mass average UCSB Table } 7.1 \text { values; no } \\
\text { uncertainties }\end{array}$ & $\begin{array}{l}\text { Mass average UCSB Table } 7.1 \text { values; uncertainties associated with } \\
\text { each component's value and with mass averaging }\end{array}$ \\
\hline -Thermal Conductivity & $\begin{array}{l}\text { UCSB Table } 7.1 \text { values; reduced Appendix } \\
\text { L uncertainties }\end{array}$ & $\begin{array}{l}\text { Composition-dependent values; uncertainties from UCSB } \\
\text { Appendix L }\end{array}$ \\
\hline $\begin{array}{l}\text {-Volumetric Coefficient of } \\
\text { Expansion }\end{array}$ & $\begin{array}{l}\text { UCSB Table } 7.1 \text { value; reduced Appendix L } \\
\text { uncertainties }\end{array}$ & $\begin{array}{l}\text { Volume average UCSB Table } 7.1 \text { values; uncertainties associated } \\
\text { with each component's value and with volume averaging }\end{array}$ \\
\hline -Density & $\begin{array}{l}\text { Volume average UCSB Table } 7.1 \text { values; no } \\
\text { uncertainties }\end{array}$ & $\begin{array}{l}\text { Volume average UCSB Table } 7.1 \text { values; uncertainties associated } \\
\text { with each component's value and with volume averaging }\end{array}$ \\
\hline -Emissivity & 0.45 (UCSB tests); no uncertainties & $\begin{array}{l}\text { Median value of } 0.29 \text {; standard deviation of } 0.04 \text { (based on pub- } \\
\text { lished data) }\end{array}$ \\
\hline \multicolumn{3}{|l|}{ Vessel Wall } \\
\hline -Thermal Conductivity & $\begin{array}{l}\text { Point estimates based on UCSB Figure L.3 } \\
\text { Upper Wall: Not clear } \\
\text { Lower Wall: } 32 \mathrm{~W} / \mathrm{m}^{2} \mathrm{~K} \text {; no uncertainties }\end{array}$ & $\begin{array}{l}\text { Median values and uncertainties based on UCSB Figure L.3. } \\
\text { Upper wall: } 41 \pm 1 \mathrm{~W} / \mathrm{mK} \text {; } \\
\text { Lower Wall: } 32 \pm 2 \mathrm{~W} / \mathrm{mK}\end{array}$ \\
\hline -Melting Temperature & $1600 \mathrm{~K}$; no uncertainties & Zr-Fe phase diagram; no uncertainties \\
\hline \multicolumn{3}{|l|}{ Upper Internal Structures } \\
\hline -Thermal Conductivity & $30 \mathrm{~W} / \mathrm{mK}$; no uncertainties & $\begin{array}{l}\text { Temperature-dependent values; standard deviation of } 0.6 \mathrm{~W} / \mathrm{mK} \\
\text { (based on published data) }\end{array}$ \\
\hline -Emissivity & 0.8 ; no uncertainties & $\begin{array}{l}\text { Median value of } 0.85 \text {; standard deviation of } 0.03 \text { (based on pub- } \\
\text { lished data) }\end{array}$ \\
\hline
\end{tabular}




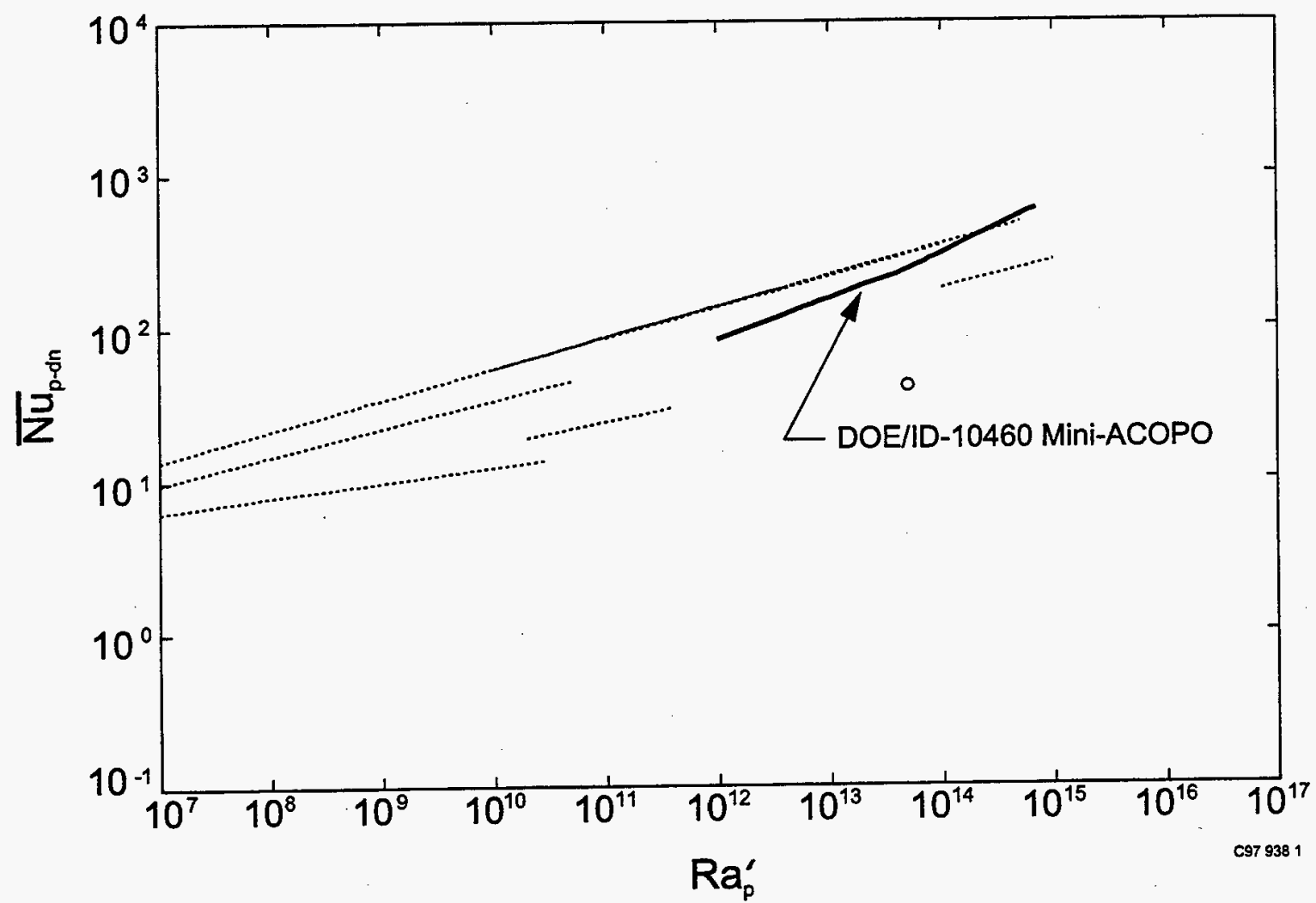

Figure B-1. Comparison of Reference 25 and Mini-ACOPO downward heat transfer correlations.

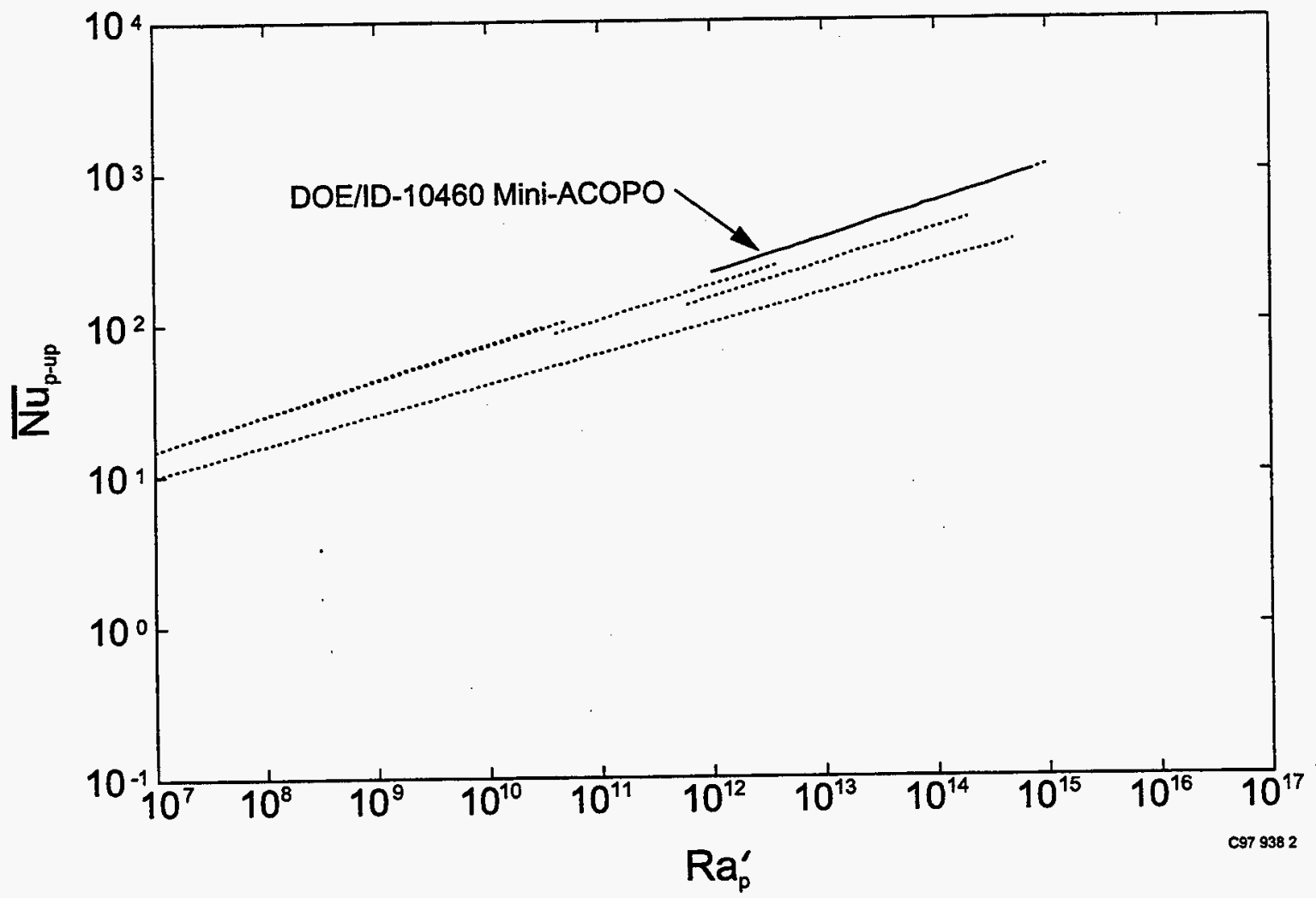

Figure B-2. Comparison of Reference 25 and Mini-ACOPO upward heat transfer correlations. 
In Reference 31, the authors present data from several ACOPO tests and correlations based 'on a "typical" ACOPO run (Run 5/28/96). INEEL digitized data from the four ACOPO tests presented in Reference 31 (Figures 13 and 15) and determined that ACOPO data were better fit with the following correlations: ${ }^{\mathrm{a}}$

$$
\begin{aligned}
& \overline{N u}_{p-d n}=0.1857 \mathrm{Ra}_{p}^{\prime 0.2304}\left(\frac{\mathrm{H}}{\mathrm{R}}\right)^{0.25} \\
& \overline{\mathrm{Nu}}_{\mathrm{p}-\mathrm{up}}=2.4415 \mathrm{Ra}_{\mathrm{p}}^{\prime} 0.1722
\end{aligned}
$$

Since the time that INEEL completed this analysis, a revised version of DOE/ID-10460 was published with ACOPO data added to Appendix V. The new Appendix V ACOPO run (Run 5/28/96) data and correlations differ from Reference 31 data and correlations. ${ }^{b}$ Recent information ${ }^{32}$ indicates that UCSB study authors believe that the data presented in Appendix V are more accurate. In Reference 12, UCSB study authors assert that mini-ACOPO data were confirmed by the ACOPO data. However, Figures B-3 and B-4 indicate that Mini-ACOPO correlations differs from ACOPO data and correlations presented by UCSB in DOE/ID-10460 Appendix V and Reference 31 (PSA '96) and from INEEL best fit ACOPO correlations for Rayleigh numbers of interest $\left(\sim 10^{15}-10^{16}\right)$. Nevertheless, UCSB-recommended ACOPO correlations presented in Appendix V and in Reference 31 predict similar Nusselt numbers for Rayleigh numbers of interest. Because the two UCSB correlations yield similar Nusselt numbers and because INEEL considered uncertainties in their correlations, INEEL did not modify the correlations based on Reference 31 [Equations (B-1) and (B-2)] data to consider revised Appendix V information.

INEEL-digitized ACOPO data from Reference 31 (Figures 13 and 15) were used to obtain appropriate uncertainty distributions for predicting upward and downward heat transfer. For these correlations, there are uncertainties associated with the method selected for simulating natural convection in the AP600 reactor vessel, the reproducibility of the tests, the variability associated with performing tests in different facilities, and experimental instrumentation error. Comparisons with results obtained from other experimentalists investigating natural convection phenomena suggest that there is typically 20 to $30 \%$ uncertainty in the ability of their correlations to predict data from their tests. ${ }^{25}$

The scatter in the data plotted on log plots (Figures B-3 and B-4) appeared uniform. Hence, logarithms were used. Base 10 logarithms were selected because the data were taken from the log-log plots shown in Figures 13 and 15 of Reference 31. A straight line was fitted to the obtained data. The random scatter around the true straight line was assumed to represent measurement error, and to be normally distributed with constant standard deviation. The fitting line was estimated using least squares. The form of the fitting line can be written

a. The Mini-ACOPO and ACOPO tests only considered cases with $H=R$. However, the Westinghouse response to RAI 480.961 indicates that UCSB assumed that the Mayinger correction factor, $H / R^{0.25}$, may be applied to their correlation. Because previous experimental data suggest that correlations should be modified to consider cases with $\mathrm{H}<\mathrm{R}$, this factor was included in the INEEL correlation.

b. Appendix V (Figures V.13 and V.15) contain data from five ACOPO tests at 200 second intervals; whereas Reference 31 (Figures 13 and 15) only contains data from four ACOPO tests at 400 second intervals. However, more data from Run 5/28/96 appear in the Reference 31 figures, and different correlations are recommended by UCSB in Appendix V and in Reference 31. 


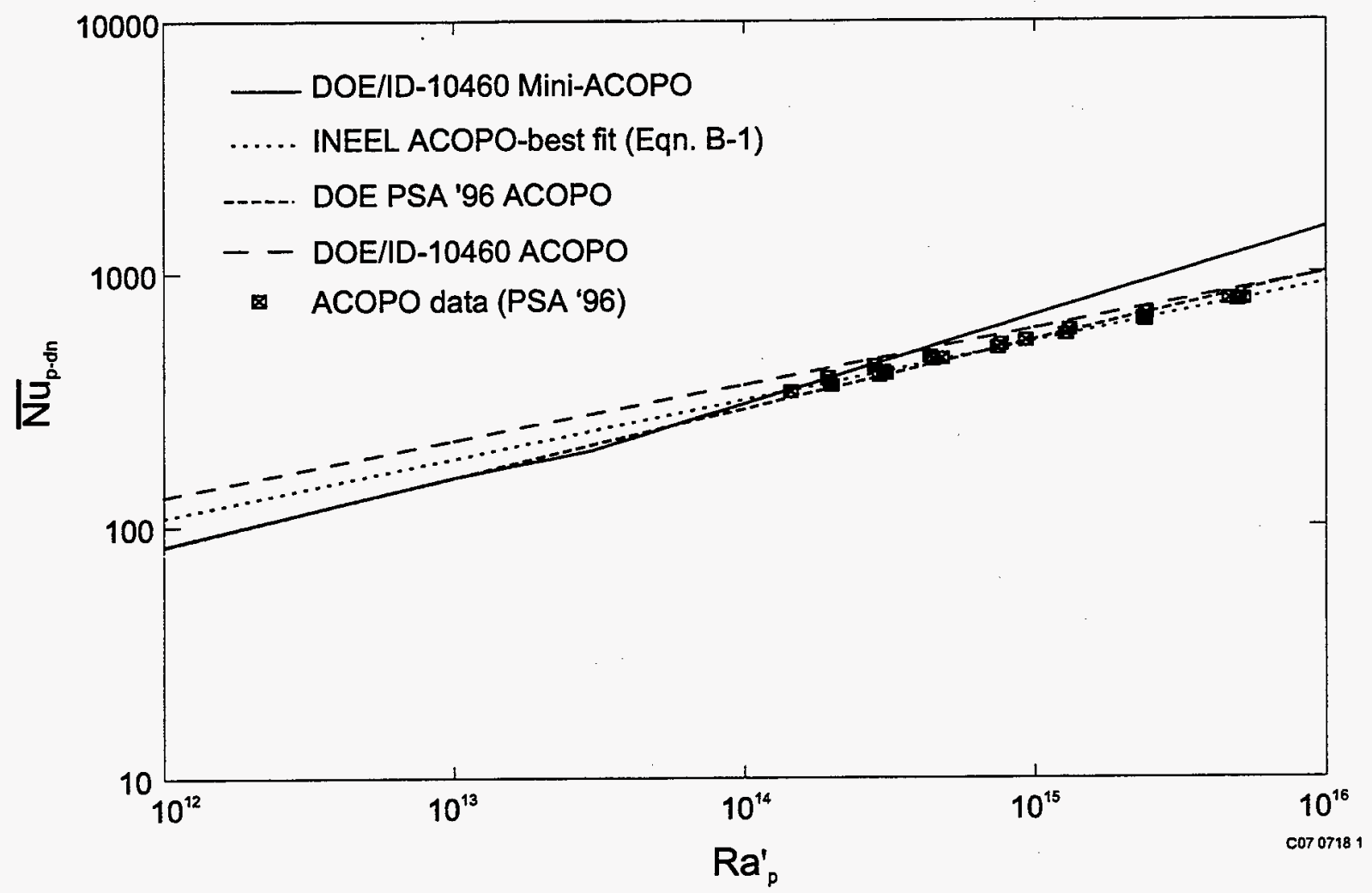

Figure B-3. Comparison of ACOPO and mini-ACOPO downward heat transfer correlations.

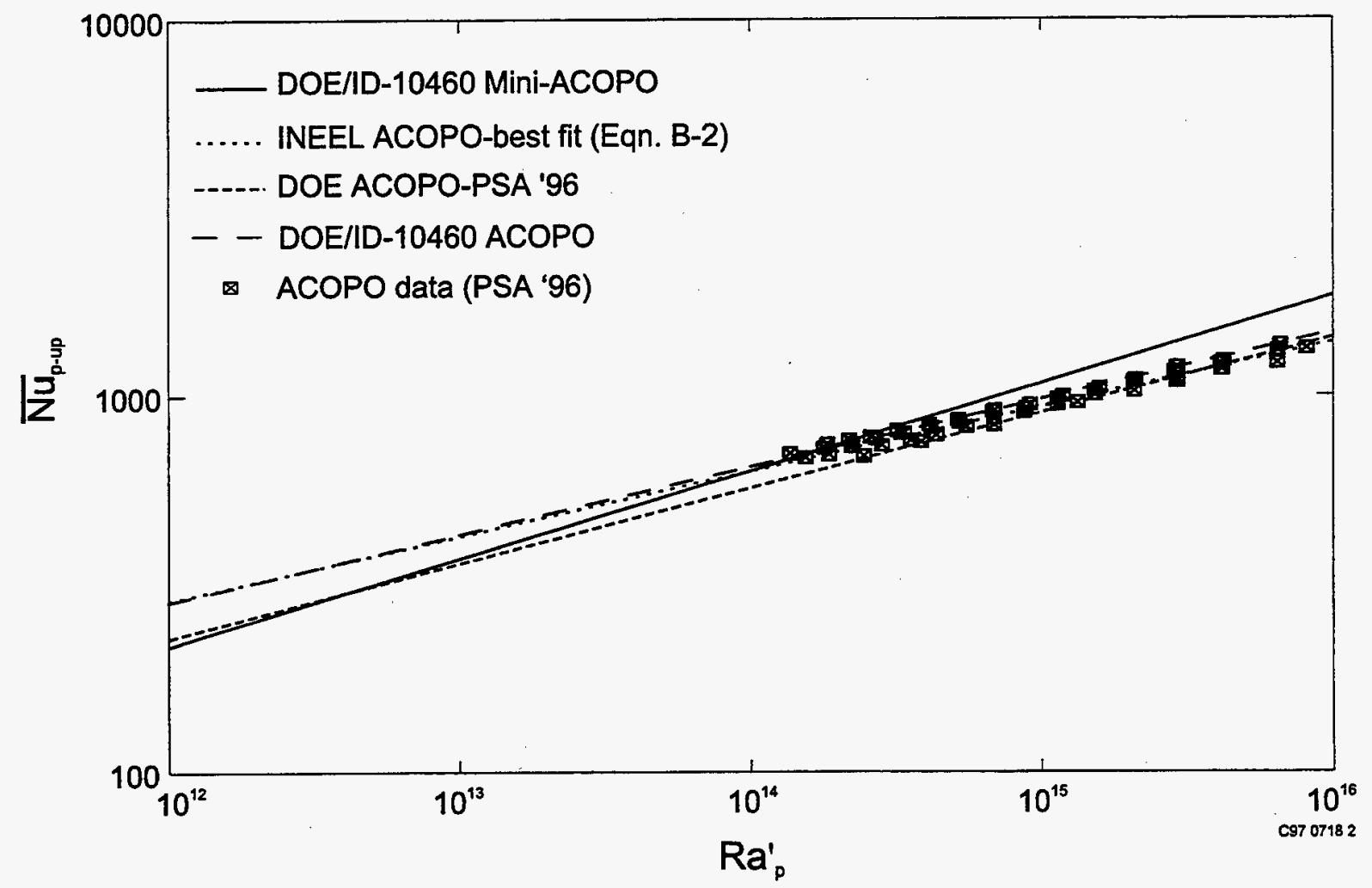

Figure B-4. Comparison of ACOPO and mini-ACOPO upward heat transfer correlations. 
$\log \overline{N u}_{p}=C_{1}+C_{2}\left(\log R a_{p}^{\prime}-\overline{\log R a_{p}^{\prime}}\right)$

where
$\mathrm{C}_{1} \quad=$
Estimated as 2.7181 for modeling downward heat transfer, and estimated as 2.9735 for modeling upward heat transfer.
$\mathrm{C}_{2} \quad=\quad$ Estimated as 0.2304 for modeling downward heat transfer, and estimated as 0.1722 for modeling upward heat transfer.
$\overline{\log \mathrm{Ra}_{\mathrm{p}}^{\prime}}=\quad$ The average of $\log _{10}$ of the ceramic pool Rayleigh number. Estimated as 14.9701 for modeling downward heat transfer and estimated as 15.0148 for modeling upward heat transfer.

Substituting the nominal values for $\mathrm{C}_{1}$ and $\mathrm{C}_{2}$ into Equation (B-3) yields Equations (B-1) and (B-2). However, the average, $\overline{\log \mathrm{Ra}_{\mathrm{p}}^{\prime}}$, is subtracted in Equation (B-3) in order to allow the equation to be expressed in a form so that the estimators of the parameters $C_{1}$ and $C_{2}$ are statistically independent. The usual confidence interval for $\log \mathrm{Nu}$ is based on the fact that the quantity

$$
\frac{\text { Estimator of } \log \overline{N u}_{p}-\text { true } \log \overline{N u}_{p}}{\left[\mathrm{se}_{1}^{2}+\mathrm{se}_{2}^{2}\left(\log R \mathrm{Ra}_{\mathrm{p}}{ }^{\prime}-\overline{\log R \mathrm{Ra}_{\mathrm{p}}^{\prime}}\right)^{2}\right]^{1 / 2}}
$$

has a Student's $t$ distribution with degrees of freedom equal to the number of data points, $n$, minus the number of estimated parameters, $2\left(C_{1} . C_{2}\right)$. Here, $s_{1}$ and $s_{2}$ are the standard errors of $C_{1}$ and $C_{2}$, respectively. Writing the above expression as $T$ and rearranging terms yields the recommended Bayesian uncertainty distributions for $\log \mathrm{Nu}$.

Estimator of $\log \overline{\mathrm{Nu}}_{\mathrm{p}}+\left[\mathrm{se}_{1}^{2}+\mathrm{se}_{2}^{2}\left(\log \mathrm{Ra}_{\mathrm{p}}{ }^{\prime}-\overline{\log R \mathrm{a}_{\mathrm{p}}^{\prime}}\right)^{2}\right]^{1 / 2} T$

where $T$ has a Student's $t$ distribution with $n-2$ degrees of freedom. This distribution was selected because it accounts for the error in estimating the true variability from the observed scatter in a limited amount of data. The Student's $t$ yields uncertainty intervals that are numerically the same as the usual confidence intervals.

Therefore, VESTA applies the following uncertainty distribution for $\log \overline{\mathrm{Nu}}_{\mathrm{p}-\mathrm{dn}}$

$\log \overline{\mathrm{Nu}}_{\mathrm{p}-\mathrm{dn}}=2.7181+0.2304\left(\log R \mathrm{a}_{\mathrm{p}}{ }^{\prime}-14.9701\right)+\left[0.0023^{2}+0.0040^{2}\left(\log \mathrm{R} \mathrm{a}_{\mathrm{p}}{ }^{\prime}-14.9701\right)^{2}\right]^{\frac{1}{2}} T(\mathrm{~B}-6)$

where $T$ has a Student's $t$ distribution with 22 degrees of freedom (corresponding to the number of data points displayed in Figure 15 of Reference 31 minus the 2 estimate parameters). For upward heat transfer, VESTA applies the following uncertainty distribution for $\log \overline{\mathrm{Nu}}_{\mathrm{p} \text {-up }}$

$\log \overline{\mathrm{Nu}}_{\mathrm{p}-\mathrm{up}}=2.9735+0.1722\left(\log R \mathrm{a}_{\mathrm{p}}{ }^{\prime}-15.0148\right)+\left[0.0021^{2}+0.0035^{2}\left(\log R \mathrm{a}_{\mathrm{p}}{ }^{\prime}-15.0148\right)^{2}\right]^{\frac{1}{2}} T(\mathrm{~B}-7)$

where $T$ has a Student's $t$ distribution with 53 degrees of freedom (corresponding to the 55 data points displayed in Figures 13 of Reference 31 minus the 2 estimate parameters). 


\section{B.1.2 Local Heat Transfer from a Volumetrically Heated Molten Pool}

DOE/ID-10460 Approach. The UCSB study applied data from UCSB Mini-ACOPO tests to obtain the following equations (Equation 5.30a and 5.30b of DOE/ID-14060) for predicting heat transfer as a function of angle along the bottom of the hemisphere.

$$
\begin{aligned}
& \frac{N u_{p-d n}(\theta)}{\overline{N u}_{p-d n}}=0.1+1.08\left(\frac{\theta}{\theta_{\text {tot }}}\right)-4.5\left(\frac{\theta}{\theta_{\text {tot }}}\right)^{2}+8.6\left(\frac{\theta}{\theta_{\text {tot }}}\right)^{3} ; \quad 0.1 \leq\left(\frac{\theta}{\theta_{\text {tot }}}\right) \leq 0.6 \\
& \frac{\mathrm{Nu}_{\mathrm{p}-\mathrm{dn}}(\theta)}{\overline{\mathrm{Nu}}_{\mathrm{p}-\mathrm{dn}}}=0.41+0.35\left(\frac{\theta}{\theta_{\text {tot }}}\right)+\left(\frac{\theta}{\theta_{\text {tot }}}\right)^{2} ; \quad 0.6<\left(\frac{\theta}{\theta_{\text {tot }}}\right) \leq 1.0
\end{aligned}
$$

where

$$
\begin{array}{lll}
\theta & = & \text { Angle from bottom of the ceramic pool, degrees } \\
\theta_{\text {tot }}= & \text { Maximum angle at upper surface of ceramic pool, degrees } \\
\mathrm{Nu}_{\mathrm{p}-\mathrm{dn}}(\theta)= & \text { Pool Nusselt number in the downward direction at angle, } \theta \\
\overline{\mathrm{Nu}}_{\mathrm{p}-\mathrm{dn}}= & \text { Average ceramic pool Nusselt number in the downward direction }
\end{array}
$$

The UCSB study neglected uncertainty in the above correlations.

In Appendix V (Figure V.11) and in Reference 31 (Figure 11), location-dependent Nusselt data from

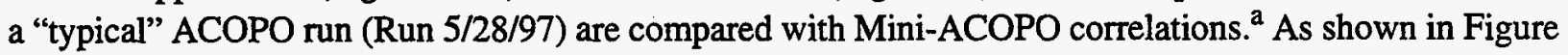
B-5, ACOPO data vary from the Mini-ACOPO correlation. However, the authors conclude in Appendix V that the Mini-ACOPO correlation "represents a fair representation through the middle of the data."

INEEL Approach. The UCSB approach did not consider any uncertainties. In general, there are uncertainties associated with the ability of an experiment to simulate the situation of interest, the reproducibility of the data, and experimental measurement techniques. In this case, the Mini-ACOPO and ACOPO tests used a hemispherical facility, whereas the UCSB FIBS analysis assumed ceramic melt masses that resulted in a pool maximum angle of only $\sim 75^{\circ}$. Although no data are presented to support this assertion, UCSB authors claim that the normalized angle in their correlation makes it valid for such cases.

It is difficult, if not impossible, to appropriately account for all of the uncertainties associated with applying the Mini-ACOPO correlation. In VESTA calculations, INEEL used the variability between ACOPO data and the Mini-ACOPO correlation as an estimate for uncertainty. DOE/mD-10460 Appendix $\mathrm{V}$ data suggest that the uncertainty in localized heat transfer is normally distributed with a standard deviation of 0.12 . This standard deviation describes scatter of the data around the Mini-ACOPO correlation, not uncertainty in the value of the curve. However, it is probably a conservative bound on the standard deviation corresponding to uncertainty in the curve because the standard deviation of data is typically greater than the standard deviation of the fitted mean. Mini-ACOPO and ACOPO data indicate

a. Data displayed in Figure 11 of Reference 31 and Figure V.11 of Appendix V appear identical. 


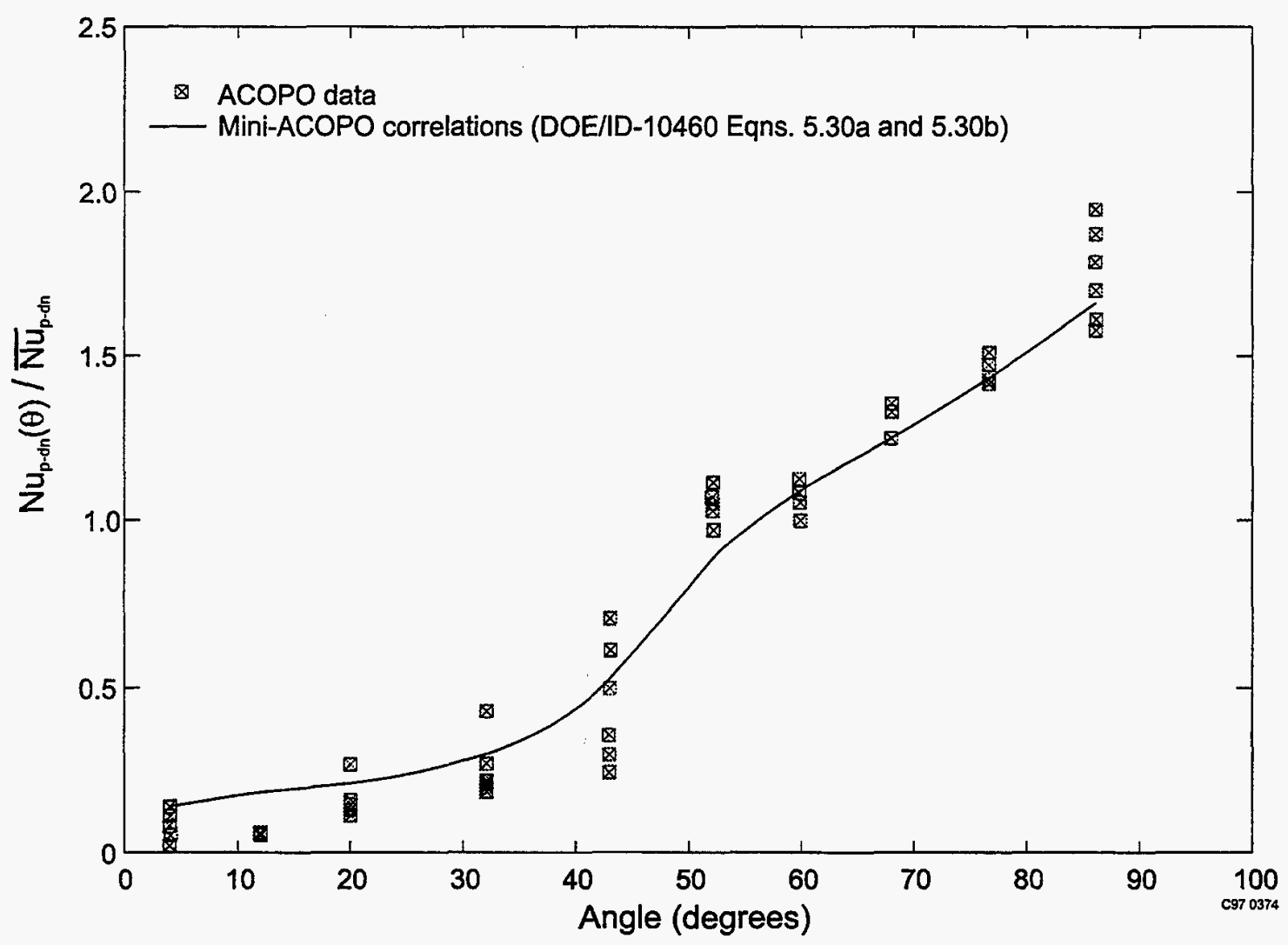

Figure B-5. Comparison of typical ACOPO data (Run 5/28/96) with Mini-ACOPO correlation. that the values for $\theta / \theta_{p} \leq 0.6$ and $\theta / \theta_{p}>0.6$ are related. Hence, VESTA simulates uncertainty for these relationships by including in each equation a new variable, which is normally distributed with a median value of 0.0 and a standard deviation of 0.12 . Because the value for $\mathrm{Nu}_{\mathrm{dn}}(\theta)$ must be positive, VESTA limits the minimum value of $\mathrm{Nu}_{\mathrm{dn}}(\theta)$ to a small number $(0.01)$.

\section{B.1.3 Critical Heat Flux from a Vessel to a Flooded Cavity}

DOE/ID-10460 Approach. DOE/1D-10460 predicts CHF using a "lower bound" correlation based on data from the UCSB ULPU Configuration II tests without insulation (see Figure B-6). Natural circulation occurred in these tests. The gravity head that existed in these tests resulted in a water depth to vessel radius ratio of approximately $4(\mathrm{H} / \mathrm{R}=4)$. This gravity head is estimated to result in approximately $14 \mathrm{~K}$ subcooling at the bottom center of these tests. The UCSB study assumed zero uncertainty in this correlation because it is supposed to be a lower bound correlation for ULPU Configuration II data. In the Reference 12 response to RAI Question 480.448, Westinghouse states that the uncertainty in the CHF is below the $20 \%$ uncertainty normally associated with experimental tests because of advantages in the ULPU facility that allowed them to "zero-in" on the CHF value by successive runs. After the UCSB report was issued, additional tests were completed in ULPU to assess the impact of reactor vessel insulation on ex-vessel heat transfer. The ULPU data shown in Figure B-6 suggests that there are no distinct differences between ULPU Configuration II and Configuration III data. 


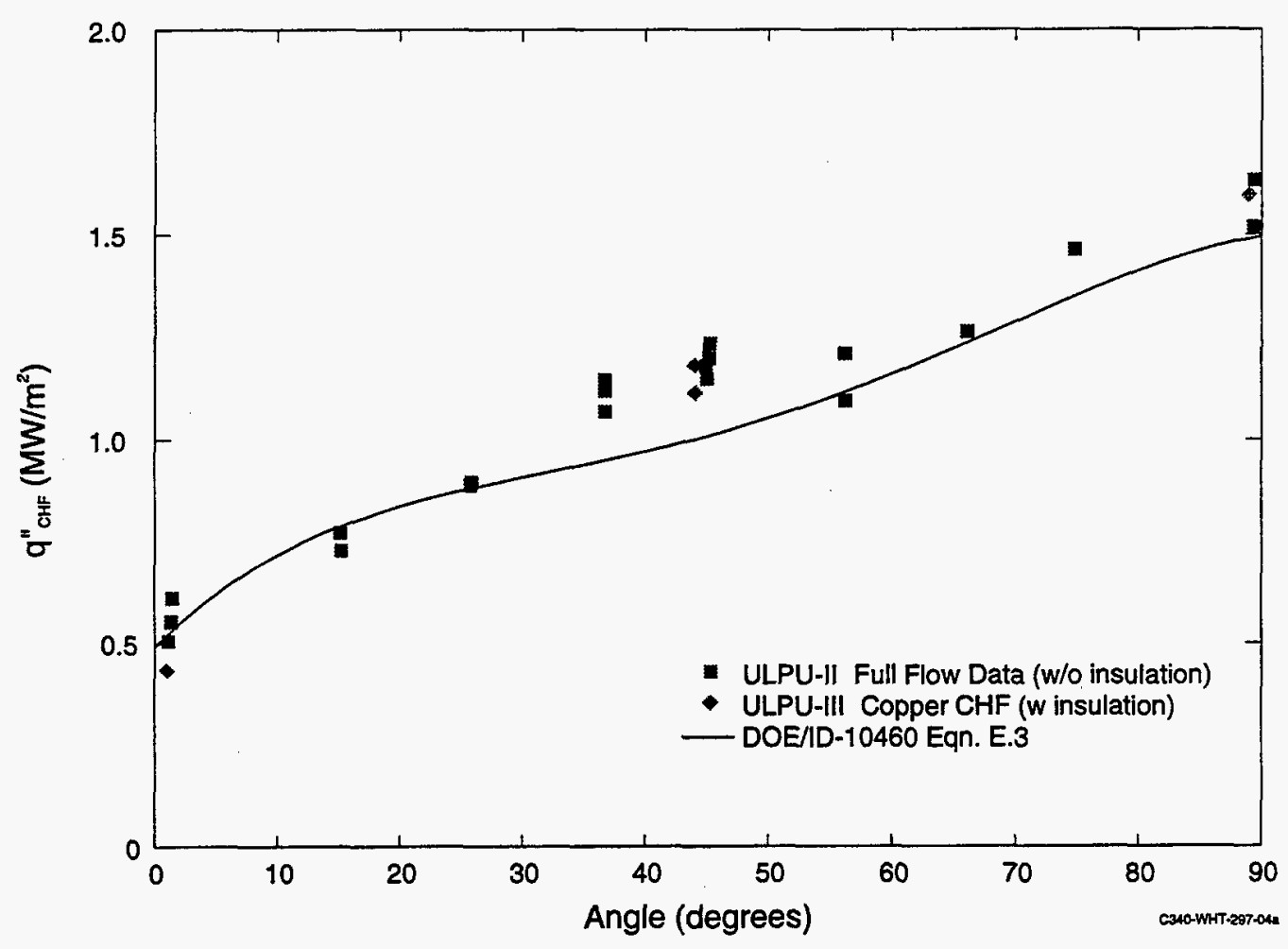

Figure B-6. Comparison of UCSB "lower bound" CHF correlation (DOE/ID-10460 Eqn. E.3) with ULPU Configuration II and III data.

INEEL Approach. Cheung et al. developed a scaling law for estimating CHF as a function of several parameters, such as coolant pressure, local coolant subcooling (associated with gravity head), coolant velocity, vessel size, and position. ${ }^{33}$ In Reference 33 , Cheung demonstrates that this scaling relationship successfully predicts data from the Subscale Boundary Layer Boiling (SBLB) tests ${ }^{34}$ and the ULPU Configuration II tests. Figure B-7 compares results from this scaling relationship applied to an AP600 reactor vessel with coolant at atmospheric pressure. Three cases are shown to reflect the difference in CHF due to local coolant subcooling associated with gravity head (denoted by the ratio of the reactor cavity coolant height to vessel radius, H/R). As shown in Figure B-7, CHF increases with coolant height (because of increased subcooling associated with coolant head). The lower bound ULPU Configuration II correlation, which is also plotted in Figure B-7, ranges between correlations with water depth to vessel radius ratios between 1 and $3(1 \leq H / R \leq 3)$ for angles less than $75^{\circ}$ from the bottom of the vessel and exceeds $\mathrm{H} / \mathrm{R}$ for angles greater than $75^{\circ}$. 


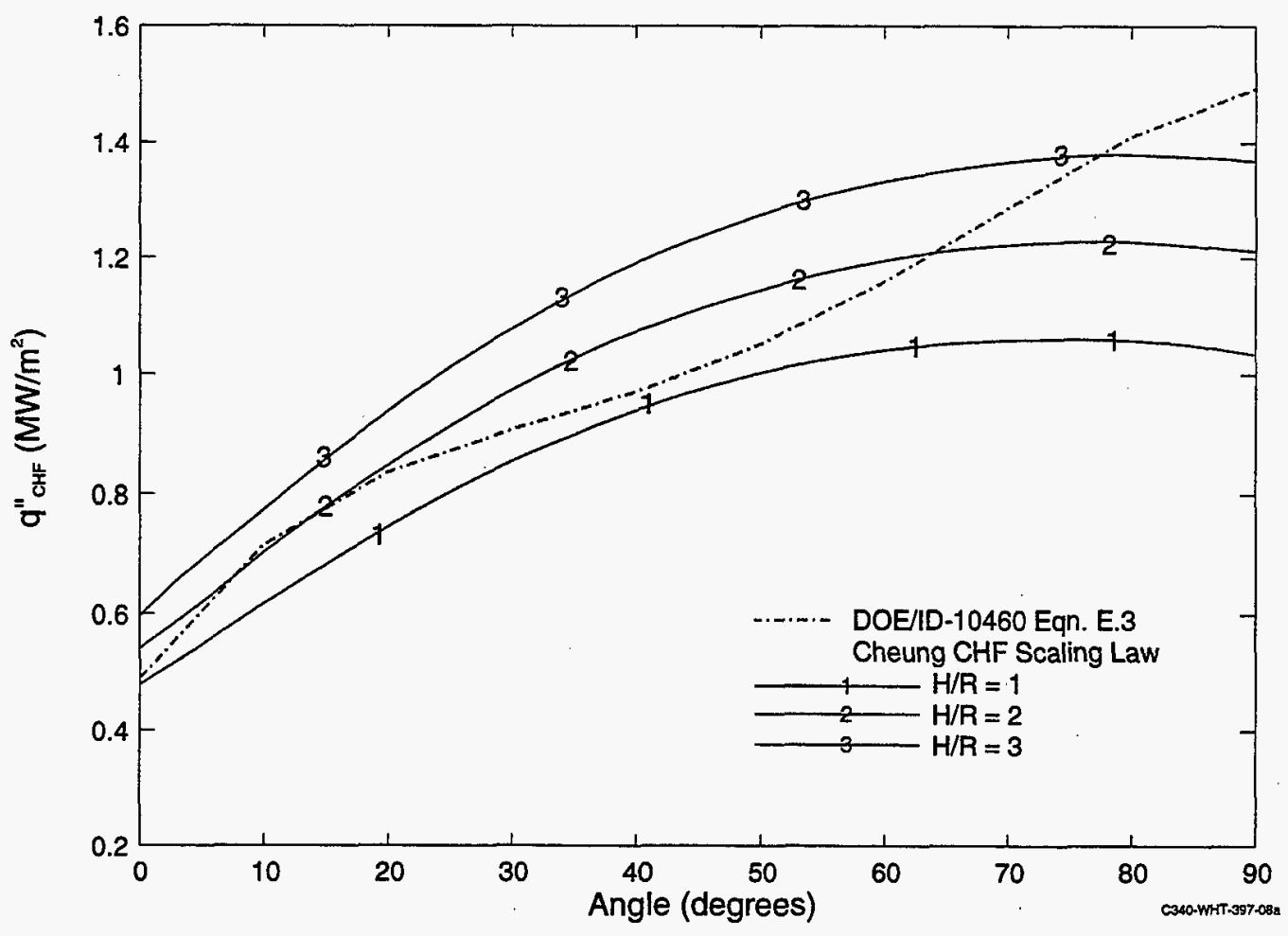

Figure B-7. Comparison of ULPU and Cheung SBLB correlations.

Figure B-8 illustrates time-dependent cavity water levels based on information presented in Section 39 of the AP600 PRA. ${ }^{1}$ This figure shows cavity water levels for cases in which one and two cavity flooding lines are assumed open. Figure B-8 water levels assume that water in the cavity prior to operatorinitiated flooding (due to water exiting the break) causes the cavity water height to initially be near the top of the hemisphere of the vessel. ${ }^{\mathrm{a}}$ SCDAP/RELAP5, ${ }^{3}$ MELCOR, ${ }^{4 b}$ and MAAP4 ${ }^{5,36}$ calculated times for when molten pools would occur in the lower head for AP600 3BE-type transients are plotted in Figure B8. In Appendix O of the UCSB study, the authors estimate that their assumed FIBS occurs at approximately 120 minutes after the operator initiates flooding. Differences in estimated molten pool formation times are primarily attributed to differences in assumptions pertaining to failure of the reflector, failure of the core plate, and debris quenching during relocation. Although estimated molten pool

a. A review of MAAP4 calculations for cases with one cavity flooding line and no IRWST gravity injection found that coolant exiting the RCS caused the cavity water to be near the top of the hemisphere. However, there was considerable variation in MAAP4 predictions for the time between the point where the initial water exited the break and the time when the operator initiated cavity flooding and in predictions for the operator-initiated cavity flooding fill rates. Because Westinghouse has initiated an AP600 Severe Accident Management Guideline (SAMG) change that would reduce the time till the operator initiates cavity flooding, cavity flooding rates were based on information in Section 39 of Reference 1 (which assumes that cavity flooding is initiated near the time of the break).

b. These calculations were performed assuming no material interactions or eutectic formation. ${ }^{35}$ Earlier molten pool formation times would be predicted if materials interaction models were invoked. 
formation times differ, the ratio of the water height to the vessel radius varies between $\sim 2$ and 4.4 (the maximum flooding height) for time periods when these references predict molten pools are present in the lower head.

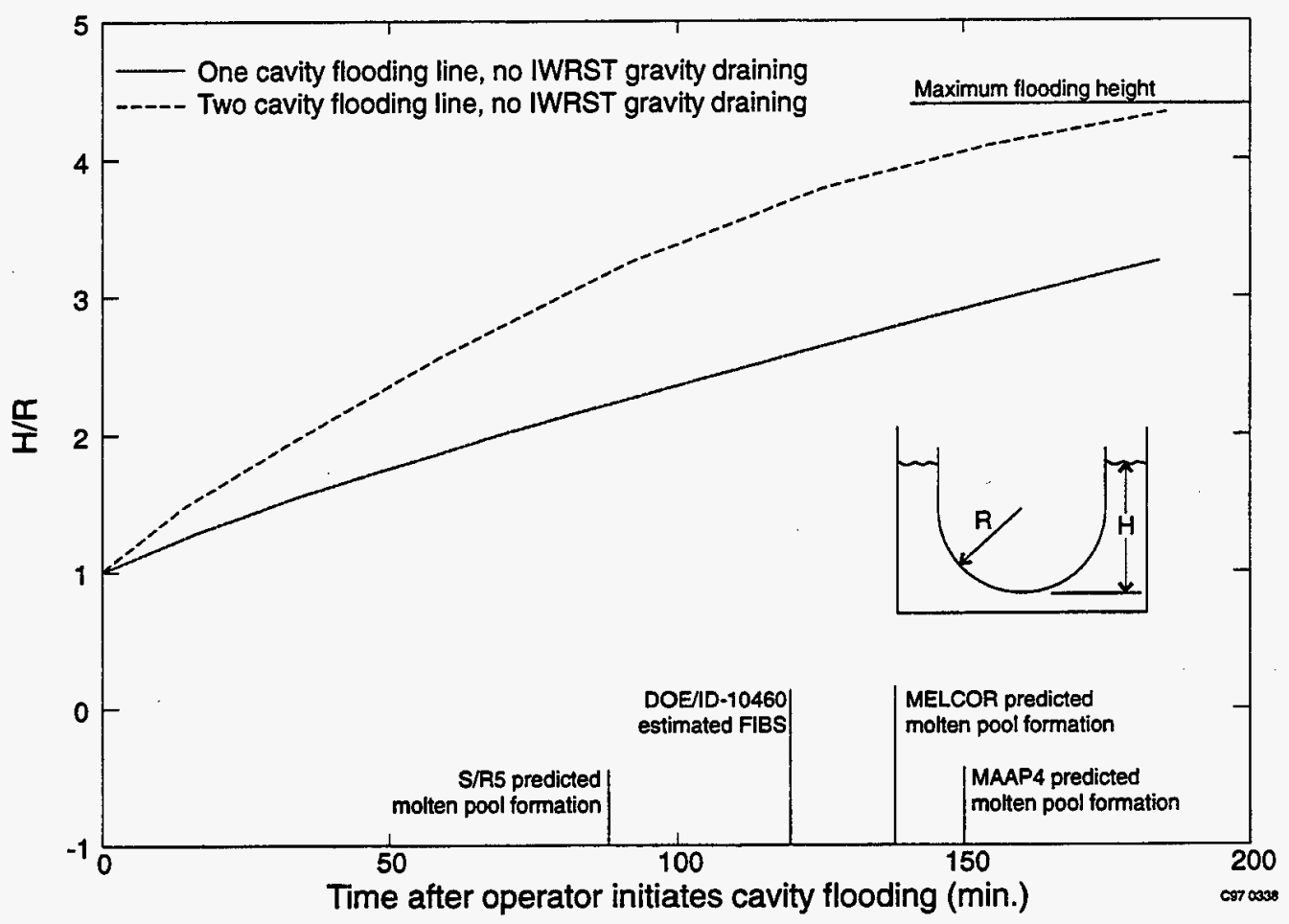

Figure B-8. Comparison of predicted molten pool formation times with cavity flooding rates shown in the AP600 PRA.

In addition to uncertainties associated with estimating coolant height (and associated subcooling) at the time of relocation and molten pool formation, experimental errors contribute to uncertainties in estimating $\mathrm{CHF}^{37}$ Cheung $^{38}$ indicates that there is typically $7 \%$ uncertainty in his correlations for predicting SBLB CHF data [because of uncertainties associated with instrumentation, reproducibility of results, geometry, surface conditions, heat flux (power shape) assumptions, etc.].

In light of the calculated molten pool formation times shown in Figure B-8, INEEL assumed the Cheung $(H / R=3)$ correlation for analyzing the UCSB-assumed FIBS and the Cheung $(H / R=2)$ correlation for analyzing various intermediate states postulated to occur following initial molten pool formation. Discussions with Cheung ${ }^{38}$ suggest that the relative uncertainty in his correlations is constant, with 95thpercent uncertainty limits of $10 \%(2 \sigma / \mu=10 \%)$. In this case, the standard deviation describes scatter of the data around the line, not uncertainty in the value of the curve. However, it is probably a conservative bound on the standard deviation corresponding to uncertainty in the curve because the standard deviation of data is typically greater than the standard deviation of the fitted mean. 
The natural logarithm of this correlation was used in order to obtain an absolute standard deviation that is independent of the magnitude of CHF. It can be shown, using a Taylor series approximation that ${ }^{39}$

$\sigma(\ln x) \approx \frac{\sigma(\mathrm{x})}{\mu(\mathrm{x})}$

As noted above, Cheung reports that $\sigma / \mu=0.05$. Therefore, INEEL chose to work with natural logarithms, and assigned 0.05 as the standard deviation of $\ln \left(\mathrm{q}_{\mathrm{CHF}}^{\prime \prime}\right)$.

INEEL neglected insulation effects. As discussed above, data from ULPU Configuration III (with insulation) don't differ significantly from data from ULPU Configuration II (without insulation). Preliminary results from SBLB tests with insulation suggest that the presence of insulation will increase heat removal. ${ }^{38}$ However, heater difficulties prevented CHF from occurring in these tests. When SBLB tests with insulation are successfully completed, the impact of insulation should be considered.

\section{B.1.4 Heat Transfer from a Molten Metallic Layer}

DOE/ID-10460 Approach. To predict heat losses from the metallic layer to the vessel wall, DOE/ID10460 Section 5 states that the following form of the Churchill and Chu correlation (Equation 5.35 of DOE/ID-10460) is used:

$\mathrm{Nu}_{1-\text { horz }}=0.076 \mathrm{Ra}_{1}{ }^{1 / 3}$

DOE/ID-10460 Section 5 also states that heat transfer across the horizontal surfaces of the metallic layer is modeled using a "specialized" version of the Globe-Dropkin correlation: ${ }^{40 a}$

$\mathrm{Nu}_{1-\mathrm{vert}}=0.15 \mathrm{Ra}_{1}{ }^{1 / 3}$

Section 6 (Equation 6.11) of the UCSB study implies that the following, more general, forms of the above correlations were applied so that the fluid's Prandtl number could be explicitly modeled.

$\mathrm{Nu}_{1-\text { horz }}=0.069 \mathrm{Ra}_{1}^{1 / 3} \mathrm{Pr}_{1}^{0.074}$

$\mathrm{Nu}_{1-\text { vert }}=\left[0.825+\frac{0.387 \mathrm{Ra}_{1}{ }^{1 / 6}}{\left[1+\left(0.492 / \mathrm{Pr}_{1}\right)^{9 / 16}\right]^{8 / 27}}\right]^{2} \approx \frac{0.15 \mathrm{Ra}_{1}{ }^{1 / 3}}{\left[1+\left(0.492 / \mathrm{Pr}_{1}\right)^{9 / 16}\right]^{16 / 27}}$

In Appendix N, the authors of the UCSB study acknowledge that there was no information in the literature that validated the application of these correlations to cases in which horizontal and vertical heat transfer occur simultaneously. To justify their approach, the authors conducted the MELAD (MEtal LAyer Demonstration) tests in which heat transfer was measured from water contained in a rectangular box (50 $\mathrm{cm}$ long, $10 \mathrm{~cm}$ wide, and $10 \mathrm{~cm}$ in height) with one side surface insulated, one side surface and the upper surface cooled, and the lower surface heated. In Appendix $N$ of DOE/1D-10460, the authors compare

a. Information in the UCSB study suggest that this specialization was performed by redefining the temperature difference as the difference between the temperature in the upper (or lower) surface and the temperature at the midplane of the metallic layer. 
MELAD data to values predicted by their Chu-Churchill/localized Globe-Dropkin model and conclude that their model is adequate. The UCSB study applies these correlations without uncertainties.

INEEL Approach. Although Appendix P of the UCSB study considered a sensitivity case in which heat was transposed to the metallic layer and Appendix R of the UCSB study acknowledges that a fraction of the fission products (and their associated decay heat will be retained by the metallic layer), the UCSB study neglected the impact of volumetric heat sources on heat transfer from the metallic layer. Furthermore, neither the Globe-Dropkin, the Chu-Churchill, nor the MELAD tests considered heat transfer from a fluid layer above a volumetrically heated fluid. Therefore, INEEL evaluated the impact of volumetric heating within and below the metallic layer on heat transfer and used MELAD data to quantify appropriated uncertainty for the metallic layer heat transfer correlations.

For the various debris configurations analyzed by INEEL, volumetric heat sources within the metallic layers resulted in Rayleigh numbers ranging from $2 \times 10^{8}$ to $3 \times 10^{12}$. As discussed in Section 5 of the UCSB study, many of the turbulent natural convection heat transfer correlations developed for pools with Rayleigh numbers within this range. Hence, INEEL compared Nusselt numbers estimated from selected natural convection heat transfer correlations described in Reference 25 with values obtained from the Globe-Dropkin and Chu-Churchill correlations assumed in the UCSB study. In general, the values predicted from correlations based on volumetric heat sources were comparable to or lower than values predicted with the correlations assumed in the UCSB study.

As documented in Reference 40, the Globe-Dropkin tests considered a single layer fluid confined between two horizontal plates with the lower plate heated. Several references have developed correlations from tests in which an internally heated fluid layer existed below a second unheated, immiscible fluid layer. Correlations based on several of these tests [Fieg ${ }^{41}$ and Kulacki/Emara, ${ }^{42}$ which vary with the ratio of the unheated layer height to the heated layer height $\left.\left(\mathrm{L}_{1} / \mathrm{L}_{2}\right)^{\mathrm{a}}\right]$ are compared with the Globe-Dropkin correlation in Figure B-9. As shown in this figure, the Globe-Dropkin correlation predicts higher upward heat losses than the Fieg or Kulacki/Emara correlations.

The above information suggests that there is considerable uncertainty in assumptions related to heat transfer from the metallic layer because of the presence of volumetric heat sources within the metallic layer and within the lower ceramic layer. Additional experimental tests are required to reduce the uncertainty associated with heat transfer from the metallic layer. However, the various correlations typically yielded Nusselt numbers with the same order of magnitude for the pool Rayleigh numbers investigated by INEEL. ${ }^{b}$ Although the UCSB-sponsored MELAD A tests neglected the impact of volumetric heat sources, these tests did consider simultaneous heat transfer in the horizontal and vertical directions. Therefore, INEEL used MELAD A test data to estimate heat transfer from the metallic layer. It is interesting to note that recent Royal Institute of Technology calculations ${ }^{8}$ indicate that MELAD A test data agree with the correlations recommended by two other references for predicting heat transfer from an unheated layer above a volumetrically heated layer ${ }^{43}$ and from a volumetrically-heated boiling pool. ${ }^{44}$

\footnotetext{
a. Although many of the Reference 42 correlations were developed in terms an internal Rayleigh number based on the heights of both layers, the Kulacki/Emara correlation compared in Figure B-9 was developed in terms of a modified Rayleigh number based on the upper layer's height and a maximum possible temperature difference across the unheated layer (see Figure 4.7 of Reference 42).

b. The manner in which INEEL formulated the Configuration $B$ and $C$ analyses did not require that the metallic layer heat transfer coefficient be assumed. Hence, these values were only required for the UCSBassumed FIBS and Configuration A calculations.
} 


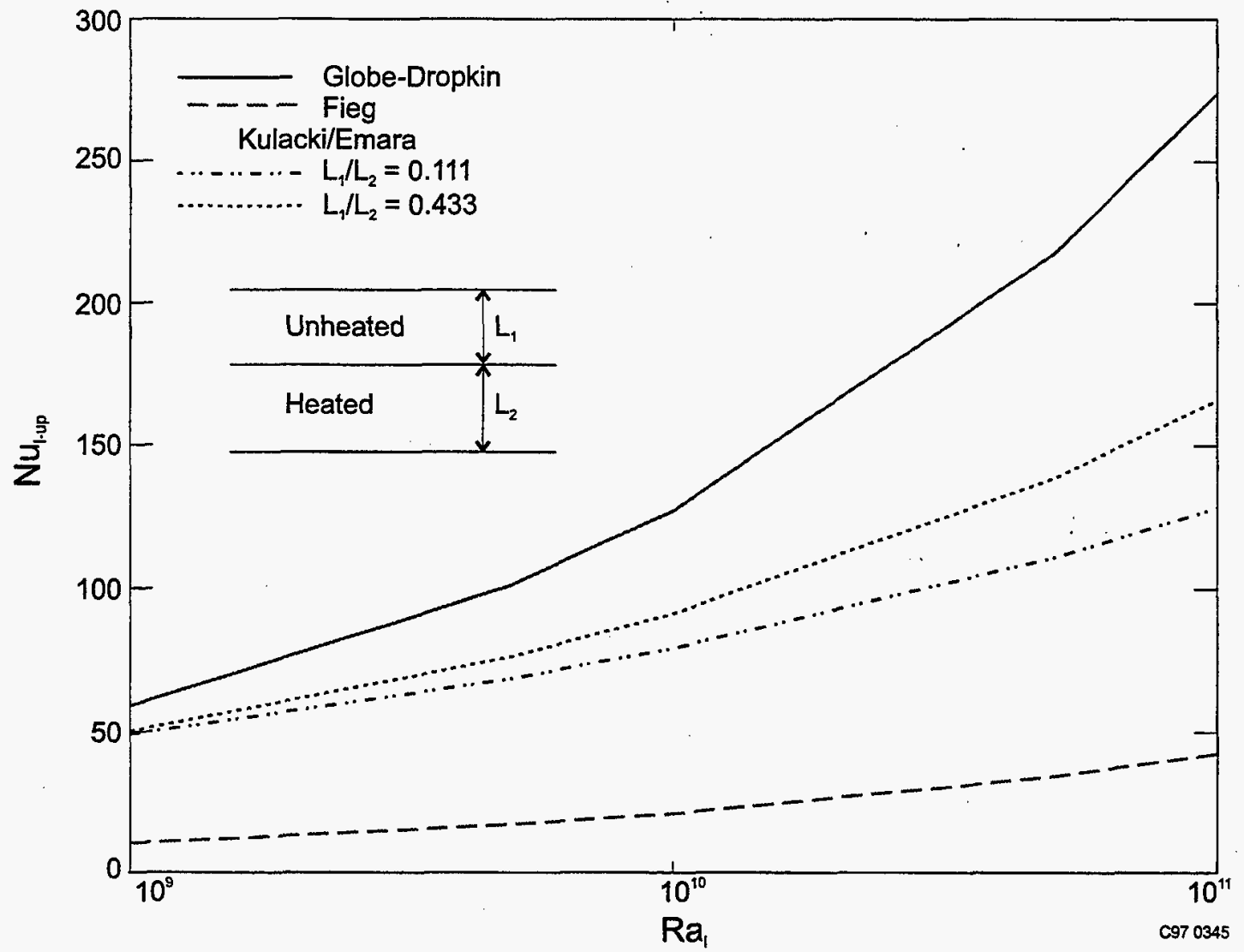

Figure B-9. Comparison of correlations for predicting upward heat transfer from the metallic layer.

Similar to the approach followed in the UCSB study, INEEL assumed Prandtl-number-dependent versions of the "specialized" form of the Globe-Dropkin correlation for vertical heat transfer and the ChuChurchill correlation for horizontal heat transfer. MELAD A test data presented in DOE/ID-10460 Appendix $\mathrm{N}$ were manipulated to obtain the Nusselt number versus Rayleigh number plots shown in Figures B-10 and B-11. Variances between MELAD data and correlation predictions were calculated for each heat transfer direction. For horizontal heat transfer, the relative standard deviation $(\sigma / \mu)$ was found to equal 8.8\%; for vertical heat transfer, the relative standard deviation $(\sigma / \mu)$ was found to equal $15 \%$. Here, the standard deviation describes scatter of the data around the assumed correlations, not correlation uncertainty. However, it provides a conservative bound on the $\sigma$ corresponding to correlation uncertainty because the standard deviation of data is typically greater than the standard deviation of the fitted mean. The natural logarithms of these heat transfer correlations [Equations (B-13) and (B-14)] were used so that an absolute standard deviation could be obtained [see Equation (B-10)]. Because there were limited data for measuring heat transfer, INEEL used a Student's $t$ distribution to represent the uncertainty in these correlations. As discussed above, a Student's $t$ distribution accounts for the error in estimating the true variability from the observed scatter in a limited amount of data and yields uncertainty intervals that are numerically the same as the usual confidence intervals. The assumed correlations were developed independently from MELAD data, and there were no estimated parameters (see discussion about degrees of freedom in Section B.1.1). Hence, three degrees of freedom were assumed for estimating uncertainty in horizontal heat transfer (corresponding to the three data points in the horizontal direction). For vertical heat transfer, six degrees of freedom were assumed (corresponding to the three data points taken in the upward direction and the three points taken in the downward direction). 


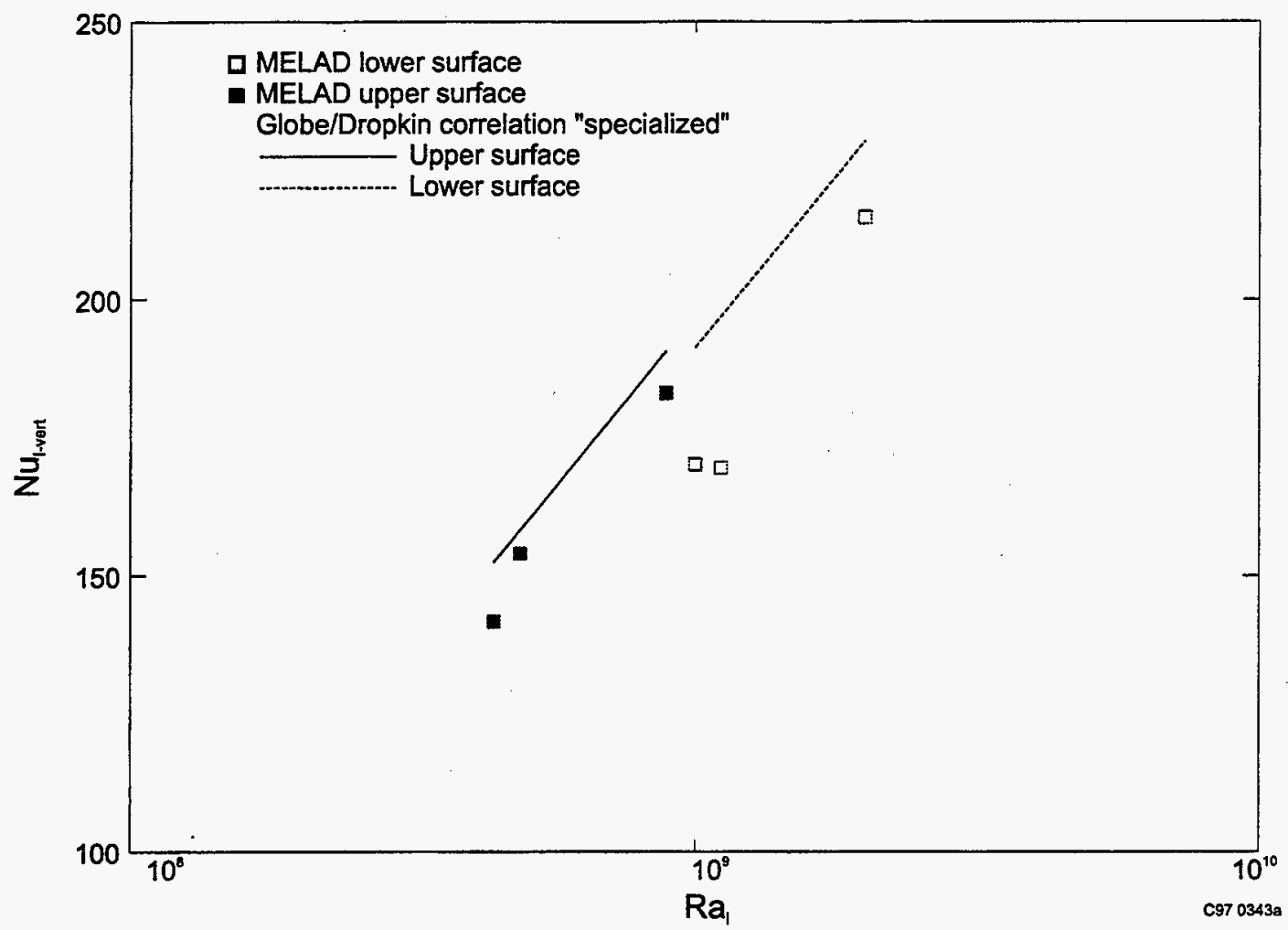

Figure B-10. Comparison of MELAD A data with "specialized" Globe-Dropkin correlations.

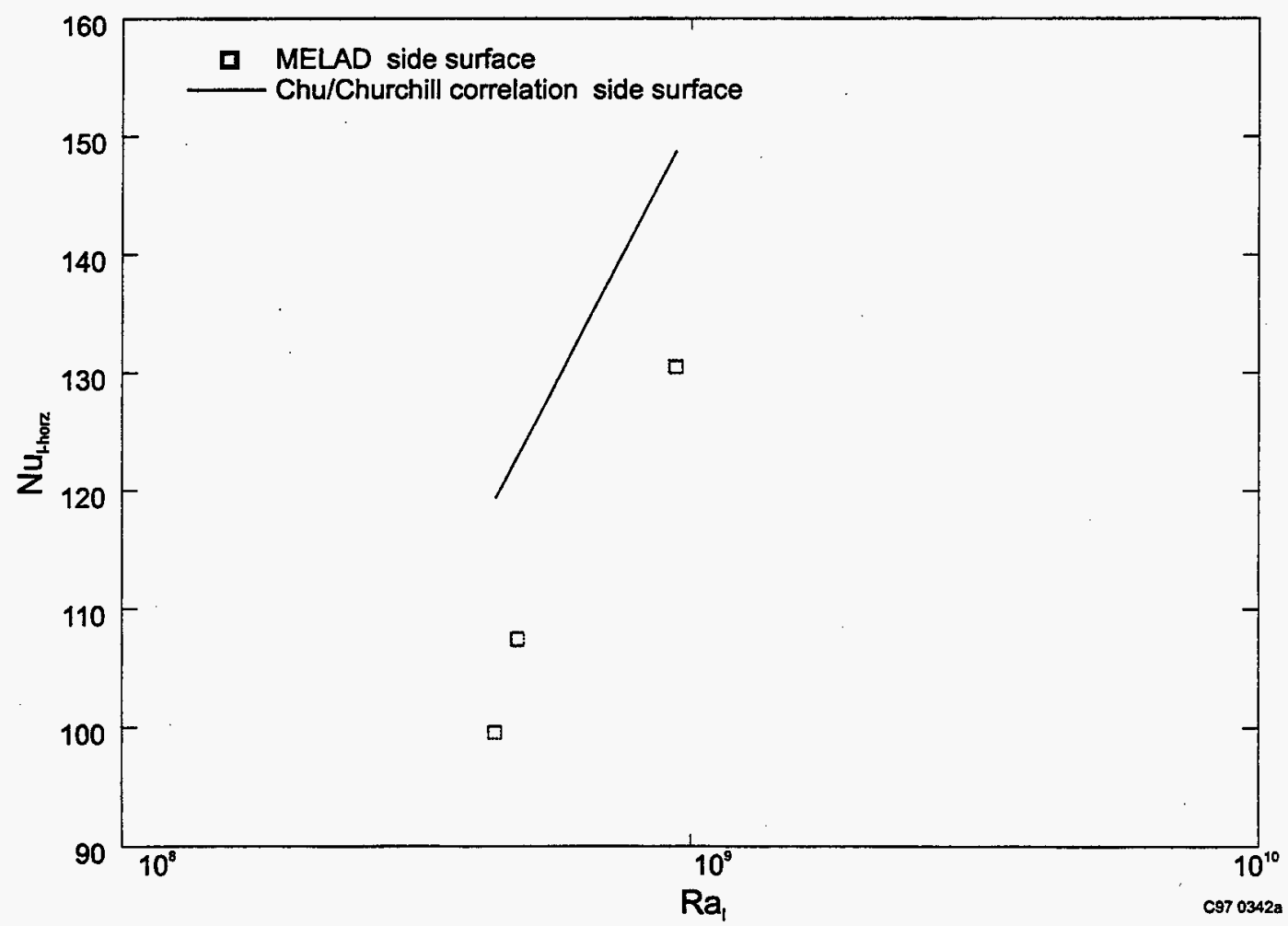

Figure B-11. Comparison of MELAD A data with the Chu-Churchill correlation. 


\section{B.2 Decay Heat Assumptions}

\section{B.2.1 Decay Power Density}

DOE/TD-10460 Approach. The pdf assumed for the decay power density in the UCSB analysis was derived by statistically combining the decay power curve (which included some treatment of volatile fission products) shown in DOE/ID-10460 Figure 7.1 and pdfs for the fraction of zirconium oxidized (DOE/ID-10460 Figure 7.3) and the core relocation time (DOE/ID-10460 Figure 7.7). DOE/ID-10460 Figure 7.8 illustrates the pdf obtained by statistically combining their assumed values.

INEEL Approach. For timeframes of interest during a reactor accident, decay heat is primarily produced by fission products and actinides present in core material. It appears that the UCSB approach is basically sound. However, their decay power density pdf does not appropriately account for uncertainties in the decay power curve or core relocation time. Consequently, the edge of spectrum value (with an assigned probability of zero), was non-conservatively limited to only $1.4 \mathrm{MW} / \mathrm{m}^{3}$. INEEL imposed two changes in the UCSB method for estimating decay power density. First, INEEL considered ANS 5.1-recommended uncertainties in the decay power curve shown in Figure 7.1 of the UCSB study. Second, INEEL reduced the melt relocation time shown in DOE/ID-10460 Figure 7.7 by one hour. Reasons for these recommendations are discussed below.

The decay power remaining in relocated melt is influenced by irradiation history, heatup transient, cooling time, enrichment, and neutron spectrum. Although decay power may vary more because of assumptions pertaining to these factors, INEEL believes that, as a minimum, the UCSB study should have considered the uncertainties in calculating decay heat for the particular power history and cooling time. According to the 1979 ANS 5.1 Standard, ${ }^{45}$ decay power predictions for a particular irradiation history and cooling time may be assumed to be normally distributed with a relative standard error of $5 \%$. In order to capture $\sim 95 \%$ of the decay power uncertainty, one should apply error bands of $10 \%(2 \sigma / \mu)$. This $10 \%$ uncertainty is consistent with the decay power uncertainties recommended by NRC. ${ }^{46}$

Table B-2 compares the decay power used in DOE/ID-10460, the decay power one would obtain by accounting for pertinent uncertainties associated with the ANS Standard, and the discrepancy relative to what was used to evaluate IVR. In their Reference 12 response to RAI Question 480.452, Westinghouse asserts that the decay power curve used to evaluate IVR is similar to an ANS decay power curve with a reported adjustment of $+2 \sigma$. However, it appears that the UCSB study non-conservatively limited $\sigma$ by only considering uncertainties associated with ${ }^{235} \mathrm{U}$, while the 1979 ANS Standard also provides a methodology for considering three-group $\left({ }^{235} \mathrm{U},{ }^{238} \mathrm{U},{ }^{239} \mathrm{Pu}\right)$ behavior. As indicated in Table B-2, the UCSB study used a decay power that was generally consistent with their interpretation of the ANS 5.1 Standard and $10 \%$ lower than values that one would obtain if appropriate upper bounds on uncertainties were considered.

For the UCSB-assumed FIBS, INEEL applied the DOE/ID-10460 Figure 7.1 decay power curve (that includes volatile release). However, INEEL assumed that values from this curve were median values of normally distributed data with 95 th-percent uncertainty limits of $10 \%(2 \sigma / \mu=10 \%)$. Note that the INEEL decay power density (Column 4 of Table B-2) is later reduced by the fraction of decay heat estimated to exist in the metallic layer (see Section B.2.2). 
Table B-2. Comparison of decay powers.

\begin{tabular}{|c|c|c|c|c|}
\hline $\begin{array}{c}\text { Time after } \\
\text { Shutdown (s) }\end{array}$ & $\begin{array}{c}\text { Decay Power, } \\
\text { DOE/D-10460 } \\
\text { Figure 7.1 (MW) }\end{array}$ & $\begin{array}{c}\text { Decay Power, } \\
\text { 1979 ANS 5.1 } \\
\text { Standard (MW) }\end{array}$ & $\begin{array}{c}\text { Decay Power, 1979 } \\
\text { ANS 5.1 Standard } \\
+10 \%(\mathrm{MW})\end{array}$ & $\begin{array}{c}\text { DOE/ID-10460 } \\
\text { Decay Power } \\
\text { Discrepancy (\%) }\end{array}$ \\
\hline \hline 200 & 62 & 55.9 & 61.5 & 0.81 \\
\hline 500 & 48 & 46.8 & 51.5 & -7.29 \\
\hline 1000 & 40 & 40.1 & 44.1 & -10.3 \\
\hline 2000 & 33 & 33.2 & 36.5 & -10.6 \\
\hline 3000 & 29 & 29.3 & 32.2 & -11.0 \\
\hline 5000 & 25 & 25.0 & 27.5 & -10.0 \\
\hline 10000 & 21 & 20.4 & 22.4 & -6.67 \\
\hline 20000 & 17 & 16.9 & 18.6 & -9.41 \\
\hline 40000 & 14 & 14.0 & 15.4 & -10.0 \\
\hline
\end{tabular}

a. According to information contained in the Reference 12 response to RAI Question 480.452.

The edge of spectrum value should also bound estimated relocation time uncertainties. A high probability $(-90 \%)$ was assigned to core relocation times between 4 and $5 \mathrm{hr}$ in DOE/ID-10460 Figure 7.7. (The remainder of the distribution included a probability of $\sim 10 \%$ for core relocation times between 5 and $6 \mathrm{hr}$.) However, existing code calculations ${ }^{3,4,5}$ indicate that core relocation in an AP600 3BE transient occurs earlier. For example, both SCDAP/RELAP5 and MELCOR calculations ${ }^{3,4}$ suggest that significant amounts of core material relocate $\sim 3 \mathrm{hr}$ after shutdown. Therefore, INEEL shifted the Figure 7.7 distribution $\sim 1 \mathrm{hr}$ earlier. Using values published in the UCSB study (i.e., a decay power of $20.7 \mathrm{MW}$ at $3 \mathrm{hr}$ and a decay power of $19.2 \mathrm{MW}$ at $4 \mathrm{hr}$ ), a $1 \mathrm{hr}$ core relocation shift increases decay power by $\sim 8 \%$.

In Reference 12, Westinghouse provided arguments regarding the timing of core relocation in their response to RAI Questions $480.105,480.453$, and 480.454. In these responses, Westinghouse stated that: (1) core relocation could not occur earlier than $4 \mathrm{hr}$ after transient initiation because the reflector is massive (implying that a substantial part of the reflector must melt before core relocation), and (2) SCDAP/RELAP5 results showing core relocation at $\sim 3 \mathrm{hr}$ were not reliable because the analysis didn't include the effect of the reflector on melt progression. The SCDAP/RELAP5 code calculations do model the reflector. However, SCDAP/RELAP5 considers the potential for localized reflector failures and corresponding side-ways relocations. Specifically, at some point during asymmetric core degradation, molten materials could spread to the reflector boundary. At that time, a localized region of the reflector will be subjected to very high heat fluxes from the core side with only stagnant steam cooling on the downcomer side. SCDAP/RELAP5 calculations indicate that the reflector will melt through under those conditions in a matter of minutes. Some amount of reflector steel could be entrained following localized melt through/ablation and carried with the core debris into the lower head. However, it is also possible that the hole in the side of the reflector could be relatively small, adding only insignificant amounts of stainless steel to the debris bed. 
VESTA statistically combined distributions for decay power and relocation time with the pdf for zirconium oxidation shown in Figure 7.3 of DOE/ID-10460. Results, shown in Figure B-12, suggest that the most probable values for decay power density increase by $9 \%$ and that the edge of spectrum decay power density increases from 1.4 to $1.7 \mathrm{MW} / \mathrm{m}^{3}$.

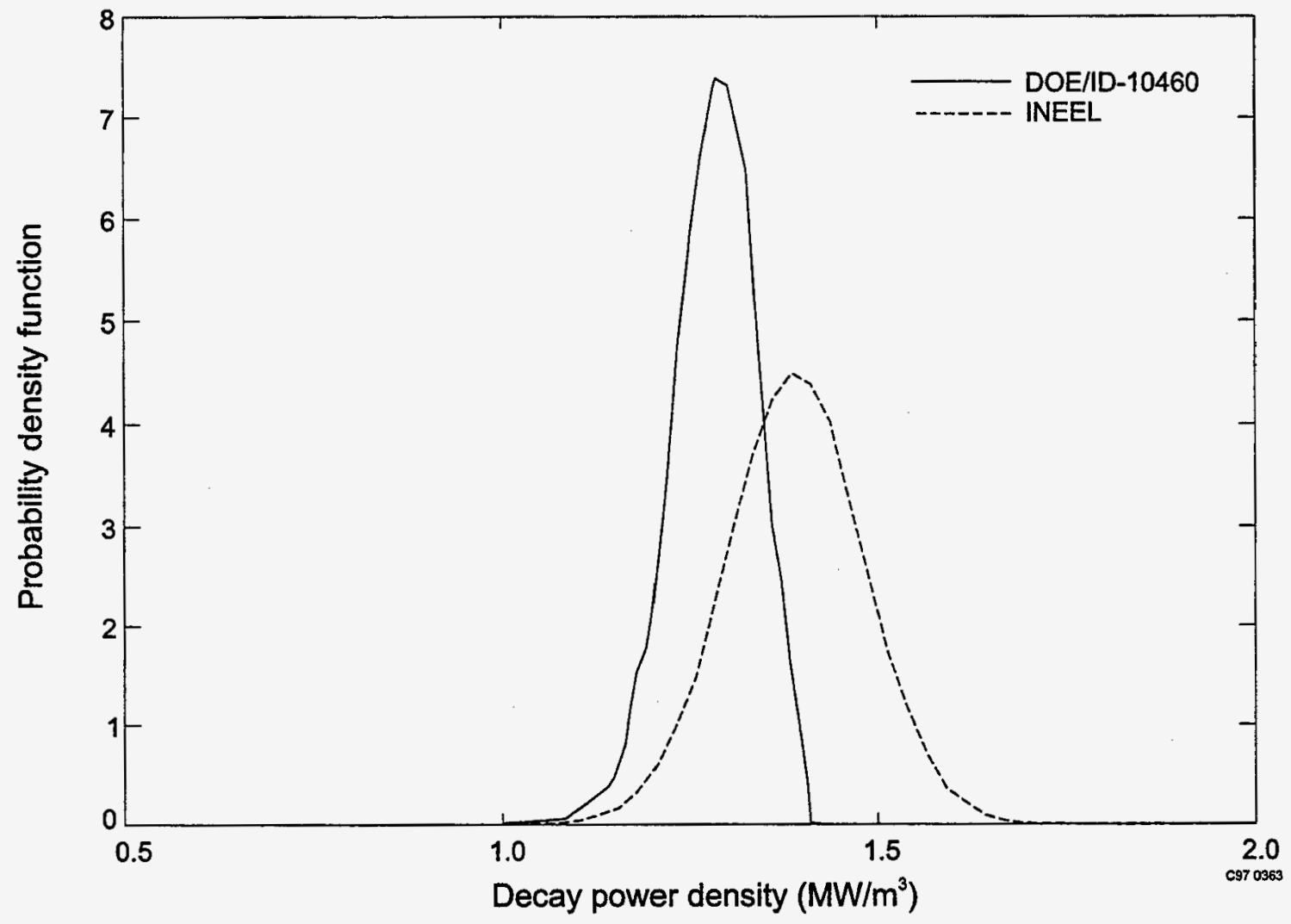

Figure B-12. Comparison of DOE/ID-10460 and INEEL pdfs for decay power density.

It is worth noting that a decay power density of $1.7 \mathrm{MW} / \mathrm{m}^{3}$ agrees with the adjusted value calculated by SCDAP/RELAP5 at the time when peak thermal loads occur on the lower head. ${ }^{3}$ (The SCDAP/ RELAP5 value was adjusted for a $+10 \%$ uncertainty in decay power and the segregation of metallics consistent with the approach used in DOE/ID-10460.) Finally, it should be noted that in an independent review of DOE/ID-10460, ${ }^{14}$ NRC-RES also concluded that the decay power density should be higher than $1.4 \mathrm{MW} / \mathrm{m}^{3}$.

\section{B.2.2 Power in Metallic Layer}

DOE/ID-10460 Approach. For the FIBS analysis, the UCSB study neglected heat sources associated with the presence of decay heat from fission products in the metal layer and any heat addition associated with oxidation or activation of the metal. In Appendix O, the UCSB study states that uranium dissolution into zirconium is a "non-confirmed hypothesis (by Powers)." However, DOE/ID-10460 Appendix R indicates that $5 \%$ to $10 \%$ of fission product decay heat may be present in the metallic layer. In Appendix $\mathrm{P}$ (Figure P.5), UCSB presents results from sensitivity studies in which various fractions of the ceramic pool's decay heat (from 0 to $50 \%$ ) was transferred to the metallic layer and the vessel. As discussed in Appendix P, even a 50\% shift wasn't adequate to "compromise integrity in the Base Case." However, 
Figure P.5 indicates that the ratio of $q^{\prime \prime}(\theta) / q^{\prime \prime}(\theta)_{C H F}$ went from 0.4 (with no power in the metallic layer) to 0.7 (with $50 \%$ of the power shifted to the metallic layer).

In the Reference 12 response to RAI Question 480.456, Westinghouse responded that there is approximately $100 \mathrm{~kg}$ of steam present in the RCS that is available for oxidation. However, Westinghouse also observed that an oxide layer will form on top of the metallic layer, noting that this oxide layer will inhibit further oxidation and transfer heat more efficiently because of its higher emissivity.

INEEL Approach. The INEEL-developed VESTA code considers several types of volumetric heat sources in the metallic layer in conjunction with uncertainties associated with other input parameters. VESTA allocates the fraction of decay heat in the metallic layer by estimating the contribution to decay heat associated with actinides and fission products that were retained in the metallic layer. INEEL determined which species were retained in the metallic layer using information in Appendix $R$, comments by Peer Reviewer Olander in Appendix V, and other pertinent references discussing the most probable chemical states of these species. ${ }^{15,47,48,49,50} \mathrm{INEEL}$ also considered the impact of energy sources due to metallic layer oxidation and structural material activation. However, INEEL neglected oxidation energy source because scoping calculations suggest that this additional energy source will only be non-negligible for small periods of time ( $<5$ minutes). Because scoping calculations suggest that the energy source associated with structural material activation isn't negligible, INEEL performed sensitivity calculations to assess the impact of this additional heat source. Additional information about the INEEL approach is provided below.

Section 2.1 describes an alternate debris configuration (Configuration $\mathrm{C}$ ) that considers the potential for uranium to dissolve into unoxidized zircaloy in the metallic layer. This dissolved uranium increases the metallic layer density and introduces volumetric heat sources associated with actinide decay heat production. VESTA allows decay heat to be separated into two contributions, decay heat associated with actinide heating, $P_{\text {decay-ACT }}\left(t_{\text {rel }}\right)$, and decay heat associated with fission products, $P_{\text {decay-FP }}\left(t_{\text {rel }}\right)$. In the INEEL calculations, this option was only invoked for Configurations A, B, and C. SCDAP/RELAP5 calculation results quantifying the fraction of decay heat associated with actinide heating weren't available for other calculations. In calculations based on the UCSB-assumed FIBS, the decay heat was based on the curve shown in DOE/DD-10460 Figure 7.1. Information in Figures 7.1 and 7.2 suggest that the UCSB study assumed that this decay heat was entirely due to fission product heating. Hence, INEEL invoked a similar assumption in calculations for the UCSB-assumed FIBS.

In Appendix R, the UCSB study presents decay heat fractions associated with various fission product release groups for the TMI-2 reactor. These decay heat fractions, which were obtained from CINDER-10 calculations, ${ }^{50}$ correspond to two different operating histories for the TMI- 2 reactor ( 96.2 effective full power days, which is the actual TMI-2 history at the time of the accident and 26,000 hours at full power). Although Appendix R acknowledges that the TMI-2 and AP600 reactors have different fuel enrichments, fuel burnup, and neutron spectrum, UCSB study authors state that these data are adequate for estimating the order of magnitude of the decay heat that may exist in the metallic layer. Of the six fission product groups identified in Appendix R, UCSB authors conclude that only the decay heat associated with the Noble Metals Group (Group 6, containing $\mathrm{Ru}, \mathrm{Mo}, \mathrm{Pd}, \mathrm{Rh}$, and $\mathrm{Tc}$ ) should be allocated to the metallic layer. In Appendix V, Peer Reviewer Olander commented that the metallic layer decay heat should also include contributions from the Tellurium Group (Group 4, containing $\mathrm{Te}$, $\mathrm{Se}$, and $\mathrm{Sb}$ ) and Rare Earth Group (Group 7, containing La, Nd, Eu, Y, Ce, Pr, Pm, Sm, Zr, Nb, etc.). Peer Reviewer Olander noted that several references indicate that tellurium is stable in the presence of zircaloy and is only released when 
the zircaloy is oxidized. Likewise, he observed that the zirconium decay heat contribution should be partitioned according to the fraction of zircaloy that is oxidized. After reviewing several references that discuss the most probable chemical state of various species, ${ }^{47,15}$ INEEL estimated the metallic layer decay heat source by considering contributions associated with all of the Noble Metal Group, all of the Tellurium Group (multiplied by the fraction of zirconium that is not oxidized), and the zirconium and niobium species of the Rare Earth Group (multiplied by the fraction of zirconium that is not oxidized). Discussions with James Sienicki, one of the authors of Appendix $R,{ }^{48}$ indicate that he concurs with INEEL's approach.

Fission product fractional decay heat contributions depend on the reactor's fuel enrichment, burnup, neutron spectrum, heatup transient, and irradiation history. INEEL investigated these sensitivities by comparing the fractional decay heat contributions for the two Appendix R TMI-2 CINDER-10 calculations with values estimated from an ORIGEN2 calculation for an AP600 fuel assembly assumed to have operated for 99,530 hours. Fractional contributions for the species and groups of interest are summarized in Table B-3. As shown in this table, the various analyses predict similar decay heat fractions for the different reactors and operating histories.

Because the AP600 operating history prior to the accident is not known and because the fractional decay heat for longer time periods are similar, INEEL estimated the decay heat associated with each species by averaging the AP600 and TMI-2 values shown in Table B-3. Specifically, TMI-2 and AP600 results were used to obtain mean values and standard deviations for the contribution of species of interest. Because the fractional decay heat contribution of each species varies with time, the fractional contributions were fit to lines with the y-intercepts and slopes indicated in Table B-3. Then, the following steps were used to estimate the decay heat present in the metallic layer.

- Select the fraction of zirconium oxidized, $\mathrm{f}_{\mathrm{ox}-\mathrm{Zr}}$, and the melt relocation time, $\mathrm{t}_{\mathrm{rel}}$.

- Find the melt relocation time, $t_{\text {Tel }}$, and the fractional decay power contribution (see Table B-3) for each group at the selected relocation time $\left[f_{\text {Group } 4}\left(t_{\text {rel }}\right), f_{\text {Group } 6}\left(t_{\text {rel }}\right), f_{\mathrm{Zr} \& ~ N b}\left(t_{\text {rel }}\right)\right]$.

- Estimate the fractional decay power in the metallic layer, $\mathrm{f}_{\text {metal }}$, by applying

$$
f_{\text {metal }}=\left(1-f_{\text {ox }-Z_{r}}\right)\left[f_{\text {Group } 4}\left(t_{\text {rel }}\right)+f_{Z_{r} \& N b}\left(t_{\text {rel }}\right)\right]+f_{\text {Group } 6}\left(t_{\text {rel }}\right)
$$

- Multiply the fission product decay power in the oxide pool, $P_{\text {decay }-F P}\left(t_{r e l}\right)$, by $\left(1-f_{\text {metal }}\right)$. Assume a metallic layer fission product decay heat source equal to $f_{\text {metal }} P_{\text {decay }-F P}\left(t_{r e l}\right)$. 
Table B-3. Fractional contributions of fission product decay heat associated with various species.

\begin{tabular}{|c|c|c|c|}
\hline Time, seconds & Group $4^{a}$ & Group $6^{b}$ & $\mathrm{Zr} \& \mathrm{Nb}$ \\
\hline \multicolumn{4}{|c|}{ TMI-2 (Actually power history; 96.2 effective full power days) } \\
\hline 7200 & 0.0440 & 0.0466 & 0.1111 \\
\hline 18,000 & 0.0273 & 0.0576 & 0.1428 \\
\hline 28,800 & 0.0267 & 0.0626 & 0.1525 \\
\hline \multicolumn{4}{|c|}{ TMI-2 (26,000 hours) } \\
\hline 7200 & 0.0477 & 0.0965 & 0.1209 \\
\hline 18,000 & 0.0316 & 0.1110 & 0.1477 \\
\hline 28,800 & 0.0300 & 0.1152 & 0.1544 \\
\hline \multicolumn{4}{|c|}{$\operatorname{AP} 600(99,530$ hours $)$} \\
\hline 7200 & 0.0481 & 0.0951 & 0.1348 \\
\hline 18,000 & 0.0321 & 0.1045 & 0.1462 \\
\hline 28,800 & 0.0305 & 0.1101 & 0.1531 \\
\hline \multicolumn{4}{|l|}{ Mean Values } \\
\hline 7200 & 0.0466 & 0.0777 & 0.1223 \\
\hline 18,000 & 0.0307 & 0.0910 & 0.1456 \\
\hline 28,800 & 0.0291 & 0.0960 & 0.1533 \\
\hline \multicolumn{4}{|c|}{ Parameters for estimating between 7,200 and 18,000 seconds } \\
\hline Slope of Line, $\mathrm{s}^{-1}$ & $-1.473 \times 10^{-6}$ & $1.236 \times 10^{-6}$ & $2.154 \times 10^{-6}$ \\
\hline Y-Intercept & 0.0572 & 0.0688 & 0.1068 \\
\hline Standard Deviation & 0.0025 & 0.0284 & 0.0070 \\
\hline \multicolumn{4}{|c|}{ Parameters for estimating between 18,000 and 28,880 seconds } \\
\hline Slope of Line, $\mathrm{s}^{-1}$ & $-1.502 \times 10^{-7}$ & $4.572 \times 10^{-7}$ & $7.197 \times 10^{-7}$ \\
\hline Y-Intercept & 0.0334 & 0.0828 & 0.1326 \\
\hline Standard Deviation & 0.0025 & 0.0284 & 0.0070 \\
\hline
\end{tabular}

a. Tellurium group; includes $\mathrm{Te}, \mathrm{Se}, \mathrm{Sb}$.

b. Noble Metals, includes $\mathrm{Ru}, \mathrm{Mo}, \mathrm{Pd}, \mathrm{Rh}, \mathrm{Tc}$. 


\section{B.3 Material Property Assumptions}

\section{B.3.1 Ceramic Pool and Crust}

\section{B.3.1.1 Specific Heat Capacity}

DOE/ID-10460 Approach. In Section 7, the UCSB study indicates that material properties were assumed to be normally distributed with the mean and $2 \sigma$ values corresponding to values provided in Appendix $L$. However, the Table 7-1 entry for specific heat indicates that point estimate values for the specific heat of $\mathrm{UO}_{2}(485 \mathrm{~J} / \mathrm{kgK})$ and $\mathrm{ZrO}_{2}(815 \mathrm{~J} / \mathrm{kgK})$ were averaged based on the mass fraction of these materials in the ceramic pool. Although Appendix $\mathrm{L}$ cites uncertainty distributions for $\mathrm{UO}_{2}$ and $\mathrm{ZrO}_{2}$ specific heats, Table 7-1 suggests that the UCSB study neglected uncertainties in the specific heat for $\mathrm{UO}_{2}$ and $\mathrm{ZrO}_{2}$ and uncertainties associated with mass averaging.

INEEL Approach. VESTA simulates uncertainties in individual specific heats and uncertainties associated with mass averaging by applying the following relationship.

$c_{p-p}=\left(f_{m-\mathrm{UO}_{2}} c_{\mathrm{p}_{-\mathrm{UO}_{2}}}+f_{\mathrm{m}-\mathrm{ZrO}_{2}} c_{\mathrm{p}_{-\mathrm{ZrO}}}\right) \mathrm{e}^{\mathrm{C}_{\mathrm{c}_{\mathrm{p}}-\mathrm{p}}}$

where

$\begin{array}{lll}\mathrm{c}_{\mathrm{p}-\mathrm{p}} & = & \text { Ceramic pool melt specific heat capacity, } \mathrm{J} / \mathrm{kg}-\mathrm{K} \\ \mathrm{c}_{\mathrm{p}_{-\mathrm{UO} \mathrm{O}_{2}}} & =\quad \mathrm{UO}_{2} \text { specific heat capacity, J/kg-K } \\ \mathrm{c}_{\mathrm{P}_{-\mathrm{ZrO}} \mathrm{O}_{2}} & =\quad \mathrm{ZrO}_{2} \text { specific heat capacity, J/kg-K } \\ \mathrm{f}_{\mathrm{m}-\mathrm{UO}_{2}}= & \mathrm{UO}_{2} \text { mass fraction in the molten pool } \\ \mathrm{f}_{\mathrm{m}-\mathrm{ZrO}_{2}}= & \mathrm{ZrO}_{2} \text { mass fraction in the molten pool } \\ \mathrm{C}_{\mathrm{c}_{\mathrm{p}}-\mathrm{p}}= & \text { Uncertainty parameter for estimating molten ceramic specific pool heat. }\end{array}$

This experimentally validated approach is consistent with the approach recommended in the MATPRO materials library. ${ }^{27}$ Based on information in Appendix L and Reference 27, INEEL assumed that $c_{\mathrm{p}_{-} \mathrm{vO}_{2}}$ has a median value of $485 \mathrm{~J} / \mathrm{kg}-\mathrm{K}$ and a standard deviation of $5 \mathrm{~J} / \mathrm{kg}-\mathrm{K}$ and that $\mathrm{c}_{\mathrm{p}_{-\mathrm{zr} \mathrm{O}_{2}}}$ has a median value of $815 \mathrm{~J} / \mathrm{kg}-\mathrm{K}$ and a standard deviation of $14 \mathrm{~J} / \mathrm{kg}-\mathrm{K}$. Note that the median values for these specific heats are consistent with the values cited in DOE/ID-10460 Table 7-1. Based on information in Reference 27, INEEL assumed that $C_{p-p}$ has a median value of 0.00 and a standard deviation of 0.10 .

\section{B.3.1.2 Thermal Conductivity}

DOE/LD-10460 Approach. In Section 7, the authors state that material properties were assumed to be normally distributed with the mean and $2 \sigma$ values corresponding to values provided in Appendix $L$. However, it appears that the UCSB study assumed thermal conductivity uncertainty distributions that correspond to a specific melt composition. For the crust in the oxide pool, Table 7-1 indicates that $2.8 \pm$ $0.4 \mathrm{~W} / \mathrm{m}-\mathrm{K}$ was assumed as the mean and $2 \sigma$ values; whereas Appendix L presents a range of uncertainty distributions $(2.0 \pm 0.3 \mathrm{~W} / \mathrm{m}-\mathrm{K}$ to $6.2 \pm 0.5 \mathrm{~W} / \mathrm{m}-\mathrm{K})$ that depend on crust composition and temperature. 
For the molten oxide pool, Table 7-1 suggests that $5.3 \mathrm{~W} / \mathrm{m}-\mathrm{K}$ was assumed as the mean and that 1.6 was assumed as $2 \sigma$; whereas Appendix $L$ presents a range of $1 \sigma$ uncertainty distributions $(4.7 \pm 1.7 \mathrm{~W} / \mathrm{m}-\mathrm{K}$ to $5.3 \pm 1.6 \mathrm{~W} / \mathrm{m}-\mathrm{K})$ that depend on the molten pool's composition, assumed eutectic temperature, and estimation method.

INEEL Approach. In VESTA, INEEL applied the approach and uncertainties presented in Appendix L. Appendix $L$ presents several possible approaches for estimating the thermal conductivity of a mixed oxide crust and molten pool. It is determined in Appendix $L$ that the various approaches yield similar values. Hence, INEEL applied the first approach described in Appendix L, which is from the SCDAP/RELAP5 MATPRO library, ${ }^{27}$ because it can easily be incorporated into VESTA (note that Appendix $L$ authors also appear to prefer this approach in their discussion about corium crust thermal conductivity).

Specifically, VESTA estimates oxide thermal conductivity using the following relationship:

$$
k_{o x}(T)=\left[f_{N-U_{2}} k_{o x-U O_{2}}(T)+f_{N-Z_{0} O_{2}} k_{o x-Z_{r} O_{2}}(T)-0.4 f_{N-U O_{2}} f_{N-Z_{0} O_{2}}\right] e^{C_{k_{o x}}}
$$

where

$$
\begin{aligned}
& \mathbf{k}_{\mathrm{ox}}(\mathrm{T})=\text { Temperature-dependent ceramic material thermal conductivity, } \mathrm{W} / \mathrm{mK} \\
& \mathrm{k}_{\mathrm{ox}-\mathrm{UO}_{2}}(\mathrm{~T})=\quad \text { Temperature-dependent thermal conductivity for } \mathrm{UO}_{2}, \mathrm{~W} / \mathrm{mK} \\
& \mathrm{k}_{\mathrm{ox}-\mathrm{ZrO}_{2}}(\mathrm{~T})=\quad \text { Temperature-dependent thermal conductivity for } \mathrm{ZrO}_{2}, \mathrm{~W} / \mathrm{mK} \\
& \mathrm{f}_{\mathrm{N}-\mathrm{UO}_{2}}=\quad \text { Mole fraction of } \mathrm{UO}_{2} \\
& \mathrm{f}_{\mathrm{N}-\mathrm{ZrO}_{2}}=\quad \text { Mole fraction of } \mathrm{ZrO}_{2} \\
& \mathrm{C}_{\mathrm{k}_{\mathrm{ox}}}=\text { Uncertainty parameter for estimating ceramic material thermal conductivity }
\end{aligned}
$$

When the above relationship is applied to the molten ceramic material in the pool, the subscript, (ox), is replaced with p; when this relationship is applied to the ceramic crust, the subscript, ox, is replaced with cr. Based on information in Appendix L, INEEL assumed a median value of 0.00 and a standard deviation of 0.05 for $C_{k-p}$ and $C_{k-c r}$. Reference 27 and Appendix $L$ recommend the temperature-dependent relationships for solid $\mathrm{UO}_{2}$ and $\mathrm{ZrO}_{2}$ solid thermal conductivity shown in Figures B-13 and B-14. For molten $\mathrm{ZrO}_{2}$, INEEL concurs with Appendix $\mathrm{L}$ that the thermal conductivity may be assumed to have a normal distribution with a median value of $3.25 \mathrm{~W} / \mathrm{mK}$ and a standard error of $1.85 \mathrm{~W} / \mathrm{mK}$. As acknowledged in Appendix $\mathrm{L}$, there are no direct measurements to support this value. For molten $\mathrm{UO}_{2}$, INEEL also concurs with Appendix $L$ that a mean value of $5.6 \mathrm{~W} / \mathrm{mK}$ with a standard error of $1.1 \mathrm{~W} / \mathrm{mK}$ may be assumed. This value is based on a numerical analysis, which evaluated several experimental test results using the THTB (Transient Heat Transfer, Version B) code. ${ }^{51}$ The THTB analysis resulted in a much lower estimate for the thermal conductivity of molten $\mathrm{UO}_{2}$ than the $11.5 \mathrm{~W} / \mathrm{mK}$ measured by $\mathrm{Kim}$, et al. $^{52}$ (the MATPRO library currently assumes the Kim, et al. value).

\section{B.3.1.3 Melting Temperature}

DOE/ID-10460 Approach. DOE/DD-10460 Figure 6.2 illustrates how the melting point of $(\mathrm{U}, \mathrm{Zr}) \mathrm{O}_{2}$ compounds vary with composition, and information in Appendix $L$ suggests that the melting temperature of the ceramic material should be estimated as a function of composition. However, Table 7-1 suggests 


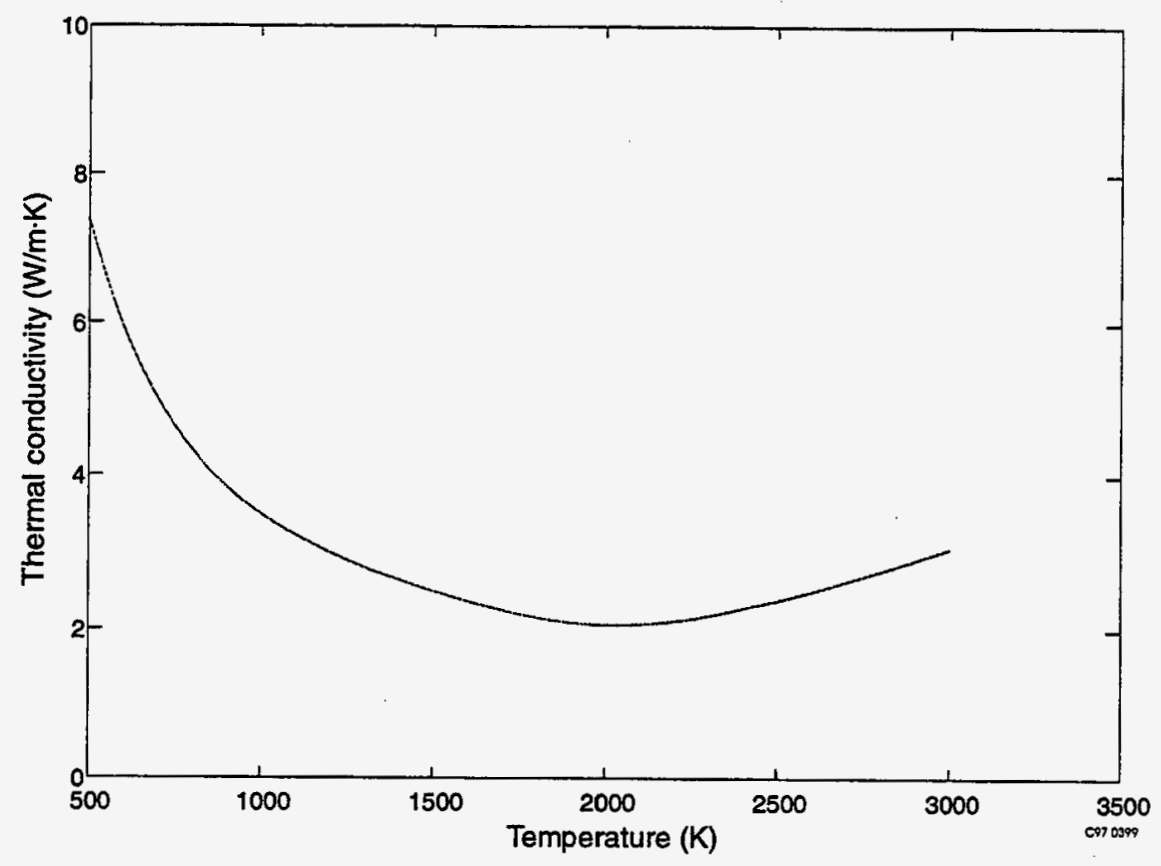

Figure B-13. Temperature-dependent thermal conductivity of solid $0.98 \mathrm{TD} \mathrm{UO}_{2}$ (Reference 27).

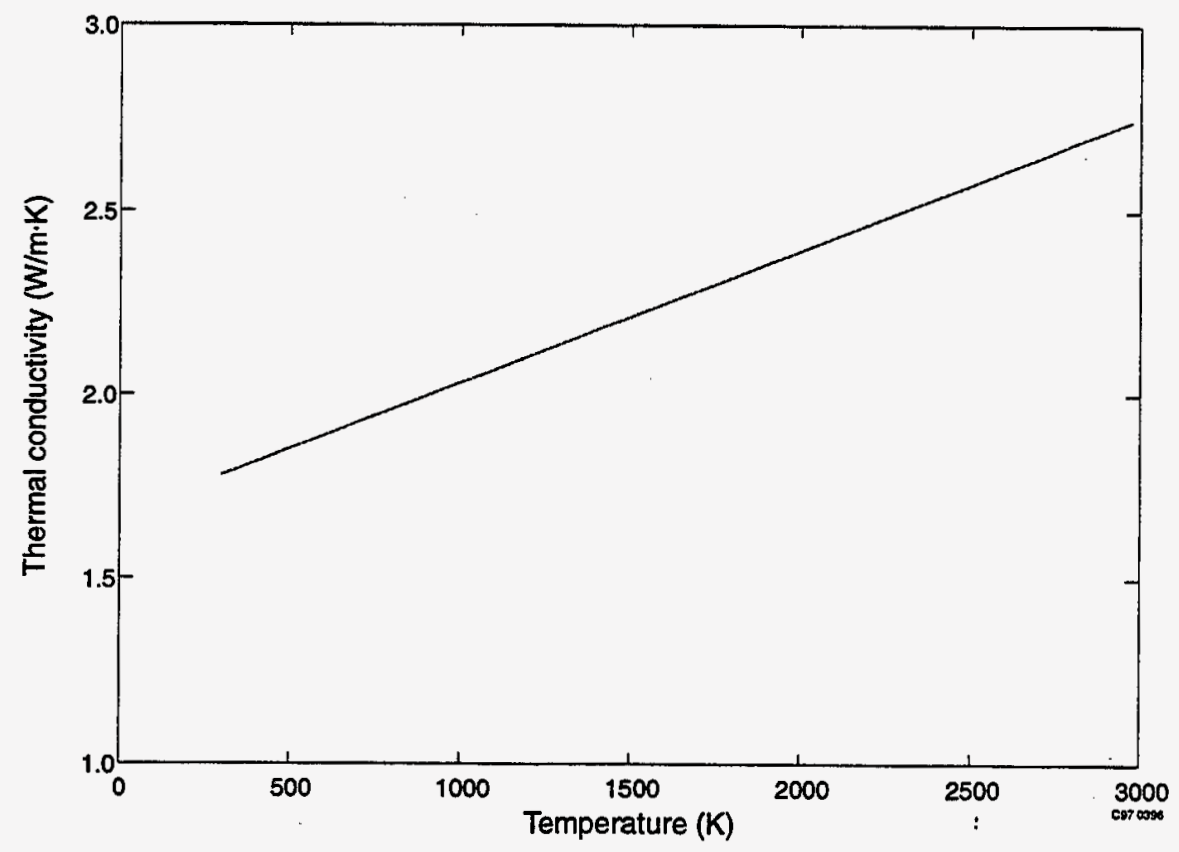

Figure B-14. Temperature-dependent thermal conductivity of solid $\mathrm{ZrO}_{2}$ (Reference 27). 
that the $(\mathrm{U}, \mathrm{Zr}) \mathrm{O}_{2}$ melting temperature was assumed as $2973 \mathrm{~K}$, irrespective of composition. The UCSB study also neglected any uncertainties in melting temperature.

INEEL Approach. The MATPRO materials library ${ }^{27}$ assumes solidus and liquidus temperatures for $(\mathrm{U}, \mathrm{Zr}) \mathrm{O}_{2}$ using the phase diagram recommended by Romberger et al. ${ }^{53}$ As shown in Figure B-15, these temperatures remain fairly constant for the $(\mathrm{U}, \mathrm{Zr}) \mathrm{O}_{2}$ compositions expected in a ceramic pool forming in an AP600 vessel lower head (between 0.10 and $0.85 \mathrm{ZrO}_{2}$ ). Hence, INEEL assumed a single melting temperature, $2850 \mathrm{~K}$, rather than the $2973 \mathrm{~K}$ value cited in Table 7-1. This higher temperature is consistent with the values shown in Figure B-15. Because no uncertainties in melting temperature were cited in either the UCSB study or the MATPRO reference manual, INEEL neglected uncertainties in $(\mathrm{U}, \mathrm{Zr}) \mathrm{O}_{2}$ compound melting temperatures.

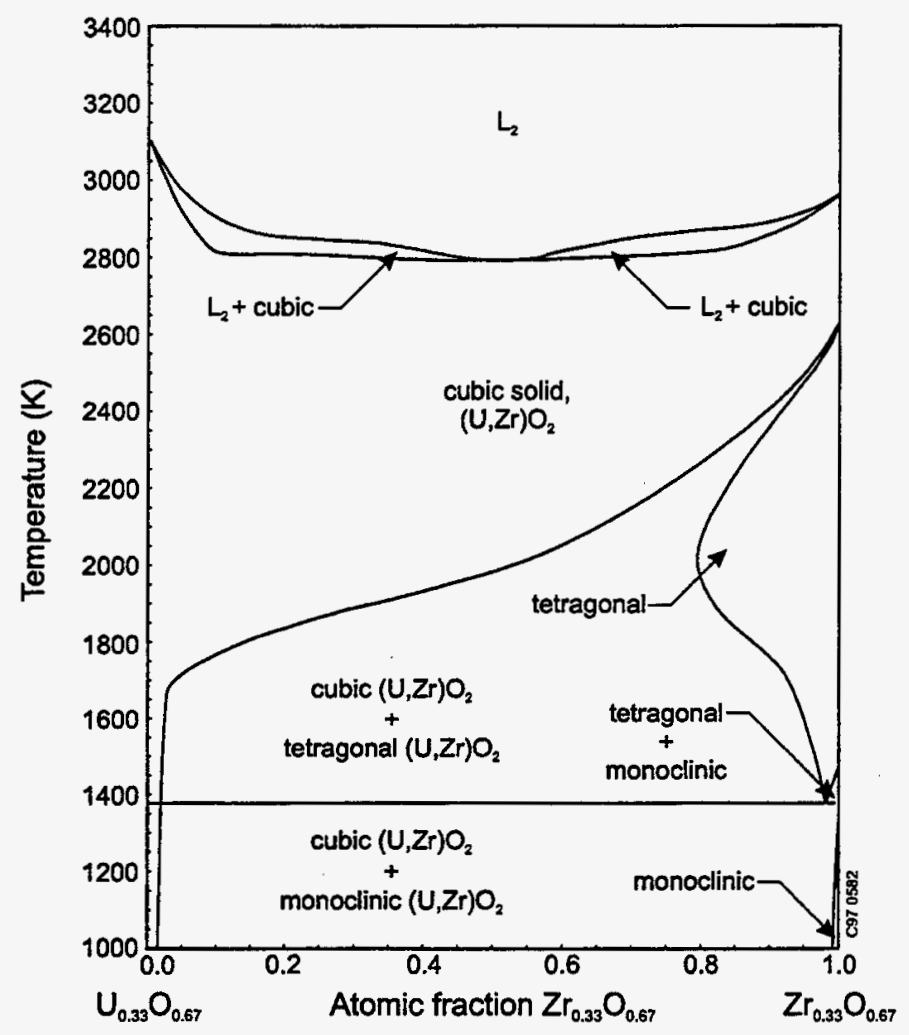

Figure B-15. Quasi binary phase diagram for $\mathrm{ZrO}_{2}-\mathrm{UO}_{2}$ system (Reference 53).

\section{B.3.1.4 Volumetric Coefficient of Thermal Expansion}

DOE/ID-10460 Approach. In Section 7, the authors state that material properties were assumed to be normally distributed with the mean and $2 \sigma$ values corresponding to values provided in Appendix $L$. In both Section 7 and Appendix L, the authors indicate that the volumetric coefficient of thermal expansion for material in the molten pool should be assumed as $1.05 \times 10^{-4} \mathrm{~K}^{-1}$. However, there appears to be a discrepancy between the uncertainty values cited in Section 7 and Appendix L. In Section 7, the volumetric coefficient of thermal expansion is assumed to have an uncertainty distribution characterized by $2 \sigma=0.12 \times 10^{-4} \mathrm{~K}^{-1}$ whereas in Appendix $\mathrm{L}$, the volumetric coefficient of thermal expansion is assumed to have an uncertainty distribution characterized by $\sigma=0.12 \times 10^{-4} \mathrm{~K}^{-1}$. 
INEEL Approach. In VESTA calculations, INEEL assumed uncertainty distributions recommended in Appendix L. Namely, INEEL assumed that the pool volumetric coefficient of thermal expansion has a normal distribution with a median value of $1.05 \times 10^{-4} \mathrm{~K}^{-1}$ and a standard deviation of $0.12 \times 10^{-4} \mathrm{~K}^{-1}$.

\section{B.3.1.5 Density}

DOE/ID-10460 Approach. Table 7-1 of DOE/ID-10460 indicates that the ceramic pool melt density was estimated based on the $\mathrm{UO}_{2}$ and $\mathrm{ZrO}_{2}$ volume fractions and the density of $\mathrm{UO}_{2}$ and $\mathrm{ZrO}_{2}$ at their liquidus temperatures. Although Appendix $\mathrm{L}$ recommends uncertainties for estimating the density of molten ceramic material, Table 7-1 suggests that the UCSB analysis neglected these uncertainties.

INEEL Approach. VESTA applies the approach recommended in Appendix L for estimating the ceramic pool density. Namely, VESTA estimates the ceramic pool melt density using $\mathrm{UO}_{2}$ and $\mathrm{ZrO}_{2}$ volume fractions with the following equation:

$\rho_{\mathrm{p}}=\left(\mathrm{f}_{\mathrm{v}-\mathrm{UO}_{2}} \rho_{\mathrm{p}-\mathrm{UO}}+\mathrm{f}_{\mathrm{v}-\mathrm{ZrO}_{2}} \rho_{\mathrm{p}-\mathrm{ZrO} \mathrm{O}_{2}}\right) \mathrm{e}^{\mathrm{c}_{\mathrm{p}-\mathrm{p}}}$

where

$$
\begin{array}{ll}
f_{\mathrm{v}-\mathrm{UO}_{2}}= & \quad \mathrm{UO}_{2} \text { volume fraction in the molten pool } \\
f_{\mathrm{v}-\mathrm{ZrO}}= & \mathrm{ZrO}_{2} \text { volume fraction in the molten pool } \\
\rho_{\mathrm{p}-\mathrm{UO}_{2}}= & \quad \text { Molten } \mathrm{UO}_{2} \text { density in the ceramic pool, } \mathrm{kg} / \mathrm{m}^{3} \\
\rho_{\mathrm{p}-\mathrm{ZrO}}= & \quad \text { Molten } \mathrm{ZrO}_{2} \text { density in the ceramic pool, } \mathrm{kg} / \mathrm{m}^{3} \\
\mathrm{C}_{\mathrm{p}-\mathrm{p}}= & \text { Uncertainty parameter for estimating the density of the ceramic pool. }
\end{array}
$$

Although the density of molten $\mathrm{UO}_{2}$ decreases with temperature, these decreases are small for temperatures of interest. ${ }^{54}$ Hence, INEEL evaluated each constituent's density at its melting temperature. The uncertainty specifications in Appendix $\mathrm{L}$ are somewhat ambiguous. Based on information in Reference 27, INEEL assumed that the parameter, $C_{p-p}$, has a normal distribution with a median value of 0.00 and a standard deviation of 0.02 .

\section{B.3.2 Metallic Layer}

\section{B.3.2.1 Specific Heat Capacity}

DOE/ID-10460 Approach. In Section 7, the authors state that material properties were assumed to be normally distributed with the mean and $2 \sigma$ values corresponding to values provided in Appendix $L$. However, the Table 7-1 entry for specific heat indicates that point estimate values for the specific heat of $\mathrm{Zr}(458 \mathrm{~J} / \mathrm{kgK})$ and $\mathrm{Fe}^{\mathrm{a}}(835 \mathrm{~J} / \mathrm{kgK})$ were averaged based on their metallic layer mass fractions. Although Appendix $L$ cites mean values and standard deviations for $\mathrm{Zr}$ and $\mathrm{Fe}$ specific heats, Table 7-1 suggests that metallic layer specific heat uncertainties were neglected.

a. The UCSB study assumed that iron properties could be used to estimate the properties for stainless steel in the metallic layer. 
INEEL Approach. VESTA estimates uncertainties in individual specific heats and uncertainties associated with mass averaging using the following relationship.

$$
c_{p-1}=\left(f_{m-Z r} c_{p_{-Z r}}+f_{m-s s} c_{p_{-s s}}+f_{m-U} c_{p_{-v}}\right) e^{c_{c_{p}-1}}
$$

where

$$
\begin{array}{lll}
\mathrm{c}_{\mathrm{p}-1} & = & \text { Metallic layer melt specific heat capacity, J/kg-K } \\
\mathrm{c}_{\mathrm{p}_{-\mathrm{Zr}}} & = & \text { Zirconium specific heat capacity, J/kg-K } \\
\mathrm{c}_{\mathrm{p}_{-\mathrm{U}}} & = & \text { Uranium specific heat capacity, J/kg-K } \\
\mathrm{c}_{\mathrm{p}_{-\mathrm{ss}}} & = & \text { Stainless steel specific heat capacity, J/kg-K} \\
\mathrm{f}_{\mathrm{m}-\mathrm{Zr}} & = & \text { Zirconium mass fraction in the metallic layer } \\
\mathrm{f}_{\mathrm{m}-\mathrm{ss}} & = & \text { Stainless steel mass fraction in the metallic layer } \\
\mathrm{f}_{\mathrm{m}-\mathrm{U}} & = & \text { Uranium mass fraction in the metallic layer } \\
\mathrm{C}_{\mathrm{c}_{\mathrm{p}-1}}= & \text { Uncertainty parameter for estimating the metallic layer specific heat. }
\end{array}
$$

Although an additional term was added to consider cases where uranium dissolves into the metallic layer, this approach is consistent with the approach suggested in Appendix L. Based on information in Appendix $L$ and References 27 and 55, INEEL assumed that $c_{\mathrm{p}_{-2 r}}$ has a normal uncertainty distribution with a median value of $458 \mathrm{~J} / \mathrm{kg}-\mathrm{K}$ and a standard deviation of $14 \mathrm{~J} / \mathrm{kg}-\mathrm{K}$, that $\mathrm{c}_{\mathrm{p}_{-s \mathrm{~s}}}$ has a normal uncertainty distribution with a median value of $835 \mathrm{~J} / \mathrm{kg}-\mathrm{K}$ and a standard deviation of $25 \mathrm{~J} / \mathrm{kg}-\mathrm{K}$, and that $c_{\mathrm{p}_{-\mathrm{u}}}$ has a normal distribution with a median value of $157 \mathrm{~J} / \mathrm{kg}-\mathrm{K}$ and a standard deviation of $8 \mathrm{~J} / \mathrm{kg}-\mathrm{K}$. Note that the median values for these specific heats are consistent with the values cited in Table 7-1 of the UCSB study. Based on information in Appendix L and Reference 27, INEEL assumed that the uncertainty parameter, $\mathrm{C}_{\mathrm{c}_{\mathrm{p}}-1}$, has a normal distribution with a median value of 0.00 and a standard deviation of 0.10 .

\section{B.3.2.2 Thermal Conductivity}

DOE/ID-10460 Approach. In Section 7, the authors state that material properties were assumed to be normally distributed with the mean and $2 \sigma$ values corresponding to values provided in Appendix $L$. However, it appears that the UCSB study assumed values and uncertainties that correspond to a specific melt composition. For the metallic layer, Table $7-1$ indicates that $25 \pm 6.3 \mathrm{~W} / \mathrm{m}-\mathrm{K}$ was assumed as the mean and $2 \sigma$ values; whereas Appendix L presents a range of $1 \sigma$ uncertainty distributions $(24.8 \pm 6.3 \mathrm{~W} /$ $\mathrm{m}-\mathrm{K}$ to $32.8 \pm 50 \mathrm{~W} / \mathrm{m}-\mathrm{K}$ ) that depend on the composition and estimation method.

INEEL Approach. For a two-component mixture, VESTA applies the Filippov equation presented in Appendix $L$ because it has been extensively tested on many types of two-component mixtures. For a metallic layer containing stainless steel and zircaloy, this equation may be written as: 


$$
k_{1}=\left(f_{m-Z r} k_{1-Z r}+f_{m-s s} k_{1-s s}-0.72 f_{m-Z r} f_{m-s s}\left|k_{1-Z r}-k_{1-s s}\right|\right) e^{C_{k-1}}
$$

where

$$
\begin{aligned}
& \mathrm{k}_{1} \quad=\quad \text { Metallic layer melt thermal conductivity, } \mathrm{W} / \mathrm{mK} \\
& \mathrm{f}_{\mathrm{m}-\mathrm{ss}} \quad=\quad \text { Stainless steel mass fraction in the metallic layer } \\
& \mathrm{f}_{\mathrm{m}-\mathrm{Zr}} \quad=\quad \text { Zirconium mass fraction in the metallic layer } \\
& \mathrm{k}_{1-\mathrm{ss}}=\quad \text { Thermal conductivity for stainless steel in the metallic layer, } \mathrm{W} / \mathrm{mK} \\
& \mathrm{k}_{\mathrm{l}-\mathrm{Zr}}=\text { Thermal conductivity for zirconium in the metallic layer, } \mathrm{W} / \mathrm{mK} \\
& \mathrm{C}_{\mathrm{k}-1}=\quad \text { Uncertainty parameter for estimating metallic layer thermal conductivity }
\end{aligned}
$$

For three-component mixtures, VESTA estimates thermal conductivity using the following approach recommended by Reference 27

$k_{1}=\left[f_{N-Z r} k_{1-Z r}+f_{N-s s} k_{1-s s}+f_{N-U} k_{1-U}\right] e^{C_{k-1}}$

where

$$
\begin{array}{lll}
\mathbf{k}_{1} & = & \text { Metallic layer melt thermal conductivity, W/mK } \\
f_{N-s s} & = & \text { Stainless steel mole fraction in the metallic layer } \\
f_{N-Z r}= & \text { Zirconium mole fraction in the metallic layer } \\
f_{N-U}= & \text { Uranium mole fraction in the metallic layer } \\
k_{1-s s}= & \text { Thermal conductivity for stainless steel in the metallic layer, W/mK } \\
k_{1-Z r}= & \text { Thermal conductivity for zirconium in the metallic layer, W/mK } \\
k_{1-U}= & \text { Thermal conductivity for uranium in the metallic layer, W/mK } \\
C_{k-1}= & \text { Uncertainty parameter for estimating metallic layer thermal conductivity }
\end{array}
$$

For molten zirconium, INEEL assumed the thermal conductivity distribution recommended by Reference 27 and Appendix L (a normal uncertainty distribution with a mean value of $36 \mathrm{~W} / \mathrm{mK}$ and a standard error of $5 \mathrm{~W} / \mathrm{mK}$ ). For molten stainless steel, INEEL assumed the distribution recommended by Appendix L (a normal distribution with a median value of $24.1 \mathrm{~W} / \mathrm{mK}$ and a standard deviation of $4.8 \mathrm{~W} / \mathrm{mK}$ ). For molten uranium, INEEL assumed the thermal conductivity distribution recommended by Reference 55 (a normal uncertainty distribution with a mean value of $49 \mathrm{~W} / \mathrm{mK}$ and a standard error of $4.9 \mathrm{~W} / \mathrm{mK}$ ). Based on information in Appendix L, INEEL assumed that $\mathrm{C}_{\mathrm{k}-1}$ has a normal uncertainty distribution with a median value of 0.00 and a standard deviation of 0.05 . 


\section{B.3.2.3 Volumetric Coefficient of Thermal Expansion}

DOE/ID-10460 Approach. In Section 7, the authors state that material properties were assumed to be normally distributed with the mean and $2 \sigma$ values corresponding to values provided in Appendix $\mathrm{L}$. In Section 7, the authors indicate that the volumetric coefficient of thermal expansion for the metallic layer should be assumed as $1.1 \times 10^{-4} \mathrm{~K}^{-1}$ with an uncertainty distribution characterized by $2 \sigma$ equal to $0.18 \mathrm{x}$ $10^{-4} \mathrm{~K}^{-1}$; whereas in Appendix $\mathrm{L}$, the authors indicate that the volumetric coefficient of thermal expansion should be based on the volume fractions of materials in the metallic layer.

INEEL Approach. Although an additional term was added to consider cases where uranium dissolves into the metallic layer, VESTA applies an approach consistent with the approach recommended in Appendix L. Namely, VESTA estimates the volumetric coefficient of thermal expansion using the following equation

$$
\beta_{1}=\left(f_{v-Z r} \beta_{Z r}+f_{v-s s} \beta_{s s}+f_{v-U} \beta_{U}\right) e^{c_{\beta-1}}
$$

where

$$
\begin{aligned}
& \beta_{1}=\text { Molten metallic layer volumetric coefficient of thermal expansion, } \mathrm{K}^{-1} \\
& \beta_{\mathrm{Zr}}=\text { Zirconium volumetric coefficient of thermal expansion, } \mathrm{K}^{-1} \\
& \beta_{\mathrm{ss}}=\text { Stainless steel volumetric coefficient of thermal expansion, } \mathrm{K}^{-1} \\
& \beta_{\mathrm{U}}=\quad \text { Uranium volumetric coefficient of thermal expansion, } \mathrm{K}^{-1} \\
& \mathrm{f}_{\mathrm{v}-\mathrm{Zr}}=\text { Zirconium volume fraction in the metallic layer } \\
& \mathrm{f}_{\mathrm{v}-\mathrm{ss}}=\quad \text { Stainless steel volume fraction in the metallic layer } \\
& \mathrm{f}_{\mathrm{v}-\mathrm{U}}=\quad \text { Uranium volume fraction in the metallic layer } \\
& \mathrm{C}_{\beta-1}=\quad \text { Uncertainty parameter for estimating the metallic layer coefficient of thermal } \\
& \text { expansion. }
\end{aligned}
$$

Based on information in Appendix L, References 27 and 55, INEEL assumed that $\beta_{\mathrm{ss}}$ has a normal distribution with a mean value of $1.20 \times 10^{-4} \mathrm{~K}^{-1}$ and a standard deviation of $0.17 \times 10^{-4} \mathrm{~K}^{-1}, \beta_{\mathrm{Zr}}$ has a normal distribution with a mean value of $0.54 \times 10^{-4} \mathrm{~K}^{-1}$ and a standard deviation of $0.11 \times 10^{-4} \mathrm{~K}^{-1}, \beta_{\mathrm{U}}$ has a normal distribution with a mean value of $8.61 \times 10^{-4} \mathrm{~K}^{-1}$ and a standard deviation of $0.60 \times 10^{-4} \mathrm{~K}^{-1}$, and the uncertainty parameter, $\mathrm{C}_{\beta-1}$, has a normal distribution with a median value of 0.00 and a standard deviation of 0.02 .

\section{B.3.3 Emissivity}

DOE/ID-10460 Approach. Table 7-1 of DOE/ID-10460 indicates that a value of 0.45 was assumed with no uncertainties. As documented in Appendix I of DOE/ID-10460, this value was based on UCSB measurements performed with carbon steel material inductively heated in an inert environment. In the Reference 12 response to RAI Question 480.449, Westinghouse states that the emissivity was considered 
as an "intangible in the ROAAM analysis" and that the "lowest possible value" was assumed. Westinghouse also notes that a sensitivity analyses was performed to assess the impact of lower emissivity assumptions. However, no uncertainty analysis was performed that incorporated the effects of emissivity uncertainty. Although UCSB authors cite one reference in which the emissivity of molten iron was measured as 0.4 , no attempt was made to determine the impact of differences in melt composition (iron versus stainless steel) or compare UCSB emissivity data with other data.

INEEL Approach. Several references ${ }^{56,57}$ report considerably lower emissivities for molten zirconium (ranging from 0.29 to 0.33 ). Although no data could be found for molten stainless steel, Reference 55 summarizes several sources of emissivity data for unoxidized solid stainless steel and zirconium. Figure B16 compares data from References 56 through 55 with data provided in Appendix I of the UCSB study. As shown in this figure, the emissivity of the carbon steel material measured in the UCSB study is typically higher than emissivities measured for stainless steel or zirconium. Higher emissivities may have been measured at low temperatures because the UCSB tests used oxidized material, which many references cite as having emissivities ranging between 0.5 and 0.9 . Furthermore, the UCSB study acknowledges that the higher emissivities measured for the test with zirconium at higher temperatures may be due to oxide being retained in the melt. Because all of the UCSB study measurements appear to be higher than available references for stainless steel and zirconium, INEEL estimated the emissivity using the zirconium and stainless steel data shown in Figure B-16 (out of the six groups of data points in this figure, the four nonDOE/ID-10460 groups of data points).

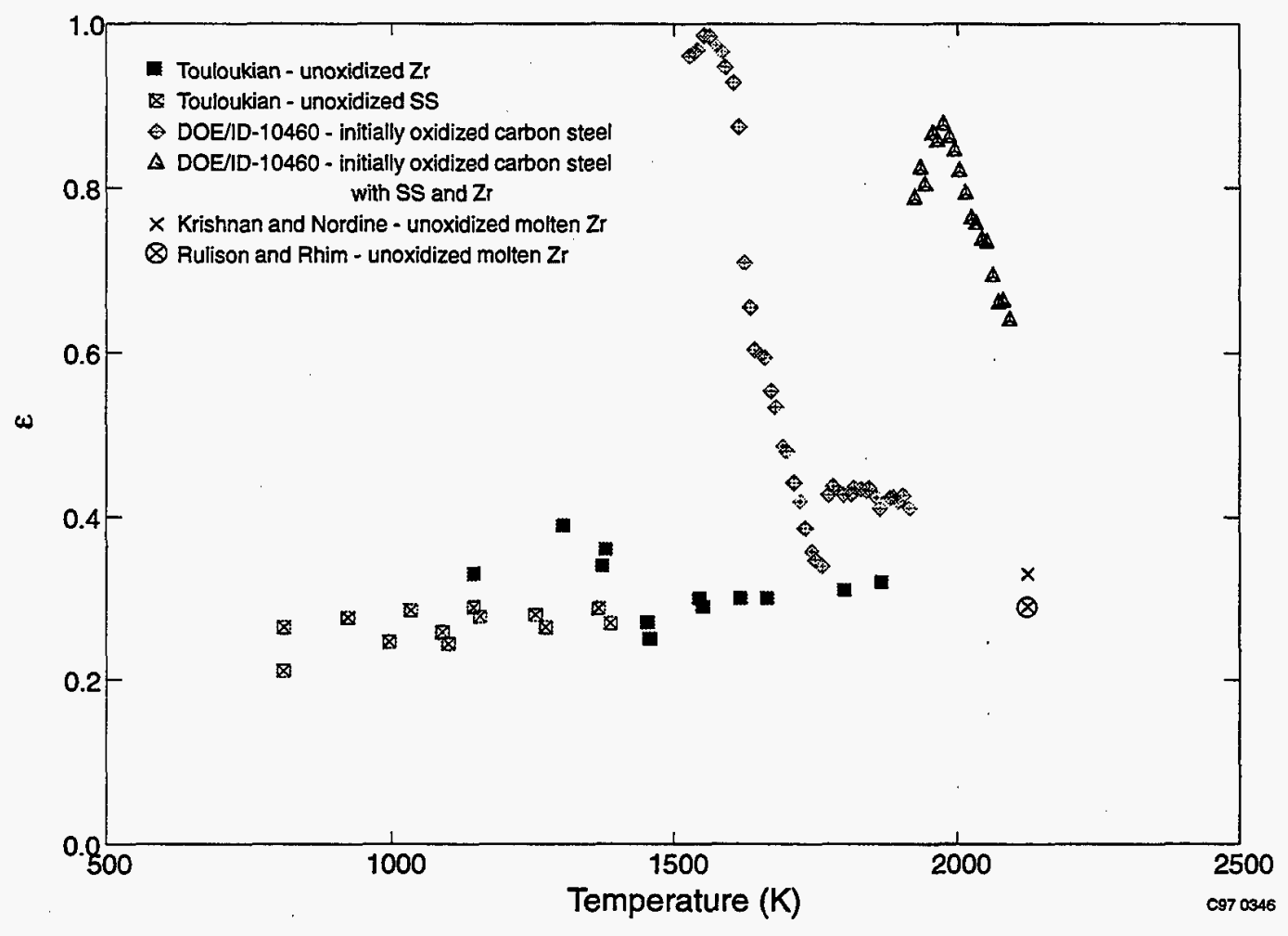

Figure B-16. Comparison of UCSB emissivity data with unoxidized stainless steel and zirconium data. 
There is considerable scatter in the unoxidized stainless steel and zirconium data in Figure B-16. Although stainless steel emissivities typically appear somewhat lower than zirconium emissivities, these differences are comparable to scatter in the data. Furthermore, there appears to be no distinct temperature dependence in emissivity. In the case of zirconium, there isn't even a distinct difference between emissivities measured above and below melting. Discussions with Donald Hagrman, a major contributor to the SCDAP/RELAP5 material properties package (MATPRO), ${ }^{58}$ indicate that there are no experimentally validated relationships available for estimating the emissivity of a compound. Therefore, estimated the emissivity of the molten metallic layer by considering all of the unoxidized stainless steel and zirconium data in Figure B-16. Assuming that these data are normally distributed, this approach yields a median value of 0.29 with a standard deviation of 0.04 . Note that this uncertainty encompasses some of the lower emissivity values measured in the UCSB study.

As discussed in Section 3.3.1, calculations for Configuration A required that an emissivity be assumed for cases where steam may be present in the reactor vessel. Although the upper surface of the metallic layer may be oxidized in such conditions, radiation heat transfer from this surface would be reduced because of the thick cloud of vapor in the RCS. Hence, Configuration A calculations assumed an emissivity distribution with a mean value of 0.2 and a standard deviation of 0.1 .

\section{B.3.3.1 Density}

DOE/ID-10460 Approach. Table 7-1 of DOE/ID-10460 indicates that the melt density was estimated using the volume fractions of Zircaloy (assumed to be primarily Zirconium) and Iron (Fe) in the metallic layer and the density of $\mathrm{Zr}$ and $\mathrm{Fe}$ at their liquidus temperatures. Appendix $\mathrm{L}$ recommends that median values and uncertainties for the metallic layer density be estimated using $\mathrm{Zr}$ and $\mathrm{Fe}$ densities and associated uncertainties. However, Table 7-1 suggests that the UCSB analysis neglected Appendix Lrecommended uncertainties.

INEEL Approach. Although an additional term was added to consider cases where uranium dissolves into the metallic layer, VESTA applies an approach consistent with the approach recommended in Appendix $L$ for estimating the density of material in the metallic layer. Specifically, VESTA applies the following equation to predict an uncertainty distribution for the linear superposition of these densities.

$\rho_{1}=\left(f_{v-Z r} \rho_{1-Z r}+f_{v-s s} \rho_{1-s s}+f_{v-u} \rho_{1-U}\right) e^{C_{p-1}}$

where

$\begin{array}{lll}f_{v-Z r} & = & \text { Zirconium volume fraction in the metallic layer } \\ f_{v-s s} & = & \text { Stainless steel volume fraction in the metallic layer } \\ f_{v-U}= & \text { Uranium volume fraction in the metallic layer } \\ \rho_{1-S s}= & \text { Stainless steel density, } \mathrm{kg} / \mathrm{m}^{3} \\ \rho_{1-\mathrm{Zr}}= & \text { Zirconium melt density, } \mathrm{kg} / \mathrm{m}^{3} \\ \rho_{1-\mathrm{U}}= & \text { Uranium melt density, } \mathrm{kg} / \mathrm{m}^{3} \\ \mathrm{C}_{\mathrm{p}-1}= & \text { Uncertainty parameter for estimating the metallic layer density. }\end{array}$


Because density data for zircaloy, stainless steel, and uranium above their liquidus temperature are limited and no data were found for the density of a $\mathrm{SS} / \mathrm{Zr} / \mathrm{U}$ or a SS/Zr mixture, INEEL evaluated the density of each constituent at its melting temperature. Based on information in Appendix L and References 27 and 55 , INEEL assumed that $\rho_{1-Z_{r}}$ is normally distributed with a median of $6,130 \mathrm{~kg} / \mathrm{m}^{3}$ and a standard deviation of $180 \mathrm{~kg} / \mathrm{m}^{3}, \rho_{1-s s}$ is normally distributed with a median of $7,020 \mathrm{~kg} / \mathrm{m}^{3}$ and a standard deviation of $90 \mathrm{~kg} / \mathrm{m}^{3}$, and $\rho_{1-U}$ is normally distributed with a median of $17,500 \mathrm{~kg} / \mathrm{m}^{3}$ and a standard deviation of $1,750 \mathrm{~kg} / \mathrm{m}^{3}$. Median values for the stainless steel and zirconium densities are consistent with the values cited in DOE/ID-10460 Table 7-1. Based on Appendix L, INEEL assumed that the uncertainty parameter, $C_{p-1}$, is normally distributed with a median of 0.00 and a standard deviation of 0.02 .

\section{B.3.4 Vessel Wall}

\section{B.3.4.1 Thermal Conductivity}

DOE/ID-10460 Approach. Table 7-1 of the UCSB study implies that a single value, $32 \mathrm{~W} / \mathrm{m}^{2} \mathrm{~K}$, was assumed for the vessel wall effective thermal conductivity with no uncertainty. The Westinghouse response to RAI 480.448 notes that this effective thermal conductivity was obtained from Figure L. 3 (by considering a vessel wall with temperatures ranging from 130 to $1300{ }^{\circ} \mathrm{C}$ ). Hence, $32 \mathrm{~W} / \mathrm{m}^{2} \mathrm{~K}$ should only be assumed as the vessel effective thermal conductivity at locations where the vessel inner surface is in contact with either ceramic debris or molten metal and the vessel outer surface is cooled by water. The UCSB model also requires that an effective vessel thermal conductivity be estimated for much cooler locations above the metallic layer, where heat transfer from the upper plenum structures is radiated (see Equation 6.12). Although the UCSB study uses the same variable name, $\mathrm{k}_{\mathrm{w}}$, for the bulk-average vessel wall thermal conductivity at both locations, INEEL calculations suggests that a higher thermal conductivity, approximately $41 \mathrm{~W} / \mathrm{m}^{2} \mathrm{~K}$, was applied for the effective vessel thermal conductivity at cooler locations (i.e., in Equation 6.12). This higher thermal conductivity is consistent with values shown in Figure L.3 over the range of temperatures predicted for the vessel wall at locations above relocated ceramic or metallic material $\left(130\right.$ to $\left.260^{\circ} \mathrm{C}\right)$.

As discussed in Appendix L, vessel steel thermal conductivities were estimated using SA508 low temperature data and iron high temperature data. Information in the UCSB study and discussions with Westinghouse indicate that either SA533B1 or SA508 steel will be used for the AP600 reactor vessel (most operating reactors use SA533B1 vessels). Appendix $L$ recommends uncertainties for vessel thermal conductivities, but information in Section 7 and the response to RAI 480.448 suggests that no uncertainties were considered for the vessel thermal conductivity in the UCSB calculations.

INEEL Approach. INEEL assumed two distinct values for the effective vessel wall thermal conductivity: one for hotter locations in contact with the ceramic debris/molten metallic layer and one for cooler locations significantly above the relocated melt (for modeling radiation heat transfer from upper plenum structures). Using SA533B1 thermal conductivity data ${ }^{59}$ and values shown in Figure L.3, INEEL estimated that the vessel thermal conductivity was $32 \pm 2 \mathrm{~W} / \mathrm{m}^{2} \mathrm{~K}$ at locations near the relocated melt and $41 \pm 1 \mathrm{~W} / \mathrm{m}^{2} \mathrm{~K}$ at locations above the relocated melt. Uncertainties in these values are based on Appendix L. Namely, INEEL assumed that the data were normally distributed with 95th-percent uncertainty limits of $4 \%(2 \sigma / \mu=4 \%)$ for temperatures between 150 and $1300 \mathrm{~K}$ and $10 \%(2 \sigma / \mu=10 \%)$ for temperatures above $1300 \mathrm{~K}$. 


\section{B.3.4.2 Melting Temperature}

DOE/ID-10460 Approach. The UCSB FIBS assumes study all of the core plate, all of the reflector, lower portions of the core barrel, and all of the lower internal structures have melted. Hence, the UCSB study presumed that it is only possible to obtain metallic layers with high iron mass fractions. The $1600 \mathrm{~K}$ vessel wall melting temperature assumed in the UCSB study corresponds to the minimum liquidus temperature for iron/zirconium eutectics that have high (more than 55\%) iron mass fractions (see Figure B-17). ${ }^{60}$ The UCSB study neglected uncertainties in this temperature. In the Reference 12 response to RAI Question 480.448 , Westinghouse reiterated their position that it is not possible to get zirconium rich compositions. However, no experimental data were supplied to support this position.

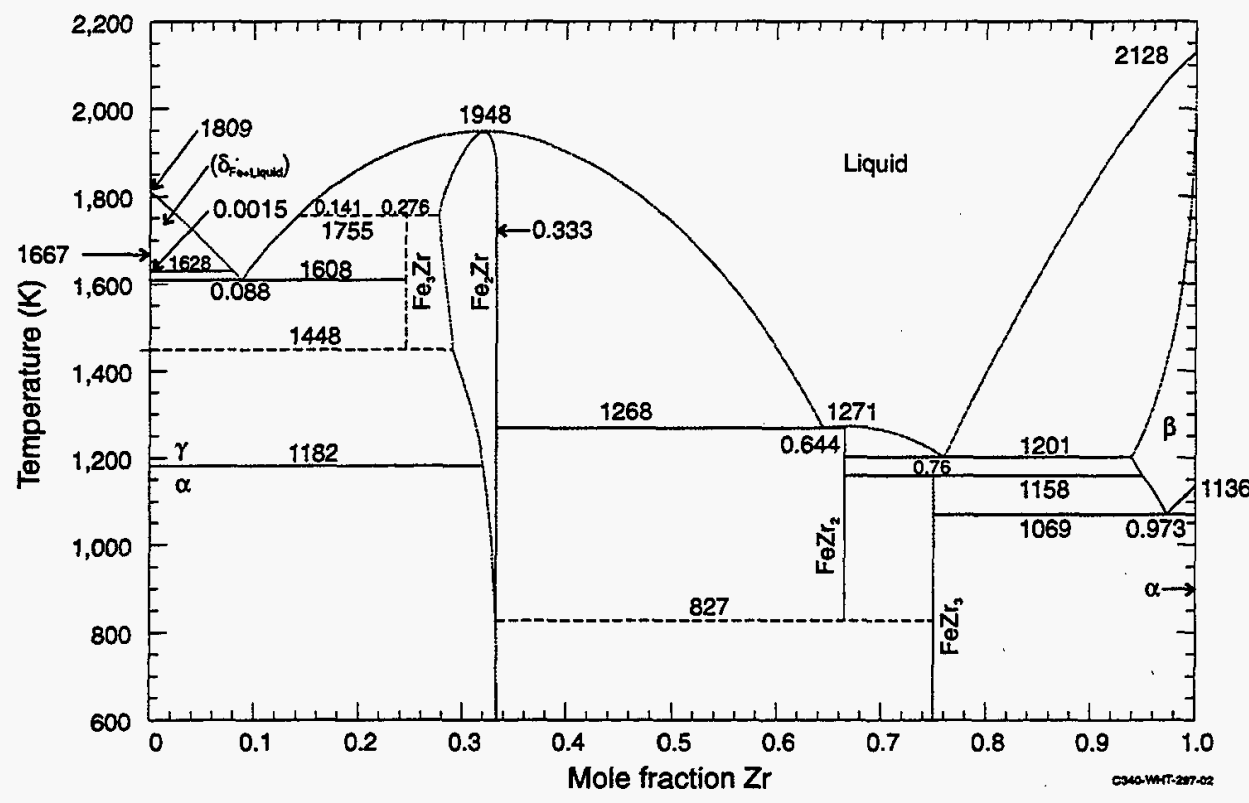

Figure B-17. Iron-zirconium phase diagram.

INEEL Approach. VESTA considers melt compositions that may occur prior to the UCSB-assumed FIBS. SCDAP/RELAP5-predicted melt compositions suggest that a broader melting temperature range ( 1400 to $1900 \mathrm{~K}$ ) should be considered. The SCDAP/RELAP5 calculations consider time-dependent relocations that occur as a result of localized reflector melting and sideways relocation of molten core materials. These calculations considered time periods before the coolant in the lower head has boiled off (prior to 12,720 seconds). In light of the fact that asymmetries may occur during core melt, that stagnation points may develop in the molten metallic layer, and that there are uncertainties in SCDAP/RELAP5 calculations, VESTA considers the entire range of liquidus temperatures shown on the iron/zirconium phase diagram ( 1200 to $2100 \mathrm{~K}$ ) by simply picking the temperature that corresponds to the mole fraction of zirconium in the metallic layer. Applying Peer Reviewer Olander's recommendations (DOE/ID-10460 Appendix T), VESTA estimates the vessel wall melting temperature by applying the following steps:

- Calculate the metallic layer zirconium mole fraction for the assumed mass of unoxidized zirconium and structural steel. 
- In the metallic layer, select the inner vessel wall temperature (for locations where the vessel steel is predicted to melt) based on the mole fraction of zirconium in the metallic layer and Figure B-17.

- In the ceramic pool, assume the inner vessel wall temperature (for locations where the vessel steel is predicted to melt) as $1809 \mathrm{~K}$ (corresponding to $100 \%$ iron in Figure B-17).

The above approach was not only applied to two-component, stainless steel and zirconium metallic layers, but also to three-component metallic layers containing dissolved uranium. Although it is recognized that the presence of dissolved uranium could impact the vessel melting temperature, information in Reference 67 suggests that impact was minimal for the mole fractions of dissolved uranium considered.

\section{B.3.5 Upper Plenum Structures}

\section{B.3.5.1 Thermal Conductivity}

DOE/D-10460 Approach. Although the UCSB study did not document what upper plenum structure thermal conductivity was assumed, the response to RAI 480.965 indicates that a value of $30 \mathrm{~W} / \mathrm{m}^{2} \mathrm{~K}$ was assumed with no uncertainties. Their response implies that the UCSB-assumed thermal conductivity was based on properties shown in Figure L.3.

INEEL Approach. INEEL estimated the thermal conductivity of the upper plenum steel structures using temperature-dependent information for stainless steel. Using stainless steel information in Reference 61, INEEL implemented the following relationship into VESTA for predicting the uncertainty distribution for the upper plenum structures' temperature-dependent thermal conductivity.

$\mathrm{k}_{\mathrm{s}}\left(\overline{\mathrm{T}}_{\mathrm{s}}\right)=\left(1.4154 \times 10^{-2} \overline{\mathrm{T}}_{\mathrm{s}}+9.9214\right) \mathrm{e}^{\mathrm{C}_{\mathrm{k}-\mathrm{s}}}$

where

$$
\begin{array}{lll}
\mathrm{k}_{\mathrm{s}}\left(\overline{\mathrm{T}}_{\mathrm{s}}\right)= & \text { Upper plenum structures thermal conductivity, W/mK. } \\
\overline{\mathrm{T}}_{\mathrm{s}} & = & \text { Upper plenum structures average temperature }\left(0.5 \mathrm{~T}_{\mathrm{s}-\mathrm{i}}+0.5 \mathrm{~T}_{\mathrm{s}-\mathrm{o}}\right), \mathrm{K} . \\
\mathrm{C}_{\mathrm{k}-\mathrm{s}}= & \begin{array}{l}
\text { Uncertainty parameter for estimating upper plenum structure's thermal } \\
\text { conductivity. }
\end{array}
\end{array}
$$

Based on information in Reference 61, INEEL assumed that the uncertainty parameter, $\mathrm{C}_{\mathrm{k}-\mathrm{s}}$, has a normal distribution with a median value of 0.00 and a standard deviation of 0.05 .

\section{B.3.5.2 Emissivity}

DOE/ID-10460 Approach. In Section 7, the UCSB study indicates that an upper plenum structure emissivity of 0.8 was assumed. Because of the large areas involved, the UCSB study concluded that emissivity uncertainties may be neglected.

INEEL Approach. Based on oxidized stainless steel data, ${ }^{55}$ INEEL assumed that the upper plenum structure emissivity has a normal distribution with a mean value of 0.85 and a standard deviation of 0.03 $(\sigma=0.03)$. 


\section{Appendix C - Listing of Input}

The main report discusses results for several debris configurations: the UCSB-assumed FIBS and three alternate configurations that were based on masses predicted by SCDAP/RELAP5 and peer reviewer comments (Configurations $\mathrm{A}, \mathrm{B}$, and $\mathrm{C}$ of Section 2.1.2). This appendix lists input assumed for each configuration. Table C-1 compares input values used by UCSB (based on information in the UCSB study and responses to RAIs) and by INEEL for analyzing the UCSB-assumed FIBS. The UCSB input was used in the benchmark calculations reported in Appendix D. Table C-2 through Table C-4 list which Table C-1 INEEL input assumptions were modified for analyzing Configurations A through $\mathrm{C}$. Variables in these tables are defined in the Nomenclature of this report.

Table C-1. Comparison of INEEL and UCSB input uncertainty distributions.

\begin{tabular}{|c|c|c|c|c|}
\hline \multirow{2}{*}{ Variable } & \multicolumn{2}{|c|}{ UCSB-assumed FIBS } & \multicolumn{2}{|c|}{ INEEL Requantification of UCSB-assumed FIBS } \\
\hline & Median Value & Distribution & Median Value & Distribution \\
\hline $\mathrm{c}_{\mathrm{p}_{-\mathrm{ss}}}, \mathrm{J} / \mathrm{kg}-\mathrm{K}$ & 835 & Point estimate & 835 & $\begin{array}{l}\text { Normal } \\
\sigma=25\end{array}$ \\
\hline $\mathrm{c}_{\mathrm{P}_{-\mathrm{UO}}}, \mathrm{J} / \mathrm{kg}-\mathrm{K}$ & 485 & Point estimate & 485 & $\begin{array}{l}\text { Normal } \\
\sigma=5\end{array}$ \\
\hline$c_{P_{-U}}, J / k g-K$ & NA & $\widehat{N A}$ & 157 & $\begin{array}{l}\text { Normal } \\
\sigma=8\end{array}$ \\
\hline$c_{P_{-Z r}}, J / k g-K$ & 458 & Point estimate & 458 & $\begin{array}{l}\text { Normal } \\
\sigma=14\end{array}$ \\
\hline$c_{\mathrm{p}_{-\mathrm{ZrO}} \mathrm{O}_{2}}, \mathrm{~J} / \mathrm{kg}-\mathrm{K}$ & 815 & Point estimate & 815 & $\begin{array}{l}\text { Normal } \\
\sigma=16\end{array}$ \\
\hline $\mathrm{f}_{\mathrm{ACT}}\left(\mathrm{t}_{\mathrm{rel}}\right)^{\mathrm{a}}$ & $\mathrm{NA}$ & NA & NA & NA \\
\hline$f_{o x-U}$ & $\mathrm{NA}$ & NA & 1.000 & Point estimate \\
\hline$f_{o x-z r}$ & 0.5 & Figure 7.3 & 0.5 & Figure 7.3 \\
\hline$f_{s s}(1)$ & NA & $\mathrm{NA}$ & 0.000 & Point estimate \\
\hline$f_{s s}(2)$ & NA & NA & 1.000 & Point estimate \\
\hline$f_{U}(1)$ & NA & $\mathrm{NA}$ & 0.000 & Point estimate \\
\hline$f_{U}(2)$ & NA & NA & 0.000 & Point estimate \\
\hline $\mathrm{f}_{\mathrm{UO}_{2}}(1)$ & NA & NA & 1.000 & Point estimate \\
\hline $\mathrm{f}_{\mathrm{UO}_{2}}(2)$ & NA & $\widehat{N A}$ & 0.000 & Point estimate \\
\hline$f_{Z_{r}}(1)$ & NA & NA & 0.000 & Point estimate \\
\hline $\mathrm{f}_{\mathrm{zr}_{\mathrm{r}}(2)}$ & NA & NA & 1.000 & Point estimate \\
\hline $\mathrm{f}_{\mathrm{ZrO}_{2}}(1)$ & NA & NA & 1.000 & Point estimate \\
\hline $\mathrm{f}_{\mathrm{ZrO}_{2}}(2)$ & NA & NA & 0.000 & Point estimate \\
\hline $\mathrm{k}_{\mathrm{cr}}, \mathrm{W} / \mathrm{mK}$ & 2.8 & $\begin{array}{l}\text { Normal } \\
2 \sigma=0.4\end{array}$ & NA & NA \\
\hline
\end{tabular}


Table C-1. Comparison of INEEL and UCSB input uncertainty distributions. (continued)

\begin{tabular}{|c|c|c|c|c|}
\hline \multirow{2}{*}{ Variable } & \multicolumn{2}{|c|}{ UCSB-assumed FIBS } & \multicolumn{2}{|c|}{ INEEL Requantification of UCSB-assumed FIBS } \\
\hline & Median Value & Distribution & Median Value & Distribution \\
\hline $\mathrm{k}_{\mathrm{cr}-\mathrm{UO}_{2}}, \mathrm{~W} / \mathrm{mK}$ & $\overline{\mathrm{NA}}$ & NA & 2.41 & $\begin{array}{l}\text { Normal } \\
\sigma=0.2\end{array}$ \\
\hline $\mathrm{k}_{\mathrm{cr}-\mathrm{ZrO}_{2}}, \mathrm{~W} / \mathrm{mK}$ & NA & NA & 2.48 & $\begin{array}{l}\text { Normal } \\
\sigma=0.25\end{array}$ \\
\hline $\mathrm{k}_{1}, \mathrm{~W} / \mathrm{mK}$ & 25 & $\begin{array}{l}\text { Normal } \\
2 \sigma=6.3\end{array}$ & $\mathrm{NA}$ & $\mathrm{NA}$ \\
\hline $\mathrm{k}_{1-\mathrm{ss}}, \mathrm{W} / \mathrm{mK}$ & NA & NA & 24.1 & $\begin{array}{l}\text { Normal } \\
\sigma=4.8\end{array}$ \\
\hline $\mathrm{k}_{\mathrm{l}-\mathrm{U}}, \mathrm{W} / \mathrm{mK}$ & NA & NA & 49.0 & $\begin{array}{l}\text { Normal } \\
\sigma=4.9\end{array}$ \\
\hline $\mathrm{k}_{1-\mathrm{Zr}}, \mathrm{W} / \mathrm{mK}$ & NA & NA & 36 & $\begin{array}{l}\text { Normal } \\
\sigma=5\end{array}$ \\
\hline $\mathrm{k}_{\mathrm{p}}, \mathrm{W} / \mathrm{mK}$ & 5.3 & $\begin{array}{l}\text { Normal } \\
2 \sigma=1.6\end{array}$ & NA & $\mathrm{NA}$ \\
\hline $\mathrm{k}_{\mathrm{p}-\mathrm{UO}_{2}}, \mathrm{~W} / \mathrm{mK}$ & $\mathrm{NA}$ & NA & 5.6 & $\begin{array}{l}\text { Normal } \\
\sigma=1.1\end{array}$ \\
\hline $\mathrm{k}_{\mathrm{p}-\mathrm{ZrO}_{2}}, \mathrm{~W} / \mathrm{mK}$ & NA & NA & 3.25 & $\begin{array}{l}\text { Normal } \\
\sigma=1.85\end{array}$ \\
\hline $\mathrm{k}_{\mathrm{s}}\left(\overline{\mathrm{T}}_{\mathrm{s}}\right), \mathrm{W} / \mathrm{mK}$ & 30 & Point estimate & $\begin{array}{l}\text { Temperature-dependent } \\
\text { values [Equation (A-113)] }\end{array}$ & $\begin{array}{l}\text { Uncertainty treated in } \\
\mathrm{C}_{\mathrm{k}-\mathrm{s}} \text {. }\end{array}$ \\
\hline $\mathrm{k}_{\mathrm{ves}-\mathrm{c}}, \mathrm{W} / \mathrm{mK}$ & $41^{b}$ & Point estimate & 41 & $\begin{array}{l}\text { Normal } \\
\sigma=1\end{array}$ \\
\hline $\mathrm{k}_{\text {ves }-\mathrm{h}}, \mathrm{W} / \mathrm{mK}$ & 32 & Point estimate & 32 & $\begin{array}{l}\text { Normal } \\
\sigma=2\end{array}$ \\
\hline$t_{\text {rel }}, s$ & $1.62 \times 10^{4}$ & Figure 7.7 & $1.26 \times 10^{4}$ & $\begin{array}{l}\text { Figure } 7.7 \text { values at one } \\
\text { hour earlier }\end{array}$ \\
\hline \multicolumn{5}{|c|}{ For $0 \leq t_{\mathrm{rel}}<18,000$ seconds } \\
\hline $\mathrm{B}_{\text {Group } 4}\left(\mathrm{t}_{\text {rel }}\right)$ & NA & $\mathrm{NA}$ & 0.0572 & $\begin{array}{l}\sigma \times \text { Student's } t(6 \text { d.f }) \\
\sigma=0.0025\end{array}$ \\
\hline $\mathrm{B}_{\text {Group } 6}\left(\mathrm{t}_{\text {rel }}\right)$ & $\mathrm{NA}$ & NA & 0.0688 & $\begin{array}{l}\sigma \text { x Student's } t(6 \text { d.f. }) \\
\sigma=0.0284\end{array}$ \\
\hline $\mathrm{B}_{\mathrm{Zr} \& N \mathrm{~N}}\left(\mathrm{t}_{\mathrm{rel}}\right)$ & NA & $\mathrm{NA}$ & 0.1068 & $\begin{array}{l}\sigma \times \text { Student's } t(6 \text { d.f. }) \\
\sigma=0.0070\end{array}$ \\
\hline $\mathrm{M}_{\text {Group } 4}\left(\mathrm{t}_{\mathrm{rel}}\right), \mathrm{s}^{-1}$ & NA & NA & $-1.473 \times 10^{-6}$ & \multirow{3}{*}{$\begin{array}{l}\text { Uncertainty treated in B } \\
\text { parameters }\end{array}$} \\
\hline $\mathrm{M}_{\text {Group 6 }}\left(\mathrm{t}_{\text {rel }}\right), \mathrm{s}^{-1}$ & $\mathrm{NA}$ & NA & $1.236 \times 10^{-6}$ & \\
\hline$M_{\mathrm{Zr} \& \mathrm{Nb}}\left(\mathrm{t}_{\mathrm{rel}}\right), \mathrm{s}^{-1}$ & NA & NA & $2.154 \times 10^{-6}$ & \\
\hline \multicolumn{5}{|c|}{ For 8,000 seconds $\leq \mathrm{t}_{\mathrm{rel}}<28,880$ second } \\
\hline $\mathrm{B}_{\text {Group } 4}\left(\mathrm{t}_{\mathrm{rel}}\right)$ & NA & NA & 0.0334 & $\begin{array}{l}\sigma \times \text { Student's } t \text { (6 d.f.) } \\
\sigma=0.0025\end{array}$ \\
\hline
\end{tabular}


Table C-1. Comparison of INEEL and UCSB input uncertainty distributions. (continued)

\begin{tabular}{|c|c|c|c|c|}
\hline \multirow{2}{*}{ Variable } & \multicolumn{2}{|c|}{ UCSB-assumed FIBS } & \multicolumn{2}{|c|}{ INEEL Requantification of UCSB-assumed FIBS } \\
\hline & Median Value & Distribution & Median Value & Distribution \\
\hline$B_{\text {Group } 6}\left(t_{\text {rel }}\right)$ & NA & $\overline{\mathrm{NA}}$ & 0.0828 & $\begin{array}{l}\sigma \text { x Student's } t \text { (6 d.f.) } \\
\sigma=0.0284\end{array}$ \\
\hline $\mathrm{B}_{\mathrm{Zr} \& \mathrm{Nb}}\left(\mathrm{t}_{\mathrm{rel}}\right)$ & $\mathrm{NA}$ & $\mathrm{NA}$ & 0.1326 & $\begin{array}{l}\sigma \times \text { Student's } t(6 \text { d.f. }) \\
\sigma=0.0070\end{array}$ \\
\hline $\mathrm{M}_{\text {Group } 4}\left(\mathrm{t}_{\mathrm{rel}}\right), \mathrm{s}^{-1}$ & NA & $\mathrm{NA}$ & $-1.502 \times 10^{-7}$ & \multirow{3}{*}{$\begin{array}{l}\text { Uncertainty treated in } \mathrm{B} \\
\text { parameters }\end{array}$} \\
\hline $\mathrm{M}_{\text {Group } 6}\left(\mathrm{t}_{\mathrm{rel}}\right), \mathrm{s}^{-1}$ & NA & NA & $4.572 \times 10^{-7}$ & \\
\hline $\mathrm{M}_{\mathrm{Zr} \& \mathrm{Nb}}\left(\mathrm{t}_{\mathrm{rel}}\right), \mathrm{s}^{-1}$ & NA & NA & $7.197 \times 10^{-7}$ & \\
\hline$\overline{C_{\text {bot }}}$ & NA & $\mathrm{NA}$ & 0.000 & $\begin{array}{l}\sigma \times \text { Student's } t(6 \text { d.f. }) \\
\sigma=0.088\end{array}$ \\
\hline $\mathrm{C}_{\mathrm{CHF}}$ & NA & NA & 0.0 & $\begin{array}{l}\text { Normal } \\
\sigma=0.05\end{array}$ \\
\hline$\overline{C_{\text {dec }}}$ & NA & $\mathrm{NA}$ & 0.000 & $\begin{array}{l}\text { Normal } \\
\sigma=0.05\end{array}$ \\
\hline$\overline{\mathrm{C}_{\mathrm{k}-\mathrm{cr}}}$ & NA & $\mathrm{NA}$ & 0.000 & $\begin{array}{l}\text { Normal } \\
\sigma=0.05\end{array}$ \\
\hline$\overline{C_{k-p}}$ & NA & NA & 0.000 & $\begin{array}{l}\text { Normal } \\
\sigma=0.05\end{array}$ \\
\hline$\overline{C_{k-1}}$ & NA & NA & 0.000 & $\begin{array}{l}\text { Normal } \\
\sigma=0.05\end{array}$ \\
\hline$\overline{C_{k-s}}$ & NA & $\mathrm{NA}$ & 0.000 & $\begin{array}{l}\text { Normal } \\
\sigma=0.05\end{array}$ \\
\hline$\overline{C_{\text {local }}}$ & NA & NA & 0.00 & $\begin{array}{l}\text { Normal } \\
\sigma=0.12\end{array}$ \\
\hline $\mathrm{C}_{\mathrm{c}_{\mathrm{p}}-1}$ & NA & $\overline{N A}$ & 0.000 & $\begin{array}{l}\text { Normal } \\
\sigma=0.10\end{array}$ \\
\hline$\overline{C_{c_{p}-p}}$ & NA & $\mathrm{NA}$ & 0.000 & $\begin{array}{l}\text { Normal } \\
\sigma=0.10\end{array}$ \\
\hline$\overline{C_{\text {side }}}$ & NA & NA & 0.000 & $\begin{array}{l}\sigma \times \text { Student's } t \text { (3 d.f.) } \\
\sigma=0.15\end{array}$ \\
\hline$\overline{C_{\text {top }}}$ & $\mathrm{NA}$ & $\mathrm{NA}$ & 0.000 & $\begin{array}{l}\sigma \times \text { Student's } t(6 \text { d.f. }) \\
\sigma=0.088\end{array}$ \\
\hline$\overline{C_{\beta-1}}$ & $\mathrm{NA}$ & $\mathrm{NA}$ & 0.000 & $\begin{array}{l}\text { Normal } \\
\sigma=0.02 \\
\end{array}$ \\
\hline $\mathrm{C}_{\mu-1}, \mathrm{~Pa}-\mathrm{s}$ & NA & NA & 0.000 & Normal; $\sigma=1.1 \times 10^{-3}$ \\
\hline $\mathrm{C}_{\mu-\mathrm{p}}, \mathrm{Pa}-\mathrm{s}$ & NA & NA & 0.000 & Normal; $\sigma=2.5 \times 10^{-3}$ \\
\hline$\overline{C_{p-1}}$ & NA & NA & 0.000 & $\begin{array}{l}\text { Normal } \\
\sigma=0.02\end{array}$ \\
\hline$\overline{C_{p-p}}$ & NA & NA & 0.000 & $\begin{array}{l}\text { Normal } \\
\sigma=0.02\end{array}$ \\
\hline
\end{tabular}


Table C-1. Comparison of INEEL and UCSB input uncertainty distributions. (continued)

\begin{tabular}{|c|c|c|c|c|}
\hline \multirow{2}{*}{ Variable } & \multicolumn{2}{|c|}{ UCSB-assumed FIBS } & \multicolumn{2}{|c|}{ INEEL Requantification of UCSB-assumed FIBS } \\
\hline & Median Value & Distribution & Median Value & Distribution \\
\hline $\mathrm{C}_{1}, \mathrm{~W} / \mathrm{m}^{2}$ & $4.90 \times 10^{5}$ & Point estimate & $5.864 \times 10^{5}$ & \multirow{5}{*}{$\begin{array}{l}\text { Uncertainty treated in } \\
\mathrm{C}_{\mathrm{CHF}}{ }^{\mathrm{c}}\end{array}$} \\
\hline $\mathrm{C}_{2}, \mathrm{~W} / \mathrm{m}^{2}$ & $3.02 \times 10^{4}$ & Point estimate & $2.081 \times 10^{4}$ & \\
\hline $\mathrm{C}_{3}, \mathrm{~W} / \mathrm{m}^{2}$ & $-8.88 \times 10^{2}$ & Point estimate & $-1.467 \times 10^{2}$ & \\
\hline $\mathrm{C}_{4}, \mathrm{~W} / \mathrm{m}^{2}$ & $1.35 \times 10^{1}$ & Point estimate & $1.361 \times 10^{-1}$ & \\
\hline $\mathrm{C}_{5}, \mathrm{~W} / \mathrm{m}^{2}$ & $-6.65 \times 10^{-2}$ & Point estimate & $4.000 \times 10^{-5}$ & \\
\hline $\mathrm{C}_{6}$ & 0.345 & Point estimate & 2.4415 & $\begin{array}{l}\text { Uncertainty treated in } \\
\sigma_{\mathrm{Nu}_{\mathrm{p}-\mathrm{up}}}\left(\mathrm{Ra}_{\mathrm{p}}^{\prime}\right)^{\mathrm{d}}\end{array}$ \\
\hline $\mathrm{C}_{7}$ & 0.233 & Point estimate & 0.1722 & $\begin{array}{l}\text { Uncertainty treated in } \\
\sigma_{\mathrm{Nu}_{\mathrm{p}-\mathrm{p}}}\left(\mathrm{Ra}_{\mathrm{p}}^{\prime}\right)^{\mathrm{d}}\end{array}$ \\
\hline $\mathrm{C}_{8}$ & 0.0038 & Point estimate & 0.1857 & $\begin{array}{l}\text { Uncertainty treated in } \\
\sigma_{\mathrm{Nu}_{\mathrm{p}-\mathrm{dn}}}\left(\mathrm{Ra}_{\mathrm{p}}^{\prime}\right)^{\mathrm{d}}\end{array}$ \\
\hline$\overline{C_{9}}$ & 0.35 & Point estimate & 0.2304 & $\begin{array}{l}\text { Uncertainty treated in } \\
\sigma_{\mathrm{Nu}_{\mathrm{p}-\mathrm{dn}}}\left(\mathrm{Ra}_{\mathrm{p}}^{\prime}\right)^{\mathrm{d}}\end{array}$ \\
\hline $\mathrm{C}_{10}$ & 0.1 & Point estimate & 0.1 & \multirow{7}{*}{$\begin{array}{l}\text { Uncertainty treated in } \\
\text { C local. }\end{array}$} \\
\hline$\overline{C_{11}}$ & 1.08 & Point estimate & 1.08 & \\
\hline$\overline{C_{12}}$ & -4.5 & Point estimate & -4.5 & \\
\hline$\overline{C_{13}}$ & 8.6 & Point estimate & 8.6 & \\
\hline$\overline{C_{14}}$ & 0.41 & Point estimate & 0.41 & \\
\hline$C_{15}$ & 0.35 & Point estimate & 0.35 & \\
\hline$\overline{C_{16}}$ & 1.00 & Point estimate & 1.00 & \\
\hline $\mathrm{C}_{17}$ & 0.170 & Point estimate & 0.170 & \multirow{3}{*}{$\begin{array}{l}\text { Uncertainty treated in } C_{\text {top }} \\
\text { and } C_{\text {bot. }}\end{array}$} \\
\hline$\overline{C_{18}}$ & 0.074 & Point estimate & 0.074 & \\
\hline $\mathrm{C}_{19}$ & 0.3333 & Point estimate & 0.3333 & \\
\hline $\mathrm{C}_{20}$ & 0.150 & Point estimate & 0.150 & \multirow{2}{*}{$\begin{array}{l}\text { Uncertainty treated in } \\
\text { C }_{\text {side }}\end{array}$} \\
\hline $\mathrm{C}_{22}$ & 0.3333 & Point estimate & 0.3333 & \\
\hline $\mathrm{M}_{\mathrm{Zr}-\mathrm{tot}}, \mathrm{kg}$ & 19,200 & Point estimate & $19,200^{\mathrm{g}}$ & Point estimate \\
\hline $\mathrm{M}_{\text {ss-tot }}, \mathrm{kg}$ & 70,000 & Figure 7.5 & $70,000^{\mathrm{g}}$ & Figure $7.5^{\mathrm{e}}$ \\
\hline $\mathrm{M}_{\mathrm{UO}_{2}-\mathrm{tot}}, \mathrm{kg}$ & 75,900 & Point estimate & $75,900^{\mathrm{g}}$ & Point estimate \\
\hline$P_{\text {decay-UCSB }}\left(t_{r e l}\right), W$ & $\begin{array}{l}\text { Time-dependent } \\
\text { values shown in } \\
\text { Figure } 7.1^{\mathrm{f}}\end{array}$ & Point estimate & $\begin{array}{l}\text { Time-dependent values } \\
\text { shown in Figure } 7.1^{\mathrm{f}}\end{array}$ & $\begin{array}{l}\text { Uncertainty treated in } \\
C_{\text {dec }} .\end{array}$ \\
\hline$\overline{R, m}$ & 2 & Point estimate & $2^{g}$ & Point estimate \\
\hline
\end{tabular}


Table C-1. Comparison of INEEL and UCSB input uncertainty distributions. (continued)

\begin{tabular}{|c|c|c|c|c|}
\hline \multirow{2}{*}{ Variable } & \multicolumn{2}{|c|}{ UCSB-assumed FIBS } & \multicolumn{2}{|c|}{ INEEL Requantification of UCSB-assumed FIBS } \\
\hline & Median Value & Distribution & Median Value & Distribution \\
\hline $\mathrm{S}_{\mathrm{s}}, \mathrm{m}^{2}$ & $\overline{75.36}$ & Point estimate & $75.36^{\mathrm{g}}$ & Point estimate \\
\hline $\mathrm{T}_{\mathrm{l}, \mathrm{m}}, \mathrm{K}$ & 1600 & Point estimate & $\begin{array}{l}\text { Figure } 6.1 \text { value based on } \\
\mathrm{Zr} \text { mole fraction }\end{array}$ & Point estimate \\
\hline$T_{p, m}, K$ & 2973 & Point estimate & 2850 & Point estimate \\
\hline$T_{w}, K$ & $400^{\mathrm{K}}$ & Point estimate & $400^{\mathrm{g}}$ & Point estimate \\
\hline$T_{p-v e s, m}, K$ & 1600 & Point estimate & 1809 & Point estimate \\
\hline $\mathrm{Z}_{\mathrm{Zr}}, \mathrm{kg} / \mathrm{kg}$-moles & $91.22^{\mathrm{i}}$ & Point estimate & $91.22^{\mathrm{i}}$ & Point estimate \\
\hline $\mathrm{Z}_{\mathrm{O}}, \mathrm{kg} / \mathrm{kg}$-moles & $15.994^{\mathrm{i}}$ & Point estimate & $15.994^{\mathrm{i}}$ & Point estimate \\
\hline $\mathrm{Z}_{\mathrm{ss}}, \mathrm{kg} / \mathrm{kg}$-moles & NA & NA & $55.066^{\top}$ & Point estimate \\
\hline $\mathrm{Z}_{\mathrm{U}}, \mathrm{kg} / \mathrm{kg}$-moles & NA & NA & $238.029^{i}$ & Point estimate \\
\hline $\mathrm{Z}_{\mathrm{UO}_{2}}, \mathrm{~kg} / \mathrm{kg}$-moles & NA & NA & $270.02^{i}$ & Point estimate \\
\hline$\beta_{1-s s}, K^{-1}$ & $\mathrm{NA}$ & $\mathrm{NA}$ & $1.20 \times 10^{-4}$ & $\begin{array}{l}\text { Normal } \\
\sigma=0.17 \times 10^{-4}\end{array}$ \\
\hline$\beta_{1-U}, K^{-1}$ & NA & NA & $8.61 \times 10^{-4}$ & $\begin{array}{l}\text { Normal } \\
\sigma=0.60 \times 10^{-4}\end{array}$ \\
\hline$\beta_{\mathrm{l}-\mathrm{Z}_{\mathrm{r}}}, \mathrm{K}^{-1}$ & NA & $\mathrm{NA}$ & $0.54 \times 10^{-4}$ & $\begin{array}{l}\text { Normal } \\
\sigma=0.11 \times 10^{-4}\end{array}$ \\
\hline$\beta_{1}, \mathrm{~K}^{-1}$ & $1.10 \times 10^{-4}$ & $\begin{array}{l}\text { Normal } \\
2 \sigma=0.12 \times 10^{-4}\end{array}$ & NA & $\mathrm{NA}$ \\
\hline$\beta_{\mathrm{p}}, \mathrm{K}^{-1}$ & $1.05 \times 10^{-4}$ & $\begin{array}{l}\text { Normal } \\
2 \sigma=0.18 \times 10^{-4}\end{array}$ & $1.05 \times 10^{-4}$ & $\begin{array}{l}\text { Normal } \\
\sigma=0.12 \times 10^{-4}\end{array}$ \\
\hline$\delta_{0}, \mathrm{~m}$ & $0.2032^{\mathrm{k}}$ & Point estimate & 0.2032 & Point estimate \\
\hline$\delta_{s}, m$ & 0.0508 & Point estimate & 0.0508 & Point estimate \\
\hline$\delta_{\text {ves }}(\theta), m$ & $0.15^{1}$ & Point estimate & $0.15^{1}$ & Point estimate \\
\hline$\varepsilon_{1}$ & 0.45 & Point estimate & 0.29 & $\begin{array}{l}\text { Normal } \\
\sigma=0.04\end{array}$ \\
\hline$\varepsilon_{\mathrm{s}}$ & 0.8 & Point estimate & 0.85 & $\begin{array}{l}\text { Normal } \\
\sigma=0.03\end{array}$ \\
\hline$\rho_{1-\mathrm{ss}}, \mathrm{kg} / \mathrm{m}^{3}$ & 7020 & Point estimate & 7020 & $\begin{array}{l}\text { Normal } \\
\sigma=90\end{array}$ \\
\hline$\rho_{1-U}, \mathrm{~kg} / \mathrm{m}^{3}$ & NA & $\mathrm{NA}$ & 17,500 & $\begin{array}{l}\text { Normal } \\
\sigma=1750\end{array}$ \\
\hline$\rho_{1-Z_{r}}, \mathrm{~kg} / \mathrm{m}^{3}$ & 6130 & Point estimate & 6130 & $\begin{array}{l}\text { Normal } \\
\sigma=180\end{array}$ \\
\hline
\end{tabular}


Table C-1. Comparison of INEEL and UCSB input uncertainty distributions. (continued)

\begin{tabular}{|l|l|l|l|l|}
\hline \multirow{2}{*}{ Variable } & \multicolumn{2}{|c|}{ UCSB-assumed FIBS } & \multicolumn{2}{c|}{ INEEL Requantification of UCSB-assumed FIBS } \\
\cline { 2 - 5 } & Median Value & Distribution & Median Value & \multicolumn{1}{c|}{ Distribution } \\
\hline \hline$\rho_{\mathrm{p}-\mathrm{ZrO} \mathrm{O}_{2}}, \mathrm{~kg} / \mathrm{m}^{3}$ & 5990 & Point estimate & 5990 & $\begin{array}{l}\text { Normal } \\
\sigma=100\end{array}$ \\
\hline$\rho_{\mathrm{p}-\mathrm{UO}_{2}}, \mathrm{~kg} / \mathrm{m}^{3}$ & 8740 & Point estimate & 8740 & $\begin{array}{l}\text { Normal } \\
\sigma=200\end{array}$ \\
\hline$\sigma, \mathrm{W} / \mathrm{m}^{2} \mathrm{~K}^{4}$ & $5.672 \times 10^{-8 \mathrm{~m}}$ & Point estimate & $5.672 \times 10^{-8 \mathrm{~m}}$ & Point estimate \\
\hline
\end{tabular}

a. It appears that the UCSB study assumed that all decay heat was produced by fission products. Hence, this parameter wasn't used in INEEL's assessment of the UCSB-assumed FIBS.

b. Consistent with Appendix $L$ recommendations for temperatures at this location.

c. For the UCSB-assumed FIBS reassessment, INEEL-assumed values correspond to a cavity water height to vessel radius ratio of three.

d. As described in Appendix B, $\sigma_{\mathrm{Nu}_{\mathrm{p}-\mathrm{up}}}\left(\mathrm{Ra}_{\mathrm{p}}^{\prime}\right)$ and $\sigma_{\mathrm{Nu}_{\mathrm{p}-\mathrm{un}}}\left(\mathrm{Ra}_{\mathrm{p}}^{\prime}\right)$ are given by:

$\sigma_{\mathrm{Nu}_{\mathrm{p}-\mathrm{p}}}\left(\mathrm{Ra}_{\mathrm{p}}{ }_{\mathrm{p}}\right)=\left[0.0021^{2}+0.0035^{2}\left(\log \left(\mathrm{Ra}_{\mathrm{p}}{ }^{\prime}\right)-15.0148\right)^{2}\right]^{1 / 2} T$

where $T$ has a Student's $t$ distribution with 53 degrees of freedom, and

$\sigma_{\mathrm{Nu}_{\mathrm{p}-\mathrm{dn}}}\left(\mathrm{Ra}_{\mathrm{p}}{ }_{\mathrm{p}}\right)=\left[0.0023^{2}+0.0040^{2}\left(\log \left(\mathrm{Ra}_{\mathrm{p}}{ }^{\prime}\right)-14.9701\right)^{2}\right]^{1 / 2} T$

where $T$ has a Student's $t$ distribution with 22 degrees of freedom

e. This mass distribution was used for the UCSB-assumed FIBS, it does not represent an expected mass distribution.

f. For time periods of interest, the following equation was used

$$
P_{\text {decay-UCSB }}=\left(-0.000333 \mathrm{t}_{\text {rel }}+19.5\right) 10^{6}
$$

g. This value was used to be consistent with values assumed by the UCSB study for their base case analysis. h. Not explicitly stated in DOE/1D-10460. Nomenclature suggests that water saturation temperature was used. However, Response to RAI 480.446 suggests that $400 \mathrm{~K}$ was used.

i. From Reference 62.

j. Estimated from Reference 62, assuming composition of $0.05 \% \mathrm{C}, 2.00 \% \mathrm{Mn}, 1.00 \% \mathrm{Si}, 10 \% \mathrm{Ni}, 0.04 \% \mathrm{P}$, $0.03 \% \mathrm{~S}, 19.00 \% \mathrm{~S}$, and $67.88 \% \mathrm{Fe}$.

$\mathrm{k}$. This value is based on AP600 plant vessel drawings. It is consistent with value specified in RAI 480.459, but differs from the value specified in RAI 480.965.

1. For locations where vessel melting doesn't occur.

m. From Reference 63. 
Table C-2. Configuration A input assumptions. ${ }^{a}$

\begin{tabular}{|c|c|c|}
\hline Parameter & Value & Uncertainty \\
\hline $\mathrm{C}_{1}, \mathrm{~W} / \mathrm{m}^{2}$ & $5.211 \times 10^{5}$ & \multirow{5}{*}{$\begin{array}{l}\text { Uncertainty treated in } \mathrm{C}_{\mathrm{CHF}} \text { Corresponds to SBLB }(\mathrm{H} / \mathrm{R}=2) \\
\text { values. }\end{array}$} \\
\hline $\mathrm{C}_{2}, \mathrm{~W} / \mathrm{m}^{2}$ & $1.743 \times 10^{4}$ & \\
\hline $\mathrm{C}_{3}, \mathrm{~W} / \mathrm{m}^{2}$ & $-7.311 \times 10^{1}$ & \\
\hline $\mathrm{C}_{4}, \mathrm{~W} / \mathrm{m}^{2}$ & $-7.643 \times 10^{-1}$ & \\
\hline $\mathrm{C}_{5}, \mathrm{~W} / \mathrm{m}^{2}$ & $4.180 \times 10^{-3}$ & \\
\hline$\varepsilon_{1}$ & 0.2 & Normal; $\sigma=0.1$ \\
\hline $\mathrm{P}_{\text {dec-UCSB }}\left(\mathrm{t}_{\mathrm{rel}}\right), \mathrm{W}$ & $8.5 \times 10^{6}$ & Uncertainty treated in $\mathrm{C}_{\mathrm{dec}}$. Corresponds to $\mathrm{S} / \mathrm{R} 5$ results. \\
\hline$t_{\text {rel }}, \mathrm{sec}$ & 12,047 & Point estimate. Corresponds to S/R5 results. \\
\hline $\mathrm{M}_{\mathrm{Zr}-\mathrm{tot}}, \mathrm{kg}$ & 7,027 & Point estimate. Corresponds to S/R5 results. \\
\hline $\mathrm{M}_{\mathrm{ss}-\mathrm{tot}}, \mathrm{kg}$ & $2,603 / 4187^{b}$ & Point estimate. Corresponds to S/R5 results. \\
\hline $\mathrm{M}_{\mathrm{UO}_{2}-\mathrm{tot}}, \mathrm{kg}$ & 37,207 & Point estimate. Corresponds to S/R5 results. \\
\hline$f_{\text {ox-Zr }}$ & 0.4544 & Point estimate. Corresponds to S/R5 results. \\
\hline $\mathrm{f}_{\mathrm{ACT}}\left(\mathrm{t}_{\mathrm{Tel}}\right)$ & 0.123 & Point estimate. Corresponds to $S / R 5$ results. \\
\hline
\end{tabular}

a. Only those input values differing from those assumed in the INEEL analysis of the UCSB-assumed FIBS are listed. Input for Configuration is based on Reference 3 SCDAP/RELAP5 calculations for a relocation time of 12,047 seconds.

b. The stainless steel mass has been increased to include the mass of control material that might be present in the metallic layer. 
Table C-3. Configuration B input assumptions. ${ }^{2}$

\begin{tabular}{|c|c|c|}
\hline Parameter & Value & Uncertainty \\
\hline $\mathrm{C}_{1}, \mathrm{~W} / \mathrm{m}^{2}$ & $5.211 \times 10^{5}$ & \multirow{5}{*}{$\begin{array}{l}\text { Uncertainty treated in } \mathrm{C}_{\mathrm{CHF}} \text {. Corresponds to SBLB }(\mathrm{H} / \mathrm{R}=2) \\
\text { values. }\end{array}$} \\
\hline $\mathrm{C}_{2}, \mathrm{~W} / \mathrm{m}^{2}$ & $1.743 \times 10^{4}$ & \\
\hline$C_{3}, W / m^{2}$ & $-7.311 \times 10^{1}$ & \\
\hline $\mathrm{C}_{4}, \mathrm{~W} / \mathrm{m}^{2}$ & $-7.643 \times 10^{-1}$ & \\
\hline$C_{5}, W / m^{2}$ & $4.180 \times 10^{-3}$ & \\
\hline$P_{\text {dec-UCSB }}, W$ & $14 \times 10^{6}$ & Uncertainty treated in $\mathrm{C}_{\text {dec }}$. Corresponds to $\mathrm{S} / \mathrm{R} 5$ results. \\
\hline trel, sec & 12,844 & Point estimate. Corresponds to S/R5 results. \\
\hline $\mathrm{M}_{\mathrm{Zr}-\mathrm{tot}}, \mathrm{kg}$ & 11,188 & Point estimate. Corresponds to S/R5 results. \\
\hline $\mathrm{f}_{\mathrm{Zr}}(1)$ & 0.0000 & Point estimate. Corresponds to S/R5 results. \\
\hline$f_{Z_{r}}(2)$ & 0.6887 & Point estimate. Corresponds to S/R5 results. \\
\hline $\mathrm{f}_{\mathrm{Zr}_{\mathrm{r}}(3)}$ & 0.0000 & Point estimate. Corresponds to S/R5 results. \\
\hline $\mathrm{f}_{\mathrm{Zr}}(4)$ & 0.3113 & Point estimate. Corresponds to S/R5 results. \\
\hline $\mathrm{f}_{\mathrm{ZrO}_{2}}(1)$ & 0.5682 & Point estimate. Corresponds to S/R5 results. \\
\hline $\mathrm{f}_{\mathrm{ZrO}_{2}}(2)$ & 0.0000 & Point estimate. Corresponds to S/R5 results. \\
\hline $\mathrm{f}_{\mathrm{ZrO}_{2}}(3)$ & 0.4318 & Point estimate. Corresponds to S/R5 results. \\
\hline $\mathrm{f}_{\mathrm{ZrO}_{2}}(4)$ & 0.0000 & Point estimate. Corresponds to S/R5 results. \\
\hline$f_{\text {ox-Zr }}$ & 0.5024 & Point estimate. Corresponds to S/R5 results. \\
\hline $\mathrm{M}_{\mathrm{ss}-\mathrm{tot}}, \mathrm{kg}$ & $6121.7^{b}$ & Point estimate. Corresponds to S/R5 results. \\
\hline$f_{s s}(1)$ & 0.000 & Point estimate. Corresponds to S/R5 results. \\
\hline$f_{s s}(2)$ & 0.6840 & Point estimate. Corresponds to S/R5 results. \\
\hline$f_{s s}(3)$ & 0.000 & Point estimate. Corresponds to S/R5 results. \\
\hline $\mathrm{f}_{\mathrm{ss}}(4)$ & 0.3160 & Point estimate. Corresponds to S/R5 results. \\
\hline $\mathrm{M}_{\mathrm{UO}_{2}-\mathrm{tot}}, \mathrm{kg}$ & 63,995 & Point estimate. Corresponds to S/R5 results. \\
\hline $\mathrm{f}_{\mathrm{UO}_{2}}(1)$ & 0.5814 & Point estimate. Corresponds to S/R5 results. \\
\hline$f_{\mathrm{UO}_{2}}(2)$ & 0.0000 & Point estimate. Corresponds to $S / R 5$ results. \\
\hline $\mathrm{f}_{\mathrm{UO}_{2}}(3)$ & 0.4186 & Point estimate. Corresponds to S/R5 results. \\
\hline $\mathrm{f}_{\mathrm{UO}_{2}}(4)$ & 0.0000 & Point estimate. Corresponds to S/R5 results. \\
\hline$f_{U}(1)$ & 0.0000 & Point estimate. Corresponds to S/R5 results. \\
\hline
\end{tabular}


Table C-3. Configuration B input assumptions. ${ }^{a}$ (continued)

\begin{tabular}{|l|l|l|}
\hline \multicolumn{1}{|c|}{ Parameter } & \multicolumn{1}{|c|}{ Value } & \multicolumn{1}{c|}{ Uncertainty } \\
\hline \hline $\mathrm{f}_{\mathrm{U}}(2)$ & 0.0000 & Point estimate. Corresponds to S/R5 results. \\
\hline $\mathrm{f}_{\mathrm{U}}(3)$ & 0.0000 & Point estimate. Corresponds to S/R5 results. \\
\hline $\mathrm{f}_{\mathrm{U}}(4)$ & 0.0000 & Point estimate. Corresponds to S/R5 results. \\
\hline $\mathrm{f}_{\mathrm{ACT}}\left(\mathrm{t}_{\mathrm{rel}}\right)$ & 0.125 & Point estimate. Corresponds to S/R5 results. \\
\hline
\end{tabular}

a. Only those input values differing from those assumed in the INEEL analysis of the UCSB-assumed FIBS are listed. Input for Configuration B is based on Reference 3 SCDAP/RELAP5 calculations for a relocation time of 12,844 seconds.

b. The stainless steel mass has been increased to include the mass of control material that might be present in the metallic layer. 
Table C-4. Configuration $\mathrm{C}$ input assumptions. ${ }^{\text {a }}$

\begin{tabular}{|c|c|c|}
\hline Parameter & Value & Uncertainty \\
\hline $\mathrm{C}_{1}, \mathrm{~W} / \mathrm{m}^{2}$ & $5.211 \times 10^{5}$ & \multirow{5}{*}{$\begin{array}{l}\text { Uncertainty treated in } \mathrm{C}_{\mathrm{CHF}} \text { Corresponds to SBLB (H/R=2) } \\
\text { values. }\end{array}$} \\
\hline$c_{2}, W / m^{2}$ & $1.743 \times 10^{4}$ & \\
\hline$c_{3}, W / m^{2}$ & $-7.311 \times 10^{1}$ & \\
\hline $\mathrm{C}_{4}, \mathrm{~W} / \mathrm{m}^{2}$ & $-7.643 \times 10^{-1}$ & \\
\hline $\mathrm{C}_{5}, \mathrm{~W} / \mathrm{m}^{2}$ & $4.180 \times 10^{-3}$ & \\
\hline $\mathrm{P}_{\text {dec-UCSB }}, \mathrm{W}$ & $8.5 \times 10^{6}$ & Uncertainty treated in $\mathrm{C}_{\mathrm{dec}}$. Corresponds to $\mathrm{S} / \mathrm{R} 5$ results. \\
\hline $\mathrm{t}_{\mathrm{Tel}}, \mathrm{sec}$ & 12,047 & Point estimate. Corresponds to S/R5 results. \\
\hline $\mathrm{M}_{\mathrm{Zr}-\mathrm{tot}}, \mathrm{kg}$ & 7,027 & Point estimate. Corresponds to S/R5 results. \\
\hline $\mathrm{f}_{\mathrm{Zr}}(1)$ & 1.0000 & Point estimate. Corresponds to S/R5 results. \\
\hline $\mathrm{f}_{\mathrm{Zr}}(2)$ & 0.0000 & Point estimate. Corresponds to S/R5 results. \\
\hline $\mathrm{f}_{\mathrm{ZrO}_{2}}(1)$ & 0.0000 & Point estimate. Corresponds to S/R5 results. \\
\hline $\mathrm{frrO}_{\mathrm{Zr}_{2}}(2)$ & 1.0000 & Point estimate. Corresponds to S/R5 results. \\
\hline $\mathrm{M}_{\mathrm{ss-tot}}, \mathrm{kg}$ & $4187^{b}$ & Point estimate. Corresponds to S/R5 results. \\
\hline$f_{s s}(1)$ & 1.000 & Point estimate. Corresponds to S/R5 results. \\
\hline$f_{s s}(2)$ & 0.000 & Point estimate. Corresponds to S/R5 results. \\
\hline $\mathrm{M}_{\mathrm{UO}_{2}-\mathrm{tot}}, \mathrm{kg}$ & 37,207 & Point estimate. Corresponds to S/R5 results. \\
\hline $\mathbf{f}_{\mathrm{UO}_{2}}(1)$ & 0.000 & Point estimate. Corresponds to S/R5 results. \\
\hline$f_{\mathrm{UO}_{2}}(2)$ & 1.000 & Point estimate. Corresponds to S/R5 results. \\
\hline$f_{U}(1)$ & 1.0000 & Point estimate. Selected to address peer reviewer comments. \\
\hline$f_{U}(2)$ & 0.0000 & Point estimate. Selected to address peer reviewer comments. \\
\hline $\mathrm{f}_{\mathrm{Ox}-\mathrm{Zr}}$ & 0.45445 & Point estimate. Corresponds to S/R5 results. \\
\hline$f_{\mathrm{ox}-\mathrm{U}}$ & 0.8692 & $\begin{array}{l}\text { Point estimate corresponding to the minimum value making } \\
\text { the metallic layer denser than the ceramic layer. }\end{array}$ \\
\hline$f_{\text {ACT }}\left(t_{\text {Tel }}\right)$ & 0.123 & Point estimate. Corresponds to S/R5 results. \\
\hline
\end{tabular}

a. Only those input values differing from those assumed in the INEEL analysis of the UCSB-assumed FIBS are listed. Input for Configuration $C$ is based on Reference 3 SCDAP/RELAP5 calculations for a relocation time of 12,047 seconds. However, a fraction of the uranium is assumed to dissolve into the metallic layer to address peer reviewer comments.

b. The stainless steel mass has been increased to include the mass of control material that might be present in the metallic layer. 


\section{Appendix D - Benchmark Calculation Results}

Figures presented in this appendix demonstrate that equations documented in the UCSB study are correctly implemented into the INEEL-developed VESTA code. These figures compare VESTA results to UCSB model results for their assumed FIBS and sensitivity calculations presented in Appendix $Q$ of the UCSB study. Figures D-1 through D-14 compare point estimate model results, and Figure D-15 presents uncertainty analysis results. As shown in these figures, the UCSB and VESTA results typically differ by less than one percent.

Differences between model predictions are attributed to slight differences between UCSB and INEEL input assumptions. Table C-1 lists the input distributions that INEEL assumed for the UCSBassumed FIBS benchmark calculations. Note that this is INEEL's interpretation of UCSB input based on information in the UCSB study and Westinghouse's response to RAIs. The three sets of UCSB-assumed FIBS results included in the UCSB study differ in vessel wall heat fluxes predicted at locations near the metallic layer. [For locations adjacent to the metallic layer, Appendix P (Figure P.5) suggests heat fluxes to the water are $550 \mathrm{~W} / \mathrm{m}^{2}$ and that the ratio of $\mathrm{q}^{\prime \prime}(\theta) / \mathrm{q}^{\prime \prime}(\theta)_{\mathrm{CHF}}$ is 0.4 ; Appendix $\mathrm{Q}$ (Figure $\mathrm{Q} .1$ ) suggests heat fluxes to the water are $500 \mathrm{~W} / \mathrm{m}^{2}$, and Section 7 (Figure 7.10) suggests that the median value of the ratio of $q^{\prime \prime}(\theta) / q^{\prime \prime}(\theta)_{C H F}$ is 0.49 .] Hence, it appears that input for the UCSB-assumed FIBS must have differed for some calculations and that the VESTA results presented in this appendix appear to match most FIBS results presented in the UCSB study.

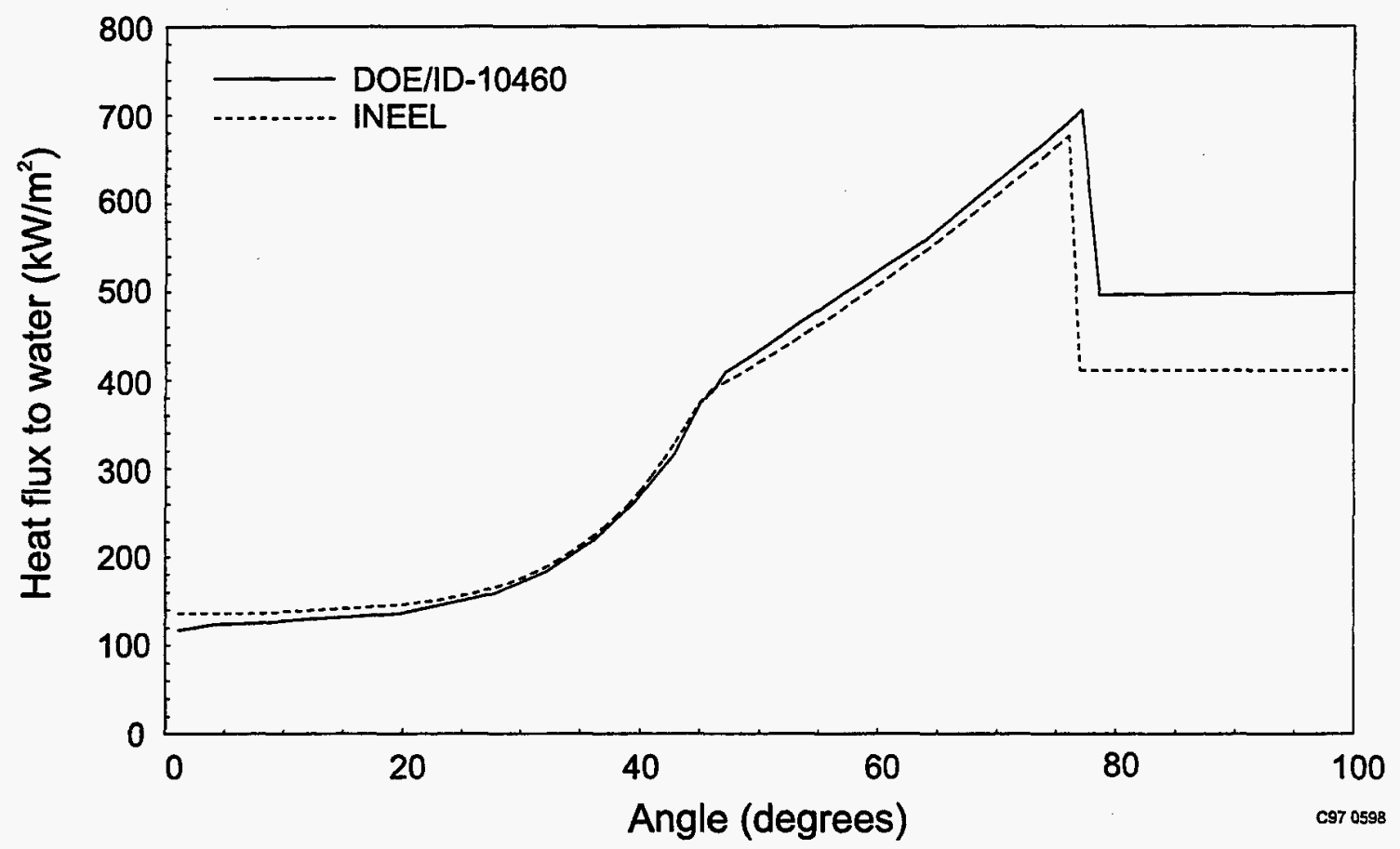

Figure D-1. INEEL VESTA and UCSB model predictions for heat flux distribution. 


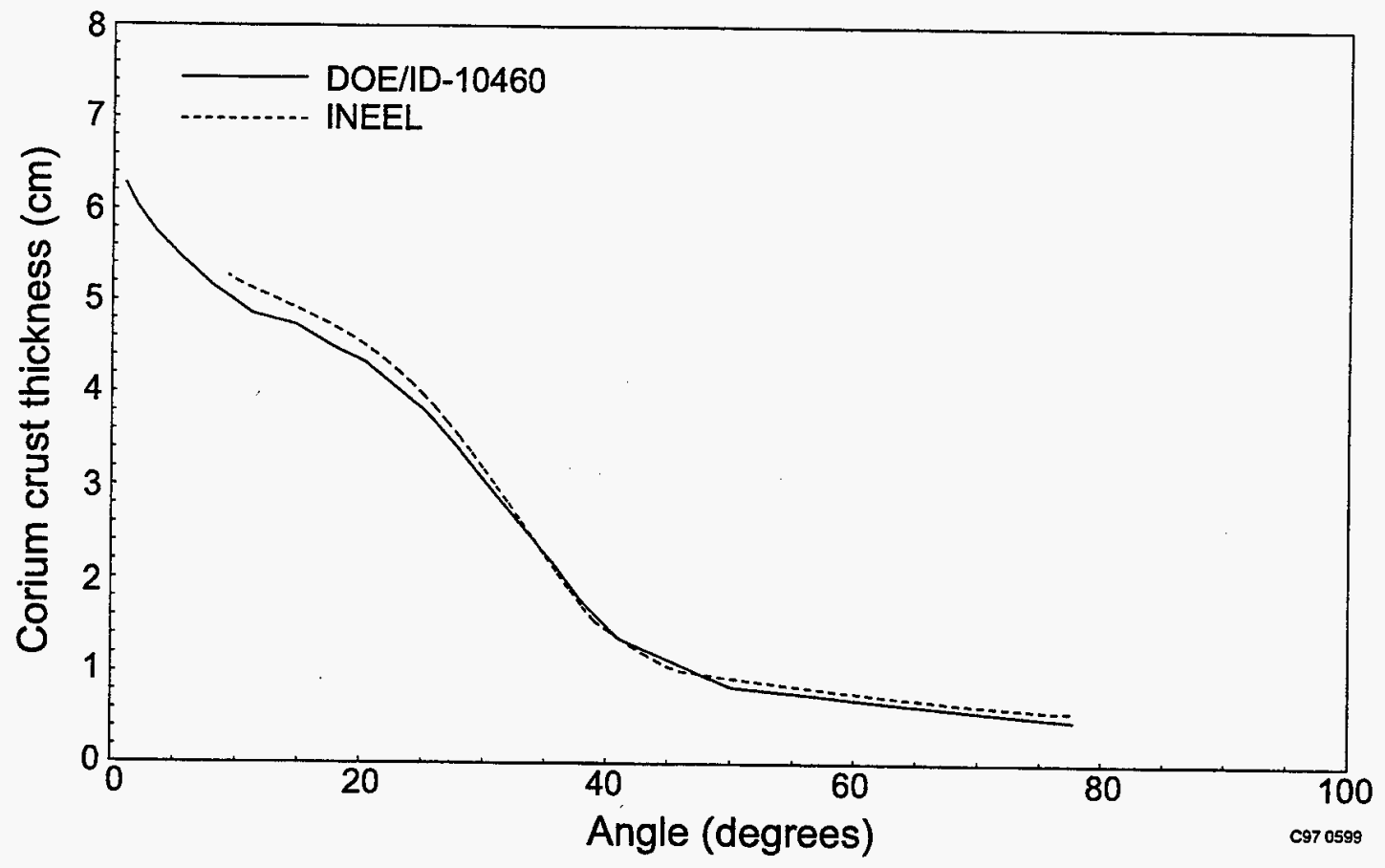

Figure D-2. INEEL VESTA and UCSB model predictions for oxide crust thickness.

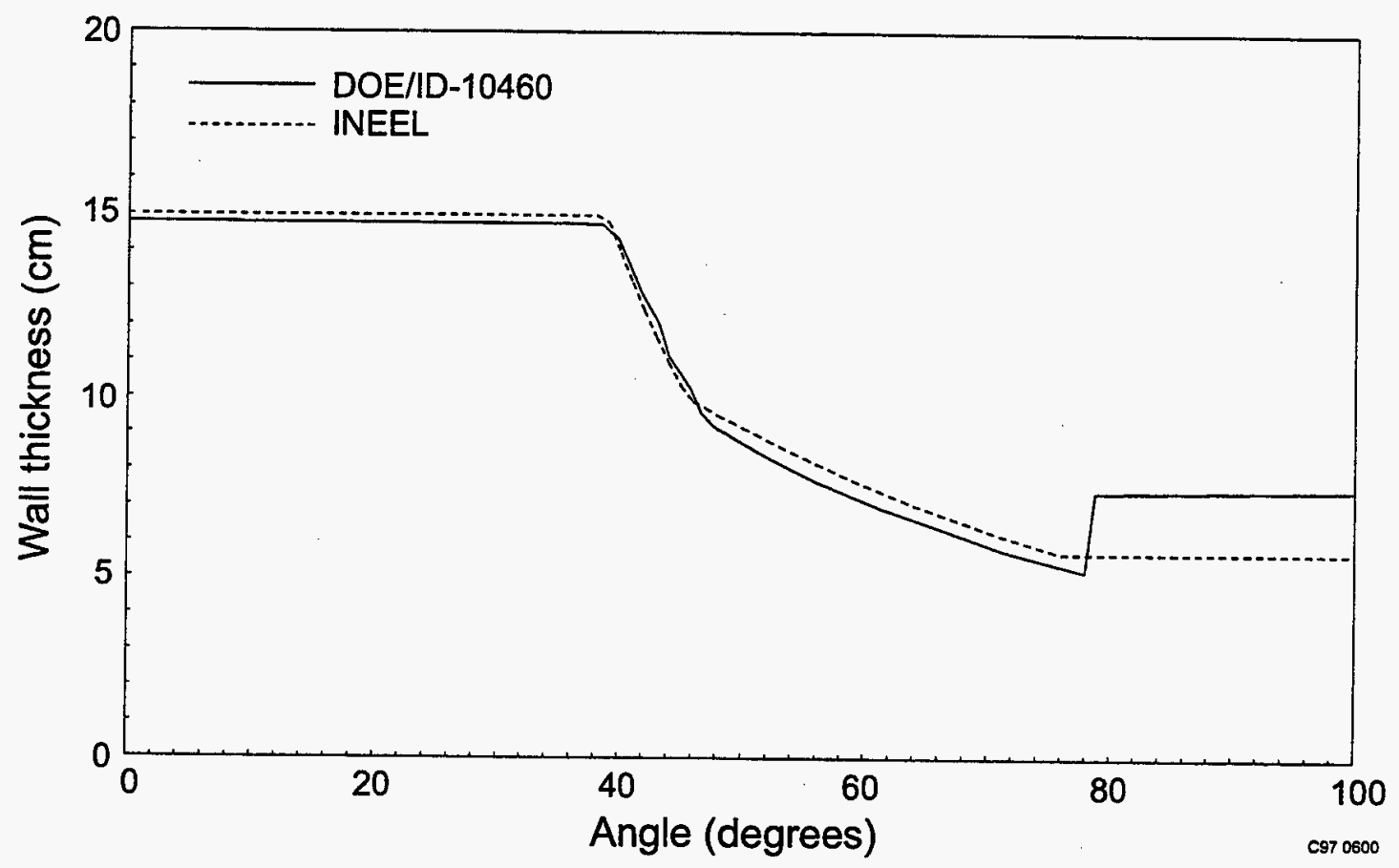

Figure D-3. INEEL VESTA and UCSB model predictions for vessel lower head thickness. 


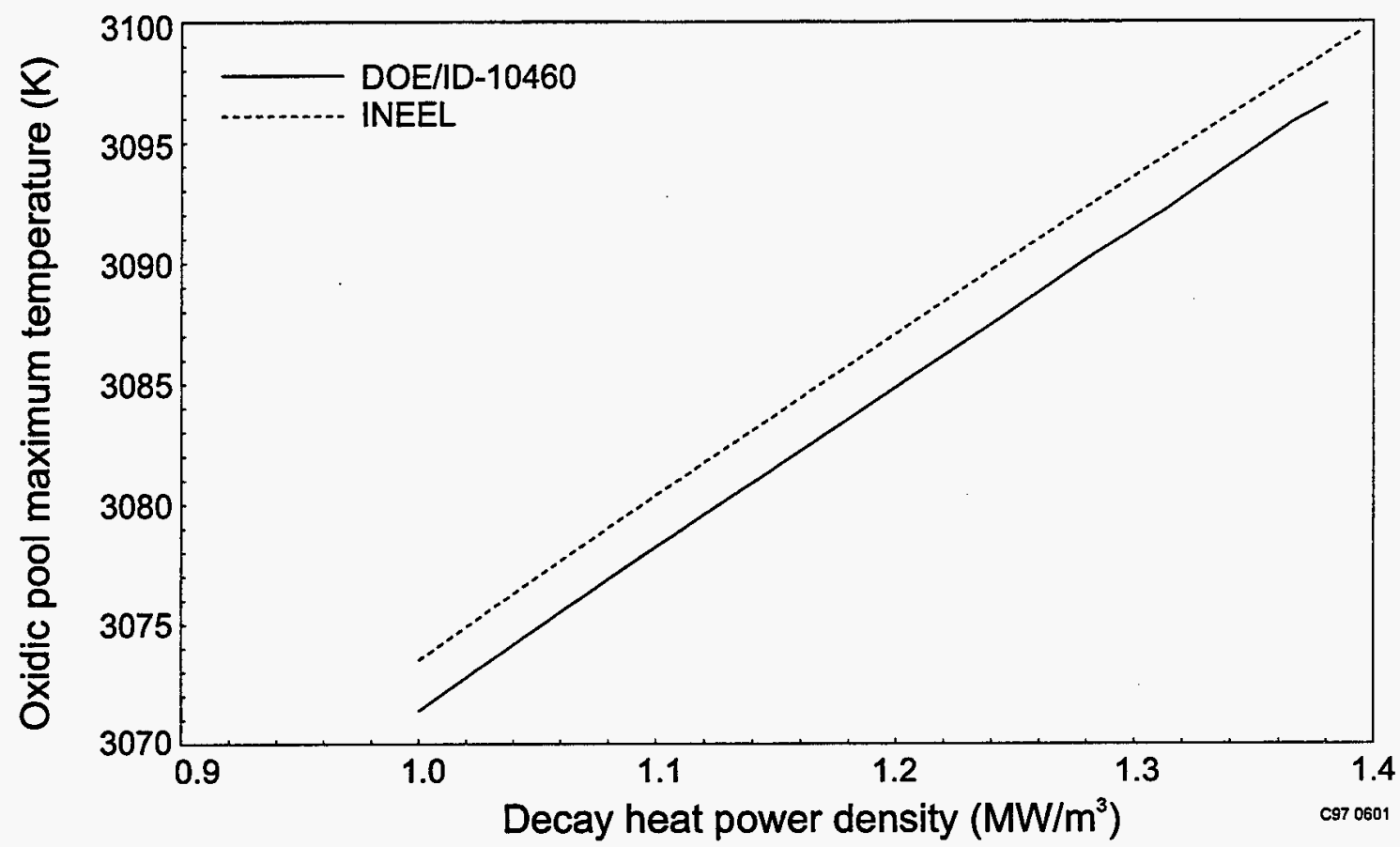

Figure D-4. INEEL VESTA and UCSB model predictions for oxidic pool maximum temperature.

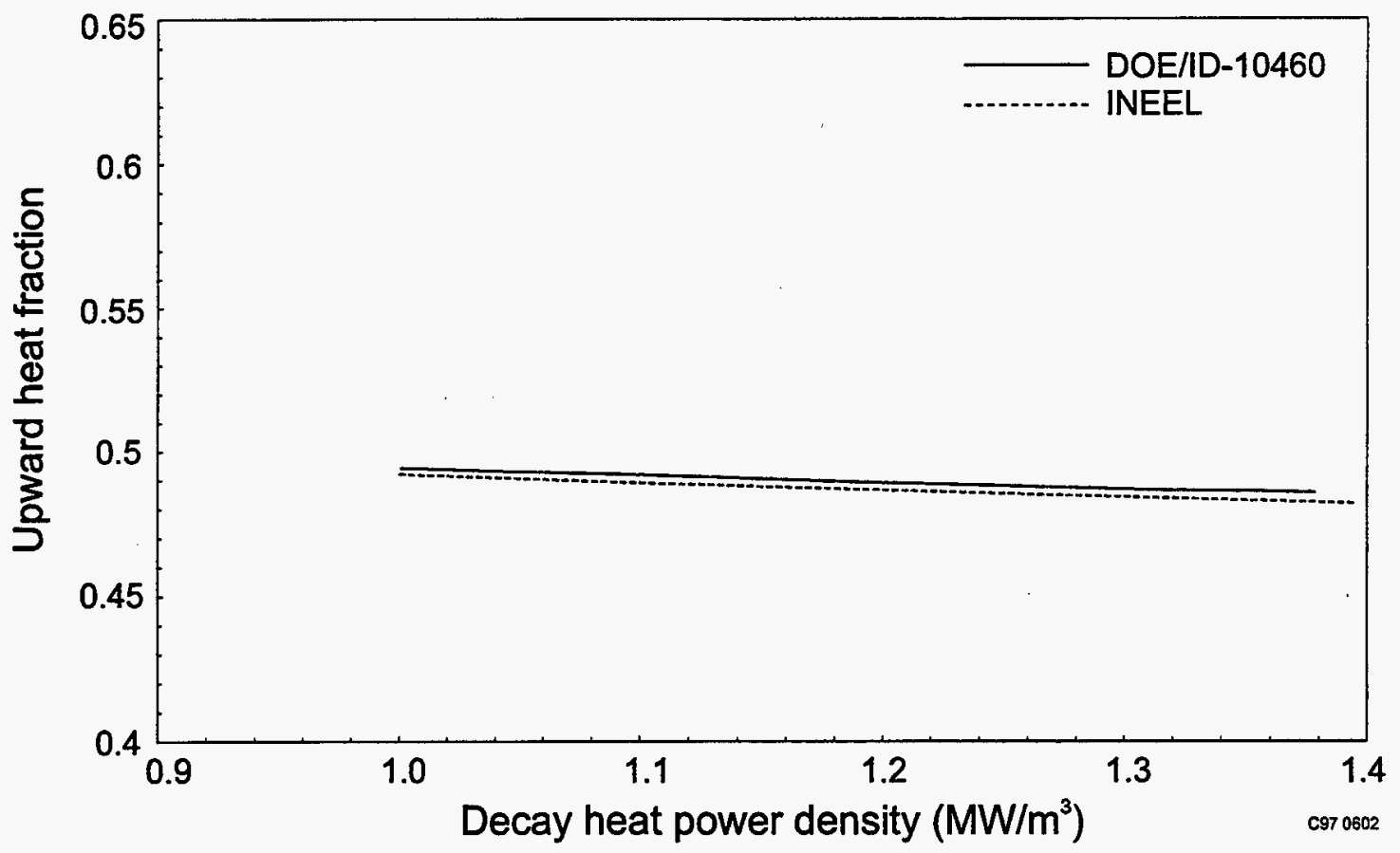

Figure D-5. INEEL VESTA and UCSB model predictions for energy flow split. 


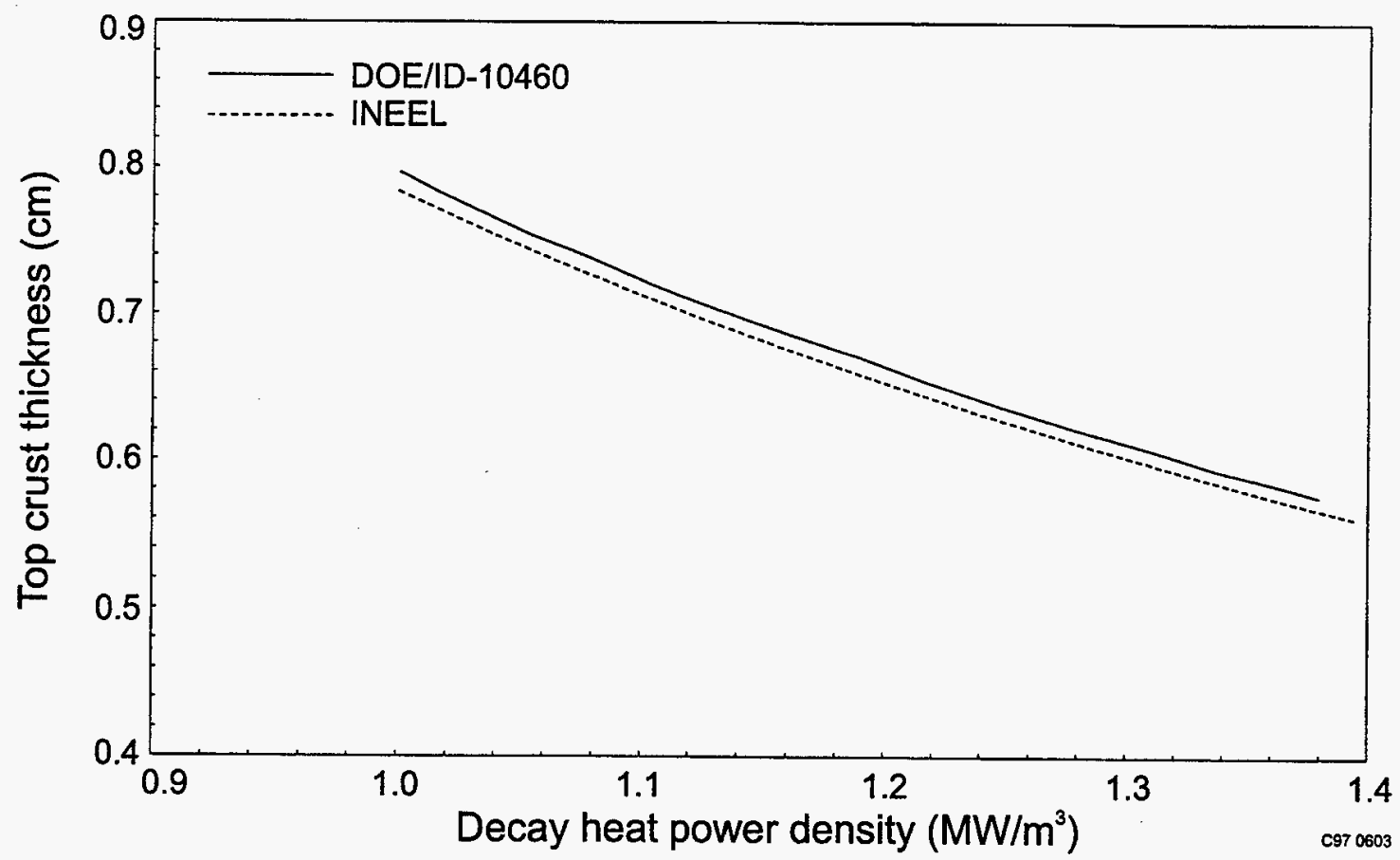

Figure D-6. INEEL VESTA and UCSB model predictions for oxidic pool top crust thickness.

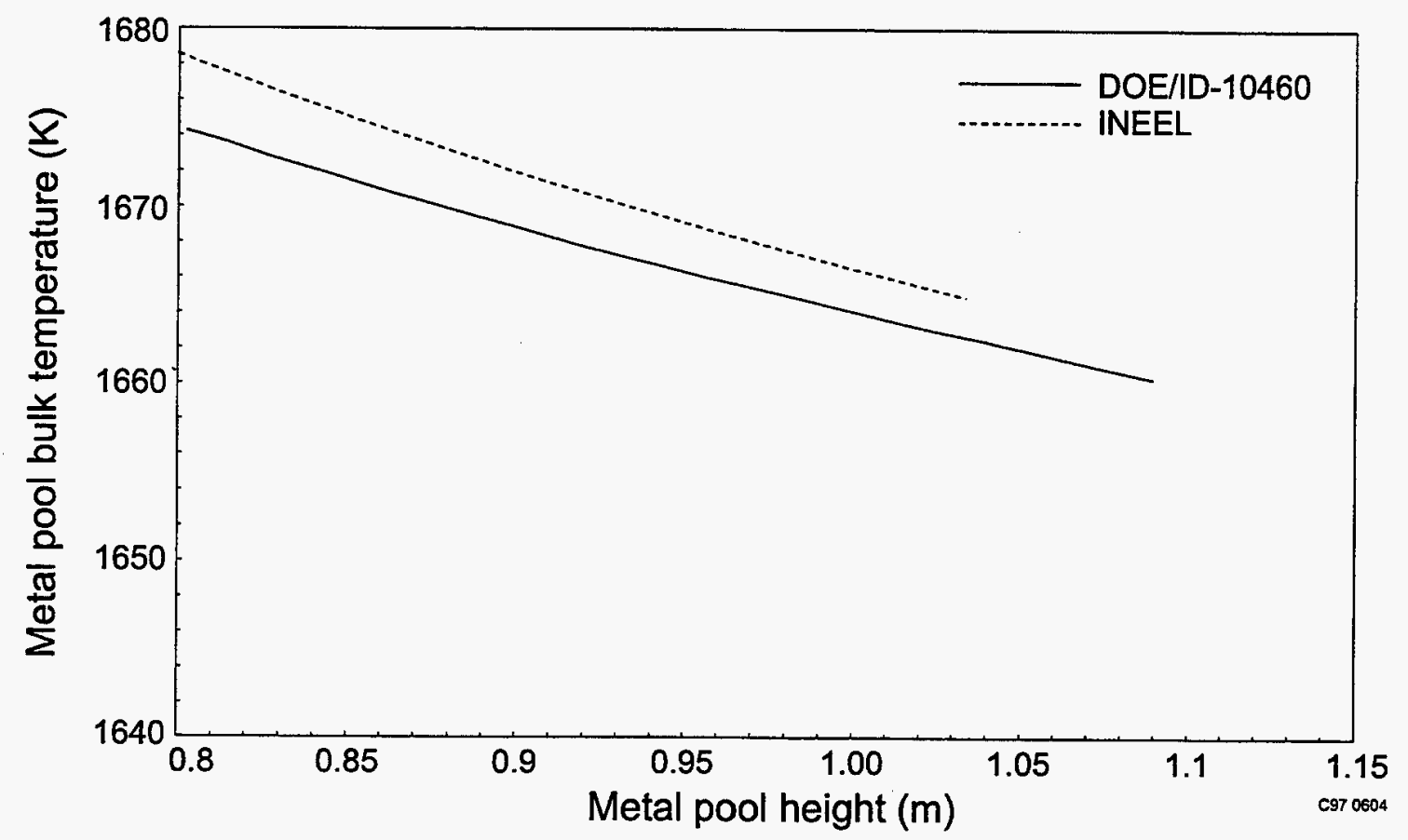

Figure D-7. INEEL VESTA and UCSB model predictions for metal layer bulk temperature. 


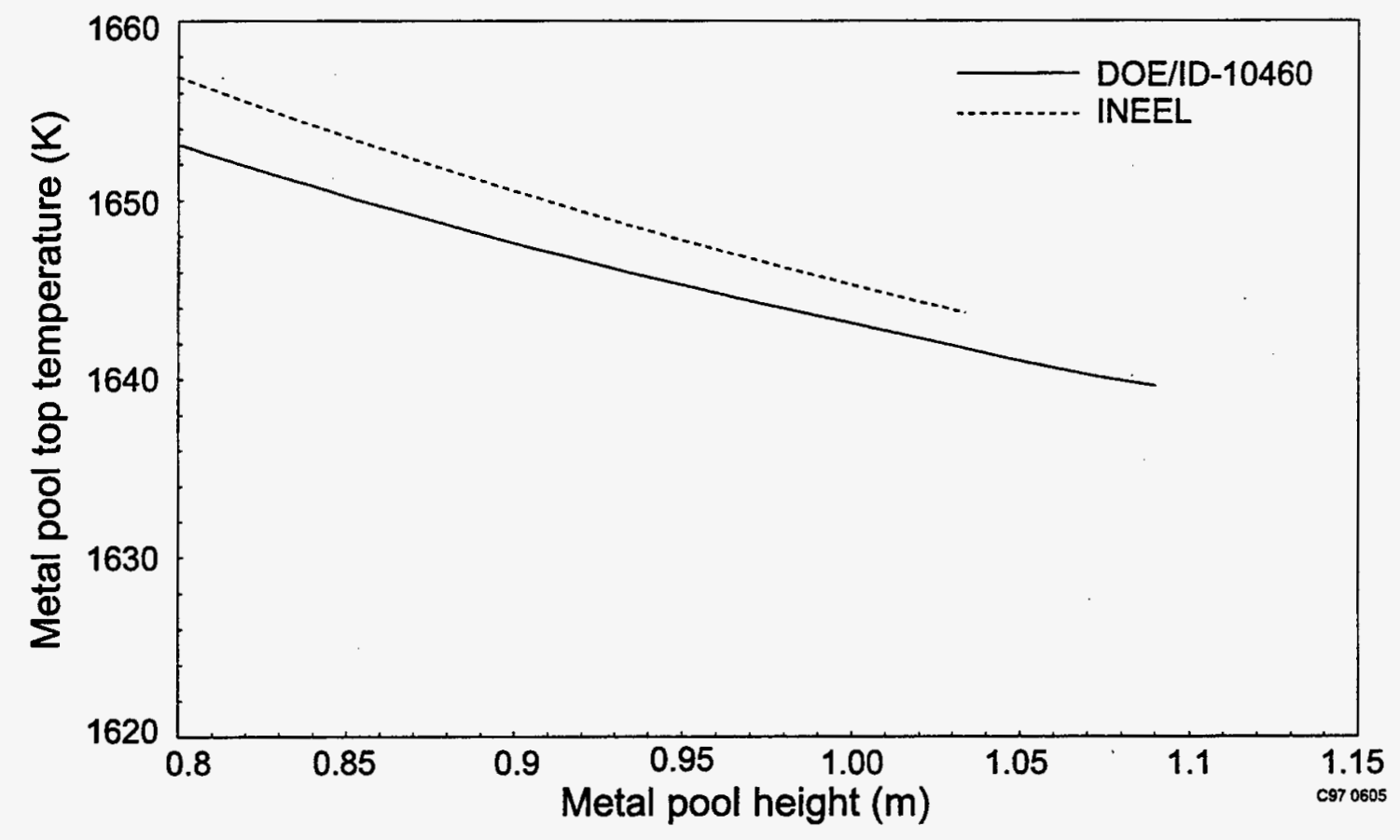

Figure D-8. INEEL VESTA and UCSB model predictions for metal layer top temperature.

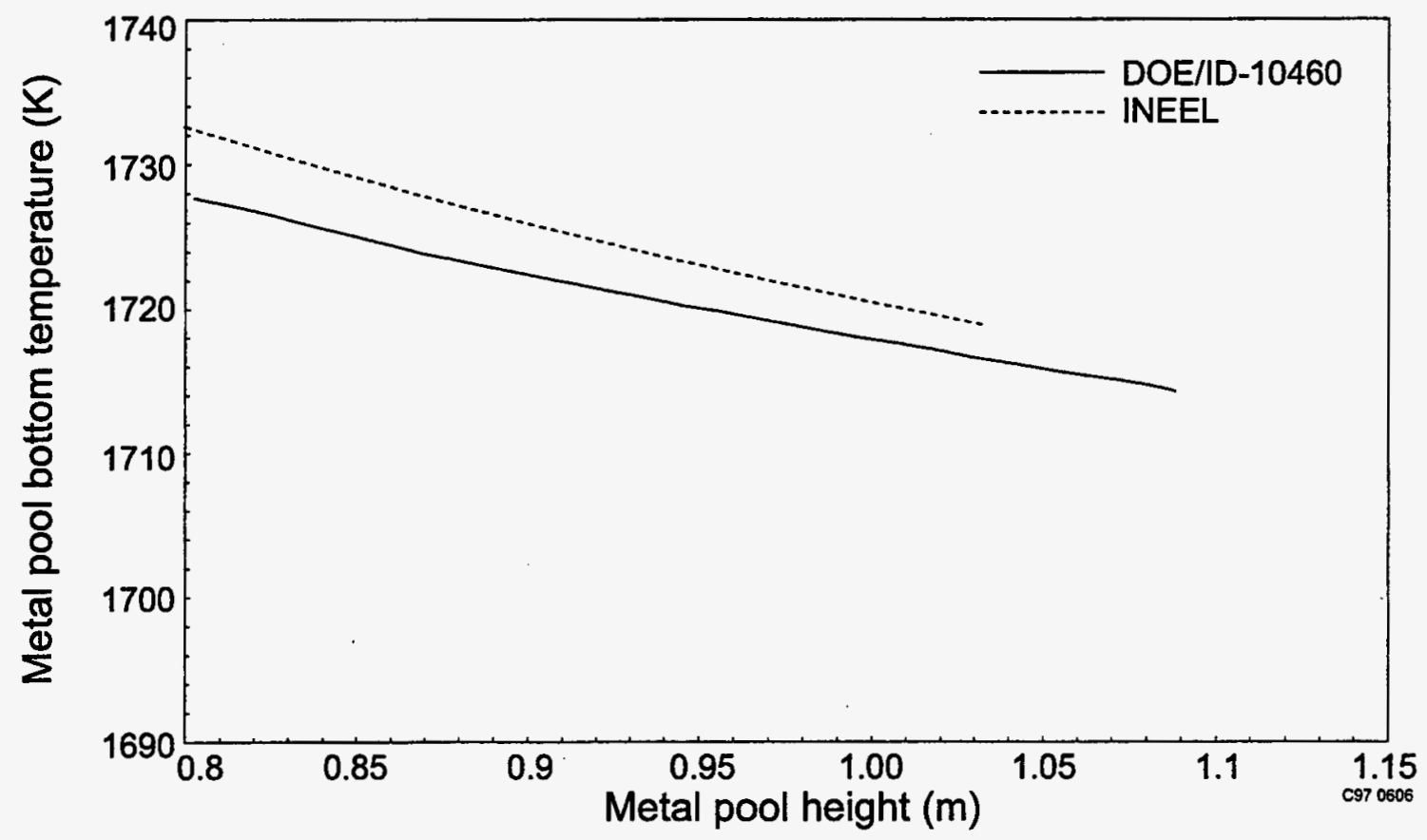

Figure D-9. INEEL VESTA and UCSB model predictions for metal layer bottom temperature. 


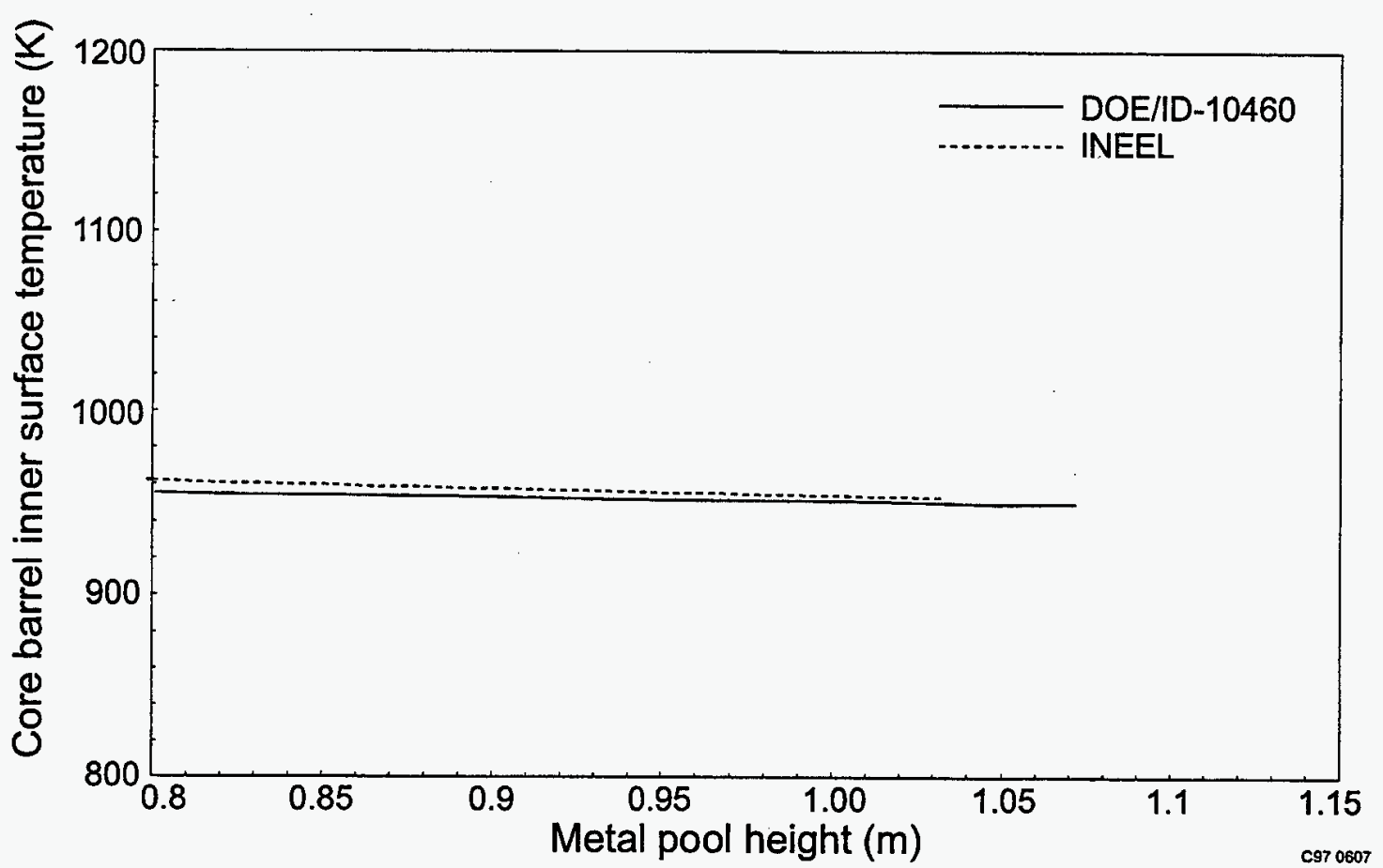

Figure D-10. INEEL VESTA and UCSB model predictions for core barrel inner surface temperature.

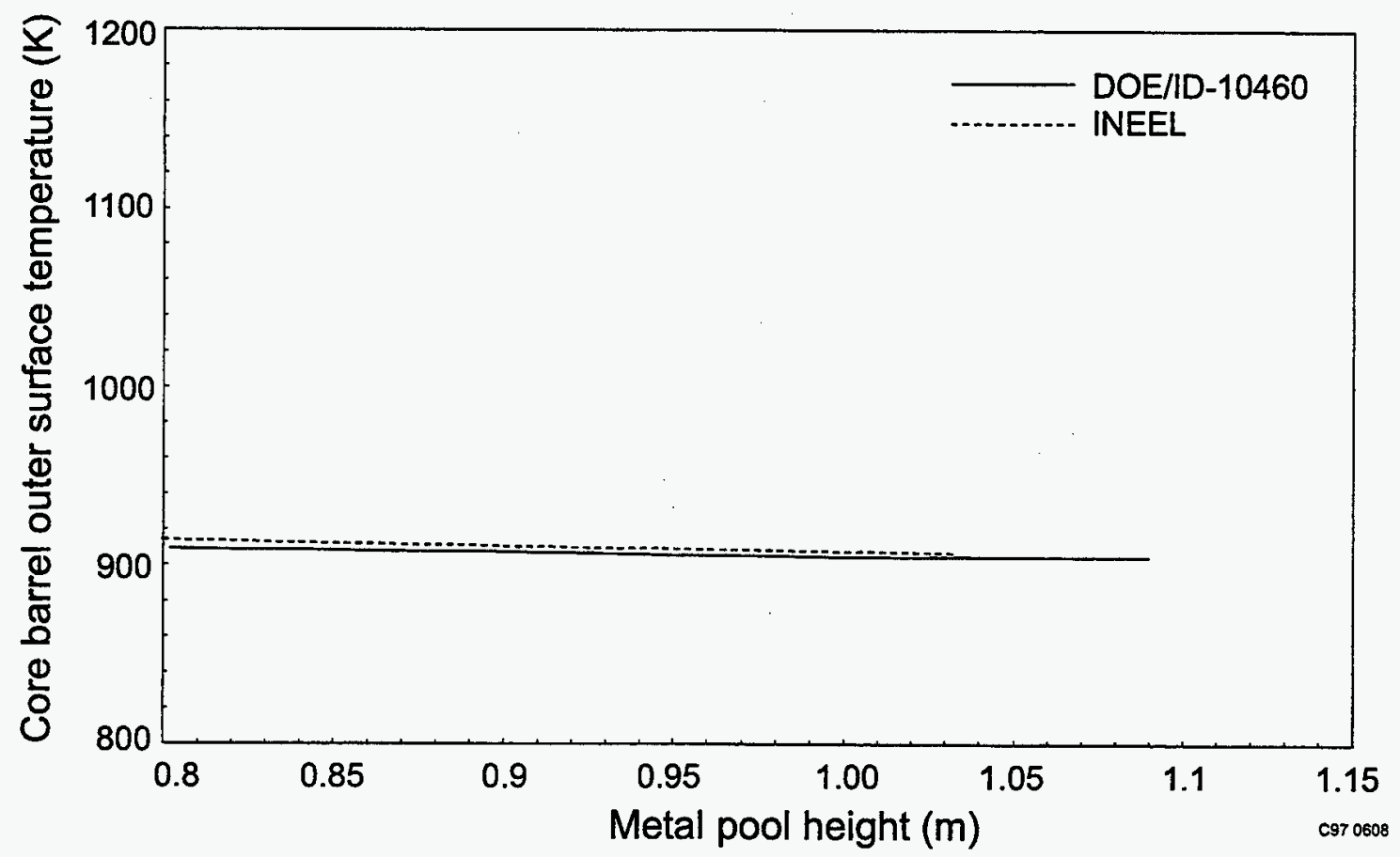

Figure D-11. INEEL VESTA and UCSB model predictions for core barrel outer surface temperature. 


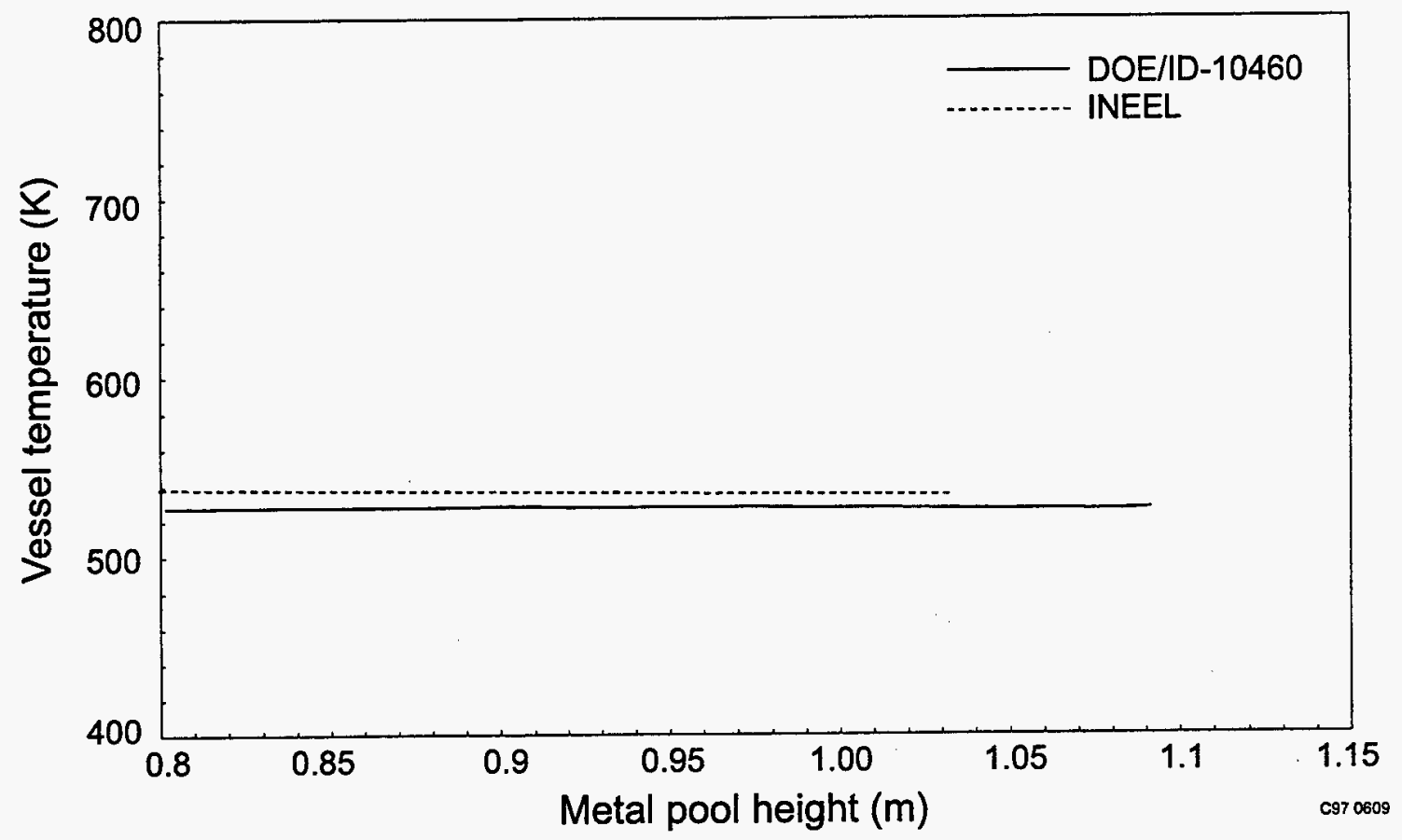

Figure D-12. INEEL VESTA and UCSB model predictions for vessel temperature.

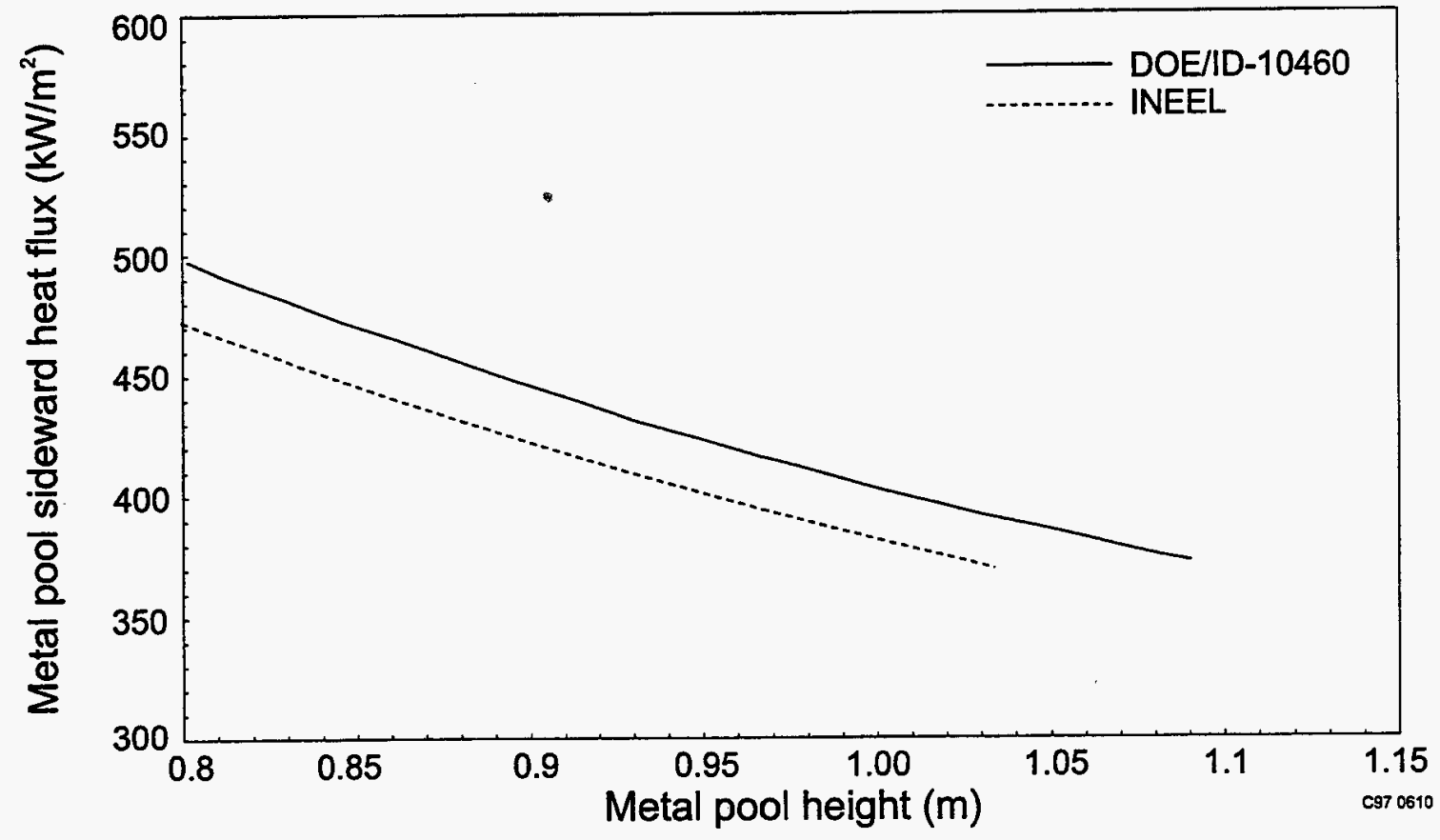

Figure D-13. INEEL VESTA and UCSB model predictions for vessel heat flux. 


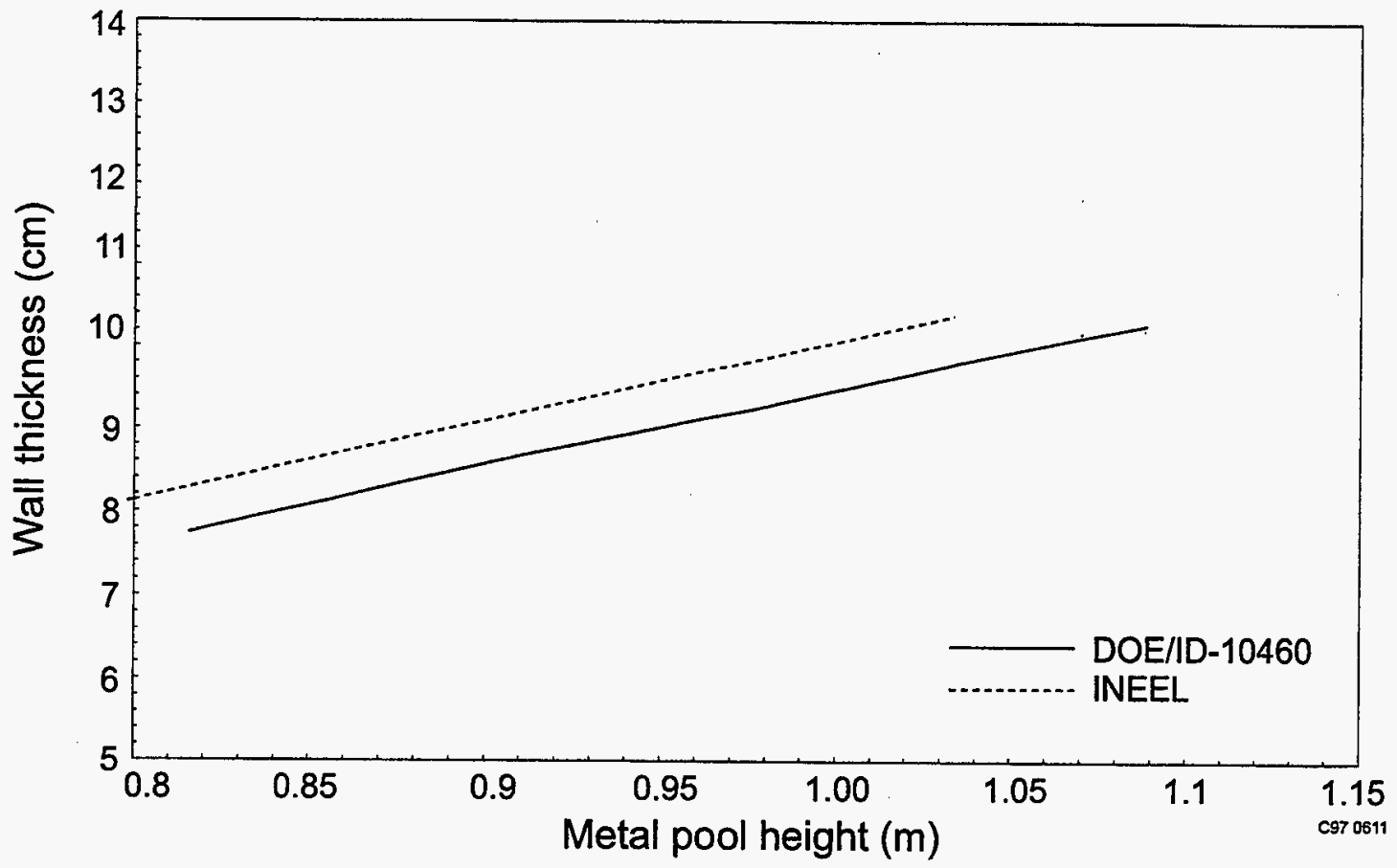

Figure D-14. INEEL VESTA and UCSB model predictions for vessel wall thickness.

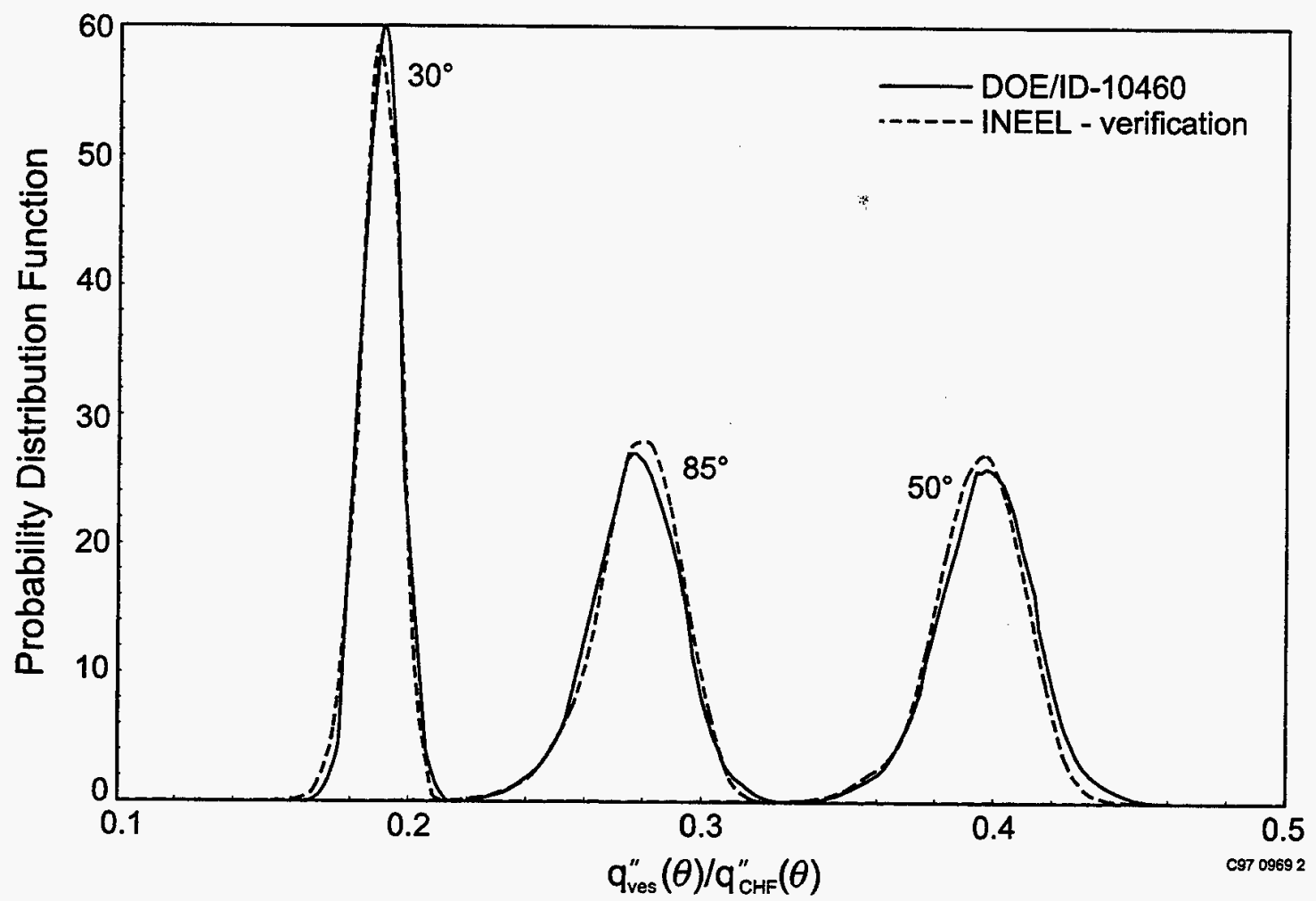

Figure D-15. INEEL VESTA and UCSB model predictions for CHF ratio pdfs. 


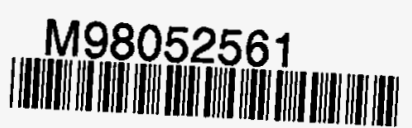

Report Number (14)INEEL/EXT--97-00779

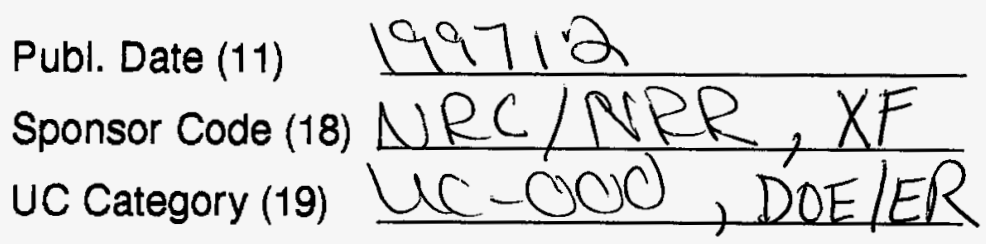

